UNIVERSIDADE DE SÃO PAULO

INSTITUTO DE GEOCIÊNCIAS

\title{
NOVA ABORDAGEM PROBABILÍSTICA DE CLASSIFICAÇÃO DE RECURSOS MINERAIS: APLICAÇÃO À MINA DE SEQUEIRINHO
}

\section{SANTIAGO DIAZ LOPEZ}

Tese apresentada ao Programa Geociências (Recursos Minerais e Hidrogeologia) para obtenção do título de Doutor em Ciências

Área de concentração: Recursos Minerais e Meio Ambiente

Orientador: Prof. Dr. Marcelo Monteiro da Rocha

São Paulo 
UNIVERSIDADE DE SÃO PAULO

INSTITUTO DE GEOCIÊNCIAS

\section{NOVA ABORDAGEM PROBABILÍSTICA DE CLASSIFICAÇÃO DE RECURSOS MINERAIS: APLICAÇÃO À MINA DE SEQUEIRINHO}

\section{SANTIAGO DIAZ LOPEZ}

Orientador: Prof. Dr. Marcelo Monteiro da Rocha

Tese de Doutorado

$\mathbf{N}^{\circ} 609$

COMISSÃO JULGADORA

Dr. Marcelo Monteiro da Rocha

Dra. Lilia Mascarenhas Sant'Agostino

Dr. Giorgio Francesco Cesare de Tomi

Dr. Ricardo Cabral de Azevedo

Dr. José Alberto Quintanilha

Dr. Saulo Batista de Oliveira

SÃO PAULO

2019 
DEDICADO: MINHA MÃE, MEU PAI, MINHA IRMÃ E MINHA ESPOSA 


\section{AGRADECIMENTOS}

Inicialmente gostaria de agradecer a todas as instituições e pessoas que fizeram isto possível, além do escritor desta tese, as quais forneceram as ferramentas necessárias para o desenvolvimento deste trabalho:

- $\quad$ Ao instituto de geociências da Universidade de São Paulo pela formação acadêmica recebida e pelo apoio logístico de sua estrutura, como também todos seus funcionários e professores;

- $\quad$ À CAPES pelo auxílio concedido na forma de bolsa de estudos durantes estes quatro anos de pesquisa;

- $\quad$ À empresa VALE S.A. pela disponibilização dos dados da mina sequeirinho;

- $\quad$ À empresa GEOVARIANCES pela disponibilização do software computacional ISATIS;

- À empresa DATAMINE pela disponibilização do software computacional STUDIO RM;

- Ao professor Dr. Marcelo Monteiro da Rocha que desde o início desta nova etapa na minha vida esteve disposto como amigo e professor a me orientar oportunamente nas épocas de dúvida.

Um profundo agradecimento ao Mario Gonzalez, Lorena e Luz Marina pelo apoio, amizade e confiança incondicional que me deram. Agradeço vocês ter me ajudado neste grande êxito, desde o começo até o fim.

A minha esposa Karla Ximena pelo constante companheirismo, dedicação, compreensão e amor, fundamental na conclusão deste trabalho.

Um profundo agradecimento ao meu amigo Allan Felippe por me ajudar nessas últimas semanas a escrever e corrigir o texto, independentemente do dia ou da hora, sempre esteve lá me apoiando nesta importante etapa final.

Agradeço a todos aqueles que direta e indiretamente fizeram parte desta nova conquista. Aos colegas do Laboratório de Informática Geológica e da sala 105 pelos momentos compartilhados. 


\section{RESUMO}

LOPEZ, S. D. Nova Abordagem Probabilística de Classificação de Recursos Minerais: Aplicação à Mina de Sequeirinho. 2019. Tese (Doutorado em Recursos Minerais e Meio Ambiente) - Instituto de Geociências, Universidade de São Paulo, São Paulo.

A declaração de recursos e reservas minerais assim como sua classificação, surgiu no início de 1970 como resposta às inúmeras fraudes que causaram perdas irreparáveis tanto a pessoas quanto à grandes mineradoras. As Normas Internacionais de Declaração de Recursos Minerais (CRIRSCO e JORC) e a Comissão Brasileira de Recursos e Reservas Minerais (CBRR) desempenham um papel essencial nos projetos e empreendimentos de mineração, pois viabilizam os direitos e deveres dos investidores, assim como, a transparência na declaração dos recursos minerais. Essas normas são regidas pelos princípios da transparência, materialidade e competência que ajudam na elaboração da declaração pública dos recursos minerais através de uma avaliação justa e auditável. Além disso, estabelecem uma subdivisão dos recursos minerais segundo a ordem crescente de confiança e conhecimento geológico como: Inferido, Indicado e Medido o que permite ao profissional avaliar o tipo de mineralização segundo as diretrizes estabelecidas. Aliás, na literatura cientifica é possível encontrar várias ferramentas geoestatísticas tanto qualitativas quanto quantitativas como por exemplo, a krigagem e a simulação que são usadas para estimar e classificar recursos minerais com maior precisão. Afinal, neste trabalho a Simulação Sequencial Gaussiana (SGS) e a Simulação de Múltiplos Pontos FILTERSIM são usadas e comparadas como métodos de estimativa dos recursos encontrados na mina de Sequeirinho, localizada em Canaã dos Carajás no sudeste do Pará. Os dados analisados correspondem às 289 perfurações realizadas em seis campanhas entre 1997 a 2003 na Mina de Cobre do Sossego.

Como critério de classificação para os métodos SGS e FILTERSIM foi utilizado a função de transferência local, denominada neste trabalho de probabilidade condicional pontual que foi aplicada às unidades/blocos de um modelo tridimensional de modo que as probabilidades encontradas resultaram da aplicação do teorema do Limite Central e da distribuição Normal. Deste modo, recursos minerais puderam ser enquadrados nas 
seguintes subdivisões: Medido, se a probabilidade condicional pontual estiver no intervalo de $(85 \%, 100 \%)$; Indicado, se estiver entre (30\%, 85\%]; e, Inferido, caso se encontre no intervalo $[0 \%, 30 \%]$.

É importante citar que frequentemente a classificação de recursos minerais resultam em artefatos. Esse problema é conhecido pela indústria mineral como "spotted dog" que pode induzir o profissional a erros grosseiros na classificação dos recursos, já que encobrem aspectos relevantes como continuidade geológica e mineralização. Para evitar tais impasses dois filtros lineares foram utilizados: Média e Gaussiano. Por fim, a seleção do modelo/janela de homogeneização de valores do filtro Gaussiano foi realizada a partir da seleção de um valor "ótimo" de sigma ou desvio padrão em um intervalo de dispersão adequado. Logo, a função usada para obter um valor "ótimo" é a de máxima verossimilhança log-normal.

Afinal o método de probabilidade pontual foi capaz de apresentar resultados satisfatórios. Aliás, o método proposto considera as características locais da distribuição de valores e as incertezas locais associadas, o qual mostra que esse critério é um método estatístico promissor para classificação de recursos minerais.

Palavras-chave: Geoestatística; Simulação Sequencial Gaussiana; Simulação de Múltiplos Pontos; Probabilidade Condicional Pontual; Incerteza; Filtro de Média; Filtro Gaussiano; Classificação de Recursos Minerais. 


\section{ABSTRACT}

LOPEZ, S. D. A New Probabilistic Approach to Mineral Resources Classification: An Application to the Sequeirinho Mine. 2019. Thesis (Doctored in Mineral Resources and Environment) - Institute of Geosciences, University of São Paulo, São Paulo.

The declaration of mineral resources and reserves, as well as their classification emerged in the early 1970s in response to the numerous frauds that caused irreparable losses to both people and large miners. The International Mineral Resources Declaration Standards (CRIRSCO and JORC) along with the Brazilian Mineral Resources and Reserves Commission (CBRR) play an essential role in mining projects and ventures, as they enable investors' rights and duties, as well as transparency in the statement of mineral resources. These standards are governed by the principles of transparency, materiality and competence that support the preparation of the public statement of mineral resources through fair and auditable assessment. In addition, they establish a subdivision of mineral resources according to the increasing order of trust and geological knowledge as: Inferred, Indicated and Measured allowing a professional evaluation of the type of mineralization according to the established guidelines. Moreover, in the scientific literature it is possible to find various geostatistical tools both qualitative and quantitative such as kriging and simulation that have been used the estimation and classification of mineral resources in order to identify different classes of mineral resources.

Thus, in this work Gaussian Sequential Simulation (SGS) and FILTERSIM Multiple Point Simulation are used and compared as mineral resource estimation methods for the Sequeirinho mine, located in Canaã dos Carajás in southeastern Pará. Data provided by Vale SA. The Sequeirinho mine corresponds to 289 drillings carried out in six campaigns from 1997 to 2003 at the Sossego Copper Mine.

As classification method for both methods (SGS and FILTERSIM) the local transfer function will be used. It is worth mentioning that in the present work this function is called point conditional probability and will be applied to the units/blocks of a threedimensional model so that the probabilities found result from the use of the Central 
Limit theorem and the Normal distribution. Thus, a mineral resource may fall into the following subdivisions: Measured if the point conditional probability is within the range of $(85 \%, 100 \%]$, Indicated if the probability is within $(30 \%, 85 \%]$ and Inferred if the probability is in the range $[0 \%, 30 \%]$.

It is important to mention that on numerous ocassions the classification of mineral resources results in artifacts. This problem is known in the mineral industry as "spotted dog" and can induce the trader to gross errors in mineral resources classification, as they mask relevant aspects such as geological continuity and mineralization. To avoid certain deadlocks, two linear filters are used: Average and Gaussian. It should be noted that the selection of the Gaussian filter model/homogenization window was made from the selection of an "optimal" sigma or standard deviation value in a suitable dispersion range. Therefore, the function used to obtain an "optimal" value is the maximum lognormal likelihood.

Keywords: Geostatistics. Sequencial Gaussian Simulation. Multiple Points Simulation. Point Conditional Probability. Uncertainty. Average filter. Gaussian Filter. Mineral Resource Classification. 


\section{SUMÁRIO}

1 INTRODUÇÃO E OBJETIVOS …………………………............................. 1

1.1 INTRODUÇÃO .......................................................................... 1

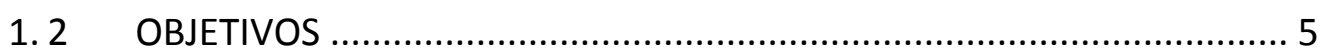

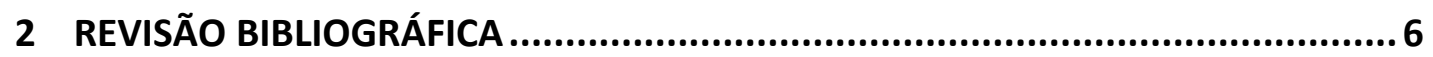

2. 1 CLASSIFICAÇÃO DE RECURSOS/RESERVAS MINERAIS .......................... 6

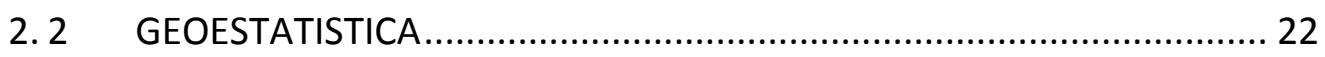

2.2.1 FUNÇÃO VARIOGRAMA E SEMIVARIOGRAMA ……...................... 25

2. 3 MÉTODOS DE ESTIMATIVA LOCAL .................................................. 30

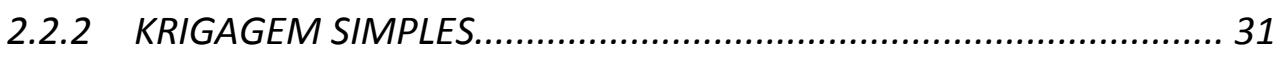

2. 4 SIMULAÇÃO CONDICIONAL GEOESTATISTICA ……............................... 32

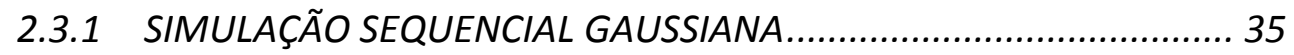

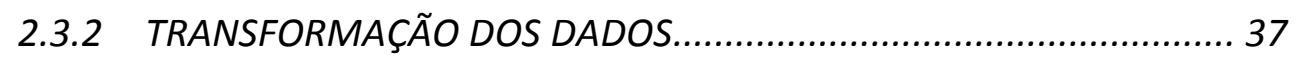

2.5 SIMULAÇÃO DE MULTIPONTOS (MPS)................................................. 39

2. 6 TRATAMENTO DE IMAGENS POR FILTROS ......................................... 55

2.7 ANÁLISE DE COMPONENTES PRINCIPAIS ......................................... 56

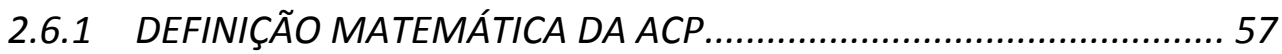

2.6.2 BIPLOT: INTERPRETAÇÃO E VISUALIZAÇÃO.................................. 59

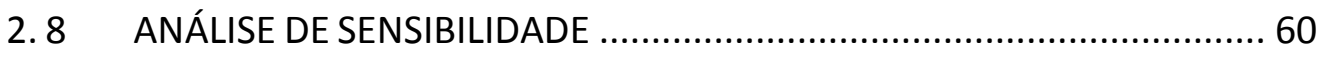

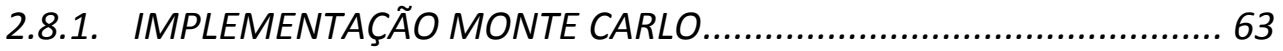

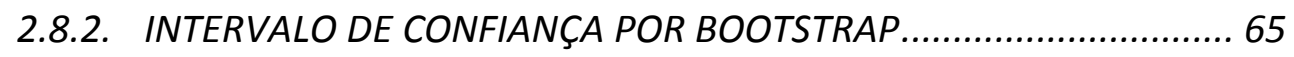

2.8.3. BOOTSTRAP: TÉCNICA DE REAMOSTRAGEM................................ 66

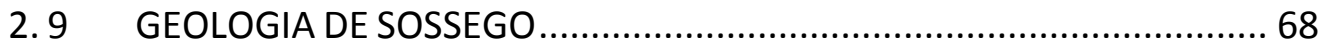

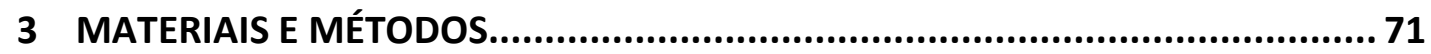

3.1. MATERIAIS E MÉTODOS.............................................................. 71

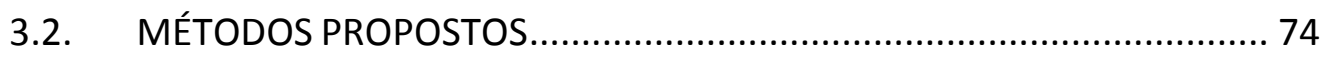

3.2.1 MÉTODO PROBABILISTICO PONTUAL .......................................... 74

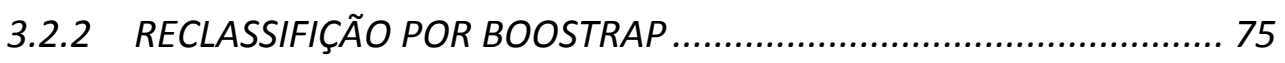

3.2.3 REAMOSTRAGEM E ANÁLISE DE SENSIBILIDADE.......................... 77 


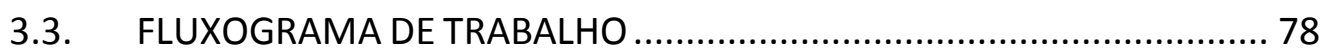

4 APRESENTAÇÃO E DISCUSSÃO DOS RESULTADOS....................................... 80

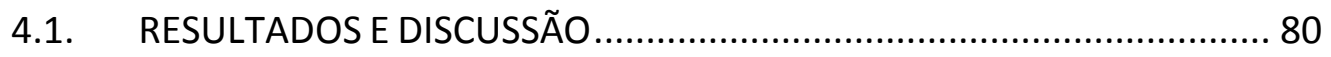

4.2. ANÁLISE EXPLORATÓRIA DA BASE DE DADOS .................................... 80

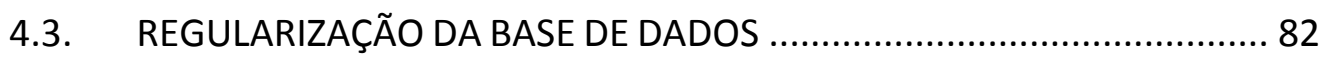

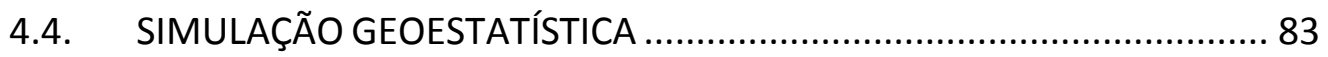

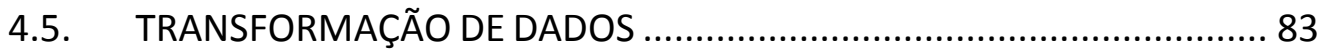

4.6. VARIOGRAMA DOS DADOS TRANFORMADOS ................................ 87

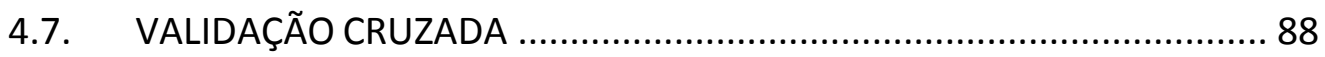

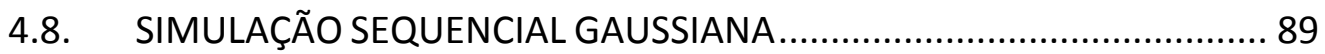

4.9. CLASSIFICAÇÃO DOS RECURSOS MINERAIS ESTIMADOS POR SGS...... 92

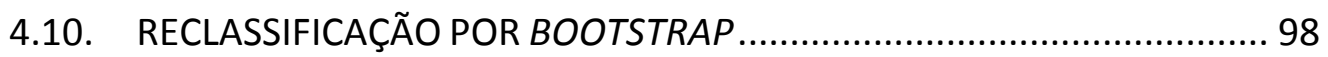

4.11. FILTROS: MÉDIA E GAUSSIANO ...................................................... 100

4.12. SELEÇÃO DA IMAGEN DE TREINAMENTO ...................................... 110

4.13. SIMULAÇÃO GEOESTATISTICA DE MULTIPLOS PONTOS ................... 111

4.14. CLASSIFICAÇÃO DOS RECURSOS MINERAIS REALIZADO A PARTIR DO FILTERSIM 115

4.15. RECLASSIFICAÇÃO POR BOOTSTRAP ........................................ 117

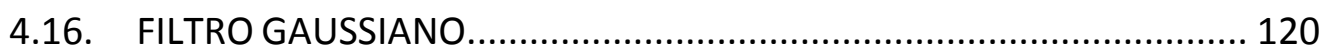

4.17. ANÁLISE DE SENSIBILIDADE POR DECOMPOSIÇÃO DA VARIÂNCIA .. 124

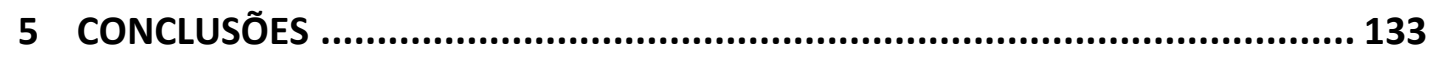

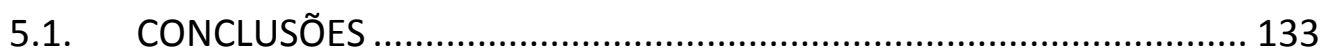

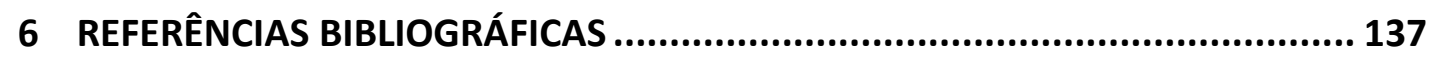


TABELA 2-1. CLASSIFICAÇÃO DE RECURSOS/RESERVAS MINERAIS COM BASE NO ERRO E GRAU DE INCERTEZA.

TABELA 2-2. CLASSIFICAÇÃO DE RECURSOS MINERAL COM BASE NO TIPO DE ESCALA (MENOR O MAIOR), DE ACORDO COM SILVA E BOISVAERT (2014)...................... 16

TABELA 2-3. PRINCÍPIO DO BOOTSTRAP NÃO PARAMÉTRICO. 67

TABELA 3-1. PARÂMETROS DOS MODELOS DE BLOCOS UTILIZADOS NA ANÁLISE DE SENSIBILIDADE E SIMULAÇÃO GEOESTATÍ́STICA. AS UNIDADES DE MEDIDA SÃO DADAS EM METROS. SGS = SIMULAÇÃO SEQUENCIAL GAUSSIANA, RM = REAMOSTRAGEM. 73

TABELA 4-1. ESTATÍSTICAS DESCRITIVAS DO CONJUNTO DE DADOS BRUTOS DA VARIÁVEL CU (\%). 80

TABELA 4-2. ESTATÍSTICA DESCRITIVA DO CONJUNTO DE DADOS REGULARIZADO DA VARIÁVEL CU (\%). 82

TABELA 4-3. ESTATÍSTICA DESCRITIVA DO CONJUNTO DE DADOS REGULARIZADO CU

(\%), TRANSFORMADOS PELA FUNÇÃO LOGARÍTMICA. 84

TABELA 4-4. TESTE DE NORMALIDADE DOS DADOS. ONDE $w$ E $p$ SÃO A ESTATÍSTICA E O VALOR DA PROBABILIDADE MÉDIA, RESPETIVAMENTE, OBTIDOS POR BOOTSTRAP. 84

TABELA 4-5. ESTATÍSTICAS DE RESUMO DOS DADOS TRANSFORMADOS DE CU (\%) PELA TÉCNICA NORMAL SCORE. 85

TABELA 4-6. TESTE DE NORMALIDADE DOS DADOS TRANSFORMADOS POR NSCORE. ONDE $w$ E $p$ RESPECTIVAMENTE SÃO A ESTATÍSTICA E O VALOR DA PROBABILIDADE MÉDIA DERIVADOS DO BOOTSTRAP. 86

TABELA 4-7. PARÂMETROS DOS MODELOS TEÓRICOS AJUSTADOS AOS VARIOGRAMAS EXPERIMENTAIS DO CONJUNTO DE DADOS TRANSFORMADOS. $\mathrm{C}=$ CONTRIBUIÇÃO ESPACIAL, T = MODELO TEÓRICO DE VARIOGRAMA E A = AMPLITUDE. 87

TABELA 4-8. ESTRATÉGIA DE BUSCA PARA SIMULAÇÃO SEQUENCIAL GAUSSIANA. ...... 89 TABELA 4-9. ESTATÍSTICA DESCRITIVA DA MÉDIA DAS REALIZAÇÕES ESTOCÁSTICAS

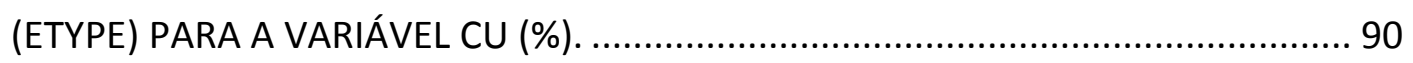
TABELA 4-10. VALORES DE CORTES ESTRATÉGICOS ENTRE OS ANOS 2011-2022. (FONTE: GOLDER ASSOCIATES, 2010). 92 
TABELA 4-11. RESULTADO DA CLASSIFICAÇÃO DOS RECURSOS MINERAIS, ATRAVÉS DOS TRÊS CRITÉRIOS DE CLASSIFICAÇÃO APRESENTADOS EM VOLUME E EM TONELADAS. 1 = MÉTODO DE RESTRIÇÃO DE BUSCA; 2 = VARIÂNCIA CONDICIONAL RELATIVA; 3 = PROBABILIDADE PONTUAL. 93

TABELA 4-12. ESTATÍSTICAS DESCRITIVAS DOS RECURSOS MINERAIS CLASSIFICADOS E RECLASSIFICADOS, POR PROBABILIDADE PONTUAL E BOOTSTRAP, RESPECTIVAMENTE. 99

TABELA 4-13. RESULTADO DA RECLASSIFICAÇÃO DE RECURSOS MINERAIS, POR MEIO DE BOOTSTRAP, EM VOLUME. 99

TABELA 4-14. RESULTADO DA CLASSIFICAÇÃO DOS RECURSOS MINERAIS EM VOLUME, OBTIDOS A PARTIR DAS DUAS TÉCNICAS DE SUAVIZAÇÃO 105

TABELA 4-15. PARÂMETROS ESTRATÉGICOS PARA A SIMULAÇÃO DE MÚLTIPLOS PONTOS FILTERSIM. 112

TABELA 4-16. ESTATÍSTICA DESCRITIVA DA MÉDIA DAS REALIZAÇÕES ESTOCÁSTICAS (ETYPE) PARA A VARIÁVEL CU (\%). 113

TABELA 4-17. RESULTADO DA CLASSIFICAÇÃO DE RECURSOS MINERAIS. 115 TABELA 4-18. RESULTADO DA RECLASSIFICAÇÃO DE RECURSOS MINERAIS, ATRAVÉS DE BOOTSTRAP, EM VOLUME. 117

TABELA 4-19. ESTATÍSTICAS DESCRITIVAS DE RECURSOS MINERAIS CLASSIFICADOS E RECLASSIFICADOS, POR PROBABILIDADE PONTUAL E BOOTSTRAP, RESPECTIVAMENTE. 118

TABELA 4-20. RESULTADO DA CLASSIFICAÇÃO DOS RECURSOS MINERAIS EM VOLUME, OBTIDOS A PARTIR DO FILTRO GAUSSIANO. 121

TABELA 4-21. ESTATÍSTICAS DE RESUMO DO CONJUNTO TOTAL DE VOLUMES OBTIDOS POR RE-AMOSTRAGEM ALEATÓRIA ESTRATIFICADA (55, 110, 165 E 220). 124

TABELA 4-22. PARÂMETROS DE CÁLCULO DO VARIOGRAMA EXPERIMENTAL PARA CADA CONJUNTO RESPECTIVO DE NOVAS AMOSTRAS. DIR = DIREÇÃO, TOL ANG = TOLERÂNCIA ANGULAR, PASSO TOL = TOLERÂNCIA DO PASSO. 125 TABELA 4-23. ESTATÍSTICA DESCRITIVA DOS PARÂMETROS DE AJUSTE DOS MODELOS TEÓRICOS DE VARIOGRAMAS ÀS NOVAS AMOSTRAS (55, 110, 165 E 220), OBTIDAS PELA MODELAGEM AUTOMÁTICA DO VARIOGRAMA EXPERIMENTAL. PARÂMETROS = PARÂMETROS DE INTERESSE (c0: EFEITO PEPITA DA DIREÇÃO $1 \mathrm{E}$ 
2, $c 1, c 2$ : CONTRIBUIÇÕES DAS DIREÇÕES 1 E 2, $a 1, a 2:$ AMPLITUDES DAS

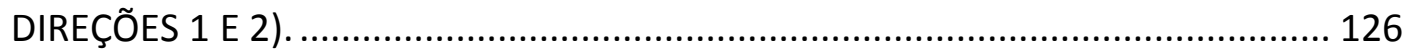

TABELA 4-24. ÍNDICES DE SENSIBILIDADE DA PRIMEIRA ORDEM E ORDEM TOTAL OBTIDOS POR BOOTSTRAP, BEM COMO SEUS INTERVALOS DE CONFIANÇA (IC). 1 = REAMOSTRAGEM 55, 2 = REAMOSTRAGEM 110, 3 = REAMOSTRAGEM 165 E 4 = REAMOSTRAGEM 200. 130 
FIGURA 1-1. CAPTURA DA VARIABILIDADE LOCAL POR MEIO DA FUNÇÃO DE TRANSFERÊNCIA DE INTERESSE. (FONTE: WWW.PRO.ARCGIS.COM)..................... 3 FIGURA 2-1. RESULTADOS DE EXPLORAÇÃO, RECURSOS MINERAIS E RESERVAS MINERAIS. (FONTE: CBRR, 2016).

FIGURA 2-2. CONCEITO DA ÁREA DE INFLUÊNCIA, OU ZONA DE INFLUÊNCIA, EM TORNO DO BLOCO A SER CLASSIFICADO, ASSIM COMO, O NÚMERO DE AMOSTRAS MÁXIMAS NO RAIO DE BUSCA PRÓXIMAS AO BLOCO DE INTERESSE. (FONTE: SINCLAIR E BLACKWELL, 2004). 7 FIGURA 2-3. CLASSIFICAÇÃO DE RECURSOS MINERAIS BASEADA NA DISTÂNCIA DE VARIOGRAMA. INTRODUZIDOS POR DOHM (2005) (A) E MARWANZA ET AL. (2016) (B), RESPECTIVAMENTE. (FONTE: GEOKRIGAGEM). 8

FIGURA 2-4. ILUSTRAÇÃO DO ESPAÇAMENTO MÉDIO ENTRE PERFURAÇÕES E A DENSIDADE AMOSTRAL. COM D1 E D2 SÃO AS DISTÂNCIAS DE SEPARAÇÃO NAS DIREÇÕES HORIZONTAIS E, A ÁREA DE COR AMARELA DEFINE O VOLUME OU ÁREA POR HECTARE DA DENSIDADE AMOSTRAL. (FONTE: MORY E DEUTSCH, 2006).

FIGURA 2-5. EXEMPLO TÍPICO DO CRITÉRIO DE CLASSIFICAÇÃO RKSD BASEADO NO NÚMERO DE AMOSTRAS USADAS NA ESTIMATIVA DO BLOCO, EM UM DEPÓSITO DE OURO EPITERMAL. (FONTE: SINCLAIR E BLACKWELL, 2002).

FIGURA 2-6. ILUSTRAÇÃO DOS TRÊS PARÂMETROS UTILIZADOS NA REGRA DE CLASSIFICAÇÃO: (1) VOLUME, (2) PRECISÃO E (3) PROBABILIDADE DE ESTAR DENTRO DA MEDIDA DE INCERTEZA. (FONTE: ADAPTADO DE ROSSI E DEUTSCH, 2014). 15

FIGURA 2-7. ILUSTRAÇÃO TRIDIMENSIONAL DE UMA SITUAÇÃO GERAL NA ESTIMATIVA DE TEORES E VOLUMES. A ZONA MINERALIZADA OU DEPOSITO É DISCRETIZADO POR UM NÚMERO DE BLOCOS EM X, Y E Z. ONDE CADA BLOCO É ESTIMADO DAS INFORMAÇÕES ADJACENTES DENTRO DE UM RAIO DE BUSCA. (FONTE: GEOKRIGAGEM).

FIGURA 2-8. MEMBROS DO COMITÊ DE RESERVA INTERNACIONAL DE RESERVAS COMBINADAS EM JULHO DE 2018. (FONTE: MEMBROS CRIRSCO, HTTP://WWW.CRIRSCO.COM/WELCOME.ASP) 
FIGURA 2-9. RELAÇÃO ENTRE A FUNÇÃO DO VARIOGRAMA E A COVARIÂNCIA (FONTE: OLEA, 1999). 26

FIGURA 2-10. ILUSTRAÇÃO IDEAL DE UM VARIOGRAMA EXPERIMENTAL E SUAS PROPRIEDADES (FONTE: YAMAMOTO, 2001). 27

FIGURA 2-11. MODELOS DE VARIOGRAMAS TEÓRICOS. (FONTE: GOOVAERTS, 1997) 29 FIGURA 2-12. ANISOTROPIA GEOMÉTRICA (A), ZONAL (B) E MISTA (C). (FONTE: YAMAMOTO, 2001). 30

FIGURA 2-13. COMPARAÇÃO ENTRE MODELO INTERPOLADO E SIMULADO. (FONTE: ROSSI E DEUTSCH, 2016). 34

FIGURA 2-14. EFEITO DE SUAVIZAÇÃO DA KRIGAGEM (LINHA PONTILHADA) CORRIGIDO POR SIMULAÇÃO ESTOCÁSTICA (LINHA TRACEJADA), E COMPARADO COM UMA SITUAÇÃO IDEALIZADA DE VALORES EM UMA SEÇÃO (LINHA CONTÍNUA). (FONTE: SINCLAIR E BLACKWELL, 2004). 35 FIGURA 2-15. FUNÇÃO DE DISTRIBUIÇÃO CUMULATIVA DE UMA DISTRIBUIÇÃO GAUSSIANA COM DIFERENTES PARÂMETROS DE M E $\Sigma$. (FONTE: AUTOR). 38 FIGURA 2-16. TRANSFORMAÇÃO GAUSSIANA POR NS. (FONTE: ROSSI E DEUTSCH, 2014). 38 FIGURA 2-17. EXEMPLOS DE POSSÍVEIS CONFIGURAÇÕES ESPACIAIS DE DOIS PONTOS, TRÊS PONTOS, QUATRO PONTOS E N PONTOS. (FONTE: MODIFICADO DE GOOVAERTS, 1997). 39

FIGURA 2-18. IMAGEM DE TREINAMENTO (À ESQUERDA), E UMA MODALIDADE (À DIREITA) GERADA PELO ALGORITMO ENESIM. A IMAGEM DE TREINAMENTO REPRESENTA UMA SEÇÃO TRANSVERSAL DE UMA AREIA CRUZADA. (FONTE: GUARDIANO E SRIVASTAVA, 1993). 42 FIGURA 2-19. IMAGENS DE TREINAMENTO. (A) E (B) ESTRUTURAS GEOLÓGICAS IDENTIFICADAS A PARTIR DE UM LEVANTAMENTO GEO-RADAR (BAYER ET AL., 2012), (C) MODELO TRIDIMENSIONAL GERADO POR MÉTODOS BASEADOS EM PROCESSOS (TAHMASEBI E SAHIMI, 2016A), (D) MODELO SINTÉTICO DE UM RESERVATÓRIO ALUVIAL OBTIDO A PARTIR DO ALGORITMO DE SIMULAÇÃO FLUMY (LOPEZ ET AL., 2008). 46

FIGURA 2-20. FILTROS LOCAIS EM UM ESPAÇO BIDIMENSIONAL: ONDE OS PESOS SÃO DADOS PELA ESCALA EM CINZA. (FONTE: ZHANG ET AL., 2006). 48 
FIGURA 2-21. EXEMPLO DE UM MODELO 3 X 3 (OU TEMPLATE) EM 2D APLICADO A UMA MALHA BIDIMENSIONAL TAMANHO 11 X 11. (FONTE: ARPAT E CAERS, 2007). 49

FIGURA 2-22. ESPAÇO DE FILTRO DE PONTUAÇÕES (FONTE: ZHANG ET AL., 2006)..... 49 FIGURA 2-23. APLICAÇÃO AUTOMÁTICA DA SELEÇÃO ÓTIMA DO TEMPLATE EM UM RESERVATÓRIO FLUVIAL EM 2D. A FIGURA ILUSTRA A IMAGEM DE TREINAMENTO (À ESQUERDA), A CURVA DE ENTROPIA MÉDIA (AO CENTRO) E O LOGARITMO NATURAL DA FUNÇÃO DE PROBABILIDADE (À DIREITA). COM O VALOR DE TEMPLATE IDEAL IGUAL A $n x^{\prime}=13$ e $n y^{\prime}=13$. (FONTE: HONARKHAH, 2011).55 FIGURA 2-24. REPRESENTAÇÃO BÁSICA DO BIPLOT E SUAS INTERPRETAÇÕES BÁSICAS. (FONTE: SALINAS, ET AL., 2013) 60 FIGURA 2-25. PRINCÍPIO DO BOOTSTRAP NÃO PARAMÉTRICO PARA ESTIMAR A FUNÇÃO DE DISTRIBUIÇÃO $F$ DE UM ESTIMADOR DE PARÂMETROS $\theta$. (FONTE: ZOUBIR E ISKANDER, 2004). 68 FIGURA 2-26. VISTA AÉREA DA CAVA AO AR LIVRE DO SEQUEIRINHO (À ESQUERDA) E SOSSEGO (À DIREITA). (FONTE: GOLDER ASSOCIATES, 2010). 69 FIGURA 2-27. SIMPLIFICAÇÃO GEOLÓGICA DA LOCALIZAÇÃO DOS CORPOS, SEQUEIRINHO E SOSSEGO. (FONTE: MONTEIRO ET AL., 2008A). 70 FIGURA 2-28. SEÇÃO ESQUEMÁTICA DA DISTRIBUIÇÃO DAS ZONAS DE ALTERAÇÃO HIDROTERMAL NOS CORPOS DE SOSSEGO E SEQUEIRINHO, MINA DE SOSSEGO. (FONTE: MONTEIRO ET AL., 2008A). 70 FIGURA 3-1. LOCALIZAÇÃO BIDIMENSIONAL DOS FUROS DE PERFURAÇÃO REALIZADOS NAS DIFERENTES CAMPANHAS. 72 FIGURA 3-2. VISTA EM 3D DO MODELO DE BLOCOS ENVOLVENDO TODOS OS FUROS. 73

FIGURA 3-3. FLUXOGRAMA ANALÍTICO DA RECLASSIFICAÇÃO POR BOOTSTRAP PROPOSTA. 76 FIGURA 3-4. FLUXOGRAMA DE METODOLOGIAS APLICADAS NA ESTIMATIVA E CLASSIFICAÇÃO DE RECURSOS MINERAIS. A FIGURA ILUSTRA AS ATIVIDADES REALIZADAS DURANTE A INVESTIGAÇÃO. OS PROCESSOS EM VERMELHO FORAM REALIZADOS UNICAMENTE PARA A SIMULAÇÃO GEOESTATÍSTICA DE MÚLTIPLOS PONTOS (FILTERSIM). 79 
FIGURA 4-1. HISTOGRAMA DA VARIÁVEL CU (\%) PARA AMBAS AS LITOLOGIAS

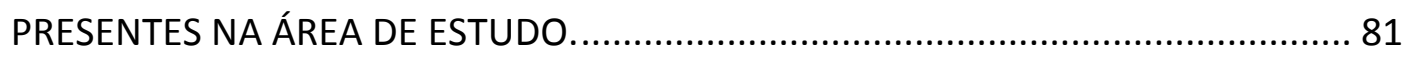
FIGURA 4-2. BOX-PLOT PARA A VARIÁVEL CU (\%) LIMITADO EM ÉPSILON ATÉ O VALOR 2.09. 81

FIGURA 4-3. HISTOGRAMA DA VARIÁVEL REGULARIZADA CU (\%). 82 FIGURA 4-4. GRÁFICO DE VALORES DE PROBABILIDADE PARA AS 100 REAMOSTRAGENS OBTIDAS POR BOOTSTRAP PARA O TESTE DE NORMALIDADE DOS DADOS. A LINHA AZUL INDICA O VALOR DA PROBABILIDADE LIMITE DE 0,05 E OS PONTOS VERMELHOS MOSTRAM OS VALORES P ESTIMADOS. 84 FIGURA 4-5. DISTRIBUIÇÃO DA VARIÁVEL CU (\%) TRANSFORMADA POR NSCORE. ...... 85 FIGURA 4-6. GRÁFICO DE VALORES DE PROBABILIDADE PARA AS 100 REAMOSTRAGENS OBTIDAS POR BOOTSTRAP PARA O TESTE DE NORMALIDADE DOS DADOS TRANSFORMADOS NSCORE. A LINHA AZUL INDICA O VALOR DE PROBABILIDADE LIMITE DE 0,05 E OS PONTOS VERMELHOS MOSTRAM OS VALORES P ESTIMADOS. 86 FIGURA 4-7. TESTE DE BI-GAUSSIANIDADE DADA PELA RAZÃO ENTRE A RAIZ QUADRADA DO VARIOGRAMA E O MADOGRAMA. 87 FIGURA 4-8. VARIOGRAMA EXPERIMENTAL E MODELO DE VARIOGRAMA AJUSTADO. O LADO ESQUERDO DA FIGURA ILUSTRA O VARIOGRAMA EXPERIMENTAL CALCULADO PRIMEIRAMENTE NAS DIREÇÕES 160/45, 250/0 E 160/-45ㅇ, NA AVALIAÇÃO DA ANISOTROPIA, E AO LADO DIREITO DA FIGURA É ILUSTRADO O VARIOGRAMA EXPERIMENTAL RECALCULADO PARA DIREÇÕES DE 160\%/45 E 160\%-45, ASSIM COMO SEU MODELO TEÓRICO DE VARIOGRAMA AJUSTADO.. 88 FIGURA 4-9. DIAGRAMA DE DISPERSÃO ENTRE OS VALORES ESTIMADOS E REAIS PARA A VARIÁVEL TRANSFORMADA CU (\%), COM CORRELAÇÃO DE 0,89 89 FIGURA 4-10. ETYPE DAS 100 REALIZAÇÕES GEOESTATÍSTICA POR SGS DA VARIÁVEL CONTÍNUA CU (\%) PARA VALORES ACIMA DO VALOR DE CORTE DE 0,33\%.......... 90 FIGURA 4-11. DESVIO PADRÃO DAS 100 REALIZAÇÕES GEOESTACIONÁRIAS PELA SGS DA VARIÁVEL CONTÍNUA CU (\%) PARA VALORES ACIMA DO VALOR DE CORTE $0,33 \%$. 91 FIGURA 4-12. HISTOGRAMA DA VARIÁVEL CU (\%) OBTIDA A PARTIR DA MÉDIA DAS REALIZAÇÕES (ETYPE). 91 
FIGURA 4-13. HISTOGRAMA DO DESVIO PADRÃO CONDICIONAL OBTIDO A PARTIR DAS 100 REALIZAÇÕES ESTOCÁSTICAS

FIGURA 4-14. NÚMERO TOTAL DE METAL QUANTIFICADO PARA CADA CORRESPONDENTE CATEGORIA PARA OS CRITÉRIOS DE CLASSIFICAÇÃO POR RESTRIÇÃO ELIPSOIDE DE BUSCA, VARIÂNCIA CONDICIONAL RELATIVA E PROBABILIDADE PONTUAL. 96

FIGURA 4-15. MODELO DE BLOCOS RESULTANTE DA CLASSIFICAÇÃO DOS RECURSOS MINERAIS, PELO CRITÉRIO DE CLASSIFICAÇÃO RESTRIÇÃO DO ELIPSOIDE DE BUSCA. 97

FIGURA 4-16. MODELO DE BLOCO RESULTANTE DA CLASSIFICAÇÃO DOS RECURSOS MINERAIS ESTIMADOS, PELO CRITÉRIO DE CLASSIFICAÇÃO VARIÂNCIA CONDICIONAL RELATIVA. 97

FIGURA 4-17. MODELO DE BLOCO RESULTANTE DA CLASSIFICAÇÃO DOS RECURSOS MINERAIS, PELO CRITÉRIO DE CLASSIFICAÇÃO PROBABILIDADE PONTUAL. .......... 98 FIGURA 4-18. NÚMERO TOTAL DE METAL QUANTIFICADO PARA CADA CORRESPONDENTE CATEGORIA, OBTIDOS A PARTIR DA RECLASSIFICAÇÃO POR BOOTSTRAP. 100

FIGURA 4-19. BLOCOS CLASSIFICADOS COMO RECURSOS MINERAIS MEDIDOS ANTES (AO LADO ESQUERDO) E APÓS (AO LADO DIREITO) DA RECLASSIFICAÇÃO POR BOOTSTRAP. AO LADO DIREITO DA FIGURA SE ILUSTRA SUPERPOSIÇÃO DOS BLOCOS MEDIDOS. 101

FIGURA 4-20. BLOCOS CLASSIFICADOS COMO RECURSOS MINERAIS INDICADO ANTES (AO LADO ESQUERDO) E APÓS (AO LADO DIREITO) DA RECLASSIFICAÇÃO POR BOOTSTRAP. AO LADO DIREITO DA FIGURA SE ILUSTRA A SUPERPOSIÇÃO DOS BLOCOS MEDIDOS. 102

FIGURA 4-21. BLOCOS CLASSIFICADOS COMO RECURSOS MINERAIS INFERIDOS ANTES (AO LADO ESQUERDO) E APÓS (AO LADO DIREITO) DA RECLASSIFICAÇÃO POR BOOTSTRAP. AO LADO DIREITO DA FIGURA SE ILUSTRA A SUPERPOSIÇÃO DOS BLOCOS INFERIDOS. 103

FIGURA 4-22. LOGARITMO NATURAL DA FUNÇÃO DE PROBABILIDADE COM VALOR ÓTIMO DE DESVIO PADRÃO IGUAL À UNIDADE. 104 
FIGURA 4-23. NÚMERO TOTAL DE BLOCOS QUANTIFICADOS PARA CADA CATEGORIA CORRESPONDENTE, OBTIDOS A PARTIR DO PÓS-PROCESSAMENTO DAS PROBABILIDADES SUAVIZADAS PELOS FILTROS DA MÉdIA (SUPERIOR) E GAUSSIANA (INFERIOR). 105

FIGURA 4-24. RESULTADO PARA A CLASSE DE RECURSOS MINERAIS MEDIDOS OBTIDO A PARTIR DA SUAVIZAÇÃO PELO FILTRO MÉDIO E GAUSSIANO, COM TAMANHOS DE JANELA DE HOMOGENEIZAÇÃO IGUAL A 5 X 5 X 5 . A FIGURA A E B REPRESENTA O RECURSO MINERAL MEDIDO APÓS A APLICAÇÃO DO FILTRO MÉdIO E GAUSSIANO, RESPECTIVAMENTE. 107

FIGURA 4-25. RESULTADO PARA A CLASSE DE RECURSOS MINERAIS INDICADOS OBTIDO A PARTIR DA SUAVIZAÇÃO PELO FILTRO MÉDIO E GAUSSIANO, COM TAMANHOS DE JANELA DE HOMOGENEIZAÇÃO IGUAL A 5 X 5 X 5. A FIGURA A E B REPRESENTA O RECURSO MINERAL INDICADO APÓS A APLICAÇÃO DO FILTRO MÉDIO E GAUSSIANO, RESPECTIVAMENTE. 108 FIGURA 4-26. RESULTADO PARA A CLASSE DE RECURSOS MINERAIS INFERIDOS OBTIDO A PARTIR DA SUAVIZAÇÃO PELO FILTRO MÉDIO E GAUSSIANO, COM TAMANHOS DE JANELA DE HOMOGENEIZAÇÃO IGUAL A 5 X 5 X 5. A FIGURA A E B REPRESENTA O RECURSO MINERAL INFERIDO APÓS A APLICAÇÃO DO FILTRO MÉDIO E GAUSSIANO, RESPECTIVAMENTE. 109

FIGURA 4-27. BITPLOT DAS 103 IT NO EIXO DE COORDENADAS F1 E F2. O CONJUNTO DE PONTOS AGRUPADOS CORRESPONDE ÀS REALIZAÇÕES IGUALMENTE PROVÁVEIS DA SIMULAÇÃO SGS (CHAMADAS SGTRANS); K.O: CU (\%) É O IT OBTIDO PELO KRIGAGEM ORDINÁRIO; K.O.T: CU (\%) É O IT OBTIDO PELO KRIGAGEM ORDINÁRIO TRANSFORMADO DA VARIÁVEL NORMAL (NSCORE); ETYPE: CU (\%) É A IMAGEM DE TREINAMENTO DERIVADA DAS 100 REALIZAÇÕES ESTOCÁSTICAS DA SGS. 110

FIGURA 4-28. SELEÇÃO IDEAL DO MODELO. OS DIAGRAMAS DE BARRAS DOS PLANOS XY E XZ, RESPECTIVAMENTE, SÃO MOSTRADOS À ESQUERDA E À DIREITA. ........ 112 FIGURA 4-29. ETYPE DAS 100 REALIZAÇÕES GEOESTATÍSTICAS GERADAS POR FILTERSIM DA VARIÁVEL CU (\%). ILUSTRANDO-SE UNICAMENTE OS VALORES ACIMA DO TEOR DE CORTE 0,33\%. 113 
FIGURA 4-30. DESVIO PADRÃO DAS 100 REALIZAÇÕES GEOESTATÍSTICAS GERADAS POR FILTERSIM DA VARIÁVEL CU (\%). ILUSTRANDO-SE UNICAMENTE OS VALORES ACIMA DO VALOR DE CORTE 0,33\%. 113

FIGURA 4-31. HISTOGRAMA DA MÉDIA DAS REALIZAÇÕES DA VARIÁVEL CU (\%)...... 114 FIGURA 4-32. HISTOGRAMA DO DESVIO PADRÃO CONDICIONAL DAS 100 REALIZAÇÕES ESTOCÁSTICAS POR FILTERSIM 114 FIGURA 4-33. MODELO DE BLOCO RESULTANTE DA CLASSIFICAÇÃO DOS RECURSOS MINERAIS ESTIMADO, PELO CRITÉRIO DE CLASSIFICAÇÃO PROBABILIDADE PONTUAL. 115

FIGURA 4-34. NÚMERO TOTAL DE BLOCOS QUANTIFICADOS PARA CADA CORRESPONDENTE CATEGORIA CALCULADO A PARTIR DA PROBABILIDADE PONTUAL. 116

FIGURA 4-35. MODELOS DE BLOCOS RESULTANTES DA RECLASSIFICAÇÃO DOS RECURSOS MINERAIS ESTIMADOS POR BOOTSTRAP. 119 FIGURA 4-36. NÚMERO TOTAL DE METAIS QUANTIFICADOS PARA CADA CORRESPONDENTE CATEGORIA OBTIDOS A PARTIR DA RECLASSIFICAÇÃO POR BOOTSTRAP. 120

FIGURA 4-37. LOGARITMO NATURAL DA FUNÇÃO DE PROBABILIDADE COM VALOR “ÓTIMO" DE DESVIO PADRÃO IGUAL A 1,05. 121

FIGURA 4-38. NÚMERO TOTAL DE METAIS QUANTIFICADOS PARA CADA CORRESPONDENTE CATEGORIA, OBTIDOS A PARTIR DO PÓS-PROCESSAMENTO DAS PROBABILIDADES SUAVIZADAS PELO FILTRO GAUSSIANO. 122 FIGURA 4-39. MODELOS DE BLOCOS RESULTANTE DA CLASSIFICAÇÃO DOS RECURSOS MINERAIS ESTIMADA PELO CRITÉRIO DE CLASSIFICAÇÃO PROBABILIDADE PONTUAL, APÓS A HOMOGENEIZAÇÃO DAS PROBABILIDADES MÁXIMAS OBTIDAS POR BOOTSTRAP 123 FIGURA 4-40. HISTOGRAMA DO VOLUME POR GRUPOS PARA CADA NOVA AMOSTRA $(55,110,165$ E 220). 125 FIGURA 4-41. DISTRIBUIÇÃO DO PARÂMETRO EFEITO PEPITA PARA CADA NOVA AMOSTRAGEM 55, 110, 165 E 220. 126 FIGURA 4-42. DISTRIBUIÇÃO DO PARÂMETRO CONTRIBUIÇÃO ESPACIAL DA 1응 DIREÇÃO PARA CADA NOVA AMOSTRAGEM 55, 110, 165 E 220. 127 
FIGURA 4-43. DISTRIBUIÇÃO DO PARÂMETRO CONTRIBUIÇÃO ESPACIAL DA 2o DIREÇÃO PARA CADA NOVA AMOSTRAGEM 55, 110, 165 E 220....................... 127 FIGURA 4-44. DISTRIBUIÇÃO DO PARÂMETRO AMPLITUDE DA 1ㅇ DIREÇÃO PARA CADA

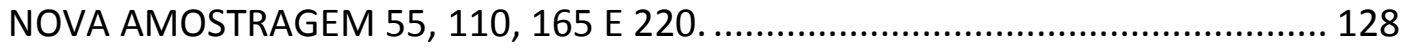
FIGURA 4-45. DISTRIBUIÇÃO DO PARÂMETRO AMPLITUDE DA 2 DIREÇÃO PARA CADA NOVA AMOSTRAGEM 55, 110, 165 E 220. 128 


\section{Introdução e Objetivos}

\subsection{INTRODUÇÃO}

A criação de sistemas internacionais e nacionais responsáveis pela declaração de recursos e reservas minerais assim como sua classificação, surgiu no início de 1970 como resposta às inúmeras fraudes que causaram perdas irreparáveis tanto a pessoas quanto à grandes mineradoras. As Normas Internacionais de Declaração também conhecidas como Códigos de Relatórios Minerais são essenciais em qualquer empreendimento de mineração para sua regularização judicial. Assim sendo, o investidor pode ter suas garantias protegidas além de transparência na declaração dos recursos minerais. Aliás, os códigos refletem diferentes restrições governamentais para cada país e região, embora haja semelhanças na aplicação de termos e definições principais.

Em geral, os padrões internacionais de declaração de recursos/reservas minerais podem ser subdivididos em duas classes: Sistemas Internacionais e Códigos/Padrões Nacionais. Os mais notórios são CRIRSCO (CRIRSCO, 2013) e JORC (JORC, 2012). Ambos têm como princípio a subdivisão da alocação mineral em três tipos: Resultados de Exploração, Recursos Minerais e Reservas Minerais que ajudam avaliar o grau de flexibilidade técnico-econômica de projetos voltados a mineração. Esses códigos são baseados em três princípios que regem o funcionamento e a aplicação das seguintes diretrizes: transparência, materialidade e competência que ajudam na elaboração da declaração pública dos recursos minerais, possibilitando uma avaliação justa e auditável. Além disso, essas normas estabelecem que os recursos devem ser subdivididos em ordem crescente de confiança e conhecimento geológico como: Inferido, Indicado e Medido permitindo assim que um profissional possa avaliar tais recursos a partir das normas e de sua experiência sobre o tipo de mineralização. Afinal, vale destacar a importância do grau da qualificação do teor e tonelagem do recurso mineral por parte do profissional que viabilize sua classificação do modo mais preciso possível. 
Essas classes aplicadas a um depósito mineral são definidas com base na distribuição espacial das unidades amostrais e na incerteza dos valores estimados. Tais incertezas têm várias fontes como, por exemplo: o espaçamento entre sondagens, a qualidade dos dados e a continuidade da mineralização. No entanto, o método de quantificação de incerteza não é estabelecido nos sistemas de classificação, assim como o método de estimativa a ser aplicado. Neste sentido, diversas abordagens geoestatísticas vêm sendo adaptadas ao longo do tempo com intuito de identificar as diferentes classes de recursos minerais com maior rigor.

Os critérios de classificação desenvolvidos atualmente podem ser agrupados em métodos tradicionais qualitativos e quantitativos de geoestatística. Vale citar que as incertezas dos recursos minerais classificados nos dias de hoje são oriundas de uma série de propostas da krigagem ordinária devido à sua simplicidade e aceitação na indústria mineral. Entre essas propostas estão: a variância de krigagem e da interpolação, o desvio padrão relativo da variância da krigagem e a densidade amostral. No entanto, a literatura discute se a variância da krigagem captura a variabilidade local dos dados, já que a mesma depende da função do variograma e não dos valores amostrais. Consequentemente, a variância da krigagem é vista como um índice de configuração espacial local dos dados e não como uma medida de variabilidade.

Objetivando a classificação dos recursos minerais além da análise de risco e tomada de decisão pelo profissional, a indústria mineral nos últimos anos vem utilizando a simulação condicional como uma ferramenta capaz de classificar os recursos e quantificar suas incertezas. A popularidade desse método deve-se à sua vantagem sobre a krigagem e seus múltiplos modelos plausíveis a realidade. Esses modelos permitem calcular as incertezas para cada bloco/unidade do conjunto de realizações estocásticas independentes a partir de uma função de transferência local como por exemplo: o coeficiente de variação condicional, a variância condicional ou a razão entre a variância condicional e o quadrado da média. (Figura 1-1). 


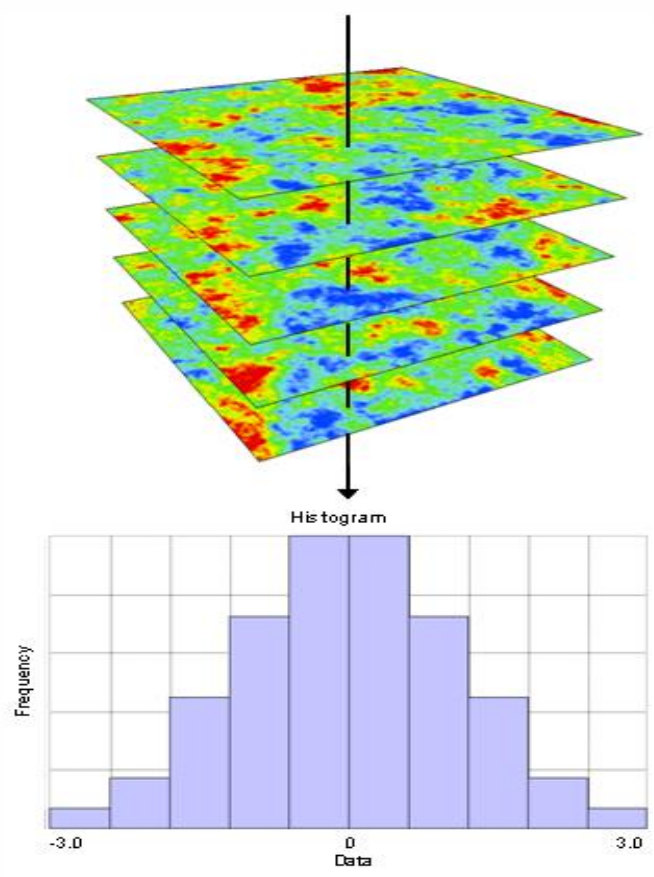

Figura 1-1. Captura da variabilidade local por meio da função de transferência de interesse. (Fonte: www.pro.arcgis.com).

A krigagem e a simulação são utilizadas na classificação de recursos minerais que dependem da função variograma, assim como a escolha arbitrária de parâmetros apropriados para a classificação dos recursos estimados. Tanto o variograma quanto a hipótese de linearidade da variável estimada e/o simulada, são vistas como uma limitação dessas ferramentas. Assim, este trabalho propõe o uso da simulação estocástica de estatísticas de ordem superior FILTERSIM (MPS) como método de estimativa dos recursos minerais, além do estudo comparativo entre o método SGS que é uma técnica consolidada na geoestatística e o FILTERSIM; juntamente com o cálculo das incertezas associadas a cada bloco através de uma função de transferência local. A função de transferência usada nesta pesquisa denomina-se probabilidade condicional pontual. Essa função é aplicada nos métodos de simulação condicional geoestatística (SGS e FILTERSIM), para estimar os recursos minerais por meio de imagens estocásticas equiprováveis dos minerais de interesse. Aliás, as unidades/blocos do modelo tridimensional simulado foram classificadas segundo seu grau de confiança geológica e estatística segundo as subdivisões: Medido, Indicado e Inferido, através do uso do teorema do Limite Central e da distribuição Normal. O critério probabilístico aplicado as múltiplas realizações estocásticas apresentam várias vantagens como por exemplo: as vantagens da simulação estocástica da geoestatística, as probabilidades 
obtidas através da distribuição normal aplicada nas ciências da terra, a consideração das incertezas locais bem como o efeito proporcional e por fim sua aplicabilidade em qualquer tipo de depósito natural caracterizado por ter uma distribuição simétrica ou assimétrica.

Vale mencionar que as aplicações de métodos de estimativa geoestatística frequentemente resultam em artefatos causados pela falta de uma análise geológica profissional, já que não são consideradas por essas ferramentas matemáticas. Esses artefatos são conhecidos na indústria mineral como "spotted dog" e podem induzir o profissional a sérios erros na classificação dos recursos minerais, pois mascaram aspectos importantes como a continuidade geológica e a mineralização. Assim sendo, dois filtros lineares foram empregados para remover/diluir possíveis "ruídos" presentes na imagem (em 2D ou 3D): o filtro de Média e filtro Gaussianos. Ambos os métodos foram testados como uma solução "parcial" ao problema do "spotted dog". Por fim, foi realizada uma análise de sensibilidade dos parâmetros essenciais da modelagem do variograma a partir da decomposição da variância. 


\subsection{OBJETIVOS}

O trabalho tem como objetivo indicar se existem vantagens na aplicação do método estatístico de ordem superior (FILTERSIM) sobre o método baseado nas estatísticas de dois pontos (SGS), a partir da comparação dessas técnicas de simulação geoestatística. Além disso, a comparação será realizada através da quantificação das incertezas das classificações dos recursos minerais em um depósito de cobre. Assim, este estudo visa aplicar uma nova medida de incerteza para classificar os recursos minerais dentro das diferentes classes ou categorias derivadas da função de distribuição condicional da Normal padrão, denominada, probabilidade condicional pontual.

A probabilidade condicional pontual como critério de classificação será aplicado, analisado e comparado com o método tradicional conhecido como área de influência do variograma, assim como o método de variância condicional relativa, sendo o primeiro o mais utilizado na indústria mineral. Além disso, uma análise de sensibilidade dos parâmetros matemáticos da modelagem variográfica será elaborada a partir da reamostragem do conjunto total de dados do depósito mineral visando o estudo dos parâmetros que apresentam maior influência nas estimativas.

Para atingir os objetivos o trabalho será executado em quatro etapas principais:

i. Seleção adequada de um modelo geológico conceptual em 3D (Imagem de Treinamento) usando: análise dos componentes principais e o mapa cientifico Bitplot.

ii. Aplicação e avaliação dos recursos minerais estimados através dos métodos estocásticos SGS e FILTERSIM.

iii. Classificação e reclassificação dos recursos minerais pelos processos probabilísticos condicional pontual e Bootstrap.

iv. Decomposição da variância da função escalar para cada nova amostragem obtida do conjunto de dados total. 


\section{Revisão Bibliográfica}

\section{1 CLASSIFICAÇÃO DE RECURSOS/RESERVAS MINERAIS}

Sistemas internacionais de classificação que estabelecem padrões/códigos (Figura 2-1) enfatizam as três classes primárias que subdividem os Recursos Minerais, bem como o nível de confiança ou grau de certeza associado ao estimado, no entanto, não apontam quais procedimentos e metodologias que devem ser adotados. Como consequência, em um depósito mineral, o cálculo dessas categorias, varia amplamente de acordo com a seleção do método de avaliação e a experiência dos profissionais responsáveis pela classificação (Sabourin, 1983).

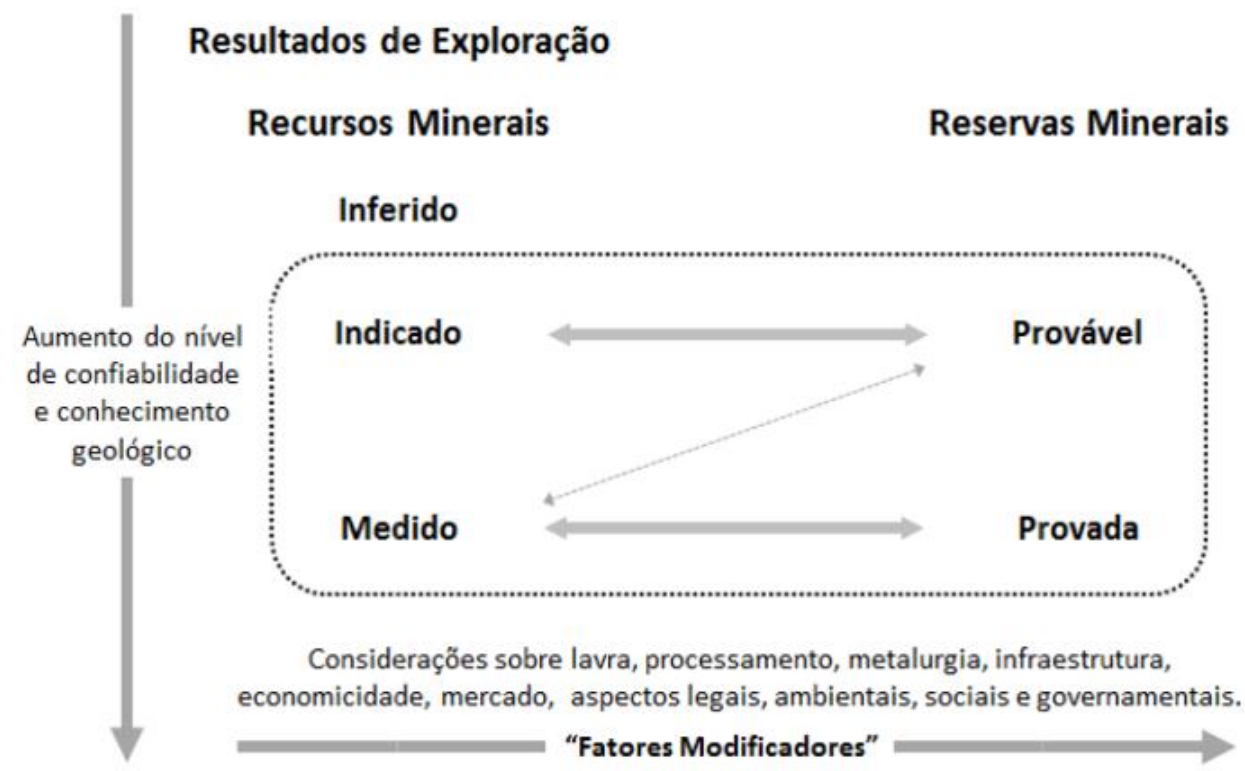

Figura 2-1. Resultados de Exploração, Recursos Minerais e Reservas Minerais. (Fonte: CBRR, 2016).

Tradicionalmente, os métodos de classificação de um recurso mineral como o baseado em interpretações seccionais, a distância mínima de influência até a amostra mais próxima ou o número de amostras máximas no raio de busca (Figura 2-2), são abordagens qualitativas e subjetivas que variam de depósito para depósito (Sabourin, 
1983; Sabourin, 1984; Annel, 1991; Snowden, 1996; Abzalov, 2016), de modo que, a classificação racional dos recursos não está bem determinada (Abzalov, 2016). Devido a várias limitações das técnicas anteriores, os modernos sistemas de informação promovem a integração de ferramentas geoestatísticas na definição coerente e não subjetiva das diferentes categorias de recursos minerais (JORC, 2012; CRIRSCO, 2013).
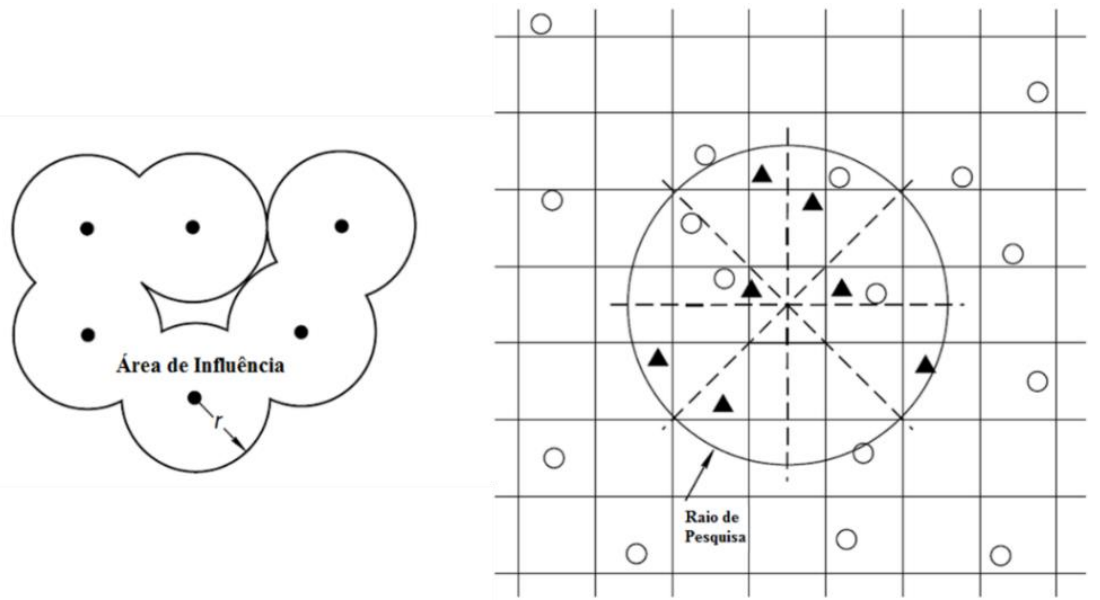

Figura 2-2. Conceito da área de influência, ou zona de influência, em torno do bloco a ser classificado, assim como, o número de amostras máximas no raio de busca próximas ao bloco de interesse. (Fonte: Sinclair e Blackwell, 2004).

O uso da geoestatística na estimativa de recursos/reservas minerais tem sido amplamente utilizado desde meados da década de 1980 (Champigny e Armstrong, 1993, Kwa e Mousset-Jones, 1986, apud Sinclair e Blackwell, 2004), resultando em diferentes medidas quantitativas. Nesse sentido, a geoestatística sempre fará parte da classificação, em relação à segurança geológica. Embora, considerações geológicas sempre predominem sobre qualquer medida matemática (Emery et al., 2006).

Posteriormente, para a classificação do recurso com base em restrições geométricas, ou seja, o número e a configuração das amostras pertencentes a determinado raio de busca, um procedimento similar foi proposto por Dohm (2005). De acordo com Dohm (2005), os recursos são categorizados como Inferido quando as perfurações estão espaçadas a distâncias maiores do que a amplitude de influência do variograma. Enquanto isso, um recurso é considerado medido se o espaço de perfuração estiver localizado entre dois terços da variabilidade total, e o restante até a amplitude se considera indicado. 
Da mesma forma, Marwanza et al. (2016) propõem um método para classificar recursos com base nas diferentes geometrias concêntricas obtidas a partir da amplitude do modelo de variograma. Neste método os recursos são agrupados em Medido, Indicado e/ou Inferido para distâncias inferiores a 1/3 da amplitude, 2/3 da amplitude e amplitude, respectivamente. Essa abordagem (distância do variograma, Figura 2-3) pode ser difícil de interpretar quando a contribuição espacial é uma pequena proporção da variabilidade total e, em contraste, a proporção do componente efeito pepita, no variograma é muito alta. Assim, os diferentes intervalos de amplitude do variograma são de pouca utilidade como critério de classificação de recursos (Sinclair e Blackwell, 2002; Dohm, 2005).
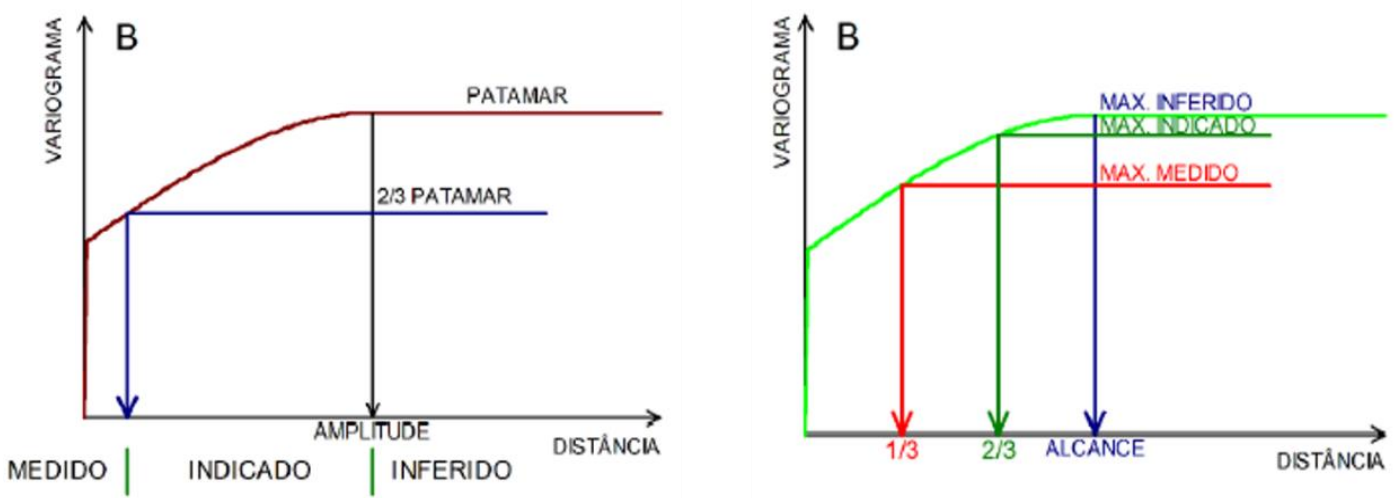

Figura 2-3. Classificação de recursos minerais baseada na distância de variograma. Introduzidos por Dohm (2005) (A) e Marwanza et al. (2016) (B), respectivamente. (Fonte: Geokrigagem).

Rossi e Deutsch (2014) propõem uma alternativa derivada do modelo de variograma, o qual é obter a média ponderada das distâncias de todas as observações usadas na estimativa de um bloco. Esses mesmos autores enfatizam que este método pode ser uma opção razoável, se todas as unidades amostrais utilizadas na estimativa forem consideradas. De modo que as diferentes relações espaciais possam ser refletidas pelas distâncias anisotrópicas e/ou isotrópicas. Ainda de acordo com esses autores, existem duas grandes limitações com este sistema: (1) A falta de uma medida de incerteza e; (2) Os critérios simples usados.

Na mesma linha, Mory e Deutsch (2006) usam o modelo de autocorrelação espacial como critério de classificação conjuntamente com as abordagens de densidade de amostragem e espaçamento de dados. Esses autores propõem um algoritmo robusto 
para calcular a separação entre perfurações (DHS - Drillhole Spacing), verticais e não verticais, para fenômenos anisotrópicos contínuos e/ou categóricos em 2D e 3D.

No caso bidimensional, a separação de dados é definida como a média aritmética do bloco em cada direção (equação 2.1), conforme ilustrado na Figura 2-4. A densidade local para cada localização é dada pelo número de amostras por hectare que estão dentro de uma área retangular ou elíptica, dividida pela área A, como ilustrado na equação 2.2. Onde a área $\mathrm{A}$, depende da forma e da anisotropia, e pode ser calculada para uma forma elíptica e retangular como, nas equações 2.3.

No caso tridimensional em que as perfurações não são paralelas ou verticais, é necessário calcular o número nominal de perfurações a partir do número de perfurações paralelas verticais, contendo o mesmo número de amostras que as perfurações reais no mesmo volume (Mory e Deutsch, 2006). O número nominal de perfurações, para o mesmo suporte c, é calculado como mostrado na equação 2.2. Em seguida, a densidade de amostragem e a separação de dados são finalmente calculadas substituindo a expressão $n_{s}$ por $n_{d h}$ na equação 2.1 .

\section{Espaçamento de Perfuração}

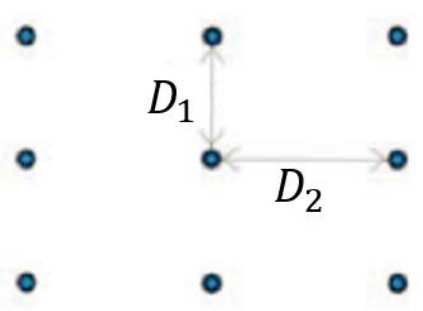

\section{Densidade Amostral}

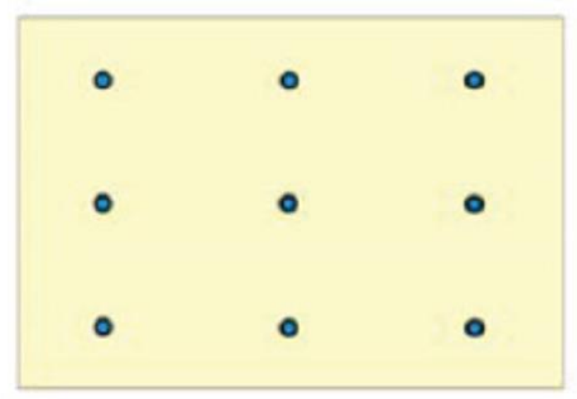

Figura 2-4. Ilustração do espaçamento médio entre perfurações e a densidade amostral. Com $D_{1}$ e $D_{2}$ são as distâncias de separação nas direções horizontais e, a área de cor amarela define o volume ou área por hectare da densidade amostral. (Fonte: Mory e Deutsch, 2006).

$$
\operatorname{DHS}(u)=\frac{D_{1}+D_{2}}{2}=\sqrt{\frac{10000}{D H D(u)}}
$$


onde DHD (u) é definido como (Mory e Deutsch, 2006, p. 309):

$$
D H D(u)=\frac{n_{s}(u)}{A} * 10000
$$

E a área, de acordo com sua forma, é dada por:

$$
\begin{aligned}
& A=\pi *\left(s h_{\text {max }} * a_{h}\right)^{2} \\
& A=\left(2 * s h_{\text {max }} * a_{h}\right)^{2}
\end{aligned}
$$

onde, $s h_{\max }$ é o raio máximo de busca no eixo horizontal, e $a_{h}$ é o fator de anisotropia horizontal definido como a relação de anisotropia.

$$
n_{d h}=\frac{n_{s}(u) * c * a_{v}}{2 * s h_{\max }}
$$

onde c é um comprimento de composição constante e $a_{v}$ é o fator de anisotropia vertical obtido através da relação de anisotropia.

Com o uso da geoestatística como método quantitativo de classificação de recursos minerais, o profissional da indústria mineral tenta expressar com certo grau de confiança os recursos classificados como Medido, Indicado e/ou Inferido. O "nível de confiança", ou confiabilidade, dos recursos pode ser explicado quantitativamente através da variância da estimativa (VK), que é uma das ferramentas mais importantes da geoestatística (Sabourin, 1983). A variância da krigagem depende do modelo de correlação espacial (modelo de variograma), da configuração das observações e da quantidade de informação em relação ao bloco de interesse (Sabourin, 1983; Dohm, 2005; Emery et al., 2006).

Neste aspecto, a VK mescla duas características importantes: que são a geometria e conhecimento geológico. Mas, na prática estes critérios de classificação são baseados na escolha arbitrária de um parâmetro limiar (Royle, 1977; Sabourin, 1983, Froidevaux, Roscoe e Valiant, 1986; Snowden, 1996), com base na experiência profissional e conhecimento do depósito. Por essa razão, a abordagem geoestatística seria tão subjetiva quanto a abordagem tradicional da classificação de recursos minerais (Sabourin, 1984). Nesse sentido, segundo Sabourin (1983), a pergunta que precisa ser 
respondida é: Quais valores devem dividir a variância da estimativa, para que os recursos minerais de um depósito sejam delineados da melhor maneira possível?

Em resposta à sua pergunta, Sabourin (1983), propõe o uso do valor absoluto da diferença entre a variância experimental do bloco em questão, e a variância real do bloco, que é: $\left|D^{2}(Z)-D^{2}\left(Z^{*}\right)\right|$. Desta forma, os recursos são classificados como Medido se a diferença entre as variâncias não excederem $10 \%$ do total. Da mesma forma, se a diferença relativa for menor ou maior que $20 \%$ do total, então os recursos são classificados como Indicado e/ou Inferido, respectivamente. Segundo este mesmo autor, a diferença relativa deve ser aplicada uniformemente a qualquer depósito mineral como critério técnico possível.

Sabourin (1984) propõe um método de classificação de recursos baseado na quantidade de tonelagem local usando os limites da variância da krigagem determinados a partir da variância dos blocos. Estes parâmetros limítrofes são calculados usando a relação proporcional dada por:

$$
\sigma_{K}^{2}=K * \sigma_{b}^{2}
$$

onde $K$ é uma constante arbitraria, selecionada da experiência e dependente do tipo de depósito. Este autor usa os parâmetros limiares como: $K=0,2, K=0,4$ e $K=0,8$ para classificar os recursos como Medido, Indicado e Inferido, respectivamente.

Segundo Dohm (2004), o uso da variância da krigagem como medida de dispersão de dados e método quantitativo de classificação de recursos minerais, é controverso, uma vez que a única relação que a variância de estimativa tem com as observações locais é o modelo de correlação espacial. Isto é, a variância de estimativa é o mesmo, para uma amostra fixa, ainda quando as distribuições espaciais dos valores adjacentes são mais homogêneas ou heterogêneas.

Portanto, a variância da krigeagem é vista como um índice de configuração espacial dos dados e não uma medida de variabilidade (Yamamoto, 1999; Rossi e Deutsch, 2014). Esta limitação levou à introdução de técnicas de classificação com base no conceito de variações relativas, com a finalidade de reconhecer a configuração e a variabilidade dos dados locais (Dohm, 2004). Essa aproximação é obtida a partir da 
razão entre a variância estimada e o quadrado do valor estimado para cada bloco do modelo (Dohm, 2005; Emery et al., 2006; Abzalov, 2016), também conhecido em sua sigla em inglês como RKV.

Blackwell (1998, apud Sinclair e Blackwell, 2002; Dohm, 2005), propõe o uso do desvio padrão relativo da variância da krigagem (RKSD), isto é, a raiz quadrada da RKV. Dois valores limiares são selecionados arbitrariamente, com base no conhecimento do depósito mineral, para separar apropriadamente as classes de recursos minerais. O valor RKSD é plotado em função do número de amostras usadas na estimativa do valor desconhecido do bloco por krigagem, como ilustrado na Figura 2-5. De acordo com Sinclair e Blackwell (2002), o sistema de classificação RKSD é útil em depósitos de pórfiros e epitermais de cobre, e pode ser realizado através de três etapas como segue:

i. Verificar a continuidade geológica

ii. Identificar os blocos estimados acima do teor de corte

iii. Classificar os blocos selecionados em (ii) com base no desvio padrão relativo da krigagem.

Inferido $\geq 0.5>$ Indicado $>0.3 \geq$ Medido 


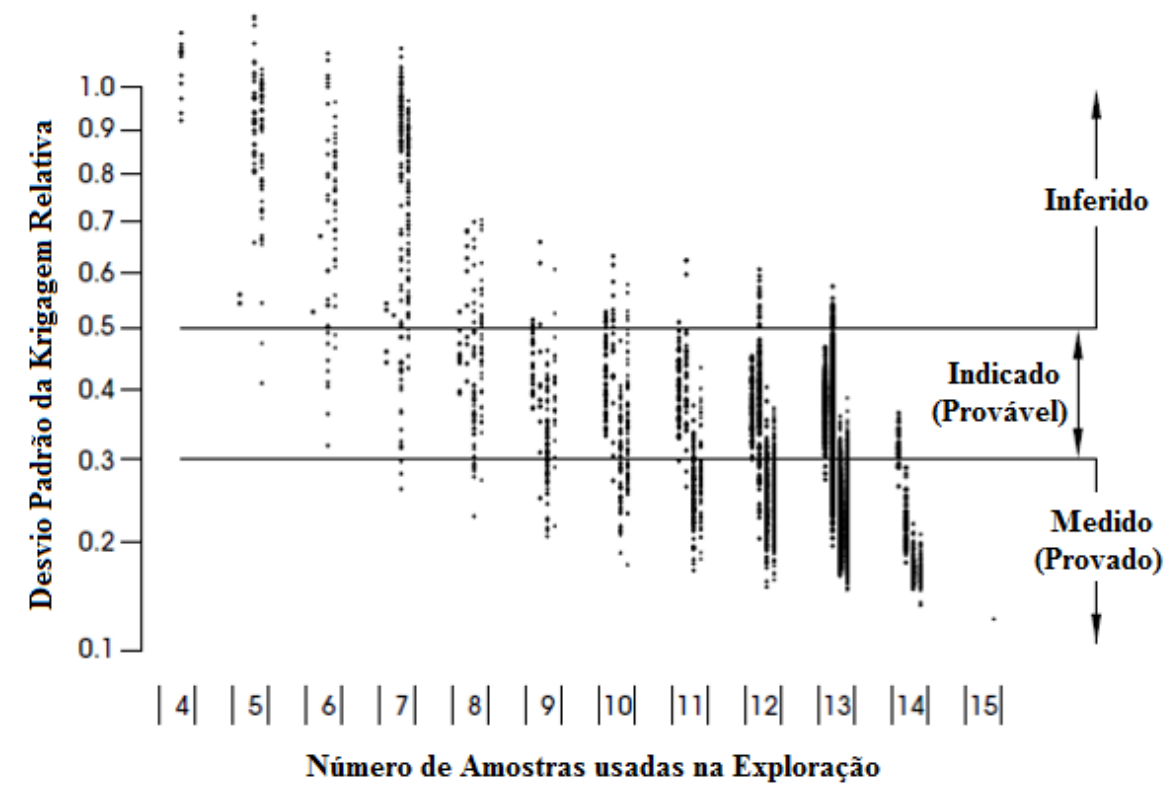

Figura 2-5. Exemplo típico do critério de classificação RKSD baseado no número de amostras usadas na estimativa do bloco, em um depósito de ouro epitermal. (Fonte: Sinclair e Blackwell, 2002).

Em relação ao conceito de erro e grau de certeza, baseado na noção de probabilidade do intervalo de confiança, vários autores propuseram vários níveis de erro na limitação e classificação dos recursos minerais, resumidos na Tabela 2-1 (Dielh e David, 1982; Wellmer, 1983; Yamamoto, 1999; Camisani-Calzoralo et al., 2000).

Tabela 2-1. Classificação de recursos/reservas minerais com base no erro e grau de incerteza.

\begin{tabular}{|c|c|c|c|c|}
\hline \multirow[b]{2}{*}{ Autor } & \multicolumn{2}{|c|}{ Medido } & Indicado & \multirow{2}{*}{$\begin{array}{l}\text { Inferido } \\
\text { Inferido }\end{array}$} \\
\hline & Provado & Provável & Possível & \\
\hline \multirow{2}{*}{$\begin{array}{c}\text { Dielh e David } \\
(1982)\end{array}$} & Erro: $\pm 10 \%$ & Erro: $\pm 20 \%$ & Erro: $\pm 40 \%$ & Erro: $\pm 60 \%$ \\
\hline & C.L: $>80 \%$ & C.L: $>60-80 \%$ & C.L: $>40-60 \%$ & C.L: $>20-40 \%$ \\
\hline \multirow[t]{2}{*}{ Wellmer (1983) } & Erro: $\pm 10 \%$ & Erro: $\pm 20 \%$ & Erro: $\pm 30 \%$ & Erro: $\pm 50 \%$ \\
\hline & C.L: $>90 \%$ & C.L: $>90 \%$ & C.L: $>90 \%$ & C.L: $>90 \%$ \\
\hline \multirow[t]{2}{*}{ Yamamoto (1998) } & \multirow{2}{*}{\multicolumn{2}{|c|}{$\begin{array}{c}\text { Erro: } \pm 0-20 \% \\
\text { C.L: }>90 \%\end{array}$}} & Erro: $\pm 20-50 \%$ & Erro: $\pm 50 \%$ \\
\hline & & & C.L: $>90 \%$ & C.L: $>90 \%$ \\
\hline \multirow{2}{*}{$\begin{array}{c}\text { Camisani-Calzoralo } \\
\text { et al. }(2000)\end{array}$} & Erro: $\pm 5 \%$ & Erro: $\pm 10 \%$ & Erro: $\pm 15 \%$ & Erro:Nulo \\
\hline & C.L: $>90 \%$ & C.L: $>90 \%$ & C.L: $>90 \%$ & C.L: $>90 \%$ \\
\hline
\end{tabular}

Nas duas últimas décadas, a indústria mineral concentrou seus esforços na aplicação de técnicas de simulação condicional, com base em estatísticas de dois pontos para apoiar a classificação de recursos minerais. Durante vários anos, algumas variantes foram propostas sob a premissa "com uma confiança de 90\%, é esperado que para um 
período específico de produção, a estimativa do bloco em questão, a percentagem de erro não exceda 15\% da variabilidade total" (Dohm, 2005; Murphy, 2005; Silva e Boisvert, 2014; Rossi e Deutsch, 2014), que inclui em sua filosofia o conceito de certeza, probabilidade e erro. Dohm (2005) propôs o uso do coeficiente de variação (CV) como medida de confiabilidade no recurso estimado para diferentes volumes de produção: Local; Mensal e; Anual.

O $C V_{\text {local }}$ é obtido a partir da simulação condicional, e os valores de $C V_{\text {mensal }}$ e $C V_{\text {anual }}$, se derivam dos períodos de produção que são obtidos a partir da análise estatística de dados históricos. Segundo Dohm (2005), uma modificação de suporte é necessária para representar a variabilidade equivalente com um período de produção no modelo de blocos, chamado de fator de produção (FP). O FP é usado para definir as diferentes classes, onde cada bloco do modelo de recursos minerais é classificado em ordem decrescente de confiança em Medido, Indicado e Inferido, conforme:

$$
\begin{aligned}
& \text { i. } \quad C V_{b} \leq C V_{\text {Medido }}=\frac{15 \% \times \frac{C V_{\text {local }}}{C V_{\text {mensal }}}}{z_{\frac{\alpha}{2}}} \\
& \text { ii. } \quad C V_{\text {Medido }}<C V_{b} \leq C V_{\text {Indicado }}=\frac{15 \% \times \frac{C V_{\text {local }}}{C V_{\text {anual }}}}{z \frac{\alpha}{2}} \\
& \text { iii. } \quad C V_{b}>C V_{\text {Indicado }}
\end{aligned}
$$

onde, $C V_{b}$ é o coeficiente de variação do bloco dado pela razão entre o desvio padrão e o valor estimado do krigagem e, $Z_{\frac{\alpha}{2}}$ é o valor da distribuição normal padronizada com nível de confiança, $\alpha$.

Segundo Dohm (2005), a regra que engloba os conceitos de certeza, probabilidade e erro, é um procedimento empírico bem aceito na indústria mineral, embora seu desenvolvimento seja baseado no conceito de intervalo de confiança. Há três aspectos importantes a serem considerados na classificação de recursos com base nessa regra (Rossi e Deutsch, 2014): (1) Volume de um período de classificação específico; (2) Precisão e; (3) Probabilidade dentro da faixa de precisão específica. A Figura 2-6 ilustra os parâmetros usados neste método de classificação. 


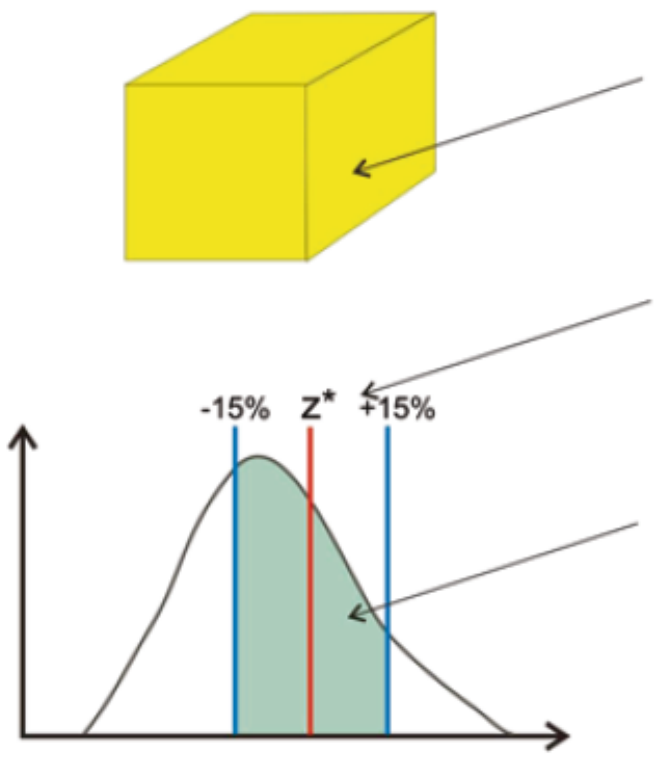

\section{Volume, avaliação técnico-econômica}

\section{Valor estimado e seleção da medida da incerteza $+/-15 \%$}

\section{Probabilidade de estar dentro da medida da incerteza}

Figura 2-6. Ilustração dos três parâmetros utilizados na regra de classificação: (1) volume, (2) precisão e (3) probabilidade de estar dentro da medida de incerteza. (Fonte: Adaptado de Rossi e Deutsch, 2014).

Nessa mesma linha, Duggan e Dimitrakopoulos (2005), propõem o uso do coeficiente de variação condicional (CVC), ou desvio padrão condicional relativo, como medida de incerteza e classificação dos recursos minerais. Essa aproximação é independente do período de produção (mensal e anual) para a definição das classes de recursos minerais. O critério de classificação é baseado na seleção arbitrária de um parâmetro limiar, em que um bloco pode ser classificado em Medido se o CVC for menor que $2 \%$ da variabilidade total, Indicado se o CVC for menor que $4 \%$ e superior a $2 \%$ da variabilidade total, e será Inferido se o CVC exceder $4 \%$.

Em relação ao que será proposto nesta tese, apenas dois artigos são mais semelhantes ao proposto, apresentados por Duggan e Dimitrakopoylos (2005) e Emery et al. (2006). O primeiro trabalho calcula a probabilidade de um valor estar dentro de um intervalo $(\mathrm{a}, \mathrm{b})$, sem referenciar ou destacar este processo como um método de classificação de recursos. O objetivo do trabalho de Duggan e Dimitrakopoulos (2005) é utilizar o coeficiente de variação condicional como medida de quantificação da incerteza e método de classificação. Já Emery et al. (2006) classificam o recurso mineral de acordo com diferentes valores que subdividem a variância condicional relativa (VCR) dada pela razão entre a variância condicional de cada bloco e o quadrado da média condicional dos blocos simulados. Desde o ponto de vista probabilístico, o 
critério de classificação de Emery et al. (2006), pode ser visto como a desigualdade de Chebyshev, se cada VCR do bloco é dividido pelo número de realizações, e escrito matematicamente conforme apresentado na equação (2.6):

$$
P(|X-\mu| \geq k) \leq \frac{\sigma^{2}}{n * k^{2}}
$$

com $k$ igual à média condicional para cada bloco e $n$ o número total de modelos igualmente prováveis.

Silva e Boisvert (2014) propõem uma nova técnica de classificação, que preserva as vantagens da variância da krigagem sobre as técnicas geométricas. Estes autores utilizam o método de verificação de erros de estimativa da krigagem combinado com a variância da krigagem, que denominam de variância de validação cruzada (CVV). Adicionalmente, Silva e Boisvert (2014) destacam a redução de artefatos causados pela variância da krigagem e a incorporação do conhecimento da variabilidade e continuidade espacial dos dados.

O VVC é realizado em três etapas principais: (1) Extração da (s) perfuração (ões) com maior peso da krigagem; (2) Cálculo da variância da krigagem com os demais dados e; (3) Aplicação dos parâmetros limiares de classificação. Além disso, o critério de classificação, VVC, depende da escala do modelo, como mostrado na Tabela 2-2.

Tabela 2-2. Classificação de recursos mineral com base no tipo de escala (menor o maior), de acordo com Silva e Boisvaert (2014).

\begin{tabular}{ccc}
\hline Tipo de Escala & Medido & Indicado \\
\hline Menor & Erro: $\pm 30 \%$ & Erro: $\pm 30 \%$ \\
& C.L: $90 \%$ & C.L: $90 \%$ \\
Maior & Erro: $\pm 15 \%$ & Erro: $\pm 30 \%$ \\
& C.L: $95 \%$ & C.L: $80 \%$ \\
\hline
\end{tabular}

Segundo Silva e Boisvaert (2014), o uso da simulação condicional como auxílio na classificação dos recursos minerais apresenta dois importantes inconvenientes que dependem em grande parte do profissional responsável pela modelagem: (1) A seleção adequada de uma função de covariância espacial e; (2) O modelo de tendência, que torna a divulgação de recursos minerais menos transparente para os investidores. 
De acordo com o exposto, observa-se que nas últimas décadas várias tentativas têm sido feitas para classificar os recursos minerais através de diferentes metodologias, mas nenhum método ganhou aceitação internacional e até o momento, nenhum trabalho emprega o conceito de valor de corte (parâmetro que separa o bloco de mineiro do estéril) juntamente com a probabilidade condicional pontual. Desta forma, este trabalho tem como objetivo, avaliar a estimativa pontual do parâmetro de interesse como medida de classificação e incerteza dos recursos minerais, cujos resultados serão comparados com aqueles métodos "clássicos" de classificação. Além disso, a falta na literatura, de um método ou mecanismo que seja adequado para descrever a natureza da mineralização no depósito em estudo é frequentemente observada e, portanto, neste trabalho é explorada a possibilidade do uso de técnicas de simulação de múltiplos pontos na estimativa e classificação dos recursos minerais.

Por outro lado, muitas vezes, a aplicação das diferentes ferramentas quantitativas de geoestatística (krigagem e simulação sequencial), é baseada no uso de parâmetros matemáticos que não foram adequadamente testados, talvez pela falta de informação ou tempo. Assim, neste trabalho é realizada uma análise de sensibilidade, principalmente dos parâmetros essenciais, da modelagem do variograma experimental, a partir da decomposição de variância (DV). Este DV é sistematicamente avaliado usando diferentes tamanhos de amostras utilizando como referência à base de dados real, calculando as estatísticas, variogramas e recursos minerais associados.

\subsubsection{DEFINIÇÃO E CLASIFICAÇÃO DE RECURSOS/RESERVAS MINERAIS}

A quantificação de elementos naturais, da crosta terrestre, em termos de teores e volumes pode ser realizada através de procedimentos numéricos disponíveis na geoestatistica. De acordo com Sinclair e Blackwell (2002), teores e volumes que são normalmente baseados em estudos de viabilidade econômica são classificados como reservas, e teores e volumes onde eles não foram rigorosamente avaliados, isto é, viabilidade econômica, são geralmente classificados como recursos. Em geral, a estimativa/simulação de recursos/reservas minerais é determinada, regularmente, a partir do discretizado cartesiano (bidimensional ou tridimensional) do deposito mineral, 
onde cada valor central da célula/bloco é estimado e/ou simulado usando os vizinhos subjacentes (Figura 2-7).

Naturalmente, a qualidade da aproximação do valor em cada bloco estimado/simulado depende essencialmente de quatro fatores principais: Dados de condicionamento, configuração e continuidade espacial, e a natureza de seus valores locais (Emery et al., 2006).

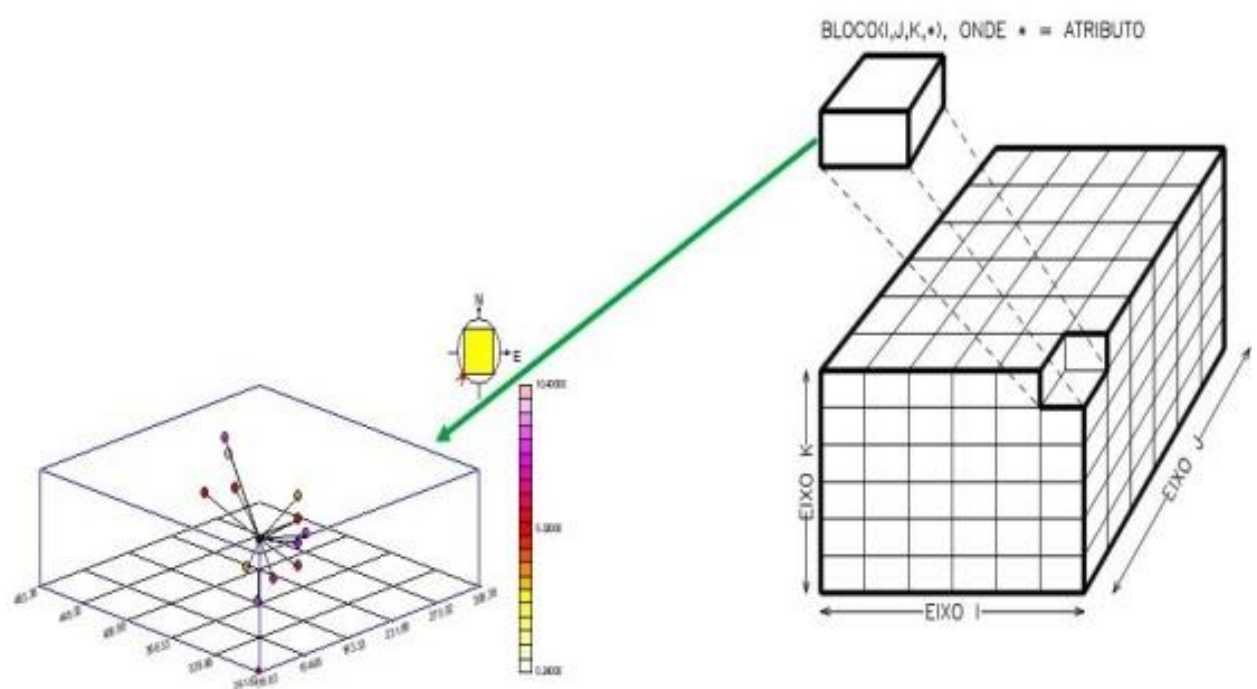

Figura 2-7. Ilustração tridimensional de uma situação geral na estimativa de teores e volumes. A zona mineralizada ou deposito é discretizado por um número de blocos em X, Y e Z. Onde cada bloco é estimado das informações adjacentes dentro de um raio de busca. (Fonte: Geokrigagem).

Segundo Snowden (1996), a classificação de recursos/reservas minerais é importante porque define o risco associado às tonelagens e qualidade dos recursos existentes, permitiendo o 'melhor' julgamento sobre o valor dos recursos existentes na declaração de recursos minerais. Sinclair e Blackwell (2002) resumem em cinco razões essenciais para a classificação de recursos e reservas minerais deve ser realizada:

i. Criação de um inventário formal dos principais ativos da empresa;

ii. Documentação de ativos para demonstrar o potencial de produção a médio ou longo prazo;

iii. Arrecadar fundos no mercado financeiro;

iv. Fornece um nível de confiança para as instituições financeiras; 
v. Fornece uma base para o cálculo de royalties, impostos, uso da terra, entre outros.

Esses mesmos autores também destacam dois motivos principais, pelos quais se faz a classificação de recursos/reservas minerais. O primeiro é introduzir um parâmetro, ou estimador, quantitativo ou semi-quantitativo de incerteza e o segundo é o desenvolvimento de um conjunto de padrões internacionais. De acordo com Revuelta (2018), a classificação de estimativas de recursos minerais é utilizada com o objetivo de organizar as diferentes informações sobre matérias-primas e/ou produtos com valor econômico.

Devido à grande importância histórica da mineração em países como Austrália, África do Sul, Estados Unidos e Canadá, e junto com a Europa, promoveram por décadas as diferentes normas, ou códigos, usadas em todo o mundo (Revuelta, 2018), entre as principais estão a SME americana (Sociedade Americana de Mineração, Metalurgia e Exploração), o código sul-africano SAMREC (Comitê de Recursos Minerais da África do Sul), as normas canadenses CMI (Instituto Canadense de Mineração, Metalurgia e Petróleo) e o Reino Unido IMM (Instituto de Minas e Metalurgia), e o pioneiro e mais conhecido Código Internacional de Classificação de Reservas e Recursos JORC (1989), publicado pelo Comitê Conjunto de Reservas Mineral Australasia. Revuelta (2018), enfatiza que em todos esses códigos há uma grande similaridade entre os muitos termos e definições, mas entre eles algumas diferenças ainda persistem. Estas normas/códigos resultantes da globalização da indústria mineral destinam-se a proporcionar um certo nível de confiança aos investidores e outras partes interessadas quanto à qualidade e utilidade da avaliação dos depósitos minerais (Revuelta, 2018). Além disso, segundo Rossi e Deutsch (2014), esses códigos de classificação têm como prioridade a proteção ao investidor, bem como a necessidade de transparência na publicação de recursos minerais, como resposta a alguns casos de fraudes existentes. As seguintes definições são tiradas de CBRR (2016) e CRIRSCO (2012):

- Um recurso mineral é "uma concentração ou ocorrência de material de interesse econômico intrínseco ou sobre a crosta terrestre, de tal forma e quantidade que existam perspectivas razoáveis para uma eventual extração econômica. As características do mineral (localização, 
quantidade, continuidade, entre outras) são estimadas ou interpretadas a partir de evidências e conhecimentos geológicos, como amostras de exploração das perfurações". Os recursos minerais são subdivididos, de acordo com o crescimento da confiança geológica, entre três categorias: inferidas, indicadas e medidas.

- Uma reserva mineral "é a parte economicamente lavrável de um Recurso Mineral Medido e/ou Indicado. Isso inclui diluição e perdas que podem ocorrer quando o material é lavrado ou extraído e é definido apropriadamente pelos estudos nos níveis de Pré-Viabilidade ou de Viabilidade que incluem a aplicação de Fatores Modificadores. Tais estudos demonstram que, no momento da declaração, sua extração pode ser adequadamente justificada. "

Ilustra-se na Figura 2-1 as relações gerais entre os resultados da exploração mineral e recursos e reservas minerais, pode-se observar que os recursos minerais são classificados em três categorias: Inferido, Indicado e Medido e que essas categorias são vinculadas, respectivamente, ao aumento do conhecimento e confiabilidade geológica. De acordo com Revuelta (2018), como no recurso Inferido a confiabilidade é muito baixa para permitir a aplicação de fatores modificadores, não há ligação direta entre essa categoria e qual quer classe de reservas minerais. Já um recurso mineral Indicado possui nível de confiança tal que permite a aplicação de fatores modificadores, que se favoráveis, fazem com que o recurso seja convertido em reserva, porém como a incerteza ainda é alta a reserva será provável. O recurso mineral Medido possui confiabilidade suficiente para, aplicados os fatores modificadores, convertê-lo em uma reserva mineral provada (Revuelta, 2018). A classificação de recursos minerais, segundo Miskelly (2003), deve refletir os diferentes níveis de confiança geológica e diferentes graus de avaliação técnico-econômica do deposito mineral.

Por outro lado, as responsabilidades dos relatórios públicos, bem como a classificação e transformação de Recursos em Reservas Minerais, de forma adequada, dependem fortemente dos critérios de seleção de uma Pessoa Qualificada/Competente. Miskelly (2003), Rossi e Deutsch (2014) e Revuelta (2018) enfatizam que uma pessoa competente (PC) deve ser profissional na indústria mineral com pelo menos 5 anos de 
experiência no mesmo tipo de depósito ou estilo de mineralização. Uma vez que, recaem, sobre ele decisões importantes sobre o processo de avaliação de um Recurso Mineral, como a escolha do método de estimativa e a classificação dos Recursos Minerais.

Hoje em dia, os representantes das organizações responsáveis pelo desenvolvimento dos padrões e boas práticas a serem aplicadas a relatórios para declaração de Reservas/Recursos minerais da Australásia (JORC), do Brasil (CBRR), do Canadá (CIM), do Chile (Comitê Nacional), da Colômbia (CCRR), da Europa (PERC), da Indonésia (KOMBERS-KCMI), do Cazaquistão (KAZRC), da Mongólia (MPIGM), da Rússia (NAEN), da África do Sul (SAMREC), da Turquia (UMREK) e dos EE. UU (SME), compõem o agora conhecido Comitê de Reserva Internacional de Reservas Combinadas (CRIRSCO) (Figura 2-8). Atualmente, esses países representam mais de $80 \%$ do capital cotado da indústria mineral no mercado de ações. $\mathrm{O}$ grupo CRIRSCO foi fundado em 1993, inicialmente chamado Grupo CMMI, sob os auspícios do Conselho de Instituições de Mineração e Metalúrgica (Miskelly, 2003).

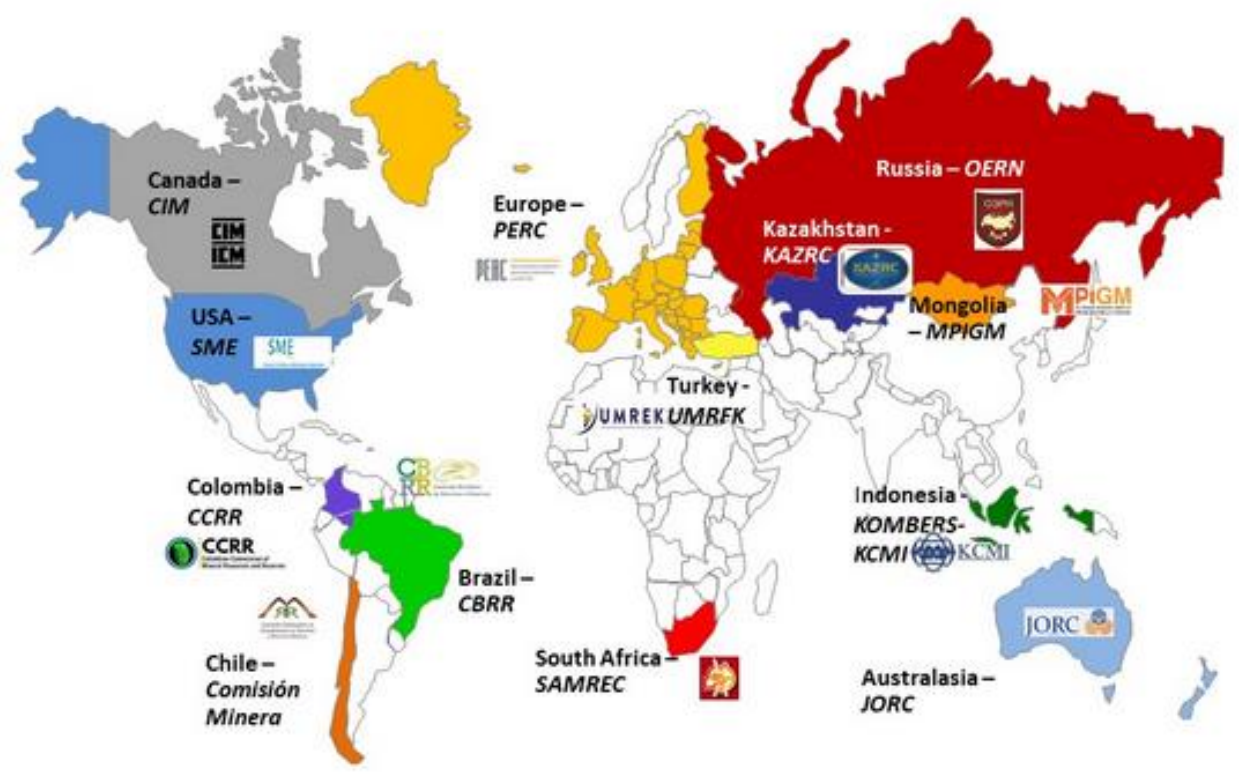

Figura 2-8. Membros do Comitê de Reserva Internacional de Reservas Combinadas em julho de 2018. (Fonte: Membros CRIRSCO, http://www.crirsco.com/welcome.asp)

Aproximadamente em meados de 2006, a CRIRSCO lançou modelo de informação internacional (TII), concebido como uma forma de um guia de boas práticas, em que resume o conteúdo dos sistemas de classificação existentes. No 
entanto, a palavra código é deliberadamente evitada. O TII, de acordo com CRIRSCO (2013), serve como uma orientação para os países/regiões que não possuem sistemas estabelecidos de códigos de declaração mineral, ou que desejam modificar seus padrões existentes para uma forma internacionalmente aceitável. Existe a necessidade de um padrão genérico internacional devido à globalização da indústria mineral e à falta de uniformidade na jurisdição governamental de um país para o outro. O modelo CRIRSCO adota os melhores padrões de informação amplamente aceitos em todo o mundo pela indústria mineral, comunidade financeira e órgãos de controle, como o código JORC (Australásia), o padrão SAMREC (África do Sul), o padrão de relatório PERC (Europa), as diretrizes da CIM (Canadá), o guia SEM (EUA) e o código de certificação do Chile.

Em 2015, a Comissão Brasileira de Recursos e Reservas (CBRR), foi criada no Brasil devido à aliança e iniciativa entre as três maiores e mais importantes associações do setor mineral brasileiro: a ABPM (Associação Brasileira de Empresas de Pesquisa Mineral), a ADIMB (Agência Brasileira de Desenvolvimento Tecnológico da Indústria Mineral) e o IBRAM (Instituto Brasileiro de Mineração). A CBRR torna-se parte do grupo de representantes de países ou regiões que compõem as Organizações Nacionais de Notificação (ONR). A adesão à CBRR deve-se ao memorando de entendimento celebrado em novembro de 2015, com o Comitê de Reserva Internacional de Reservas Combinadas.

\subsection{GEOESTATISTICA}

A estimativa de teores e volumes até a década de 1950 com o desenvolvimento da geoestatística foi considerada uma ciência empírica e aplicada, onde a experiência e o julgamento do responsável pela estimativa tinham importância fundamental (Sinclair e Blackwell, 2002). Em meados do século XX diversas ferramentas foram desenvolvidas com o objetivo de estimar a tonelagem e o grau de mineralização de depósitos. Tais ferramentas ficaram conhecidas como métodos: tradicional, clássico, 
geométrico ou convencional. O método clássico pode ser identificado em seis tipos (David, 1977; Sinclair e Blackwell, 2002; Abzalov, 2016; Revuelta, 2018): (1) Método das seções; (2) Método poligonal; (3) Método triangular; (4) Malha ou matrizes regulares de Blocos; (5) Inverso da potência da distância; e (6) Método de contorno.

Esses métodos resistiram aos avanços da indústria mineral apesar de algumas limitações como por exemplo: a falta de uma medida de incerteza e a quantificação do erro associado, a subjetividade envolvida na seleção do raio de influência (Sinclair e Blackwell, 2002; Revuelta, 2018), e a não diferenciação espacial dos diferentes padrões presentes na área (Abzalov, 2016). Portanto, esses processos geométricos são considerados na literatura como métodos empíricos e seu uso é baseado na experiência geológica adquirida em depósitos similares (Sinclair e Blackwell, 2002; Abzalov, 2016). Tais metodologias continuam a ser aplicadas em diversas situações, bem como na verificação dos resultados obtidos por meio de técnicas geoestatísticas (Revuelta, 2018).

Segundo Sinclair e Blackwell (2002), a geoestatística considera três características importantes em suas aproximações quantitativas em contraste com métodos convencionais que envolvem decisões subjetivas:

i. Área de influência de uma amostra.

ii. Influência da geometria dos dados na estimativa, incluindo o efeito causado pelos agrupamentos.

iii. O uso de um único suporte para o processo de estimativa.

A geostatística ou estatística espacial é um ramo da matemática aplicada que teve lugar na indústria mineral no início da década de 1960 para auxiliar na melhoria do cálculo das reservas/recursos minerais (Wackernagel, 2003). Os trabalhos pioneiros da área foram realizados por HJ Wijs (De Wijs, 1951, 1953) professor da Universidade Técnica de Delft na Holanda e Daniel G. Krige (Krige, 1951) engenheiro que trabalhou nas minas de ouro de Rand na África do Sul. A partir das ideias inovadoras de Krige e Wijs, o matemático francês George Matheron construiu os pilares matemáticos da geoestatística no que ele define como a Teoria das Variáveis Regionalizadas (Wackernagel, 2003). Segundo David (1977), etimologicamente o termo geoestatística refere-se ao estudo estatístico dos fenômenos naturais. Abzalov (2016), cita vários 
exemplos de depósitos minerais como a continuidade espacial de características geológicas de elementos terrestres de importância econômica, além da concentração de elementos nocivos ou características geotécnicas de rochas. Nesse sentido, a geoestatística se preocupa em caracterizar a distribuição espacial de uma ou mais variáveis do fenômeno natural através do conceito de variáveis regionalizadas (Olea, 1991).

Para Abzalov (2016), qualquer função aleatória distribuída no espaço ou no tempo que defina o valor de uma variável de interesse é considerada uma variável regionalizada (VR). Wackernagel (2003), explica que uma VR é uma coleção infinita de informações do mesmo tipo em algum domínio de interesse $\mathrm{D}$, ou seja, $z(x), \forall x \in D$. Em particular, um conjunto de dados $\left\{z\left(x_{\alpha}\right), \alpha=1, \ldots, n\right\}$ em D, é visto como uma coleção de poucos valores da variável regionalizada. Esse mesmo autor, destaca dois importantes aspectos geométricos que devem ser levados em consideração em qualquer estudo de uma VR: (1) domínio e (2) suporte. Além disso, uma variável regionalizada do ponto de vista da geoestatística é interpretada como sendo uma realização particular de uma função aleatória (David, 1977). Neste sentido as VR são conceituadas no campo probabilístico da estatística (Wackernagel, 2003).

Segundo Olea (1991), Deutsch e Journel (1998), Wackernagel (2003), uma função aleatória (FA) é definida como uma família ou coleção de variáveis aleatórias. Ademais, para Goovaerts (1997), o conceito de (FA) permite explicar as estruturas das variações espaciais do atributo, assim como, as incertezas derivadas do conjunto de realizações de modelos de funções aleatórias. Aliás, a Teoria das Variáveis Regionalizadas segundo Yamamoto (2001), tem por finalidade resolver problemas de estimativa mediante o estudo e representação das propriedades estruturais das variáveis regionalizadas. Um conceito essencial na geoestatística é a hipótese intrínseca sobre o domínio que uma função aleatória deve respeitar se for estacionária de segunda ordem, ou seja, a média e a covariância são invariantes a qualquer vetor de translação (Olea, 1991; Wackernagel, 2003).

A hipótese intrínseca implica que qualquer função que descreva $o$ comportamento espacial da VR também é inerente à regionalização (Yamamoto, 2001). Sob essa premissa, pode-se obter a ferramenta básica da geoestatística, o variograma, 
cuja função é medir a dependência espacial entre dois pares de unidades amostrais que depende unicamente da distância e da orientação entre os pontos Yamamoto (2001).

\subsubsection{FUNÇÃO VARIOGRAMA E SEMIVARIOGRAMA}

A geoestatística permite medir a variabilidade e continuidade espacial de um fenômeno em estudo ou variável regionalizada através das diferentes relações espaciais entre os dados. Conceitualmente, em termos probabilísticos, o variograma é definido como o valor esperado da diferença ao quadrado de duas variáveis aleatórias, onde h é um vetor de distância e a metade do variograma que define o semivariograma.

$$
2 \gamma(h)=E\left\{[Z(x)-Z(x+h)]^{2}\right\}
$$

O semivariograma é uma medida de dissimilaridade em contraste com a função de covariância que é uma medida de similaridade. Em outras palavras, a taxa de variação espacial da função aleatória aumenta a variância espacial de acordo com a distância à medida que a covariância diminui (Olea, 1991) (Figura 2-9). Portanto, essa relação variograma-covariância é válida apenas se a função aleatória for estacionária de segunda ordem onde C (0) é a covariância para distâncias nulas (equivalente a variância) e C (h) é a covariância entre pontos:

$$
\gamma(h)=C(0)-C(h)
$$

De acordo com Gringarten e Deutsch (2003), a relação dada pela expressão (2. 2) constitui a base fundamental para a interpretação estatística do variograma, ou seja: (1) a variância a priori dos dados é o patamar do variograma (correlação linear nula); (2) a correlação linear entre as variáveis $Z(x) e Z(x+h)$ é positiva quando, a variância espacial é limitada pelo patamar; (3) a correlação é negativa quando, o variograma excede a variância a priori dos dados. 


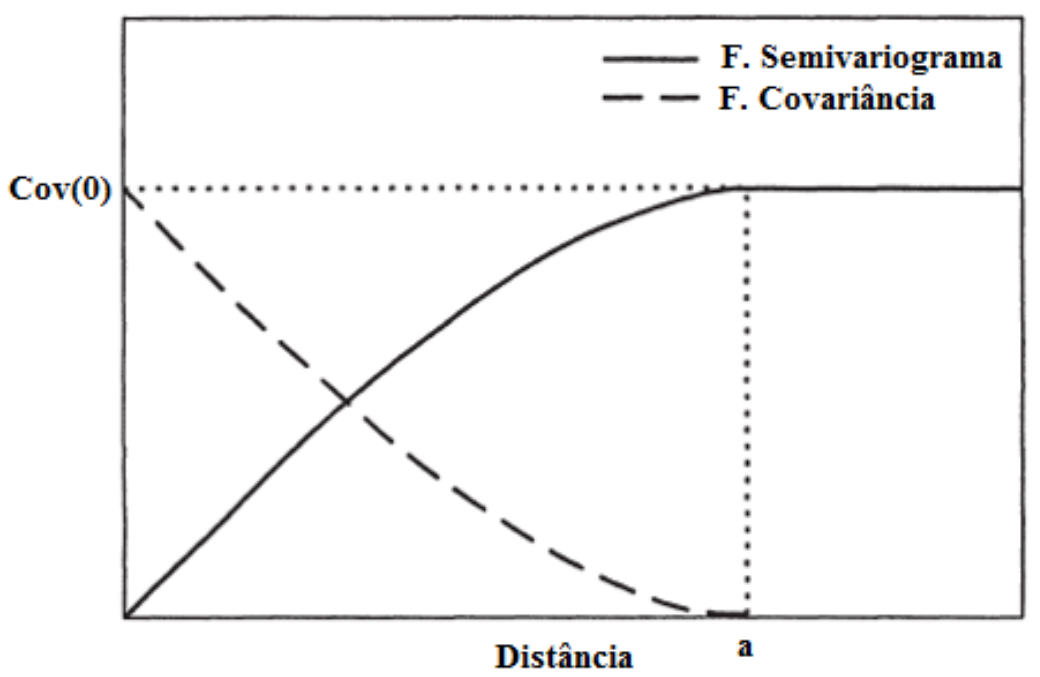

Figura 2-9. Relação entre a função do variograma e a covariância (Fonte: Olea, 1999).

Em geral, o estimador não-viesado imparcial do semivariograma é também chamado de semivariograma experimental que é definido como:

$$
\gamma(h)=\frac{1}{2 N} \sum_{i=1}^{N}\left[z\left(x_{i}\right)-z\left(x_{i}+h\right)\right]^{2}
$$

Onde $\mathrm{N}$ é o número de pares de dados separados por uma distância h, sendo: $z\left(x_{i}\right) \mathrm{e}$ $z\left(x_{i}+h\right)$, valores regionalizados localizados respectivamente em $x_{i}$ e $x_{i}+h$. Segundo Olea (1999), a expressão (2. 9) é um estimador não robusto e implica uma suposição ergódica, ou seja, uma única realização é suficiente para determinar as propriedades do conjunto de todas as realizações possíveis.

Os principais aspectos do variograma experimental são ilustrados na Figura 2-10 e descritos como (Yamamoto, 2001):

- Amplitude ou Alcance: A distância que separa o campo estruturado do campo aleatório. Isto é, a distância máxima onde há uma influência espacial entre as amostras.

- Efeito Pepita: Descontinuidade próxima à origem. Teoricamente, esse valor é sempre zero, mas na prática deve-se a vários fatores como o erro de amostragem e/ou variabilidade natural do depósito.

- Variância Espacial: É a contribuição espacial da variável regionalizada calculada a partir da diferença entre a variância a priori e o efeito pepita. 
- Patamar: É a resultante entre a soma do efeito pepita e a contribuição espacial, na qual o variograma experimental se estabiliza.

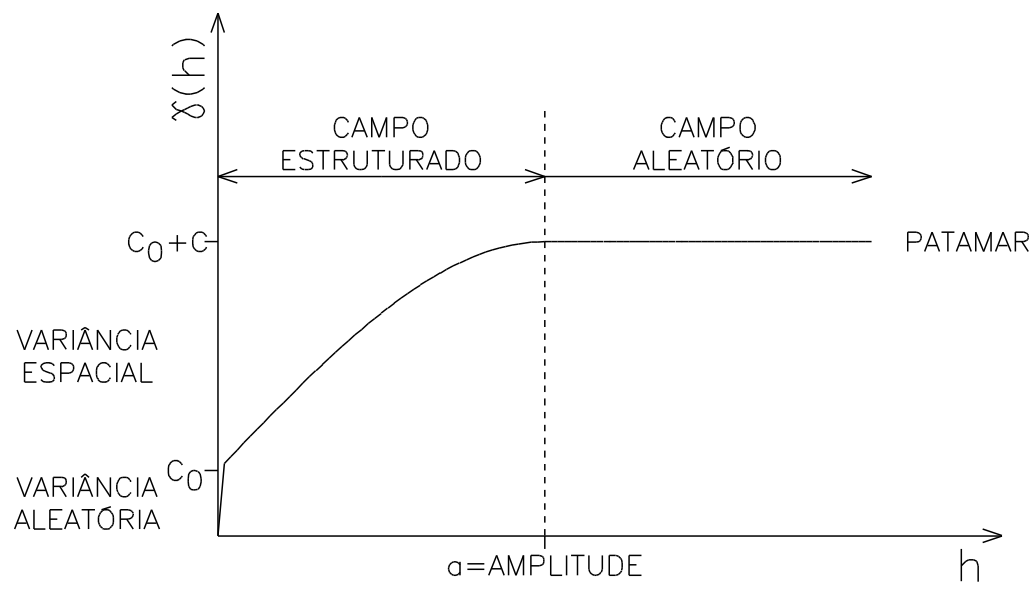

Figura 2-10. Ilustração ideal de um variograma experimental e suas propriedades (Fonte: Yamamoto, 2001).

Conforme Goovaerts (1997), uma vez calculado o variograma experimental a função contínua deve ser ajustada, pois para qualquer distância ou amplitude a variância espacial poderia ser necessária em qualquer das ferramentas geoestatísticas e também para suavizar as flutuações da amostragem. Para que uma função seja um modelo de variograma ela deve ser negativa definida que também é conhecida como funções permissíveis, Christakos (1984, apud Olea, 1999).

Segundo Sinclair e Blackwell (2002), um modelo de semivariograma definido positivo, garante uma solução única das equações da krigagem normais estendidas, bem como tendo uma variância resultante positiva. Para Goovaerts (1997), existem cinco modelos principais que podem ser agrupados em duas grandes classes: Modelos de potência e Modelos com amplitude definida (Figura 2-11):

i. Modelo de Efeito Pepita: O modelo de variograma atinge seu patamar que passa a ser caracterizado pela falta de correlação espacial. Assim, o fenômeno em estudo pode ser analisado pela estatística clássica.

$$
\gamma(h)=\left\{\begin{array}{c}
0 \text { si } h=0 \\
1 \text { caso contrario }
\end{array}\right.
$$


ii. Modelo esférico ou Matheron: É caracterizado por dois componentes importantes (Sinclair e Blackwell, 2002): (1) um componente puramente aleatório e (2) um componente estruturado, caracterizado pela amplitude de uma função autocorrelacionada. Para Olea (1999), trata-se de um modelo transitivo, ou seja, com amplitude e patamar finitos.

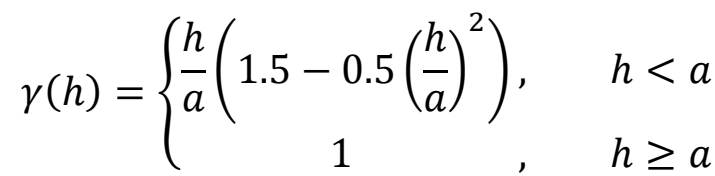

iii. Modelo exponencial: Ao contrário do modelo esférico, o modelo exponencial só atinge seu patamar assintoticamente, sendo que 95\% do seu valor de patamar correspondem geometricamente três vezes a amplitude na prática (Olea, 1999).

$$
\gamma(h)=1-\exp \left(-\frac{3 h}{a}\right)
$$

iv. Modelo Gaussiano: Da mesma forma que o modelo exponencial, o patamar é atingido assintoticamente e seu alcance na prática pode ser considerado igual a $\sqrt{3}$ (Sinclair e Blackwell, 2002).

$$
\gamma(h)=1-\exp \left(-\frac{3 h^{2}}{a^{2}}\right)
$$

v. Modelo de Potência: Este variograma não tem patamar e alcance, seu crescimento é indefinido como:

$$
\gamma(h)=h^{w} \operatorname{com} 0<w<2
$$



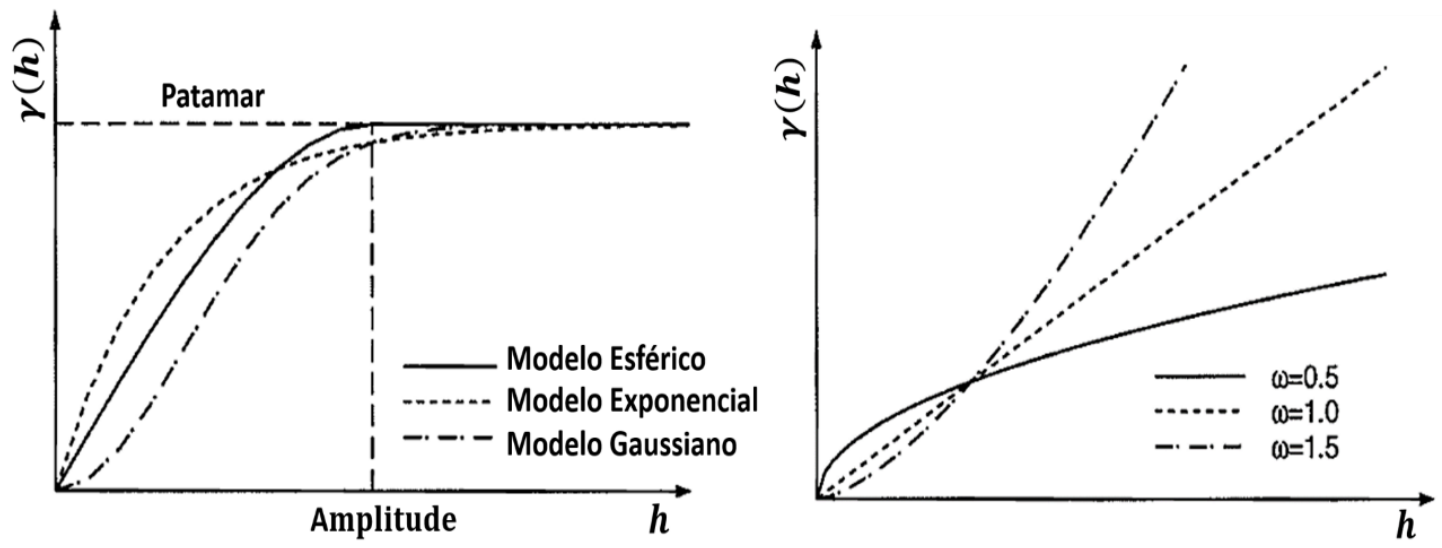

Figura 2-11. Modelos de variogramas teóricos. (Fonte: Goovaerts, 1997)

O variograma experimental pode revelar diferentes comportamentos de acordo com a direção analisada, essa característica é conhecida como anisotropia (Wackernagel, 2003). Os modelos teóricos de variograma são definidos para domínios isotrópicos, consequentemente, deve ser realizada uma transformação matemática de caráter geométrico, de tal forma que as contribuições espaciais das direções maior, media e menor continuidade possam ser consideradas em uma única quantidade.

Conforme Yamamoto (2001), a existência da anisotropia pode ser identificada através do cálculo de variogramas direcionais. Segundo autor, três tipos de anisotropias podem ser reconhecidos teoricamente em um domínio de interesse: (1) geométrica, (2) zonal, e (3) mista. Embora na prática, especificamente em aplicações de estimativa de teores e volumes, dois tipos de anisotropias são reconhecidos: Geométrico e Zonal (Sinclair e Blackwell, 2002). Na anisotropia geométrica (Figura 2-12.A), a amplitude varia em função da distância, mas o patamar permanece constante. Já na anisotropia zonal (Figura 2-12.B), o patamar varia de acordo com as direções, assim que as amplitudes permanecem invariáveis. Por fim, a anisotropia mista (Figura 2-12.C), combina diferentes variações da região geométrico-zonal, isto é, a amplitude e o patamar variam de acordo com as diferentes direções. 

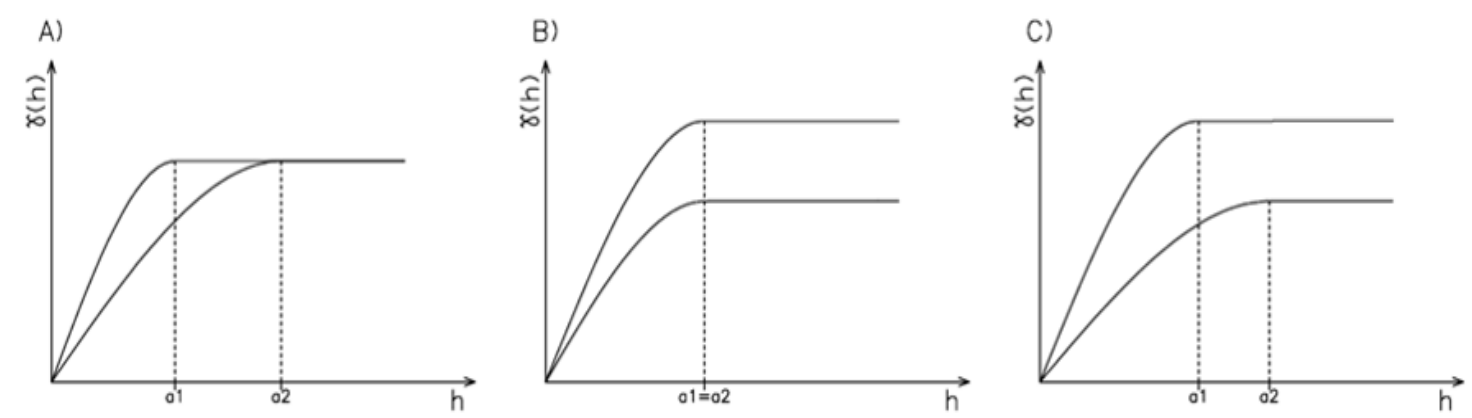

Figura 2-12. Anisotropia geométrica (A), zonal (B) e mista (C). (Fonte: Yamamoto, 2001).

\section{3 MÉTODOS DE ESTIMATIVA LOCAL}

Atualmente os métodos geoestatísticos têm sido o foco principal na estimativa do valor e tonelagem de recursos/reservas minerais (Abzalov, 2016). Isso se deve à existência de um modelo de dependência espacial que permite lidar com o problema dos atributos não amostrados por meio de técnicas de estimativa que minimizam a variância do erro por meio de procedimentos de regressão linear multivariada. Sendo a mais utilizada a família de estimadores lineares, conhecida como krigagem. Krigagem é um termo genérico aplicado a uma gama de métodos de estimativa de_variáveis contínuas em bloco ou ponto, cujo termo foi cunhado pelo matemático francês G. Matheron em homenagem aos trabalhos empíricos de D. Krige na predição de teores de ouro encontrado nas minas da África do Sul (Sinclair e Blackwell, 2002). Esses métodos são frequentemente associados ao acrônimo, BLUE (Melhor estimador linear não-viesado) (Isaaks e Srivastava, 1997; Sinclair and Blackwell, 2002).

Segundo Abzalov (2016), as expressões "melhor" e "sem viés" possuem significado puramente matemático, associado aos procedimentos utilizados na krigagem. O termo "linear" é atribuído as estimativas que são combinações lineares ponderadas dos dados disponíveis. Já a expressão "sem viés", se restringe à condição de que a esperança estatística do erro seja igual a zero. Por fim, o termo "melhor" se aplica a variância de erro mínimo.

Conforme Sinclair e Blackwell (2002), as técnicas de geoestatística são atrativas na estimativa de teores e volumes, uma vez que seus procedimentos envolvem uma apreciação quantitativa do erro associado à estimativa, o que anteriormente não foi 
possível devido aos métodos convencionais existentes na época. Segundo os autores, o conceito de erro é fundamental na caracterização espacial dos recursos/reservas minerais.

Todos os estimadores da krigagem são uma regressão de mínimos quadrados generalizados do estimador linear básico, definido como (Goovaerts, 1997; Deutsch e Journel, 1998):

$$
Z(x)^{*}-m(x)=\sum_{i=1}^{n(x)} \lambda_{i}(x)\left[Z\left(x_{i}\right)-m\left(x_{i}\right)\right]
$$

onde $\lambda\left(x_{i}\right)$ é o peso associado a cada valor regionalizado $z\left(x_{i}\right)$, interpretado como a realização de uma variável aleatória $Z\left(x_{i}\right)$ e as grandezas $m(x)$ e $m\left(x_{i}\right)$ são valores esperados das respectivas variáveis aleatórias $Z(x)$ e $Z\left(x_{i}\right)$. Segundo Goovaerts (1997), na prática, apenas $n(x)$ valores adjacentes são retidos na estimativa de um ponto/bloco não amostrado.

Neste trabalho, será descrito apenas o algoritmo de estimativa da krigagem simples e outras descrições podem ser consultadas nas seguintes fontes: Isaaks e Srirvastava (1989), Goovaerts (1997), Deutsch e Journel (1998), Olea (1999), Wackernagel (2003), Chilès e Delfiner (2012), Yamamoto e Landim (2013), Rossi e Deutsch (2014).

\subsubsection{KRIGAGEM SIMPLES}

A técnica de estimativa krigagem simples (KS), segundo Wackernagel (2003), é uma transposição de regressão múltipla em um contexto espacial e é a forma mais básica entre as ferramentas da krigagem, no sentido de que o modelo é o mais simples em sua formulação matemática (Olea, 1999). Além disso, segundo Goovaerts (1997), o estimador KS é caracterizado por ser um interpolador exato, ou seja, honra os valores regionalizados $z\left(x_{i}\right)$ em sua localização dada: $z_{S K}^{*}(x)=z\left(x_{i}\right), \forall x=x_{i}$ e $i=$ $1, \ldots, n$. 
Segundo Goovaerts (1997), o método krigagem simples considera o componente de tendência $m(x)$ como uma média conhecida e constante, em todo o domínio de interesse, portanto, o estimador linear a partir da expressão (2. 15) é definida como:

$$
Z_{S K}^{*}(x)=\sum_{i=1}^{n(x)} \lambda_{i}^{S K}(x) Z\left(x_{i}\right)+\left[1-\sum_{i=1}^{n(x)} \lambda_{i}^{S K}(x)\right] m
$$

onde, os pesos $\lambda_{i}^{S K}(x)$ para o $n(x)$ são determinados, tal que a variância do erro é mínima $\left(\min \sigma_{E}^{2}=\operatorname{Var}\left[Z_{S K}^{*}(x)-Z(x)\right]\right)$ sob o condicionamento da esperança matemática do erro seja igual a zero $\left(E\left[Z_{S K}^{*}(x)-Z(x)\right]=0\right)$. Desta forma, o sistema de equações da krigagem simples, em termos de covariância, é dado por:

$$
\sum_{j=1}^{n(x)} \lambda_{j}^{S K}(x) C\left(x_{i}-x_{j}\right)=C\left(x_{i}-x\right), \operatorname{com} i=1, \ldots, n(x)
$$

os termos à esquerda e à direita da expressão (2. 17), descrevem as covariâncias entre as amostras e entre cada amostra e o ponto a ser estimado, respectivamente.

Uma segunda expressão de grande importância é a variância da estimativa, o que pode ser deduzido pela substituição de alguns termos da variância do erro pela expressão (2. 17) (Goovaerts, 1997):

$$
\sigma_{S K}^{2}(x)=C(0)-\sum_{i=1}^{n(x)} \lambda_{i}^{S K}(x)-C\left(x_{i}-x\right)
$$

\section{4 SIMULAÇÃO CONDICIONAL GEOESTATISTICA}

Simulação geoestatística em um contexto de mineração significa imitação de condições (Sinclair e Blackwell, 2004). Segundo Sinclair e Blackwell (2004), uma simulação não é uma estimativa, mas tal "imitação" compõe um conjunto de valores (2D ou 3D) caracterizados estatisticamente da mesma maneira que os dados originais. Esses mesmos autores esclarecem que, em certos aspectos, um valor simulado é considerado como uma estimativa do valor real na coordenada simulada, mesmo que este valor simulado não seja a melhor estimativa e seu erro associado seja o dobro do 
erro correspondente ao krigagem. Sinclair e Blackwell (2004), ainda destacam seis princípios fundamentais do uso da simulação na indústria mineral: (1) Estudo da continuidade de valor; (2) Otimização de planos de amostragem; (3) Avaliação do método para estimar recursos/reservas minerais; (4) Planejamento de minas; (5) Otimização em usinas de beneficiamento e; (6) Análise de risco financeiro.

Segundo Rossi e Deutsch (2014), os processos de estimativa local da incerteza não consideram a variabilidade de um lugar para outro, e nesse sentido a simulação geoestatística através de múltiplas realizações permite capturar, entre e dentro dos blocos, representações mais completas das incertezas. Estas ferramentas de simulação transferem as incertezas, por meio da aplicação dos princípios da simulação estocástica de Monte Carlo (mais precisamente, método da transformação inversa), para os valores regionalizados (Abzalov, 2016).

A simulação estocástica é um processo de seleção aleatória, igualmente provável, de múltiplas realizações das variáveis aleatórias do mesmo modelo espacial (Deutsch e Journel, 1998). As realizações múltiplas (também chamadas de imagens estocásticas, IE) $\left\{z^{l}(x), x \in D\right\}, l=1, \ldots, L$, representam $\mathrm{L}$ resultados possíveis da distribuição espacial das variáveis regionalizadas $z(x)$ no domínio $\mathrm{D}$, onde cada IE deve refletir as propriedades inferidas dos valores regionalizados que foram impostos ao modelo FA (Deutsch e Journel, 1998). Mesmo que todas as realizações respeitem as características estatísticas e geoestatísticas dos dados originais, elas diferem em alguns detalhes (Abzalov, 2016).

Em contraste com as técnicas de estimativa local, caracterizadas pela propriedade do efeito de suavização (Figura 2-13 e 2-14), devido à minimização da variância do erro, que fornece o melhor estimador linear de um valor não amostrado. As simulações condicionais permitem avaliar as incertezas, bem como reproduzir a variabilidade original dos valores regionalizados, que resulta na preservação dos valores extremos da distribuição original dos dados observados (Rossi e Deutsch, 2014), conforme ilustrado na Figura 2-13. 


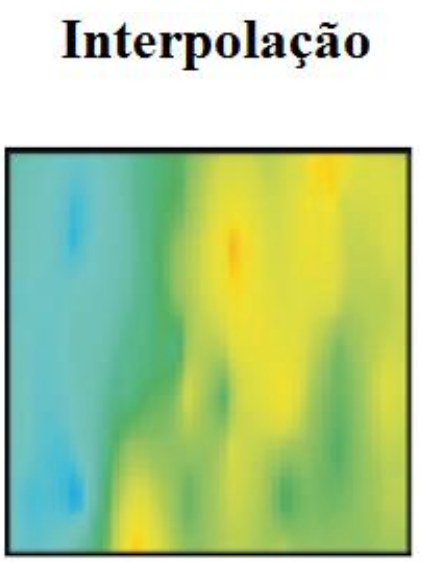

Versão suavizada da realidade

Ruim para modelagem de valores extremos

\section{Simulação}

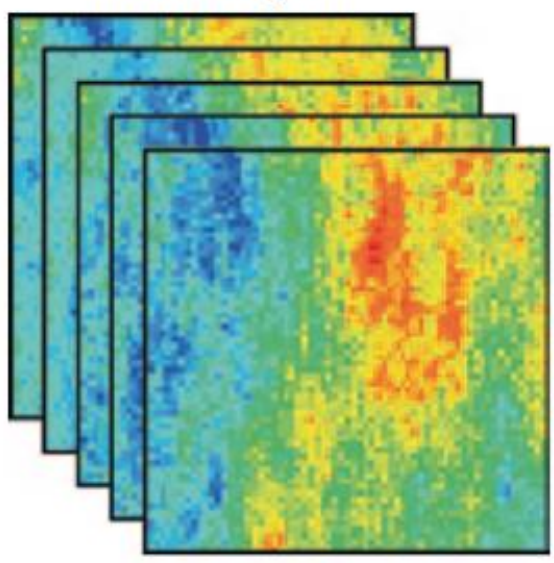

Imagens equiprováveis com a mesma variabilidade espacial da realidade

Bom para modelagem dos valores extremos

Figura 2-13. Comparação entre modelo interpolado e simulado. (Fonte: Rossi e Deutsch, 2016).

A popularidade dos métodos de simulação Gaussiana deve-se essencialmente a suas propriedades convenientes, inferidas a partir da distribuição de probabilidade mais utilizada na modelagem de fenômenos naturais, a distribuição Normal, bem como de sua fácil aplicação, mas também porque resultam em representações razoáveis das características espaciais das funções aleatórias (Rossi e Deutsch, 2014).

A simulação é dita condicional se os valores simulados retiverem a mesma função de densidade (histograma) e modelo de autocorrelação (característica da continuidade espacial dos dados) (Sinclair e Blackwell, 2004), assim como as realizações devem honrar os valores iniciais em suas coordenadas originais (Deutsch e Journel, 1992). Esses métodos de simulação estocástica são baseados no paradigma da simulação sequencial: onde cada valor não amostrado é visitado a partir de um caminho aleatório gerado e, em seguida é simulado pela função de probabilidade condicional, calculada a partir dos $n$ valores ou vizinhos mais próximos, mediante um processo recursivo derivado da aplicação do teorema de Bayes (Goovaerts, 1997). 


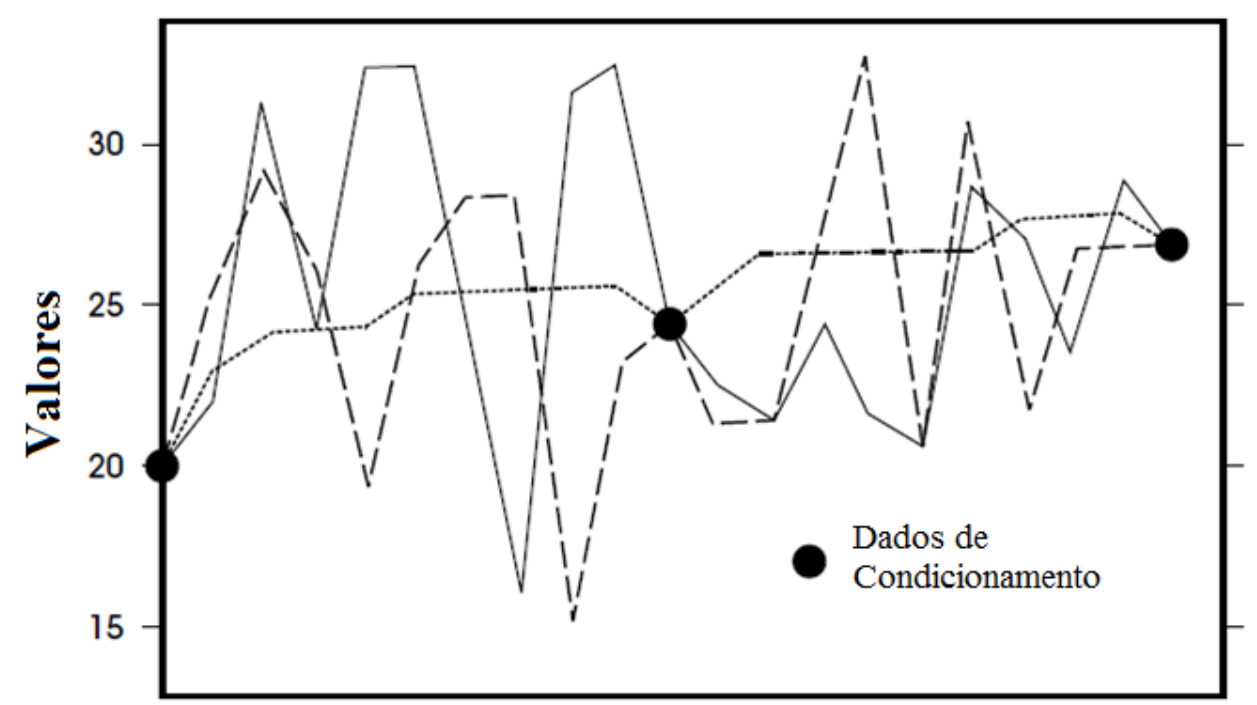

Distância

Figura 2-14. Efeito de suavização da krigagem (linha pontilhada) corrigido por simulação estocástica (linha tracejada), e comparado com uma situação idealizada de valores em uma seção (linha contínua). (Fonte: Sinclair e Blackwell, 2004).

As técnicas de simulação condicional podem reproduzir características espaciais de fenômenos contínuos e discretos, através de uma variedade de métodos de simulação encontrados na literatura, como: Goovaerts, (1997), Chilès e Delfiner (2012), Yamamoto e Landim. (2013), Rossi e Deutsch (2014). Neste trabalho apenas o método de Simulação Sequencial Gaussiana será abordado, uma vez que é o método mais difundido na indústria da mineração.

\subsubsection{SIMULAÇÃO SEQUENCIAL GAUSSIANA}

De acordo com Deutsch e Journel (1991), Rossi e Deutsch (2014), a implementação computacional da Simulação Sequencial Gaussiana baseia-se na hipótese de um modelo multivariado de função aleatória Gaussiana, que é um modelo cuja lei espacial é totalmente definida. Esta lei garante a solução da função de distribuição condicional (equação 2.19), através de sua função de covariância (Goovaerts, 1997).

$$
\begin{aligned}
F\left(x_{1}^{\prime}, \ldots, x_{N}^{\prime} ; z_{1}, \ldots, z_{N} \mid(n)\right) & \\
& =\operatorname{Prob}\left\{Z\left(x_{1}^{\prime}\right) \leq z_{1}, \ldots, Z\left(x_{N}^{\prime}\right) \leq z_{N} \mid(n)\right\}
\end{aligned}
$$


onde $z_{i}, i=1, \ldots, N$ são os valores regionalizados, coordenados em $x_{j}^{\prime}=$ $1, \ldots, N$.

Rossi e Deutsch (2014) destacam o uso da estimativa da krigagem simples, sobre todos os outros métodos de estimativa linear. Uma vez que esse processo reproduz adequadamente a média e a variância Gaussiana estimadas de qualquer modelo de FA multigussiana.

O procedimento da Simulação Sequencial Gaussiana tem os seguintes passos (Deutsch e Journel, 1998):

i. Determine a função de distribuição (também chamada de função de distribuição cumulativa e sua sigla em inglês cdf) $F_{Z}(z)$ representativa do domínio e não apenas dos valores regionalizados disponíveis;

ii. Transforme a função de distribuição acumulada em uma distribuição Normal padrão usando a normal score (seção 2.3.2);

iii. Calcule o modelo de correlação espacial-variograma dos dados transformados;

iv. Avalie a suposição de bi-gaussianidade dos dados transformados;

v. Prossegue com a Simulação Sequencial Gaussiana:

- Defina-se um caminho aleatório para o domínio a simular (modelo dimensional ou tridimensional);

- Construir uma função de distribuição condicional, ccdf, dos $n$ vizinhos mais próximos e nós previamente simulados;

- Usar a KS, com o modelo de variograma dos dados transformados, para determinar os parâmetros (primeiro e segundo momento) da $c c d f$, para a função aleatória dos valores transformados;

- Simular um valor do $c c d f$ aleatoriamente;

- Adicionar o valor simulado ao conjunto de dados;

- Simular o próximo nó definido pelo caminhamento aleatório e repetir os procedimentos apresentados em $\mathrm{V}$, até que todos os nós do modelo tenham sido simulados. 
vi. Fazer a transformação dos valores simulados $\left\{y^{l}(x), x \in D\right\}$ conforme: $\left\{z^{l}(x)=\varphi^{-1}\left(y^{l}(x), x \in D\right)\right\}$.

\subsubsection{TRANSFORMAÇÃO DOS DADOS}

Ferramentas de simulação geoestatística requerem que as distribuições dos valores regionalizados provenham de uma distribuição Gaussiana, uma vez que, os procedimentos de simulação são desenvolvidos sob a hipótese de modelos multivariados de funções aleatórias Gaussianas para a predição probabilística de propriedades contínuas. Embora, as propriedades da distribuição Gaussiana multivariada sejam bem estudadas e conhecidas, infelizmente, nas ciências da terra os fenômenos naturais não vêm de uma distribuição normal e, em virtude disto, os dados originais devem ser transformados, de tal forma que algoritmos de simulação, como a SGS, possam usar essas propriedades.

Uma função de distribuição normal é caracterizada pela esperança matemática $\mu$ e variância $\sigma^{2}$ (Figura 2-15), com função de densidade de probabilidade definida como:

$$
g_{X}\left(x \mid \mu, \sigma^{2}\right)=\frac{1}{\sigma \sqrt{2 \pi}} \exp \left[-\frac{1}{2}\left(\frac{z-\mu}{\sigma}\right)^{2}\right]
$$

E a distribuição normal com média zero e variância unitária é chamada distribuição normal padrão e obtida da expressão (2. 20):

$$
g_{X}(x \mid 0,1)=\frac{1}{\sqrt{2 \pi}} \exp \left[-\frac{z^{2}}{2}\right]
$$

$\mathrm{Na}$ literatura existem várias maneiras de transformar um conjunto de valores regionalizados em uma distribuição normal, mas comumente aplica-se a transformação direta de quantil para quantil (Figura 2-16), na qual a função de distribuição acumulada de cada variável é usada para executá-la (Rossi e Deutsch, 2014). Esse método é conhecido como transformação de normal score (NS) e sua expressão é definida em 2. 22. 


$$
y=F_{Y}^{-1}\left(F_{Z}(z)\right), \forall z
$$

que é transformado por:

$$
z=F_{Z}^{-1}\left(F_{Y}(y)\right), \forall y
$$

onde $F_{Z}(z)$ é a função de distribuição dos valores regionalizados e $F_{Y}(y)$ é a função de distribuição cumulativa dos valores transformados em $y$, por NS, em uma distribuição normal padrão.

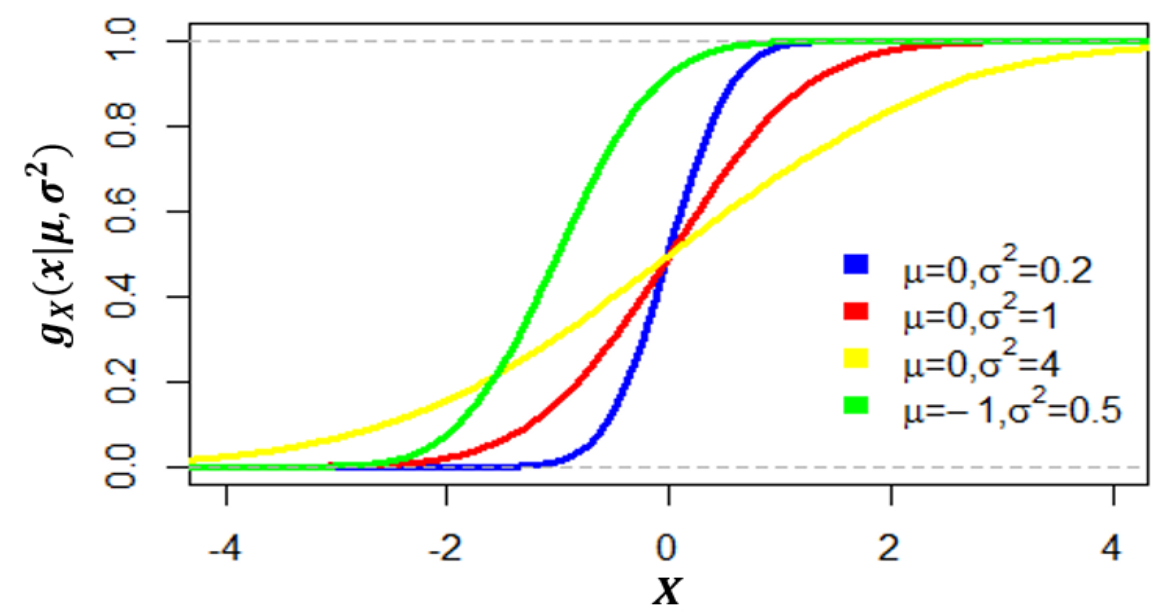

Figura 2-15. Função de distribuição cumulativa de uma distribuição Gaussiana com diferentes parâmetros de $\mu$ e $\sigma$. (Fonte: autor).
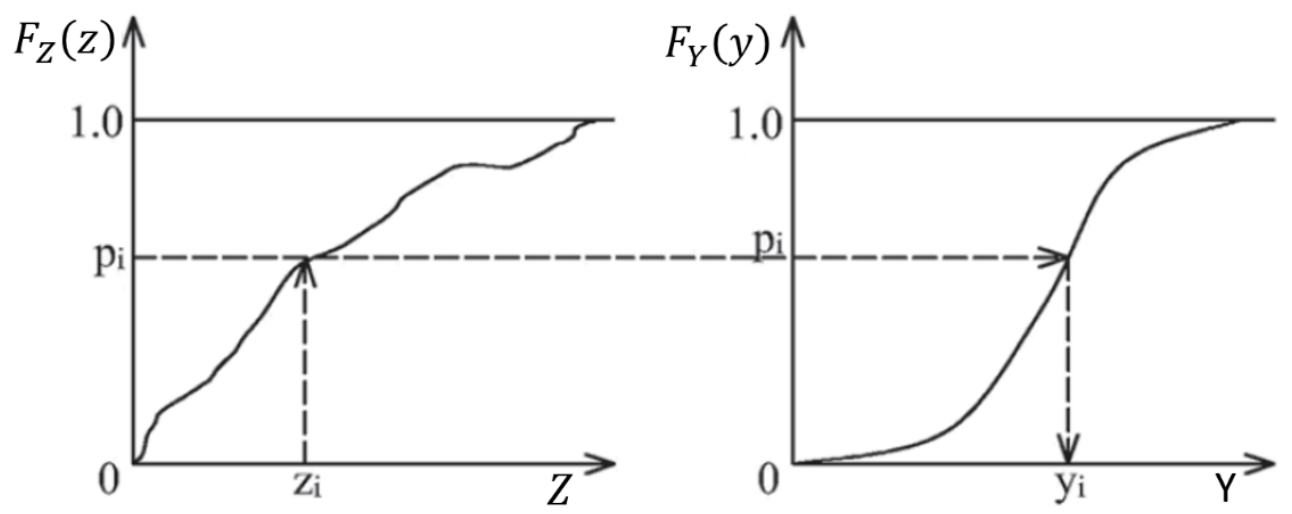

Figura 2-16. Transformação Gaussiana por NS. (Fonte: Rossi e Deutsch, 2014). 


\section{5 SIMULAÇÃO DE MULTIPONTOS (MPS)}

As técnicas de estimativa e simulação geoestatística (por exemplo KS e SGS) requerem um modelo, a priori, da variabilidade espacial e continuidade entre os valores regionalizados, conhecido como o variograma (Goovaerts, 1997; Deutsch e Journel, 1998; Olea, 1999; Yamamoto e Landim, 2013; Abzalov, 2016). Embora o variograma seja uma ferramenta que mede a dependência espacial da variável regionalizada, muitas vezes não é capaz de identificar padrões espaciais mais complexos presentes em reservatórios, como estruturas curvilíneas e geometrias serpenteantes (Guardian e Srivastava, 1993).

A captura acurada de tais características espaciais complexas deve ser aproximada por mais de dois pontos considerados ao mesmo tempo, ou seja, por três ou quatro ou mais localizações, conforme ilustrado na Figura 2-17 (Goovaerts, 1997). Explicitamente, as diferenças espaciais entre dois pontos não representam completamente as heterogeneidades do fenômeno espacial, desse modo, nos últimos anos, técnicas de simulação que podem usar mais de dois pontos simultaneamente na inferência estatística de tais padrões foram desenvolvidas no contexto geoestadistico, chamado de múltiplos pontos.
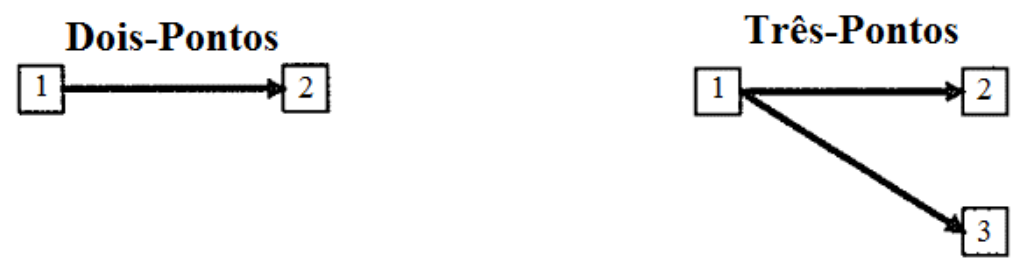

Quatro-Pontos

N- Pontos
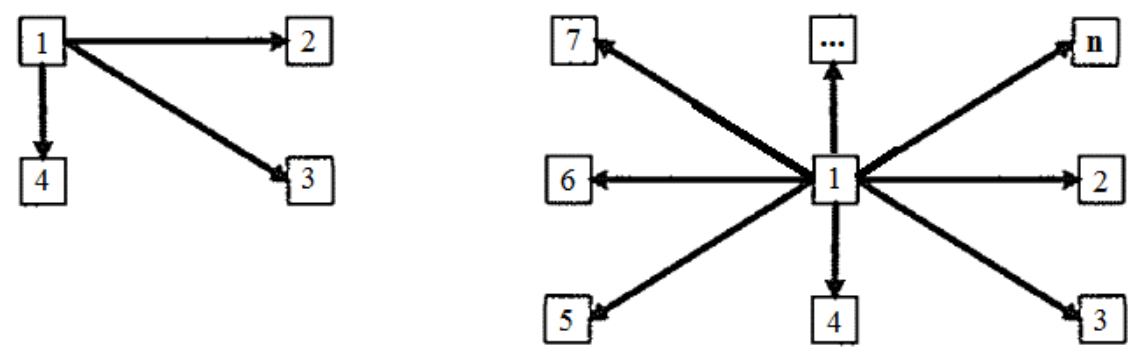

Figura 2-17. Exemplos de possíveis configurações espaciais de dois pontos, três pontos, quatro pontos e $\mathrm{n}$ pontos. (Fonte: Modificado de Goovaerts, 1997). 
Os métodos de múltiplos pontos (MPS, também chamadas de estatística de ordem superior), foram propostas teoricamente pela primeira vez por Guardiano e Srivastava (1993). Onde a aproximação é derivada do conceito da krigagem indicadora (Journel, 1983), o qual permite reproduzir um conjunto de imagens estocásticas honrando qualquer número de covariâncias indicadas de múltiplos pontos. Assim, esta técnica de simulação espacial supera a limitação dos algoritmos de estimativa e simulação, baseados no modelo de autocorrelação.

Ao contrário do uso de estatísticas de dois pontos, que são uma medida linear de continuidade espacial (Boisvert et al., 2008), o algoritmo MPS seleciona padrões a partir da imagem de treinamento (TI), que é uma imagem representativa da estrutura espacial em estudo. Embora a técnicas de múltiplos ponto utilize a TI, em vez do variograma, eles não escapam aos dois princípios fundamentais dos métodos de simulação tradicionais, que muitas vezes são esquecidos (Caers e Zhang, 2002): (1) Estacionariedade e; (2) Ergodicidade. Sob esses dois princípios, uma imagem de treinamento deve ser selecionada cuidadosamente, e não arbitrariamente, além disso, sua criação não pode ser derivada de todas as informações disponíveis.

De acordo com Caers e Zhang (2002), a decisão ou suposição de estacionaridade não é importante apenas para métodos geoestatísticos baseados em estatísticas de dois pontos está premissa também (variância média e constante) é necessária nas estatísticas de ordem superior. Ainda de acordo com Caers e Zhang (2002), os geostatísticos estão cientes das decisões de estacionariedade para o histograma e o variograma, mas frequentemente é dada menor atenção à suposição de estacionariedade dos métodos de múltiplos pontos. De fato, qualquer algoritmo de mapeamento (também não-espacial) requer o uso simultâneo de mais de dois pontos (Caers e Zhang, 2002).

Por outro lado, Caers e Zhang (2002) enfatizam que as estatísticas de ordem superior (MPS), como os métodos de simulação geoestatística convencionais (que usam as estatísticas de dois pontos), devem reproduzir as estatísticas dos dados de entrada (como o variograma e o histograma) sob certas flutuações ergódicas, comumente causadas pela extensão limitada e finita da área de interesse. Portanto, a ergodicidade é um fator importante que depende principalmente da seleção de parâmetros do modelo como da sua simulação. 
De acordo com Journel e Zhang (2006), as metodologias MPS, como os métodos Gaussianos de simulação geoestatística, podem aproximar modelos espaciais de alta entropia (isto é, para uma dada média e variância as aproximações são "desorganizadas" como foram possíveis), bem como diferentes modelos de estruturas de entropia mais baixa (por exemplo, a alta conectividade de valores extremos em um depósito), o que seria mais consistente com os dados originais.

Atualmente, existe, na literatura, uma grande variedade de metodologias de múltiplos pontos, dentre as mais citadas (em suas siglas em inglês) estão a ENESIM (Guardinano e Srivastava, 1993); a SNESIM (Strebelle, 2002); a SIMPAT (Arpat e Caers, 2005, 2007); a FILTERSIM (Zhang et al. al., 2006; Wu et al., 2008); a HOSIM (Mustapha e Dimitrakopoulos, 2010); a DISPAT (Honarkhah e Caers, 2010); a CCSIM (Tahmasebi et al., 2012; Tahmasebi et al., 2014); a WAVESIM (Chatterjee et al., 2012); e a CDFSIM (Mustapha et al., 2014). Este grupo de algoritmos integra em sua filosofia três aspectos importantes, no que diz respeito aos padrões: (1) definir, (2) armazenar e restaurar. Inicialmente os algoritmos geoestatísticos MPS foram desenvolvidos para simular variáveis aleatórias discretas (ENSIM, SNESIM, SIMPAT) ou categóricas, mas nos últimos anos essas técnicas foram estendidas para simular variáveis contínuas (FILTERSIM, HOSIM, DISPAT, CCSIM, WAVESIM e CDFSIM). A extensão se deve ao princípio do uso de distâncias de dissimilaridade na seleção do padrão mais similar (localmente) ao conjunto de padrões espaciais, pertencentes ao banco de dados condicionais, obtido a partir da imagem de treinamento. Em geral, os algoritmos MPS podem ser agrupados em duas classes: (1) Baseados em pixels; e (2) Baseados em padrões.

Segundo Chatterjee et al. (2012), a simulação espacial de variáveis contínuas/categóricas com alguma dependência espacial, comumente presente em ciências da terra como unidades geológicas, continuidade de elementos químicos em depósitos minerais, e atributos de interesse de um reservatório de petróleo e a modelagem de aquíferos são um trabalho desafiador. Além disso, esses mesmos autores destacam a importância de métodos estatísticos de ordem superior na modelagem apropriada das complexidades espaciais e, destaca a superioridade da MPS em relação aos métodos baseados em variograma, dada sua capacidade limitada de reproduzir heterogeneidades. 
O principal objetivo dos algoritmos para simulação de estatística de ordem superior é encontrar o melhor ou mais similar padrão de um banco de dados de padrões em relação ao evento condicional (Arpat e Caers, 2007; Chatterjee et al., 2012), formados pelos nós amostrados e previamente simulados. Nesse sentido, Guardiano e Srivastava (1993), propõem o primeiro algoritmo computacional denominado ENESIM, baseado, principalmente, no conceito de equações normais estendidas. Esta técnica de simulação permite aproximar com maior precisão as características espaciais do fenômeno natural (Figura 2-18), por meio da inferência estatística bivariada, trivariada, quadrivariada (ou simplesmente múltiplos pontos), através das condições impostas em modelos explícitos ou implícitos, bem como o condicionamento das realizações aos dados amostrados (Guardiano e Srivastava, 1993).

De acordo com Guardiano e Srivastava (1993), as informações fornecidas pela imagem de treinamento são transferidas para o código ENESIM, na forma de covariâncias de indicadores de múltiplos pontos. Esses mesmos autores enfatizam que o objetivo da simulação não é reproduzir a imagem de treinamento, em vez disso, pretende-se extrair as diversas características contidas nela, isto é, a TI não é o fenômeno subjacente de interesse. Uma das principais desvantagens do ENESIM é a varredura múltipla da imagem de treinamento até encontrar o melhor padrão ou padrão ideal, que é um processo realizado para cada um dos nós a serem simulados, o que torna o algoritmo impraticável e computacionalmente ineficiente.
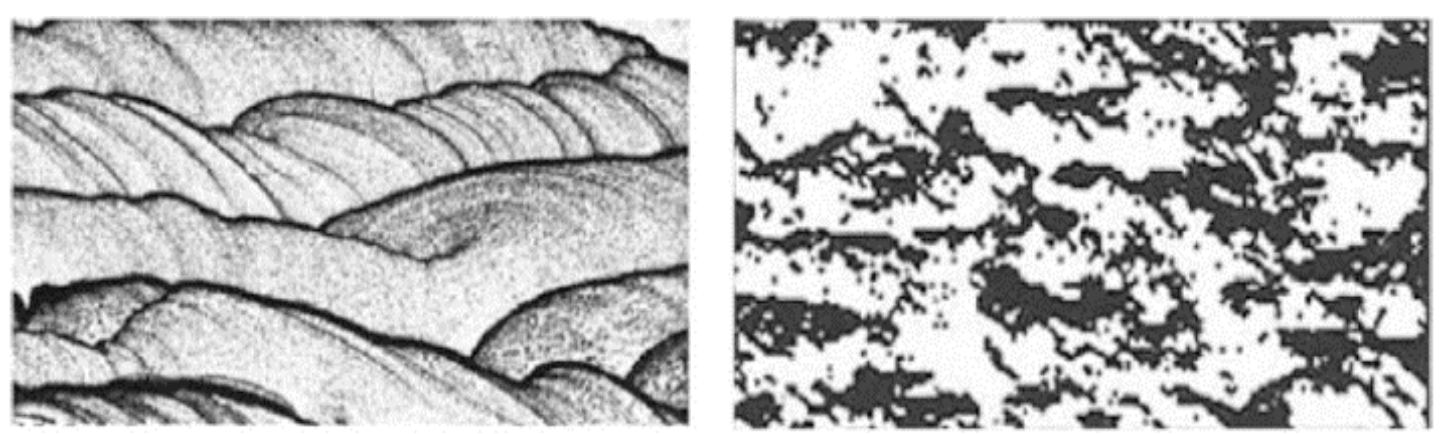

Figura 2-18. Imagem de treinamento (à esquerda), e uma modalidade (à direita) gerada pelo algoritmo ENESIM. A imagem de treinamento representa uma seção transversal de uma areia cruzada. (Fonte: Guardiano e Srivastava, 1993).

No ano de 2002, Strebelle propõe o código de simulação de múltiplos pontos, o qual ele denomina de SNESIM. O algoritmo SNESIM é uma extensão do trabalho 
pioneiro de Guardian e Srivastava (1993). E em contraste com a simulação estocástica de equações estendidas normais (ENESIM), o SNESIM é computacionalmente mais eficiente e, em virtude disso, é visto como uma evolução computacional na geoestatística de múltiplos pontos.

De acordo com Strebelle (2002), o SNESIM é uma técnica de simulação probabilística não iterativa, baseada nas equações normais simples, obtidas a partir do uso da probabilidade condicional do teorema de Bayes. O algoritmo SNESIM foi desenvolvido para simular variáveis aleatórias categóricas, por exemplo, fácies geológicas, mas sua extensão pode ser realizada para simular variáveis aleatórias contínuas, onde a função de distribuição de probabilidade é categorizada dentro de $K$ classes ou grupos. Embora, essa categorização deva ser finita e, em geral, menor do que seis classes.

Da mesma forma, que os métodos de simulação geoestatística clássicos que usam o variograma, o SNESIM é baseado no paradigma da simulação sequencial (Goovaerts, 1997): Onde cada nó simulado é visitado apenas uma única vez, através de uma sequência ou caminho aleatório, tornando-se o novo valor simulado uma "unidade amostral" que condicionará as simulações dos nós restantes.

Ao contrário da técnica de simulação ENESIM, o SNESIM varre a imagem de treinamento apenas uma vez, armazenando as configurações de padrões da TI em uma árvore de busca (Strebelle, 2006). Mais precisamente, as ocorrências de eventos de dados (padrões condicionais) armazenadas na árvore de busca como frequências/probabilidades obtidas a partir dos valores centrais da imagem de treinamento. Assim, as proporções de treinamento podem ser calculadas e retribuídas (Strebelle, 2002).

Algumas limitações importantes do algoritmo SNESIM são (Arpat e Caers, 2007; Tahmasebi et al., 2014): (1) A falta de reprodução de heterogeneidades geológicas realistas altamente interconectadas e de grande escala; (2) Características menores não são bem reproduzidas (por exemplo, estruturas curvilíneas, barreiras de corte, fraturas, entre outras); e (3) O SNESIM é ineficiente computacionalmente em aplicações que requerem modelos tridimensionais de milhões de células. Inspirados por essas razões, Arpat e Caers (2007) introduzem um novo método de simulação de múltiplos pontos, denominado SIMPAT. 
O SIMPAT é um método de simulação que substitui a noção probabilística pelo conceito de distância, a fim de reconstruir ou encontrar o padrão mais semelhante. Segundo Arpat e Caers (2007), a identificação da continuidade geológica ou espacial subjacente da TI, no SIMPAT, é feita através de uma configuração composta de múltiplos pixels, denominada padrão. Um padrão é definido, de acordo com Zhang et al. (2006), como um conjunto de valores distribuídos espacialmente em um modelo de pontos. Sob este novo conceito, a TI é vista como um banco de dados/coleção de dados (também chamado de base de padrões).

Em contraste com o algoritmo SNESIM, o SIMPAT não se baseia nas coincidências exatas entre o evento de dados de condicionamento e a base de padrões, mas explora a melhor correspondência possível (Chatterjee et al., 2012). Por outro lado, a principal vantagem deste algoritmo é a não necessidade de diminuir o número condicional de dados no evento de dados, para a retribuição do padrão mais similar. Em consequência, o SIMPAT analisa completamente a base de padrões na busca do conjunto de pixels que minimiza a distância de dissimilaridade de Manhattan, portanto, é considerada sua maior limitação, devido ao enorme custo computacional para atingir tal objetivo.

A limitação computacional do SIMPAT é superada a partir da implementação de 6 ou 9 filtros lineares, os quais geram scores ou pontuações do conjunto de padrões, denominado de FILTERSIM (Zhang et al., 2006; Wu et al., 2008). Basicamente, os padrões extraídos da imagem de treinamento são transformados, classificados e agrupados em protótipos representativos das classes no espaço de pontuação do filtro.

\subsubsection{IMAGEM DE TREINAMENTO}

A imagem de treinamento, ou padrão/modelo de controle (Goovaerts, 1997), é o mais importante modelo geológico de entrada das técnicas de simulação de MPS. Esses modelos de controle representam características geológicas espaciais de variáveis contínuas/categóricas como unidades geológicas, depósitos minerais e sedimentares, atributos de interesse na indústria de petróleo, assim como formações geológicas de 
rochas porosas e permeáveis, entre outros. Assim, obter uma TI representativa do fenômeno natural em estudo é o maior desafio nas técnicas MPS.

O uso de modelos de controle na simulação geoestatística permite reproduzir de maneira realista, heterogeneidades geológicas com diferentes continuidades espaciais. Conceitualmente, a imagem de treinamento bidimensional e tridimensional é uma representação explícita do fenômeno adjacente em estudo (Arpat e Caers, 2007). Em outras palavras, a TI é uma base conceitual das heterogeneidades do subsolo e/ou recurso geológico numérico que representa o fenômeno espacial, os padrões e a distribuição estocástica natural de um reservatório e/ou depósito mineral (Tahmasebi et al., 2012). Consequentemente, o padrão de controle (ou modelo de controle) é comumente utilizado na extração de propriedades de múltiplos pontos para aproximar um sistema geológico complexo.

De acordo com Tahmasebi et al. (2012), a natureza principal do MPS é capturar características espaciais representativas contidas na imagem de treinamento (ou ainda um banco de dados de padrões geológicos) e, além disso, destacam que os processos MPS explicitamente carregam em suas abordagens a essência de algoritmos baseados em estatísticas de dois pontos (Caers e Zhang, 2002) e baseados em objetos.

Caers e Zhang (2002) destaca a importância do uso do padrão de controle, em contraste, com a estatística de dois pontos em dois aspectos fundamentais: (1) Intuitividade e; (2) Facilidade; ambas proporcionando à validação visual de quais padrões poderiam ser usados na estimativa/simulação das múltiplas realizações estocásticas, bem como a possível inclusão de algum grau de subjetividade geológica na TI (Daya Sagar e Cheng, 2018).

Ainda segundo estes autores, é mais fácil rejeitar a uma imagem de treinamento baseada na inspeção visual e experiência geológica da área de interesse do que recusar um modelo teórico de variograma ajustado, sob critérios subjetivos. No entanto, a construção e o uso de TI estão sujeitos aos mesmos princípios dos métodos baseados no modelo de autocorrelação espacial: estacionariedade e ergodicidade (Caers e Zhang 2002).

Em geral, os modelos de controle podem ser determinados por métodos estatísticos, ou regras extraídas e observadas de dados de afloramento para cada ambiente geológico, bem como realizações não-condicionais de métodos baseados em 
objetos ou processos. Essas imagens de treinamento podem ser de qualquer tipo: desde uma imagem (2D ou 3D), até propriedades geológicas no espaço e/ou tempo. Na geologia, as imagens representam, na sua maioria, fenômenos espaciais com algum grau de complexidade e unicidade (Tahmasebi et al., 2012). Alguns exemplos de padrões de controle são ilustrados na Figura 2-19.

(a)

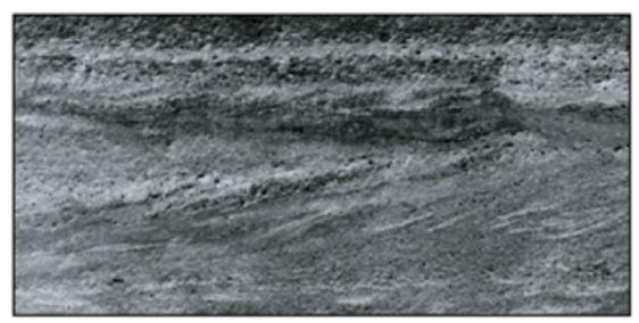

(c)

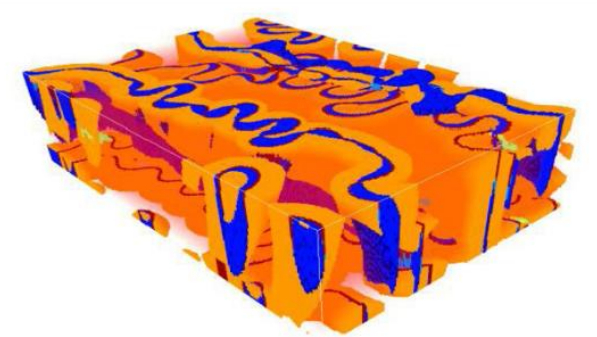

(b)

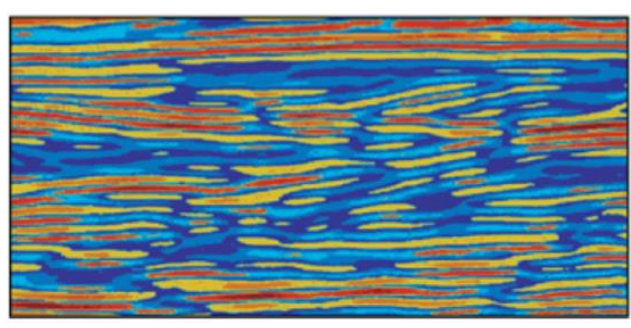

(d)

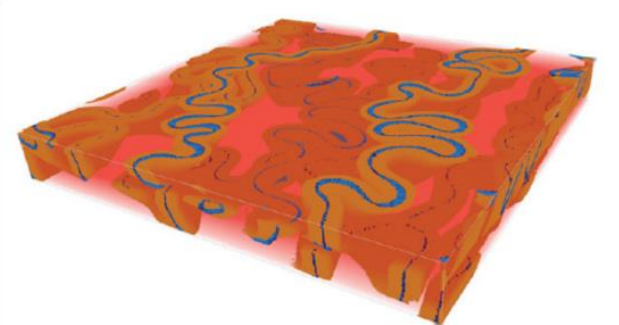

Figura 2-19. Imagens de treinamento. (a) e (b) estruturas geológicas identificadas a partir de um levantamento geo-radar (Bayer et al., 2012), (c) modelo tridimensional gerado por métodos baseados em processos (Tahmasebi e Sahimi, 2016a), (d) modelo sintético de um reservatório aluvial obtido a partir do algoritmo de simulação FLUMY (Lopez et al., 2008).

\subsubsection{FILTERSIM: MÉTODO DE SIMULAÇÃO MPS}

FILTERSIM é um algoritmo de simulação de dissimilaridade de múltiplos pontos, que tem a capacidade de preservar a continuidade e as estruturas espaciais presentes na imagem de treinamento. $\mathrm{O}$ algoritmo pertence a uma ampla família de métodos de simulação baseados em padrões, cujo objetivo principal é encontrar o padrão mais semelhante. Em contraste, com as metodologias estatísticas de ordem superior baseadas em pixels (por exemplo, ENESIM e SNESIM), o FILTERSIM permite simular um conjunto de pixels ao mesmo tempo e não um único pixel à vez.

De acordo com Zhang et al. (2006) e Wu et al. (2008), o algoritmo de simulação FILTERSIM foi desenvolvido por Zhang (2006), com o propósito de contornar algumas das limitações do SNESIM e SIMPAT: (1) O SNESIM reproduz apenas características 
de variáveis categóricas complexas; (2) Informações valiosas são desconsideradas no condicionamento, isto é, dados de eventos condicionais são reduzidos pela eliminação do valor de referência mais distante; e (3) A ineficiência computacional do método SIMPAT (Zhang, 2006), particularmente em 3D, que se deve à falta de técnicas de classificação de padrões na sua estrutura.

Durante seu processo, o FILTERSIM, utiliza seis ou nove filtros lineares na classificação dos padrões da imagem de treinamento em um espaço de filtro de pontuações, ou score de dimensão reduzida (Remy et al., 2009). Esses padrões de treinamento (também chamados de peças de quebra-cabeça), são agrupados em classes que são representadas por um padrão médio ou protótipo, de acordo com alguma medida de similaridade (Zhang et al., 2006; Wu et al., 2008).

Durante o processo de simulação, o protótipo que melhor se adapta ao evento de dados condicionais é determinado e um padrão de treinamento é selecionado da classe de protótipo, que é imediatamente "colado" no modelo numérico (ou malha de simulação). Por estas razões, segundo Remy et al., (2009) e Zhang et al. (2006), essa técnica de simulação estocástica é semelhante à construção de um quebra-cabeça, onde cada peça poderia ser usada um número finito de vezes para um conjunto local de dados de condicionamento.

De acordo com Zhang (2006), em duas dimensões, os seis diferentes filtros $f_{l}(i, j), l=1, \ldots, L$, usados no algoritmo de simulação FILTERSIM, são definidos nas equações 2.24, 2.25 e 2.26 e encontram-se ilustrados na Figura 2-20.

i. $\quad f_{1,2}:$ Filtro da média, nas direções N-S e E-W:

$$
f_{1,2}(i, j)=1-\frac{|j, i|}{n}, j, i=-n, \ldots, n \in[0,1]
$$

ii. $\quad f_{3,4}$ : Filtro do gradiente, nas direções N-S e E-W:

$$
f_{3,4}(i, j)=\frac{j, i}{n}, \in[-1,1]
$$

iii. $f_{5,6}$ : Filtro de curvatura, nas direções N-S e E-W:

$$
f_{5,6}(i, j)=\frac{2|j, i|}{n}-1, \in[-1,1]
$$


De acordo com Zhang (2006), o método FILTERSIM pode ser sucintamente descrito em quatro etapas principais: (1) Definição do modelo; (2) Geração de banco de dados; (3) Classificação de padrões e; (4) Simulação sequencial com padrões.

Na primeira etapa, o padrão de controle é varrido por uma janela de pesquisa $\mathrm{T}$ (configuração/modelo), bidimensional ou tridimensional, de tamanho fixo $n_{T}=n_{x} \times$ $n_{y} \times n_{z}$ (onde $n_{x}, n_{y}$ e $n_{z}$ são as dimensões do modelo para cada direção $X, Y$ e $Z$, respectivamente), o qual extrai os vizinhos próximos em torno de um ponto central $u$, que compõem o vetor $t i_{T}(\mathrm{u})$ :

$$
t i_{T}(u)=\left\{t i\left(u+h_{1}\right), t i\left(u+h_{2}\right), \ldots, t i\left(u+h_{\alpha}\right), \ldots, t i\left(u+h_{n_{T}}\right)\right\}
$$

onde $h_{\alpha}=(x, y, z)$ é o vetor que define a geometria da janela de pesquisa com $n_{T}$ pontos espaciais e $\alpha=1, \ldots, n_{T}$. Esse conceito anterior é ilustrado na Figura 2-21, para um modelo $2 \mathrm{D}$ quando $n_{T}=9$.

(a) $\mathrm{O}$ primeiro filtro

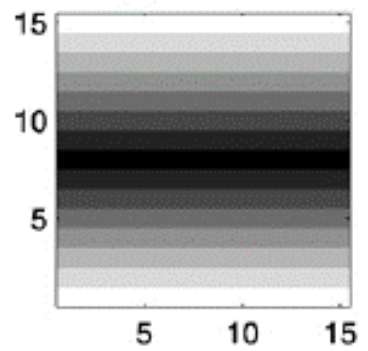

(c) $\mathrm{O}$ terceiro filtro

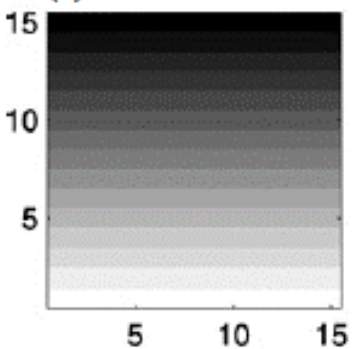

(e) $\mathrm{O}$ quinto filtro

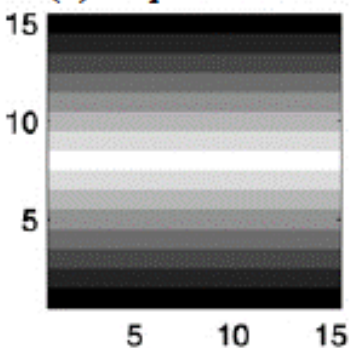

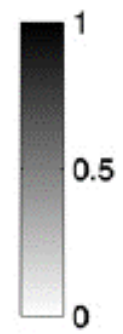
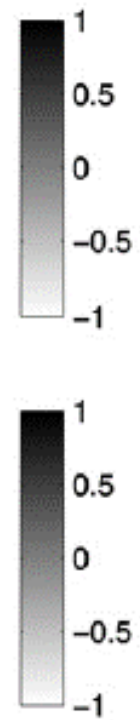

\section{(b) $O$ segundo filtro}

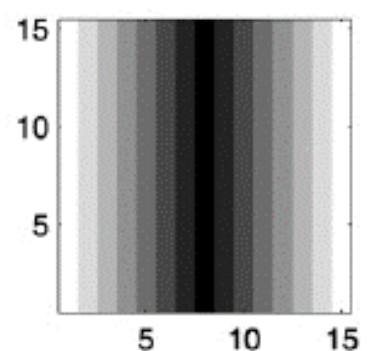

(d) $\mathrm{O}$ quarto filtro

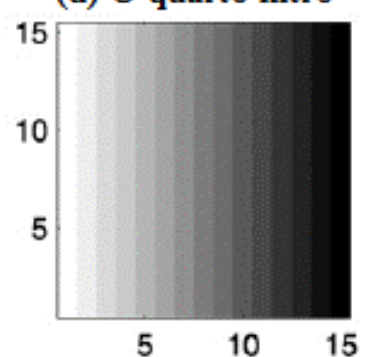

(f) $O$ sexto filtro

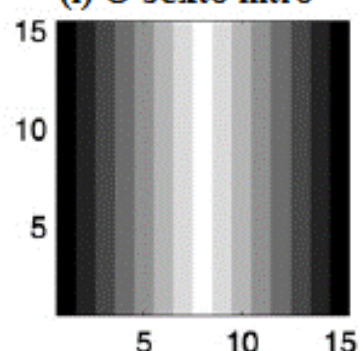

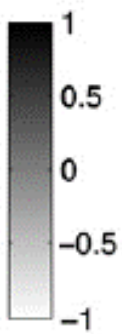
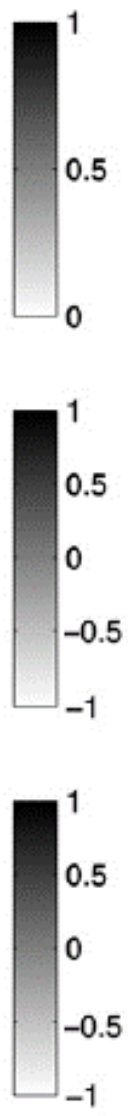

Figura 2-20. Filtros locais em um espaço bidimensional: onde os pesos são dados pela escala em cinza. (Fonte: Zhang et al., 2006). 
$\mathrm{Na}$ segunda etapa, um conjunto de 6 ou 9 filtros lineares é aplicado a cada padrão de treinamento local, de coordenada $u$, da imagem de treinamento (Figura 2-22). Para isso, é necessária que a configuração dos filtros seja a mesma (em tamanho) que a da janela de busca (Remy et al., 2009). Nesse sentido, segundo Wu et al. (2008), um filtro pode ser visto como uma coleção de pesos associados a cada ponto do modelo $T$. Os padrões de treinamento são resumidos por um conjunto de valores, $L$, para cada filtro como (Remy et al., 2009; Wu et al., 2008; Zhang et al., 2006):

$$
S_{T}(u)=\sum_{j=1}^{n_{T}} f_{l}\left(h_{j}\right) \cdot t i\left(u+h_{j}\right)
$$

onde $f_{l}\left(h_{j}\right)$ é o valor do filtro associado a um nó específico com coordenada $h_{j}$, e $t i\left(u+h_{j}\right)$ é um valor específico do vetor de múltiplos pontos de dimensão local $n_{T}$.

\begin{tabular}{|l|l|l|}
\hline$u+h_{3}$ & $u+h_{2}$ & $u+h_{9}$ \\
\hline$u+h_{4}$ & $\begin{array}{c}u+h_{1} \\
=u\end{array}$ & $u+h_{8}$ \\
\hline$u+h_{5}$ & $u+h_{6}$ & $u+h_{7}$ \\
\hline
\end{tabular}

[ a ] Modelo 2D, $3 \times 3$
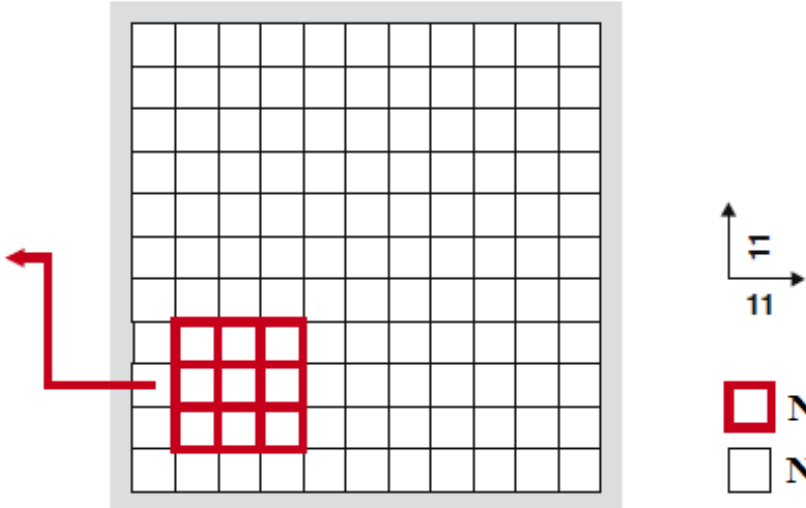

[ b ] Malha 2D, $11 \times 11$

Figura 2-21. Exemplo de um modelo $3 \times 3$ (ou template) em 2D aplicado a uma malha bidimensional tamanho 11 x 11. (Fonte: Arpat e Caers, 2007).

\section{O primeiro filtro}

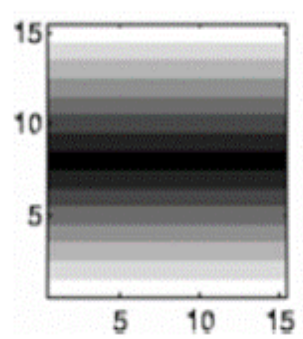

Padrão Local

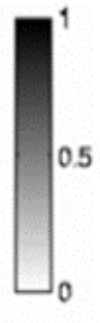

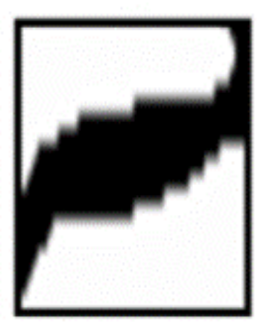

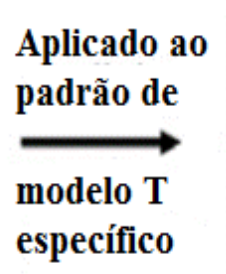

Aplicado ao padrão de

modelo $\mathrm{T}$ específico
Ponto/Score

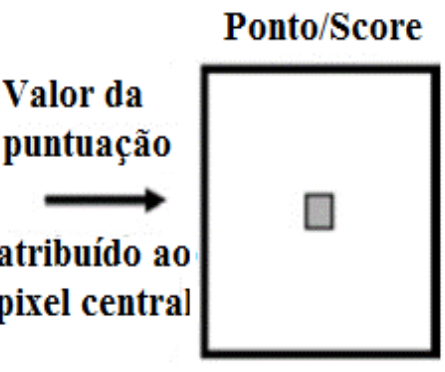

Figura 2-22. Espaço de filtro de pontuações (Fonte: Zhang et al., 2006). 
Para uma imagem de treinamento de valores contínuos, os $L$ filtros são aplicados diretamente aos valores que compõem cada padrão de treinamento (Remy et al., 2009; Wu et al., 2008). No entanto, uma TI com $K$ categorias, deve ser decomposta em um conjunto disjunto de imagens binárias $I_{k}(u)=1, \ldots, K-1, u \in T I$, conforme:

$$
I_{k}(u)= \begin{cases}1, & \text { se } u \in k-\text { ésima categoria }, \\ 0, & \text { caso contrario. }\end{cases}
$$

Assim, cada padrão categórico é representado por $\mathrm{K}$ conjuntos de padrões disjuntos, com o k-ésimo padrão binário indicando a presença/ausência de qualquer categoria em um determinado local (Remy et al., 2009; Wu et al., 2008). De modo que, os filtros são aplicados a cada um dos $K$ padrões binários resultando em um total de $\mathrm{L} \times$ K pontuações. Do anterior, uma TI contínua pode ser vista como um caso particular de uma imagem de treinamento com uma única categoria, ou seja, quando $K=1$. No entanto, uma imagem de treinamento categórica pode ser tratada como uma TI contínua, se cada categoria dentro do padrão de controle for dividida pelo número total de categorias (Wu et al., 2008, p. 779). No FILTERSIM, o banco de dados de padrões é uma base de dimensão reduzida, gerada a partir da aplicação de 6 ou 9 filtros a todos os padrões de treinamento que pertencem a uma TI categórica ou contínua.

$\mathrm{Na}$ terceira etapa, os padrões de treinamento mais semelhantes contidos no banco de dados poderiam ser agrupados em $C$ classes/grupos, através da partição do espaço de filtro de pontuação (Zhang, 2006). De acordo com o Remy et al. (2009), cada classe de padrões é representada por um protótipo de padrão, prot, calculado a partir da média de todos os padrões de treinamento pertencentes a cada grupo. Além disso, esses mesmos autores esclarecem que um protótipo deve ter o mesmo tamanho da janela de pesquisa, onde cada grupo médio é identificado por meio de um único número chave denominado ID. Para uma variável aleatória contínua, o protótipo derivado das classes de padrão capturado por um modelo de pesquisa, é definido como (Remy et al., 2009; Wu et al., 2008):

$$
\operatorname{prot}\left(h_{j}\right)=\frac{1}{c} \sum_{i=1}^{c} t i\left(u_{i}+h_{j}\right), j=1, \ldots, J
$$


com $c$ igual ao número de réplicas de treinamento dentro da classe de protótipos, $h_{j}$ é a j-ésima localização do vetor de múltiplos pontos $t i_{T}(u)$, e $u_{i}$ é o valor central de um padrão de treinamento que pertence a essa classe particular. Para uma imagem de treinamento categórica, a expressão (2.30) é aplicada a cada uma das $K$ imagens binárias derivadas da função indicadora da expressão (2.29). Consequentemente, um protótipo categórico consiste em $K$ mapas de proporções, onde cada mapa contém a probabilidade de uma determinada categoria prevalecer em um local $u_{i}+h_{j}$ na janela de busca (Remy et al., 2009; Wu et al., 2008):

$$
\operatorname{prot}\left(h_{j}\right)=\left\{\operatorname{prot}^{k}\left(h_{j}\right), k=1, \ldots, K\right\}
$$

onde $\operatorname{prot}^{k}\left(h_{j}\right)=\operatorname{Prob}\left(z\left(u+h_{j}\right)=k\right)$. Em geral, a dimensão da base de padrões é: $L \times K$, que é muito menor que o tamanho do modelo de filtro. Em virtude disso, o FILTERSIM exige menos memória computacional.

Finalmente, o último passo é simular cada localização/coordenada $u$ do modelo dimensional ou tridimensional. A simulação é calculada sob o uso do paradigma de simulação sequencial (seção 2.3), para a simulação estocástica com padrões. Dessa forma, para cada coordenada $u$, uma janela de busca $T$ é usada para extrair/capturar os dados de eventos condicionais $\operatorname{dev}(u)$ e, imediatamente, o prototipo prot mais próximo ao evento de dados condicionais é encontrado usando-se uma função de distância de dissimilaridade (Wu et al., 2008).

Na sequência, um padrão de treinamento é selecionado aleatoriamente da classe mais próxima e é "colado" inteiro na malha de simulada. Onde, o valor central do padrão selecionado é congelado e, consequentemente, é considerado como um dado "amostrado" que não poderá ser examinado novamente durante a simulação sequencial. Da mesma forma, que a simulação SNESIM, o método de simulação com padrões FILTERSIM, utiliza o conceito de múltiplas malhas (Tran, 1994). Com o objetivo de capturar estruturas de escalas maiores presentes na TI.

Conforme Zhang et al. (2006), Wu et al. (2008) e Remy et al. (2009), a função distância de dissimilaridade utilizada na seleção do protótipo mais próxima ao evento de dados é definida como: 


$$
d i s t=\sum_{i=1}^{J} w_{i} \cdot\left|\operatorname{dev}\left(u+h_{i}\right)-\operatorname{prot}\left(u_{0}+h_{i}\right)\right|
$$

onde,

J é o número total de nós que compõem o modelo de pesquisa T;

$w_{i}$ são os pesos associados a cada nó do modelo $T$;

$u$ é a localização central/coordenada do evento de dados dev;

$h_{i}$ é o deslocamento (horizontal/vertical) do nó no modelo de pesquisa;

$u_{0}$ é a localização do nó central do protótipo.

Além disso, três tipos de dados são considerados dentro do evento condicional dev: (1) Dados condicionais; (2) Previamente simulados e; (3) Valores aderidos; definido como (Remy et al., 2009):

$$
w_{i}=\left\{\begin{array}{lr}
\frac{W_{1}}{n_{T}}: & \text { dados condicionantes }(d=1) \\
\frac{W_{2}}{n_{T}}: & \text { dados previamente simulados }(d=2) \\
\frac{W_{3}}{n_{T}}: & \text { dados aderidos }(d=3)
\end{array}\right.
$$

com restrição de $\Sigma w_{i}=1$, e $n_{T}$ é o número de nós da janela de pesquisa T.

Atualmente, o algoritmo de simulação estocástica de variáveis categóricas/contínuas de estatísticas de ordem superior, FILTERSIM, está disponível no programa de computador SGeMS (Remy et al., 2009). Este algoritmo de simulação com padrões foi escrito na linguagem de programação $\mathrm{C}++$ por $\mathrm{Wu}$ et al. (2008) e os detalhes matemáticos são discutidos detalhadamente por Zhang (2006).

\subsubsection{SELEÇÃO DO TEMPLATE ÓTIMO}

Para gerar realizações estocásticas usando as estatísticas de múltiplos pontos, o parâmetro de entrada de maior importância é a definição do tamanho de janela de busca, 
porque permite adquirir as diferentes estruturas/heterogeneidades presentes na imagem de treinamento. Por exemplo, no método probabilístico de estatísticas de ordem superior SNESIM a janela de busca é usada para o cálculo de probabilidades e em métodos baseados em padrões, como SIMPAT e FILTERSIM, corresponde ao tamanho dos padrões usados na geração de imagens estocásticas (Honarkhah e Caers, 2010). Desta forma, a janela de busca, nas abordagens MPS baseadas em padrões, é vista como uma interface para recuperar as principais estatísticas de múltiplos pontos da TI (Honarkhah, 2011). Portanto, um critério de seleção de modelo ideal deve ser definido.

Para encontrar o tamanho ideal da janela de busca, a entropia da informação (Shannon, 1948), é aplicada ao conjunto de padrões de treinamento que compõem a base de padrões com o mesmo tamanho que o modelo de procura, sendo definida como:

$$
H(X=k)=-\sum_{i=1}^{K} p_{i} \cdot \log \left(p_{i}\right), i=1, \ldots, K
$$

onde $K$ é igual ao número de categorias (ou possíveis saídas) da variável aleatória $X$, e $p_{i}$ representa as probabilidades ou a função de distribuição de probabilidade. Segundo Honarkhah e Caers (2010), a entropia da informação é uma medida estatística de aleatoriedade que pode ser usada para identificar texturas/estruturas da imagem de treinamento, bem como uma medida de incerteza. De acordo com esses mesmos autores, quando esse conceito estatístico é aplicado a padrões determina-se a informação mínima necessária para representar com segurança o padrão como dígitos binários codificados.

$\mathrm{O}$ algoritmo de escolha de uma janela de pesquisa ideal começa com o préprocessamento da TI com vários tamanhos de modelo. Comumente nos métodos de simulação MPS, computacionalmente, o tamanho do modelo é representado por um quadrado/retângulo composto de um número ímpar de pontos, por exemplo, em 2D é representado como: $T_{s}=\left\{(3 \times 3),(5 \times 5), \ldots,\left(n_{x}^{\prime} \times n_{y}^{\prime}\right)\right\}$, onde $n_{x}^{\prime}, n_{y}^{\prime}$ são as dimensões do modelo nas direções $X$ e $Y$, respectivamente, selecionados arbitrariamente e $T_{S}$ é o conjunto de tamanhos de modelo na busca por um valor "ótimo" $n_{T_{S}}=n_{x}^{\prime} \times$ $n_{y}^{\prime}$. Da mesma forma, para uma TI em um espaço tridimensional, o mesmo procedimento é seguido, mas ao contrário de um padrão de controle bidimensional, o tamanho do modelo na direção vertical deve ser adicionado (Honarkhah, 2011). 
Uma vez varrida a TI (em 2D), a entropia média de todos os padrões de treinamento de tamanho $n_{T_{S}}$ é calculado como (Honarkhah, 2011):

$$
M E=\frac{1}{n_{T_{S}}} \sum_{i=1}^{n_{T_{S}}} H\left(t i_{T_{S}}\right)
$$

sendo $t i_{T_{S}}$ o vetor de multiplos pontos do conjunto de tamanho igual ao template $T_{S}$ e $n_{T_{S}}$ é o número de padrões que podem ser extraídos com um template de dimensões $\left(n_{x}^{\prime}, n_{y}^{\prime}\right)$ especifico. Esse resultado é plotado de acordo com o tamanho do modelo ou, sem perda de generalidade, em uma função de $n_{T_{S}}$. De acordo com Honarkhah (2011), a entropia da informação cresce drasticamente durante os primeiros tamanhos de $\mathrm{T}$, e à medida que $n_{T_{S}}$ se aproxima do tamanho "ótimo" do modelo, ela é atenuada. Assim, o ponto de inflexão corresponde ao tamanho "ótimo" da janela de busca, que estatisticamente é obtido usando a máxima verossimilhança, conjuntamente com a segunda derivada da curva de entropia: $f_{i}^{\prime \prime}=f_{i+2}-2 f_{i+1}+f_{i}$, onde $f$ é a função objetivo e sua igualdade é dada pela formula das diferenças finitas (Honarkhah e Caers, 2010). A abordagem anterior pode ser obtida conforme ilustrado na Quadro 2-1 e Figura $2-15$.

Quadro 2- 1. Algoritmo de seleção automática do template "ótimo" (Honarkhah, 2010).

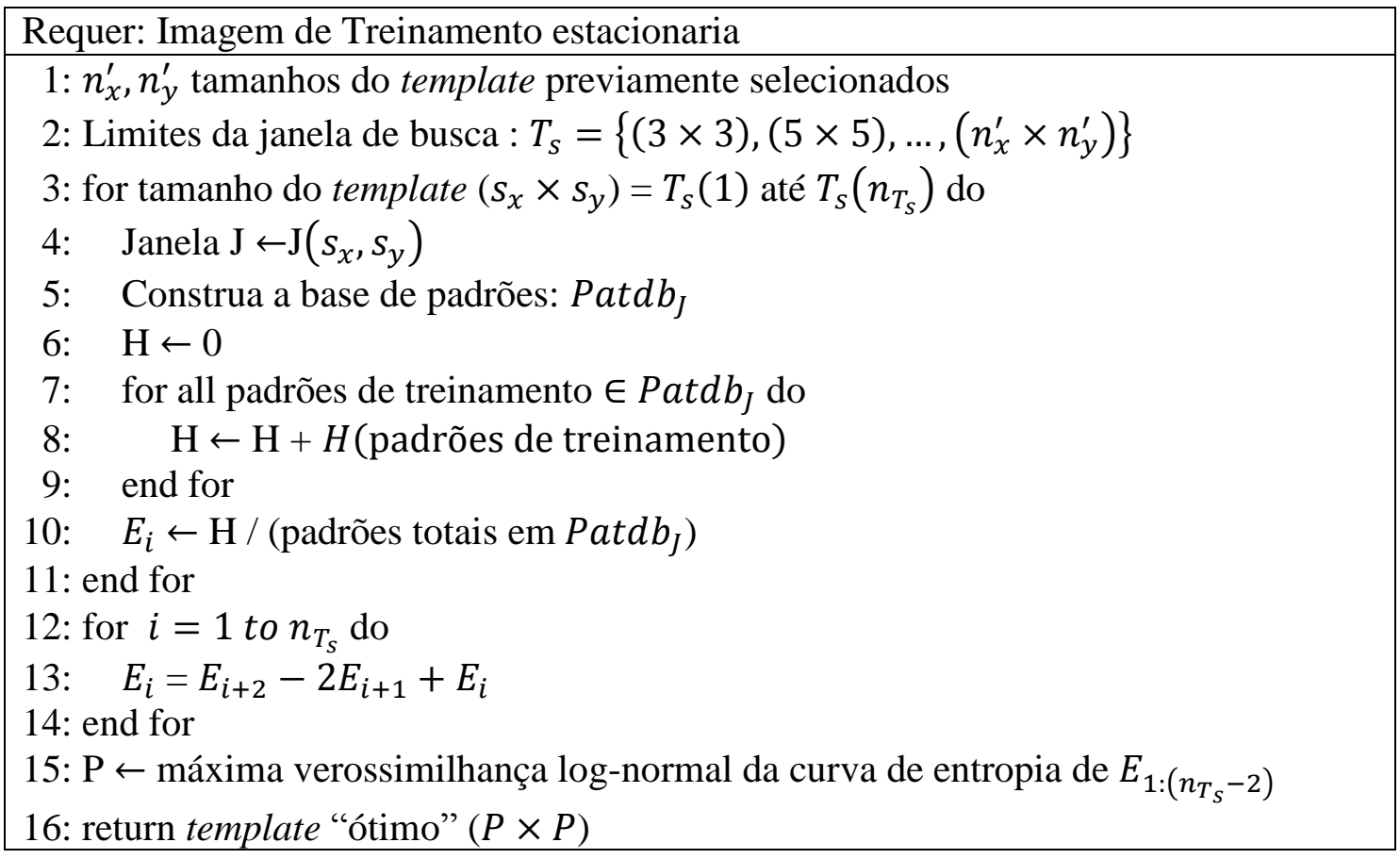


O mesmo algoritmo da Quadro 2-1, poderia ser aplicado em três dimensões. Embora, as dimensões 2D e 3D devam ser analisadas separadamente, aplicando o algoritmo (Quadro 2-1), em todas as fatias horizontais e verticais da imagem de treinamento (Honnarkhah, 2011). A Figura 2-23, ilustra um único exemplo na seleção do tamanho ideal da janela em 2D.
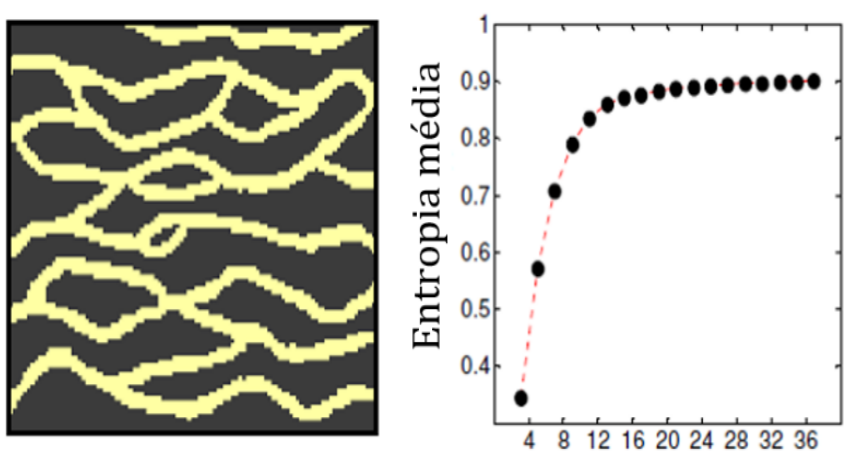

Tamanho do modelo

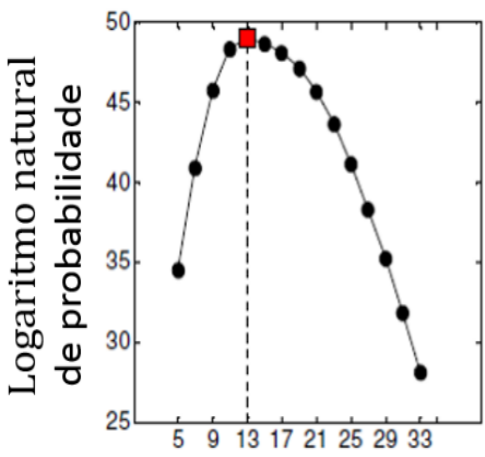

Tamanho do modelo

Figura 2-23. Aplicação automática da seleção ótima do template em um reservatório fluvial em 2D. A Figura ilustra a imagem de treinamento (à esquerda), a curva de entropia média (ao centro) e o logaritmo natural da função de probabilidade (à direita). Com o valor de template ideal igual a $n_{x}^{\prime}=13$ e $n_{y}^{\prime}=13$. (Fonte: Honarkhah, 2011).

\section{6 TRATAMENTO DE IMAGENS POR FILTROS}

A estimativa de teores e volumes por meio de métodos de interpolação/simulação geoestatística, muitas vezes gera mapas "desorganizados" que ignoram a continuidade geológica, além de apresentarem dificuldades na reprodução de importantes propriedades como a conectividade entre valores (tal problema é conhecido na literatura como "Spotted Dog"). Em consequência, a classificação dos recursos minerais de acordo com o grau de confiabilidade das classes: Medido, Indicado e/ou Inferido; não são representados espacialmente por regiões homogêneas e, em virtude disso, levam a decisões errôneas tomadas por engenheiros/geólogos a respeito do valor estimado real dos recursos minerais.

Portanto, a solução para o problema de conectividade e homogeneização espacial do fenômeno em estudo é suavizar a variável de interesse dentro de áreas 
geologicamente sensíveis e coerentes, de tal forma que suas características sejam preservadas o máximo possível de acordo com a quantidade, distribuição e qualidade dos dados (Stephenson et al., 2002, p. 7). Assim, neste trabalho, com o objetivo de remover/diluir possíveis "ruídos" presentes na imagem (em 2D ou 3D), serão utilizados dois filtros lineares comumente aplicados no processamento de imagens: (1) O filtro de média e; (2) O Filtro Gaussiano.

O filtro de média (FM ou também chamado de filtro de convolução) é o algoritmo de suavização mais usado no processamento de imagens. O FM é um simples filtro de janela ou um modelo deslizante, que substitui o valor central do modelo pelo valor médio, derivado do conjunto de valores que o compõem. Desta forma, os valores não representativos da imagem são substituídos pela média aritmética.

O filtro Gaussiano (FG) é o filtro de suavização linear mais importante e, comumente, usado no processamento de imagens. Em contraste, com o filtro da média que aplica pesos uniformemente, o FG aplica os pesos de acordo com uma distribuição Gaussiana (equação 2.36, para uma imagem bidimensional), onde o parâmetro chave é $\sigma$ (desvio padrão), o qual controla a extensão do Kernel ou janela e, consequentemente, o grau de suavização da imagem. Sua extensão na análise de imagens tridimensionais resulta do produto entre três variáveis aleatórias distribuídas independentemente com distribuição Gaussiana de média igual a zero.

$$
G(x, y)=\frac{1}{2 \pi \sigma} \exp \left(-\frac{x^{2}+y^{2}}{2 \sigma^{2}}\right)
$$

\section{7 ANÁLISE DE COMPONENTES PRINCIPAIS}

Análise de componentes principais (sigla em português, ACP), é um método estatístico cujo objetivo é a redução da dimensão e interpretação dos dados (Jhonson e Wichern, 1998). A redução da dimensionalidade dos dados por meio da técnica ACP, é alcançada se a estrutura original de um conjunto de variáveis, variância-covariância, 
puder ser explicada através de poucas combinações lineares dessas variáveis. Conceitualmente, espera-se que a variabilidade total dos dados, contidos em $\mathrm{p}$ componentes, possa ser reproduzida por um pequeno número de $k$ componentes principais (Jhonson e Wichern, 1998).

As componentes principais são aquelas combinações lineares, não correlacionadas, ordenadas da maior para a menor quantidade de informação explicada pela variância. Nesse sentido, a primeira componente principal resume da melhor maneira possível as informações contidas na matriz de dados original. Ou seja, é quem explica a variabilidade máxima dos dados. O segundo componente principal é aquele que resume a maior variabilidade restante e assim por diante. O total de componentes principais é igual ao número de variáveis originais (na matriz de dados), onde todas elas são ortogonais entre si.

ACP é um método simples, que não requer uma suposição de normalidade no conjunto de dados para redução de dimensão. Em virtude disso, a análise das principais componentes é amplamente utilizada em diferentes campos do conhecimento. Por exemplo, processamento de imagem, classificação, compreensão de dados e entre outros.

\subsubsection{DEFINIÇÃO MATEMÁTICA DA ACP}

A análise de componentes principais é uma técnica que combina duas características matemáticas durante seu processo: algébrico e geométrico. Nesse sentido, a ACP rotaciona o sistema de coordenadas das variáveis originais em um novo sistema de coordenadas ortogonais, chamadas de eixos principais, de modo que os novos eixos representem a variabilidade máxima das observações originais, resultantes da combinação linear entre variáveis.

Matematicamente, a ACP é calculada a partir do espaço da variável original, usando os autovetores e autovalores da matriz de covariância, como segue:

Seja $X$ uma coleção de imagens ou modelos de dimensão $N$, onde $L$ denota o número de modelos alternativos, tipicamente, $L<N$, isto é, 


$$
X=\left[X_{1}, X_{2}, \ldots, X_{m}\right]^{T} \text { con } m=1, \ldots, L
$$

Onde a média de cada modelo é calculada por,

$$
\mu=E[X] \cong \frac{1}{L} \sum_{m=1}^{L} X_{m}
$$

e assim, a matriz de covariância é dada como:

$$
C=\operatorname{COV}[X]=E\left[(X-\mu)(X-\mu)^{T}\right]
$$

Desta forma, os autovalores $\lambda_{m}$ e autovetores $e_{m}, m=1, \ldots, L$ da matriz de covariância podem ser obtidos a partir da solução do sistema de equações dadas por:

$$
\left|\lambda_{m} I-C\right|=0
$$

usando a decomposição em valores singulares (DVS), onde:

$$
\lambda_{1} \geq \lambda_{2} \geq \cdots \geq \lambda_{k} \geq 0
$$

com seus respectivos autovetores $e_{m}$. Os autovetores são ordenados em ordem decrescente com seus autovalores correspondentes. A seleção dos componentes principais é feita, arbitrariamente, por meio de um parâmetro limiar em que a proporção acumulada pelos primeiros autovalores $k$ excede um certo valor $t r$, conforme:

$$
\frac{\sum_{m=1}^{k} \lambda_{m}}{\sum_{m=1}^{L} \lambda_{m}} \geq t r
$$

Assim, a projeção dos dados de dimensões maiores para menores é dada usando os primeiros $k$ autovetores. 


\subsubsection{BIPLOT: INTERPRETAÇÃO E VISUALIZAÇÃO}

Biplot é um método que permite visualizar as diferentes relações entre um conjunto de variáveis, em uma representação bidimensional. Em particular, esse tipo de gráfico é comumente utilizado com a técnica de análise de dados multivariada, como é Análise de Componentes Principais (ACP).

Segundo Grabriel (1971), a ACP Biplot revela aglomerações entre unidades e mostra as distâncias entre elementos, assim como as diferentes variações e correlações existentes em uma matriz de dados. Ao contrário do gráfico de dispersão, os eixos não são perpendiculares, pois, simulam a projeção n-dimensional em uma superfície com mínima perda de informação, no qual o ângulo entre vetores corresponde à correlação entre as variáveis (Salinas et al., 2013).

A técnica de representação gráfica, Biplot, foi proposta pela primeira vez por Gabriel no ano de 1971. Em virtude da análise de dados e visualização de estruturas de dados maiores, o Biplot tem sido amplamente aplicado e modificado em diversas ciências do conhecimento como Medicina, Genética, Agricultura, Economia, e Negócios, entre outros (Salinas, et al., 2013).

De acordo com Salinas et al. (2013), o Biplot (Gabriel, 1971) baseia-se nas mesmas premissas do mesmo modo que outros métodos de redução de dimensão, e sua interpretação é baseada em conceitos geométricos de fácil entendimento. A Figura 2-24 ilustra as ideias básicas para interpretar um mapa Biplot:

i. Os objetos são simbolizados por pontos e as variáveis representadas por vetores,

ii. As distâncias entre dois casos aproximam suas semelhanças,

iii. A magnitude do vetor aproxima o desvio padrão das variáveis,

iv. Se o ângulo entre dois vetores é pequeno, então eles têm padrões de respostas semelhantes às variáveis.

Além das quatro interpretações básicas do Biplot, podemos acrescentar duas importantes interpretações (Kroonenberg, 2008): 
i. A origem representa a média ponderada de cada variável,

ii. Um objeto a grande distância da origem tem um efeito maior de interação entre os outros objetos, ou seja, as variáveis mais distantes do centro, ou origem, estão bem representadas no mapa de fatores.

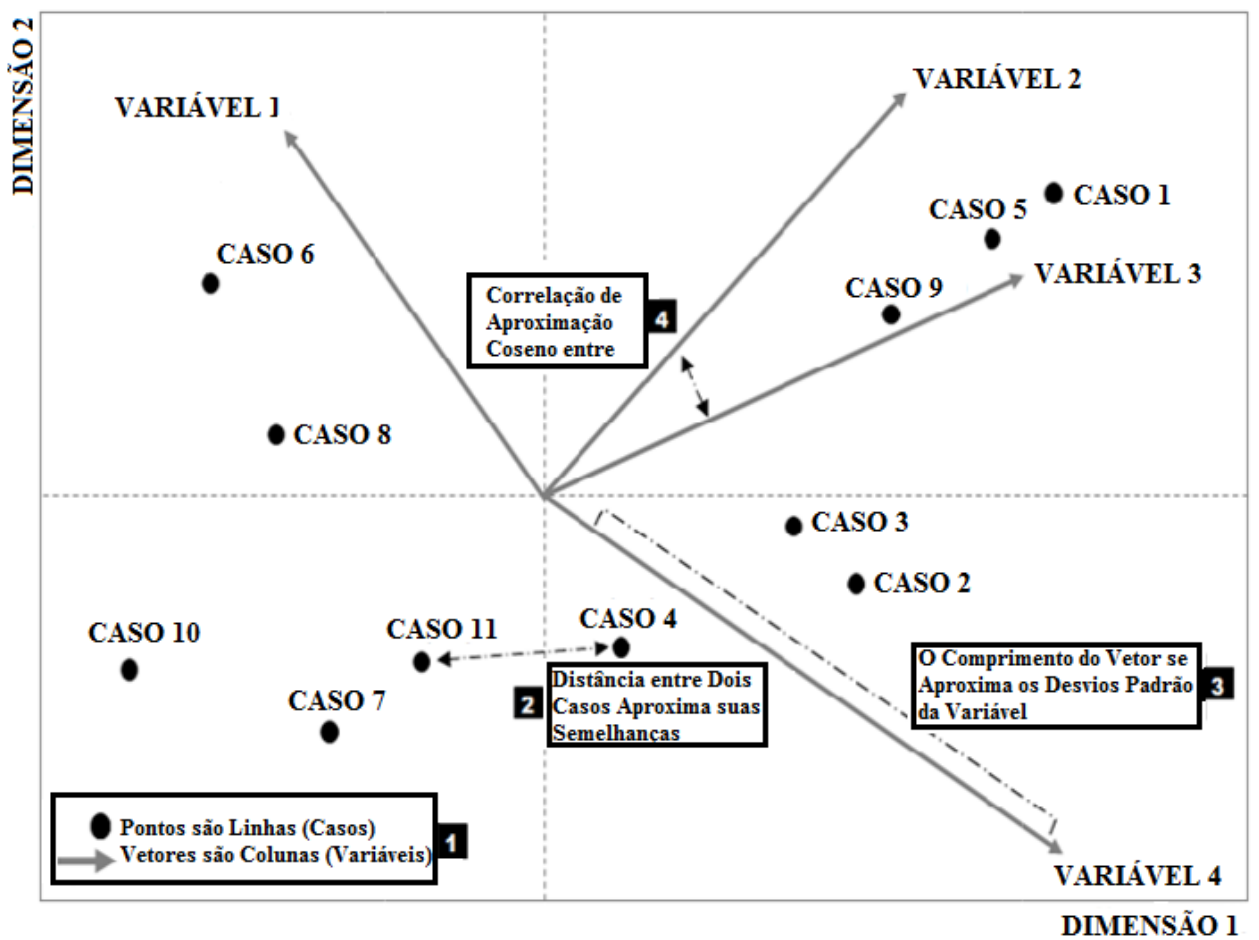

Figura 2-24. Representação básica do Biplot e suas interpretações básicas. (Fonte: Salinas, et al., 2013)

\section{8 ANÁLISE DE SENSIBILIDADE}

No ano 1993, Sobol' generalizo os métodos baseados na variância para análise de sensibilidade a partir da decomposição de variância. $\mathrm{O}$ método de aproximação de Sobol' é uma análise de sensibilidade global, capaz de calcular as diferentes medidas de sensibilidade para grupos arbitrários de fatores através do conceito de Monte Carlo (Saltelli et al., 2008). O método global de sensibilidade de Sobol' pode ser aplicado a funções e modelos não lineares e não monótonos (Sobol', 1993; Homman e Saltelli, 1996).

Para um modelo da forma $Y=f(X)=f\left(X_{1}, X_{2}, \ldots, X_{k}\right)$, onde $Y$ é uma saída de modelo escalar (ou função objetivo) e, $X=\left(X_{1}, X_{2}, \ldots, X_{k}\right)$ o vetor de parâmetros 
do modelo, a função $f(X)$ pode ser decomposta em adições de diferentes dimensões (Sobol', 1993), como:

$$
f(X)=f_{0}+\sum_{i=1}^{k} f_{i}\left(X_{i}\right)+\sum \sum_{1 \leq i \leq j \leq k} f_{i j}\left(X_{i}, X_{j}\right)+\cdots+f_{1,2, \ldots, k}\left(X_{1}, \ldots, X_{k}\right)
$$

onde cada termo de $f$ é quadrado integrável em $\Omega^{d}$ (Sobol, 1993; Saltelli et al., 2008; Homman e Saltelli, 1996). Além disso, essa decomposição é única se os fatores de entrada forem independentes e cada termo da equação (2.43) tiver média zero sobre todo o domínio e, como consequência, todas as adições são ortogonais (Saltelli et al., 2008; Saltelli, 2002).

Em particular, cada termo da expressão pode ser calculado usando a esperança condicional como:

$$
\begin{gathered}
f_{0}=E(Y) \\
f_{i}=E\left(Y \mid X_{i}\right)-E(Y) \\
f_{i j}=E\left(Y \mid X_{i}, X_{j}\right)-f_{i}-f_{j}-E(Y)
\end{gathered}
$$

Segundo Sobol '(1993), há uma relação entre os termos da decomposição de $f$ e as variâncias parciais:

$$
\begin{gathered}
V_{i}=V\left[f_{i}\left(X_{i}\right)\right]=V_{X_{i}}\left[E_{X_{\sim i}}\left(Y \mid X_{i}\right)\right] \\
V_{i j}=V\left[f_{i j}\left(X_{i}, X_{j}\right)\right] \\
=V_{X_{i} X_{j}}\left[E_{X_{\sim i j}}\left(Y \mid X_{i}, X_{j}\right)\right]-V_{X_{i}}\left[E_{X_{\sim i}}\left(Y \mid X_{i}\right)\right] \\
-V_{X_{j}}\left[E_{X_{\sim j}}\left(Y \mid X_{j}\right)\right]
\end{gathered}
$$

e assim por diante para cada termo de ordem superior. Em geral, a variância incondicional total para um modelo escalar Y, onde seus fatores são ortogonais, pode ser decomposta em termos de variância condicional (expressão 2.45) como (Sobol, 1993, Saltelli et al., 2008; Saltelli, 2002; Saltelli et al., 2004, 2008):

$$
V(Y)=\sum_{i=1}^{k} V_{i}+\sum_{i=1}^{k-1} \sum_{j=i+1}^{k} V_{i j}+V_{12 \ldots k}
$$


onde $V(Y)$ representa a variância total do modelo de saída, $V_{i}$ representa as variâncias de contribuição condicional parcial de cada fator independente e $V_{i j}$ para $V_{1,2, \ldots, p}$ constituem as interações entre os fatores. A variância condicional de primeira ordem (Saltelli et al., 2004, 2008), $V\left[E\left(Y \mid X_{i}\right)\right]$, é frequentemente chamada de efeito principal e é usada para indicar o efeito de $X_{i}$ na variância de Y. Então, este pode ser interpretado como a fração da variância da média de todos os valores possíveis do modelo escalar quando $X_{i}$ é definido como um valor em seu intervalo.

Dessa forma, os métodos baseados em variância nos permitem calcular ou estimar três índices de sensibilidade derivados da razão entre a variância total (expressão 2.46) e as variâncias parciais (expressão 2.45), ou seja, o coeficiente de sensibilidade de primeira ordem que corresponde ao parâmetro $X_{i}$ :

$$
S_{i}=\frac{V_{i}}{V(Y)}
$$

que mede a quantidade de variância do modelo de saída explicado por $X_{i}$. O coeficiente de sensibilidade de segunda ordem, ou o índice de sensibilidade de interação de primeira ordem, mede a quantidade de variância explicada a partir dos dois parâmetros $X_{i}$ e $X_{j}$ :

$$
S_{i j}=\frac{V_{i j}}{V(Y)}
$$

e o índice de sensibilidade total, que mede os efeitos de primeira ordem de $X_{i}$ e as interações com os outros parâmetros (fator de ordem superior $X_{i}$ ).

$$
S_{T_{i}}=S_{i}+\sum_{j \neq i} S_{i j}+\ldots+S_{12 \ldots p}
$$

Esses índices também podem ser definidos usando a identidade conhecida, a lei da variância total, que expressa à variância como (Saltelli et al., 2004, 2008, 2010).

$$
V(Y)=V\left[E\left(Y \mid X_{\sim i}\right)\right]+E\left[V\left(Y \mid X_{\sim i}\right)\right]
$$


Essa decomposição da variância incondicional do modelo escalar, em termos do efeito principal e dos efeitos residuais, está condicionada a todos os fatores, exceto ao valor fixo $X_{\sim i}$. Desta forma, o cálculo de $S_{T_{i}}$ pode ser definido em termos da variância induzida por $X_{\sim i}$ (Equação 2.52), conforme (Homma e Saltelli, 1996):

$$
S_{T_{i}}=1-\frac{V_{X_{\sim i}}\left[E_{X_{\sim i}}\left(Y \mid X_{\sim i}\right)\right]}{V(Y)}
$$

Na prática, os índices de sensibilidade de primeira ordem $S_{i}$ e a ordem total $S_{T_{i}}$ são amplamente investigados na análise de sensibilidade global. Os índices de ordem total nos dão informações importantes sobre as características não aditivas do modelo quando há interação entre os parâmetros. Nesse caso, a soma de todos os $S_{T_{i}}$ são maiores que a unidade e a soma dos termos de primeira ordem é menor que 1, ou seja, $\sum_{i=1}^{p} S_{i}<1$ (Saltelli et al., 2004, 2008). Por outro lado, um modelo sob a hipótese de independência dos parâmetros de entrada é completamente aditivo, se a soma de todos $S_{i}$ for igual a 1 (e todos $S_{T_{i}}$ ), e iguais a $S_{T_{i}}$ (Saltelli et al., 2004, 2008).

\subsubsection{IMPLEMENTAÇÃO MONTE CARLO}

Os métodos numéricos de integração de Monte Carlo são usados no cálculo do conjunto de índices de efeito de primeira ordem e total para modelos de $k$ fatores (Sobol ', 1993), uma vez que a solução analítica de integrais para o cálculo de variâncias de modelos complexos e não lineares é muitas vezes impossível. Portanto, o cálculo das integrais de Monte Carlo e o método proposto por Saltelli (2002) são aplicados neste trabalho.

Saltelli (2002) introduz um novo método de estimativa, dos índices de sensibilidade de primeira ordem e ordem total, que reduz o custo computacional. Esse método de aproximação é uma extensão do trabalho pioneiro de Sobol' (1993) e Homma \& Saltelli (1996).

Os índices $S_{i}$ e $S_{T_{i}}$ são estimados através do uso de duas matrizes de números aleatórios e amostras independentes $M_{1}$ e $M_{2}$, usadas no cálculo por integração de 
Monte Carlo, onde cada matriz é de dimensões $n \times k$ ( $n$ é o tamanho do número de amostras e k é o número de parâmetros) (Saltelli, 2002). A matriz $M_{1}$ é vista como uma "amostra" dos parâmetros de entrada e $M_{2}$ como uma matriz de "reamostragem" (Saltelli, 2002), onde cada vetor de linha das matrizes representa uma possível solução ao modelo escalar. Portanto, uma matriz $M_{i}$ de dimensões $n \times k$ é gerada por recombinação das amostras de $M_{2}$ e $M_{1}$, isto é, $M_{i}$ é composto de todas as colunas de $M_{2}$ exceto a i-ésima coluna, que é tirada de $M_{1}$. Desta forma, três vetores de modelos de saída são obtidos, $y_{M_{1}}, y_{M_{2}}$ e $y_{M_{i}}$. $S_{i}$ e $S_{T_{i}}$ são calculados como segue (Saltelli, 2002; Saltelli et al., 2004):

$$
\begin{gathered}
S_{i}=\frac{\frac{1}{n} \sum_{j=1}^{n} y_{M_{1}}^{(j)} y_{M_{i}}^{(j)}-f_{0}^{2}}{\frac{1}{n} \sum_{j=1}^{n}\left(y_{M_{1}}^{(j)}\right)^{2}-f_{0}^{2}} \\
S_{T_{i}}=1-\frac{\frac{1}{n} \sum_{j=1}^{n} y_{M_{2}}^{(j)} y_{M_{i}}^{(j)}-f_{0}^{2}}{\frac{1}{n} \sum_{j=1}^{n}\left(y_{M_{1}}^{(j)}\right)^{2}-f_{0}^{2}}
\end{gathered}
$$

onde $f_{0}^{2}$ é o quadrado da esperança do modelo escalar, e é definido por

$$
f_{0}^{2}=\left(\frac{1}{n} \sum_{j=1}^{n} y_{M_{1}}^{(j)}\right)^{2}
$$

Basicamente, o cálculo dos índices de sensibilidade da primeira ordem e da ordem total pelo método de Sobol' requer $n(2 k+1)$ avaliações do modelo. Mas, o número de avaliações do modelo, usando as expressões (2.52) até (2.54), na aproximação de ambas as medidas de sensibilidade (primeira e total), o custo computacional é reduzido a $n(k+2)$ (Saltelli, 2002).

O algoritmo de amostragem quase-aleatório de Sobol' é aplicado na geração das amostras independentes das matrizes $M_{1}$ e $M_{2}$ (Sobol' 1967, 1976). Esse método de amostragem faz parte de vários tipos de sequências, chamadas quase aleatórias, que têm sido propostas na literatura por diversos autores (Kucherenko et al., 2009). Em geral, as sequências quase aleatórias geram amostras tão uniformes quanto possíveis no hipercubo unitário, levando em consideração a posição dos pontos previamente 
amostrados e preenchendo as lacunas entre eles (Saltelli et al., 2010). Portanto, algoritmos sequenciais quase aleatórios evitam o agrupamento causado nas técnicas de amostragem de números aleatórios e, consequentemente, diminuem a taxa de convergência das integrais de Monte Carlo, isto é, $\frac{1}{\sqrt{n}}$ para $\frac{1}{n}$ (Kucherenko et al., 2009).

\subsubsection{INTERVALO DE CONFIANÇA POR BOOTSTRAP}

Para os índices $S_{i}$ e $S_{T_{i}}$, os intervalos de confiança são construídos usando a técnica de reamostragem Bootstrap (Efron e Tibshirani, 1993). O uso desta técnica se deve à impossibilidade de avaliar os intervalos de confiança dos modelos $n(k+2)$, que devem ser executados várias vezes. Bootstrap é uma técnica que nos permite estimar, de forma adequada e precisa os intervalos de confiança para a primeira ordem e da ordem total de Sobol' (Archer et al., 1997).

Basicamente, as $n$ amostras usadas para as avaliações do modelo devem ser reamostradas com substituição $t$ vezes, e para cada reamostragem os índices de sensibilidade são calculados. Desta forma, a distribuição dos índices de sensibilidade é obtida e os intervalos de confiança com 95\% (nível de significância de 5\%) podem ser construídos usando dois métodos (Archer et al., 1997): (1) Método de percentis e; (2) Método dos momentos.

O método do percentil é um método simples que é derivado da distribuição obtida pelo Bootstrap, que necessita de um maior número de amostras, comparado com o método dos momentos, para obter uma estimativa precisa e confiável dos percentis. Por outro lado, o método dos momentos pode resultar em uma estimativa não confiável dos intervalos de confiança, se a distribuição resultante por Bootstrap for assimétrica (Archer et al., 1997). 


\subsubsection{BOOTSTRAP: TÉCNICA DE REAMOSTRAGEM}

No ano de 1979, a técnica Bootstrap foi introduzida por Bradley Efron, que publicou sob o nome de "Bootstrap method: another jackknife perspective", inspirado no trabalho pioneiro de Quenouille (1949). Efron unificou as ideias e conectou o programa de Bootstrap simples não paramétrico, "reamostragem de dados com substituição", com ferramentas estatísticas previamente aceitas na inferência de erros, como são os métodos de jackkife e delta (Chernick, 2008).

O Bootstrap faz parte de um grupo maior de métodos que reamostra o conjunto de dados original e, em virtude disso, são chamados de métodos de reamostragem (Chernick, 2008). Estas técnicas de reamostragem substituem as derivações teóricas necessárias na aplicação de metodologias tradicionais (como substituição e linearização), na análise estatística, reamostrando repetidamente o mesmo conjunto de dados e, a partir dos novos subconjuntos de dados fazem inferências estatísticas de parâmetros de interesse e da população (Shao e Tu, 1995). Bootstrap é uma forma de reamostragem e seu nome é devido ao envolvimento da reamostragem da mesma base de dados original (Chernick, 2008).

O objetivo principal da análise estatística por inferência é extrair toda informação possível de um conjunto/coleção de dados, de modo que as propriedades da população possam ser deduzidas a partir das poucas informações e é desta maneira que a técnica de Bootstrap é usada. A princípio o Bootstrap pode ser usado tanto em distribuições paramétricas quanto não paramétricas, sob a premissa de que os dados são independentes e identicamente distribuídos. Conceitualmente, a técnica de reamostragem é desenvolvida da seguinte forma (Zoubir e Iskander, 2004):

Seja $X=\left\{X_{1}, X_{2}, \ldots, X_{n}\right\}$ uma coleção de n variáveis aleatórias independentes e distribuídas identicamente (iid), de uma distribuição desconhecida F. Onde $\hat{\theta}$ denota o parâmetro de interesse da distribuição F. Esse parâmetro pode ser a média ou variância que caracteriza a função de distribuição F.

Segundo Zoubir e Iskander (2004), sob essas hipóteses, o objetivo principal é encontrar a função de distribuição de $\hat{\theta}$, um estimador de $\theta$, obtido a partir das amostras iid de $X$. Ou seja, devemos inferir estatisticamente o parâmetro $\theta$ com base em $\hat{\theta}$. De 
acordo com esses mesmos autores, uma maneira "simples", mas impossível, de obter a distribuição de $\hat{\theta}$ é repetir o experimento um número finito de vezes, de modo que a distribuição empírica de $\hat{\theta}$ seja o mais próxima possível. Dessa forma, o procedimento descrito pode ser visto como uma simulação de Monte Carlo.

$\mathrm{Na}$ prática, o procedimento de repetição de amostras é completamente inadequado, devido a dois fatores importantes: (1) Alto custo e; (2) Condições experimentais não reprodutíveis. Em algumas aplicações, particularmente em ciências da terra, o fator mais importante envolvido é o alto custo.

O método Bootstrap indica que as amostras escolhidas de alguma distribuição devem ser reamostradas, de modo que esse processo seja o mais próximo possível de $\mathrm{F}$ em algum sentido (Zoubir e Iskander, 2004). Esta poderia ser a distribuição empírica de $\mathrm{F}$, que é a medida de probabilidade que designa um conjunto A no espaço amostral de $\mathrm{X}$ uma medida igual à proporção de valores de amostra encontrados em $\mathrm{A}$, e sob algumas premissas obtemos que $\hat{F}$ se aproxima de $F$ conforme $n$ tenda para o infinito. Reamostragem com substituição, a partir de uma coleção de variáveis aleatórias, é conhecido como um Bootstrap não paramétrico. Seu princípio computacional é ilustrado na Tabela 2-3, bem como sua (sucinta) interpretação gráfica como apresentado na Figura 2-25.

Tabela 2-3. Princípio do Bootstrap não paramétrico.

Primeiro Passo: Realize o experimento para obter a amostra aleatória

$$
X=\left\{X_{1}, X_{2}, \ldots, X_{n}\right\}
$$

e calcule o estimador de $\hat{\theta}$ das amostras X.

Segundo Passo: Construa a distribuição empírica de $\hat{F}$, com probabilidade uniforme sobre cada observação

$$
X_{1}=x_{1}, X_{2}=x_{2}, \ldots, X_{n}=x_{n}
$$

Terceiro Passo: De $\hat{F}$, selecione aleatoriamente e com substituição $N$ "amostras"

$$
X^{*}=\left\{X_{1}^{*}, X_{2}^{*}, \ldots, X_{n}^{*}\right\}
$$

denominadas de amostras Bootstrap.

Quarto Passo: Aproximar a distribuição de $\hat{\theta}$ da distribuição de $\widehat{\theta^{*}}$ obtida da amostra inicial $X$. 
Dados originais

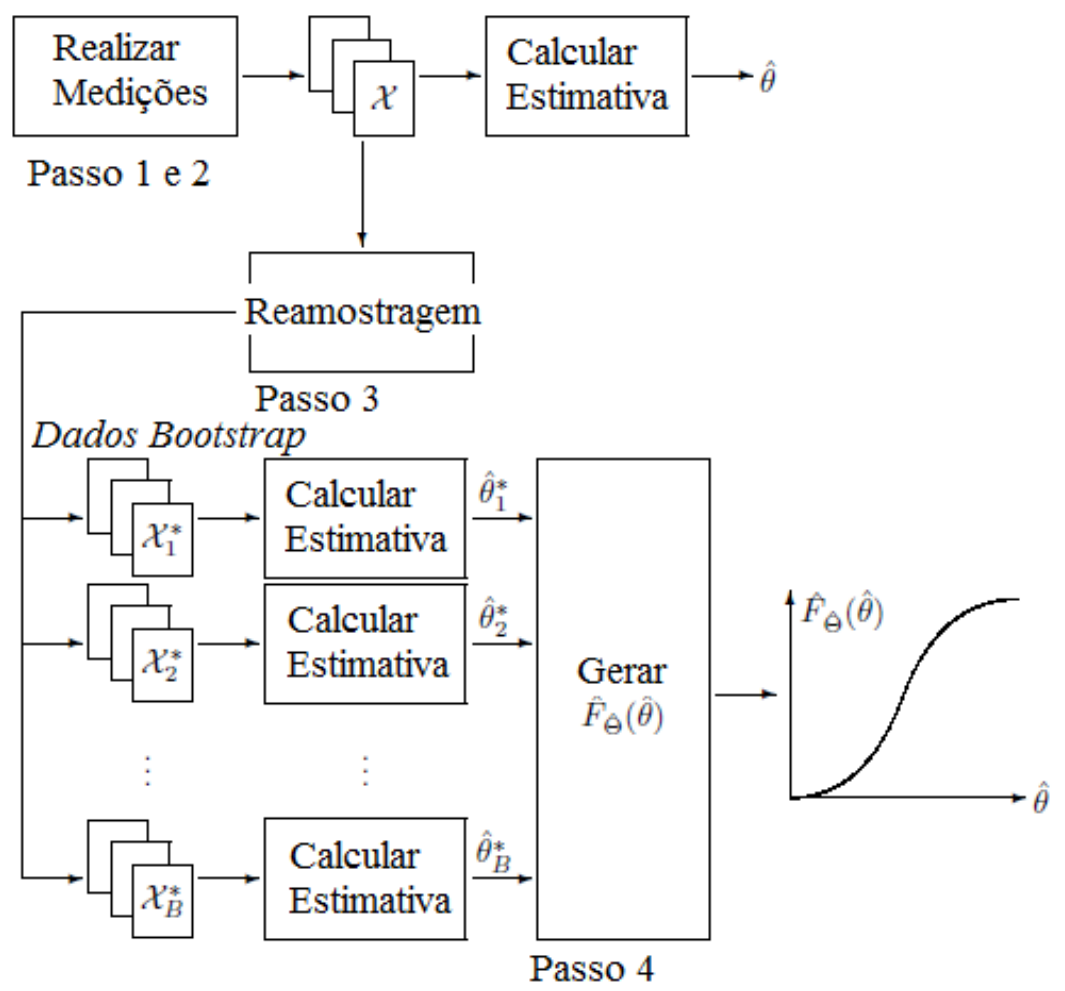

Figura 2-25. Princípio do Bootstrap não paramétrico para estimar a função de distribuição $\hat{F}$ de um estimador de parâmetros $\hat{\theta}$. (Fonte: Zoubir e Iskander, 2004).

\subsection{GEOLOGIA DE SOSSEGO}

Na província mineral de Carajás existem dois importantes corpos mineralizados (Figura 2-26), Sequeirinho e Sossego, localizados a sudoeste do Pará, no município de Canaã dos Carajás, região norte do Brasil. Esses dois corpos compõem o depósito de óxido de ferro-cobre-ouro, chamado de Sossego. A mina de cobre de Sossego faz parte do maior e mais ambicioso projeto de mineração, operado pela mineradora VALE, e uma das primeiras minas da província de Carajás, a entrar em produção em 2004. 

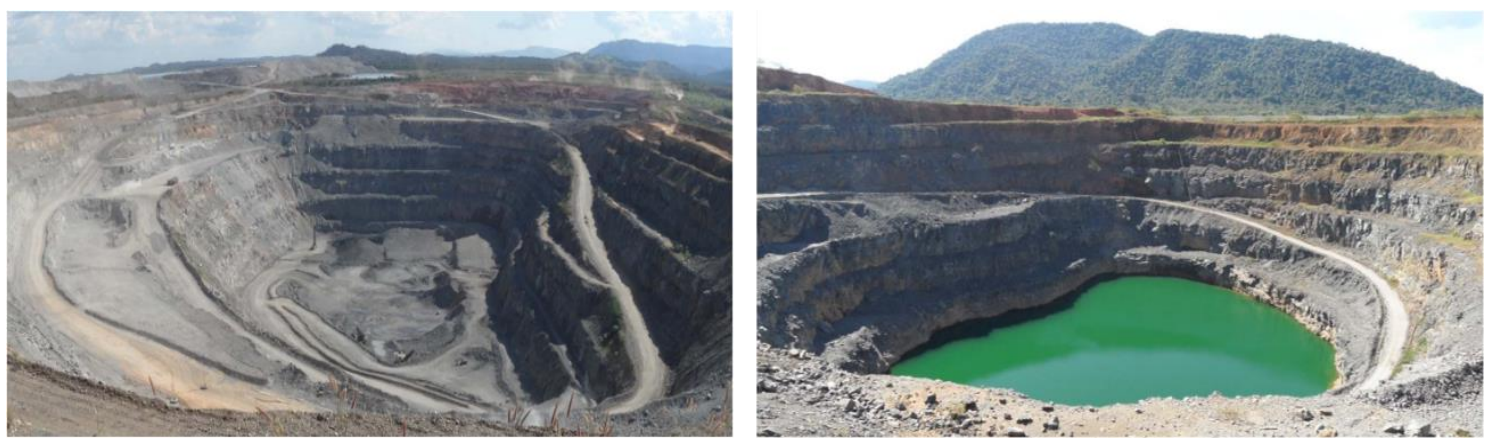

Figura 2-26. Vista aérea da cava ao ar livre do Sequeirinho (à esquerda) e Sossego (à direita). (Fonte: Golder Associates, 2010).

O depósito do Sossego compreende de leste a oeste dois grandes corpos de mineiro, Sequerinho-Baiano-Pista e Sossego-Curral (Monteiro et al., 2014). Segundo Monteiro et al. (2014), os corpos geológicos Sequeirinho e Sossego (Figura 2-27), correspondem, respectivamente, a $85 \%$ e $15 \%$ dos recursos, lavrados em duas cavas diferentes. Os dois corpos principais, estão localizados ao longo de uma zona de cisalhamento regional com direção WNW-ESSE que define o contato entre corpos rochoso metavulcanosedimentares do supergrupo Itacaiúnas, à norte, e gnaisses e migmatitos do complexo Xingu, à sul (Augusto et al., 2008).

Segundo Monteiro et al. (2008a), o corpo Sequerinho-Baiano-Pista é hospedado por intrusões de gabronoritos, granitos, rochas metavulcânicas ácidas e rochas félsicas calco-alcalinas. Por sua vez, o corpo sossego-curral é hospedado pelo granito do Sequeirinho e, pelo granito granofirico Sossego, caracterizado por dois minerais de intercrescimento: quartzo e feldspato potássico.

As mineralizações para ambos os corpos ocorrem nas brechas hidrotermais (Figura 2-28) (Augusto, et al., 2008; Monteiro et al., 2014), que compartilham em sua matriz a calcopirita. Além da calcopirita na matriz, no corpo do Sequeirinho, existem minerais como pirita, magnetita, epídoto, allanita, apatita e clorita, bem como fragmentos de actinolititos e cristais de actinolita, apatita e magnetita (Monteiro et al., 2008a, 2014). Juntamente com calcopirita na matriz, no corpo do Sossego, existem minerais como calcita, quartzo, clorita, epídoto e apatita, associados a fragmentos de magnetita de características angulosos à sub-angulares (Augusto, et al., 2008). Segundo Augusto et al. (2008), a mineralização de cobre-ouro foi posteriormente desenvolvida sob condições essencialmente de rúpteis. 

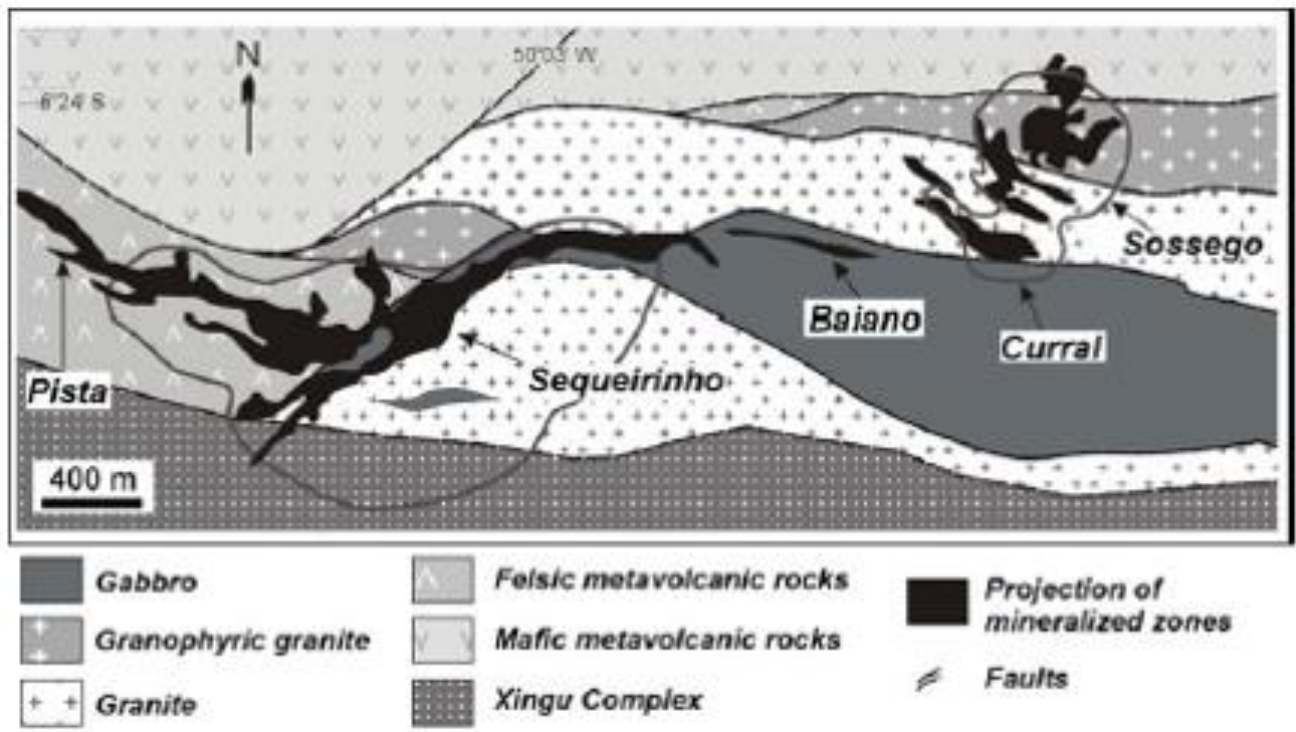

Figura 2-27. Simplificação geológica da localização dos corpos, Sequeirinho e Sossego. (Fonte: Monteiro et al., 2008a).

\section{Litotipos}

Biotita-(escapolita) milonitos

Gabro

Granite granofírico Sossego

Rocha metavulcânica félsica

Gnaisses e migmatitos (Complexo Xingu)

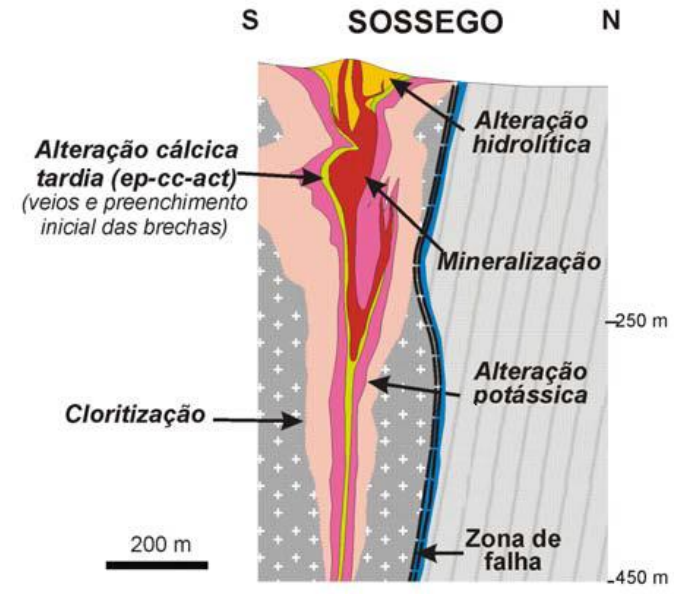

$\mathbf{s}$ SEQUEIRINHO

N

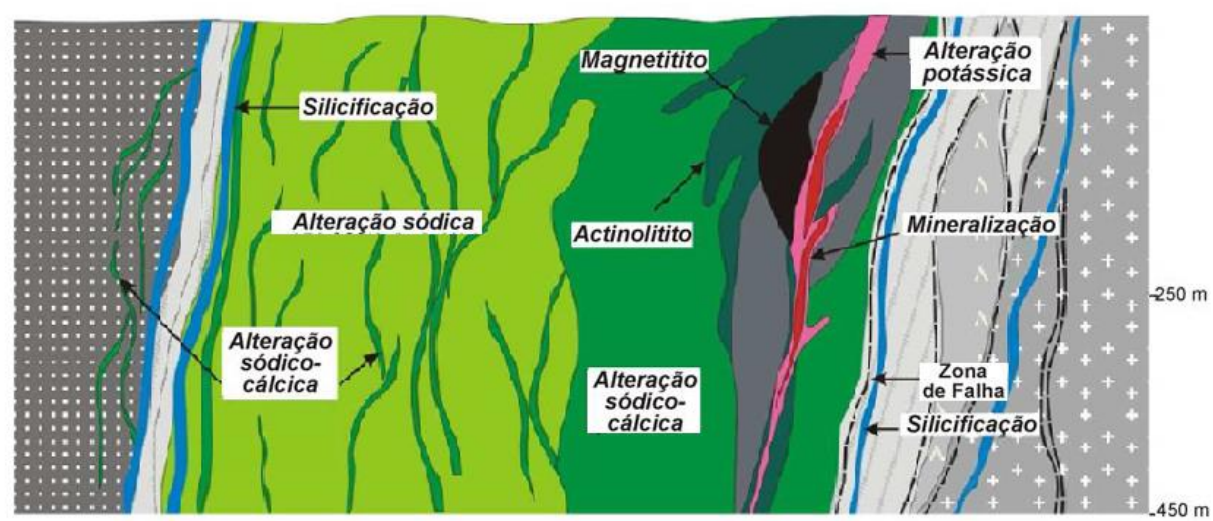

Principais tipos de alteração hidrotermal

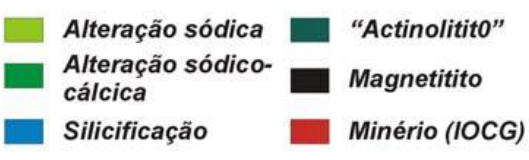

Figura 2-28. Seção esquemática da distribuição das zonas de alteração hidrotermal nos corpos de Sossego e Sequeirinho, Mina de Sossego. (Fonte: Monteiro et al., 2008a). 


\section{Materiais e Métodos}

\subsection{MATERIAIS E MÉTODOS}

Para atingir os objetivos foram utilizados diversos programas de análise estatística e geoestatística, assim como algoritmos desenvolvidos pelo autor que buscou adaptar as metodologias propostas nesta tese. Os programas de análise estatística utilizados foram: A linguagem computacional $R$ e o software de análise matricial interativa Matlab. Além disso, os programas aplicados à geoestatística são: Isatis, para a simulação geoestatística por Simulação Sequencial Gaussiana e SGeMS (Remy et al., 2009) para geração de imagens estocásticas através do algoritmo de simulação de múltiplos pontos FILTERSIM, bem como o uso dos algoritmos de código aberto GSLIB (Deutsch e Journel, 1998).

O ponto de partida deste trabalho é a base de dados de referência composta por 289 perfurações que foram realizados em seis campanhas entre 1997 a 2003 na Mina de Cobre de Sossego. Apesar de existirem 289 furos de sonda, foram analisados 257 justificado pelo fato que a localização das sondagens restantes estavam fora da área de interesse deste trabalho. A base de dados (BD) foi organizada em três arquivos de dados tabulados que estão separados por um ponto-e-vírgula, contendo as informações das 257 perfurações conhecidas como: Header.csv, Assay.csv e Survey.csv.

- A planilha Header contém as coordenadas X (leste), Y (norte) e Z (Cota) da boca dos furos de sonda, bem como a data da realização.

- A planilha Assay contém informações detalhadas de cada testemunho além da quantidade de metal, $\mathrm{Cu}(\%)$, bem como o respectivo ano de conclusão da campanha.

- A planilha Survey é composta de três informações: AT - informações de profundidade, BRG - azimute e DIP - mergulho ao longo de cada furo. 
Sinclair e Blackwell (2004) enfatizam que a análise inicial da base de dados constitui uma parte essencial da estimativa de teores e volumes, o que implica a organização e entendimento detalhado do conjunto de dados para uma estimativa mais confiável. Consequentemente, a BD foi validada através de uma exploração minuciosa das informações contidas nas planilhas (Header, Survey e Assay) e assim, importadas para o programa de Studio RM v.1.4 (licença de uso do laboratório de informática geológica - LIG). Vale citar que erros, dados duplicados e atípicos foram corrigidos e detectados de forma que os passos subsequentes podem ser aplicados. Simultaneamente, o conjunto de dados foi editado através da técnica de ponderação (composite). O mapa base é ilustrado na Figura 3-1.

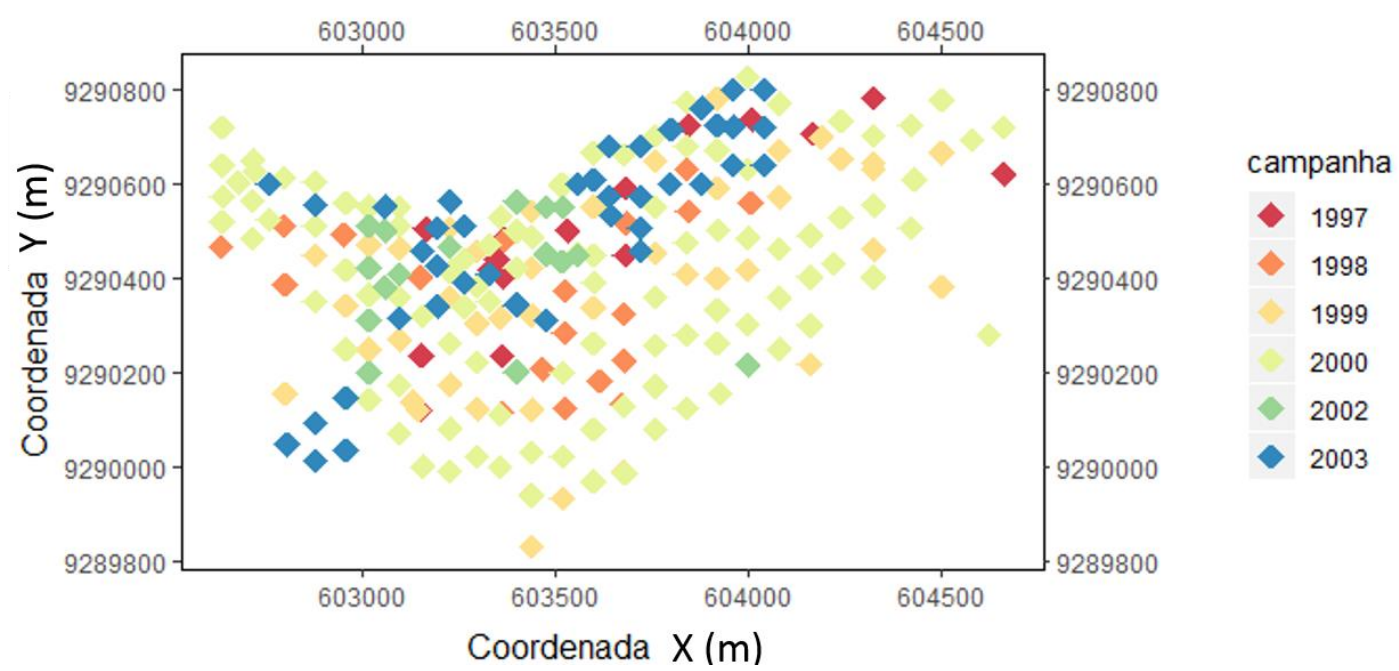
campanhas.

Figura 3-1. Localização bidimensional dos furos de perfuração realizados nas diferentes

Para realizar os passos subsequentes é necessário construir um modelo tridimensional de blocos. Este modelo representa uma matriz numérica do depósito mineral que é fundamental para estudos de viabilidade (Sinclair e Blackwell, 2004). Vale citar que os valores da quantidade mineral e outros parâmetros de interesse são atribuídos aos blocos ou unidades por meio de métodos de estimativa ou simulação. Além disso, a seleção de um tamanho "ótimo" das unidades para a estimativa de recursos minerais deve ser realizada de forma rigorosa, já que esta pequena unidade é classificada inicialmente como um recurso (Medido, Indicado ou Inferido) e em seguida como uma reserva (provada ou provável) (Sinclair e Blackwell, 2004). Para Sinclair e Blackwell (2004), essas dimensões devem ser consideradas segundo: (1) o espaçamento 
médio entre furos de sonda; (2) especificações dos equipamentos de lavra; (3) altura da bancada (se a céu aberto); e (4) características de detonação do solo.

Neste trabalho, vários modelos de tridimensionais de blocos são utilizados para as diferentes análises propostas (Tabela 3-1 e Figura 3-4). Todas as malhas tridimensionais do depósito mineral compartilham a mesma origem que foi obtida dos valores mínimos dos eixos coordenados do conjunto de dados X, Y e Z. Apesar dos modelos de blocos abrangerem a área completa do depósito Sequeirinho, somente os blocos dentro do volume ocupado pelos 257 furos de sonda (Figura 3-2) foram considerados na estimativa que resultaram em um volume próximo de $4.10 e+8 \mathrm{~m}^{3}$.

Tabela 3-1. Parâmetros dos modelos de blocos utilizados na análise de sensibilidade e simulação geoestatística. As unidades de medida são dadas em metros. SGS = Simulação Sequencial Gaussiana, RM = Reamostragem.

\begin{tabular}{|c|c|c|c|c|}
\hline & & $\mathrm{xmin}, \mathrm{ymin}, \mathrm{zmin}$ & $\mathrm{nx}, \mathrm{ny}, \mathrm{nz}$ & xsiz, ysiz, zsiz \\
\hline Modelo para & SGS & \multirow{6}{*}{$\begin{array}{c}6.02 e 05,9.28 e 06 \\
-184.54\end{array}$} & & \\
\hline Simulação & FILTERSIM & & $102,54,64$ & $20,20,7$ \\
\hline Modelos para & RM 55 & & & \\
\hline Analise de & RM 110 & & $81,43,64$ & $25,25,7$ \\
\hline \multirow[t]{2}{*}{ Sensibilidade } & RM 165 & & & \\
\hline & RM 220 & & $102,54,64$ & $20,20,7$ \\
\hline
\end{tabular}

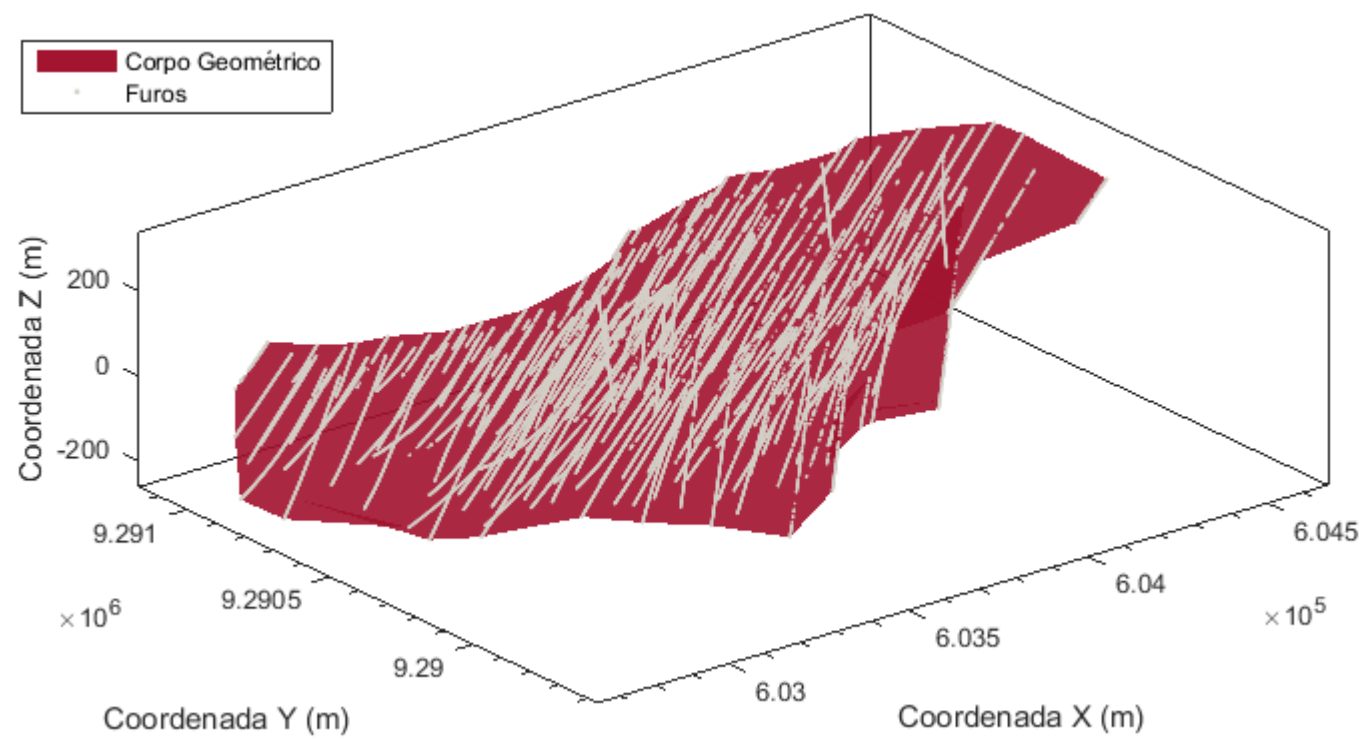

Figura 3-2. Vista em 3D do modelo de blocos envolvendo todos os furos. 


\subsection{MÉTODOS PROPOSTOS}

A Figura 3-4 ilustra o fluxo de trabalho adotado e aplicado ao conjunto de dados, que visa classificar os recursos minerais segundo seu grau de confiabilidade. Essa classificação é realizada através dos critérios clássicos de categorização e variância condicional relativa, assim como um novo método de classificação intitulado probabilístico pontual neste trabalho.

Assim, algumas das técnicas/etapas realizadas neste trabalho são: (1) classificação de recursos minerais por meio de probabilidades pontuais condicionais; (2) reclassificação de recursos através dos processos estatísticos da abordagem Bootstrap; e (3) reamostragem e analise de sensibilidade. Vale citar que outras técnicas constam na Revisão Bibliográfica.

\subsubsection{MÉTODO PROBABILÍSTICO PONTUAL}

A estimativa de parâmetros desconhecidos da população na estatística é feita a partir de funções matemáticas que combinam elementos da amostra que resultam em um único ou vários valores numéricos. Em geral, esses estimadores são denotados por

símbolos como: $\hat{\theta}, \bar{X}, S^{2}$, além de outros. Ademais, todo estimador é considerado uma variável aleatória com certa distribuição de probabilidade que a partir do teorema do limite central a probabilidade pontual pode ser calculada:

$$
P(\bar{X}>t) \approx P\left[Z>\frac{t-\bar{X}}{\sqrt{\frac{\hat{\sigma}^{2}}{n}}}\right]
$$

onde t é um parâmetro limiar ou de interesse e $\mathrm{Z}$ é a função de distribuição normal padrão (expressão 2.15), a partir da qual as probabilidades pontuais são calculadas.

Assim, para cada bloco do modelo tridimensional do depósito em estudo as probabilidades condicionais pontuais derivadas da expressão (3.1) e seus valores podem ser estimados por métodos de simulação geoestatística (SGS e FILTERSIM), 
calculando 100 realizações estocásticas para cada processo. Desta forma, os blocos podem ser classificados como Medido, Indicado e Inferido, a partir dos intervalos de discretização para a probabilidade pontual, conforme:

- Recurso Mineral Medido: a probabilidade condicional pontual encontrase no intervalo $(85 \%, 100 \%]$,

- Recurso Mineral Indicado: a probabilidade condicional pontual estiver no intervalo $(30 \%, 85 \%]$,

- Recurso Mineral Inferido: a probabilidade condicional pontual pertence ao intervalo $[0 \%, 30 \%]$.

As amplitudes obtidas dos intervalos de confiança são os mesmos usados na categorização de recursos minerais, a partir do critério da variância condicional relativa (Emery et al., 2006). No entanto, um recurso mineral é Medido se a variância condicional relativa estiver no intervalo $[0 \%, 15 \%)$ ou um recurso mineral é Indicado se a variância condicional relativa estiver no intervalo [15\%, 70\%), por fim, um recurso mineral é Inferido se a variância condicional relativa estiver no intervalo [70\%, 100\%].

\subsubsection{RECLASSIFIÇÃO POR BOOSTRAP}

A reclassificação de classes por Bootstrap é realizada a partir de realizações independentes para cada bloco do modelo tridimensional. Os dados estimados de cada bloco são considerados como uma amostra original $X_{1}, X_{2}, \ldots, X_{l}$, (número de realizações $l$ ), e as amostras de Bootstrap $X_{1}^{*}, X_{2}^{*}, \ldots, X_{B}^{*}$ são geradas por reamostragem com substituição das originais. Esse processo é detalhado da seguinte forma:

i. Obter uma coleção de amostras aleatórias $P_{1}^{*}, P_{2}^{*}, \ldots, P_{n}^{*}$ por Bootstrap com substituição do conjunto de amostras originais $X_{1}, X_{2}, \ldots, X_{l}$ de tamanho igual ao número total de realizações em cada blocos.

ii. Para cada novo conjunto de amostras de Bootstrap $X^{*(j)}=\left(X_{1}^{*}, X_{2}^{*}, \ldots, X_{B}^{*}\right) j=1, \ldots, n$, onde n é o tamanho da amostra que compõem a coleção de vetores $\left(P_{1}^{*}, P_{2}^{*}, \ldots, P_{n}^{*}\right)$ que devem ser classificados com os valores em Medido, Indicado ou Inferido, de acordo com as expressões (2.42 e 3.1). 
iii. Uma vez que as novas amostras de Bootstrap foram classificadas, as classes de probabilidade são calculadas $p_{w_{i}}=\left(\begin{array}{l}p_{w_{1}} \\ p_{w_{2}} \\ p_{w_{3}}\end{array}\right)=\left(\begin{array}{c}f(1) / B \\ f(2) / B \\ f(3) / B\end{array}\right)$ onde $f(i)$ con $i=1,2,3$, representa as frequências de um bloco específico atribuído à classe $w_{i}, i=1,2,3$, e $B$ o conjunto total de amostras geradas pelo Bootstrap. Para um bloco específico, $p_{w_{i}}$ representa a probabilidade de um bloco que pode ser atribuído a uma classe individual.

iv. A área de estudo ou modelo de bloco é reclassificada atribuindo pixels individuais à classe de probabilidade $p_{w_{i}}$ mais alta, ou seja, $\max \left(p_{w_{1}}, p_{w_{2}}, p_{w_{3}}\right)$. Neste trabalho, este processo é chamado de reclassificação por Bootstrap.

$\mathrm{Na}$ Figura 3-3, ilustramos um diagrama esquemático do procedimento de reamostragem e reclassificação. Vale ressaltar que a reamostragem por Bootstrap foi gerada de forma aleatória, a partir da técnica sequência quase aleatória.

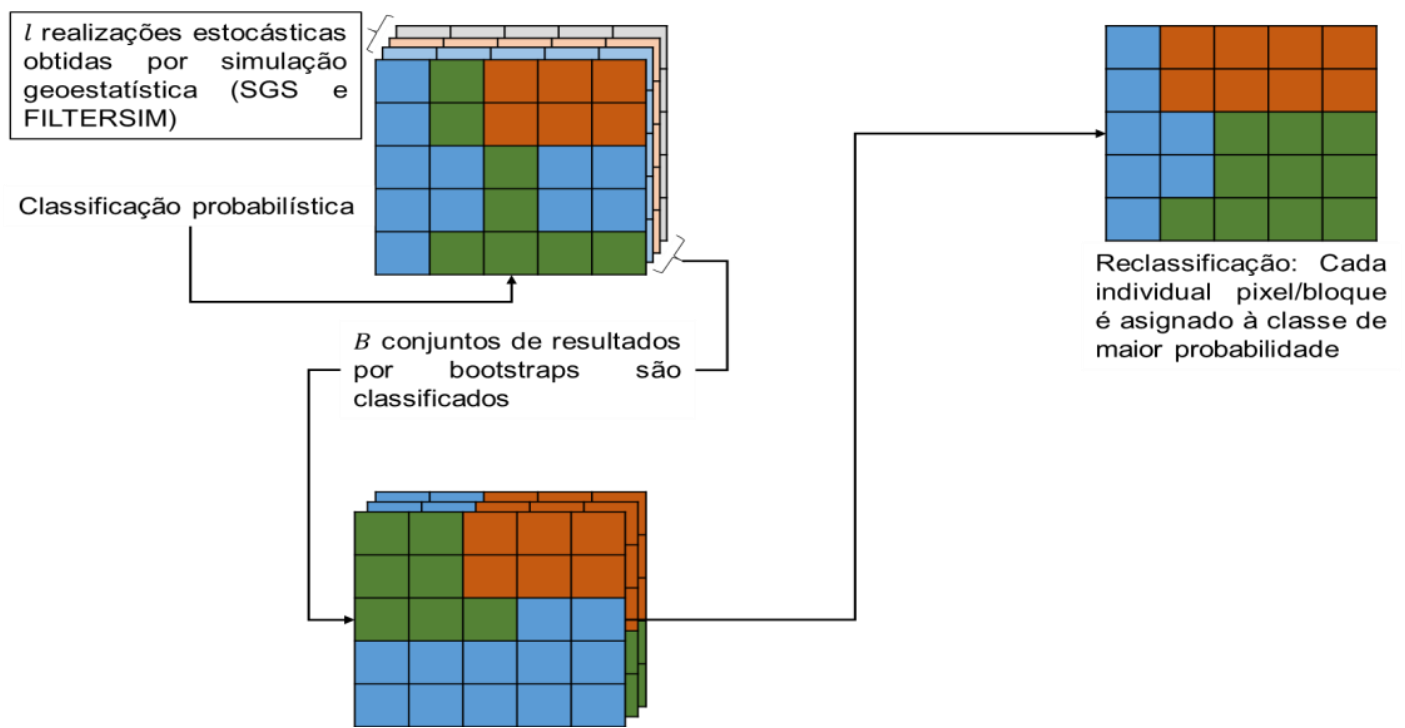

Figura 3-3. Fluxograma analítico da reclassificação por Bootstrap proposta. 


\subsubsection{REAMOSTRAGEM E ANÁLISE DE SENSIBILIDADE}

Para realizar a análise de sensibilidade dos parâmetros de ajuste de um modelo de variograma (efeito pepita, contribuição espacial e amplitude), por meio da decomposição da variância, foi aplicado o desenho probabilístico de amostragem aleatório estratificado (AAE) ao conjunto de dados original. O AAE foi efetuado para tamanhos constantes de estratos/subgrupos (ts $=10$, ts - tamanho do estrato) na seleção de 55, 110, 165 e 220 furos de sonda, de modo que as perfurações pertencentes aos diferentes estratos tenham a mesma probabilidade de ocorrer. O processo de seleção das novas amostras do conjunto total de furos $(55,110,165$ e 220$)$ foi repetido 385 vezes, assumindo este valor como representativo. Uma vez realizada a seleção e criação da nova coleção de dados, procedeu-se à análise de sensibilidade dos parâmetros de interesse da seguinte forma:

i. Para cada subconjunto composto de 385 amostras aleatórias, foram calculados diferentes variogramas experimentais.

ii. Uma função matemática (esférica, exponencial e/ou gaussiana) foi ajustada automaticamente para cada variograma experimental. Este ajuste computacional é feito usando dois métodos: método de mínimos quadrados ponderados e métodos interativos; onde pesos maiores estão associados ao conjunto de pontos mais próximos da origem. Esse processo é semelhante à simulação de Monte Carlo, já que é uma maneira de obter a distribuição dos parâmetros por meio da obtenção das distribuições empíricas (Zoubir e Iskander, 2004).

iii. O modelo geológico para cada amostra aleatória pertencente a cada subconjunto de 55, 110, 165 e 200 que foi calculado usando a técnica computacional de fronteira convexa para dados tridimensionais, de modo que, os blocos dentro dos modelos geológicos sejam os únicos valores estimados.

iv. Uma amostra do subconjunto obtido em (iii) foi selecionada aleatoriamente além de um conjunto de parâmetros (etapa ii): efeito pepita, contribuições e amplitudes espaciais. Logo após foi aplicado a 
técnica de estimativa KO (Krigagem Ordinária). Vale citar que tais processos foram repetidos 20.000 vezes.

v. Por fim, foi calculada a partir do conjunto de resultados (iv), a média aritmética, isto é, a quantidade média de porcentagem de cobre na área de interesse além das equações 2.52 até 2.54 (item 2.8). Desta forma, os parâmetros mais influentes foram obtidos através da decomposição da variância.

As etapas descritas acima são resumidas esquematicamente no fluxograma da Figura 3-4.

\subsection{FLUXOGRAMA DE TRABALHO}

Na Figura 3-4, que resume o passo a passo metodologias utilizadas e propostas nesta tese através de um fluxo de trabalho. 


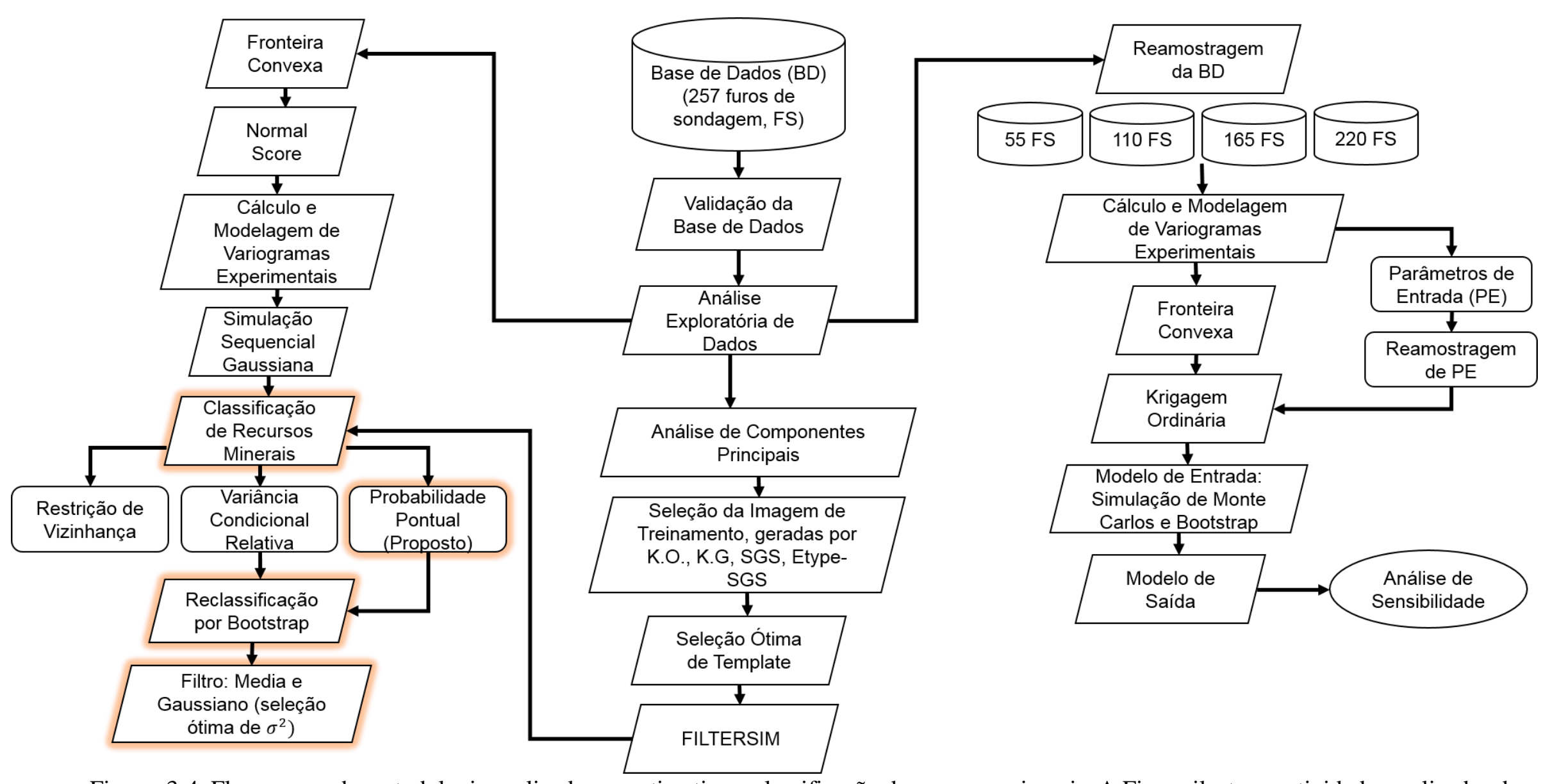

Figura 3-4. Fluxograma de metodologias aplicadas na estimativa e classificação de recursos minerais. A Figura ilustra as atividades realizadas durante a investigação. Os processos em vermelho foram realizados unicamente para a simulação geoestatística de múltiplos pontos (FILTERSIM). 


\section{Apresentação e Discussão dos Resultados}

\subsection{RESULTADOS E DISCUSSÃO}

Este capítulo está dividido em quatro seções principais: (1) validação da base de dados; (2) análise exploratória (estatística e geoestatística); (3) simulação geoestatística de dois e mais pontos além da classificação dos recursos minerais estimados, reclassificação e aplicação do filtro linear médio e Gaussiano; e (4) análise de sensibilidade dos parâmetros de interesse.

\subsection{ANÁLISE EXPLORATÓRIA DA BASE DE DADOS}

Para a variável em estudo, $\mathrm{Cu}(\%)$, as estatísticas descritivas do conjunto de dados brutos foram obtidas das 49.721 observações dos dados não regularizados pertencentes às litologias Sulfeto Disseminado e Brecha Sulfetada que estão apresentadas na Tabela 4-1.

Tabela 4-1. Estatísticas descritivas do conjunto de dados brutos da variável $\mathrm{Cu}(\%)$.

\begin{tabular}{cccccccc}
\hline $\mathrm{N}^{\mathrm{o}}$ de Amostras & Mínimo & $1^{\circ}$ Quartil & Mediana & Média & $3^{\circ}$ Quartil & Máximo & $\begin{array}{c}\text { Desvio } \\
\text { Padrão }\end{array}$ \\
\hline 49.721 & 0,01 & 0,04 & 0,13 & 0,61 & 0,5 & 39,08 & 1,40 \\
\hline
\end{tabular}

De acordo com os valores da mediana e média, Tabela 4-1, a distribuição da variável $\mathrm{Cu}(\%)$ é caracterizada por uma distribuição assimétrica positiva (Figura 4-1). 


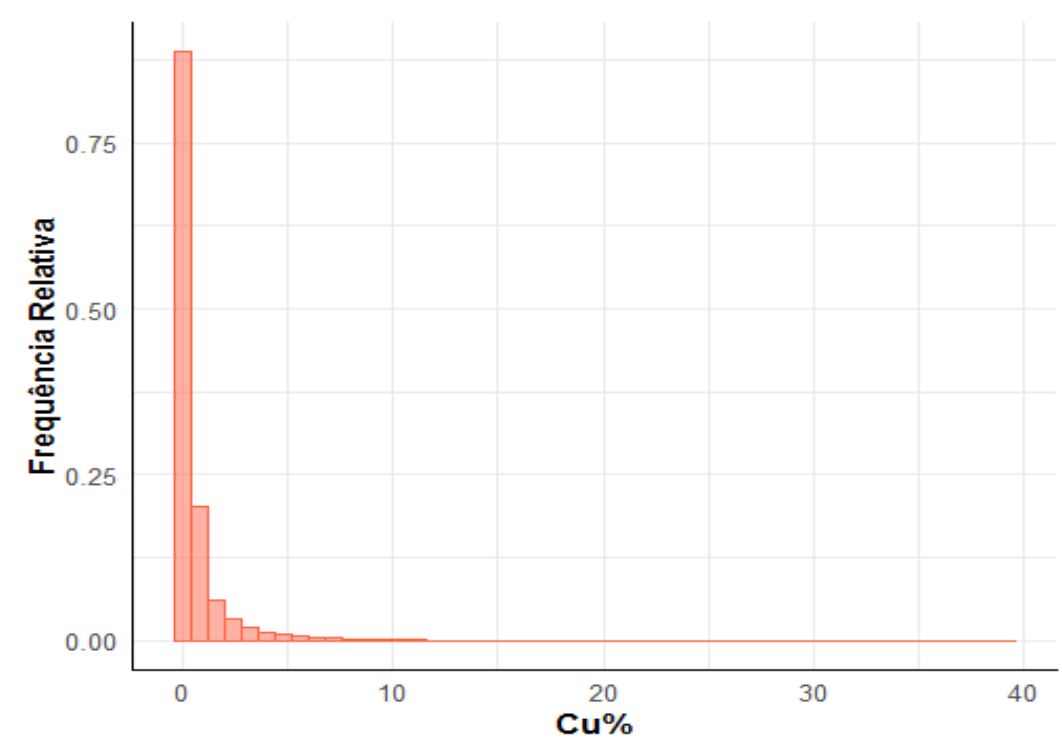
de estudo.

Figura 4-1. Histograma da variável $\mathrm{Cu}(\%)$ para ambas as litologias presentes na área

O evento de valores extremos acima de $1,19 \%$ de $\mathrm{Cu}(\%)$ é detectado a partir da equação: $Q_{3,1} \pm 1.5 I Q$, com $Q I=Q_{3}-Q_{1}(\mathrm{QI}-$ Amplitude interquartil). No entanto, esses valores (que totalizam 6.518 unidades amostrais), chamados de valores aberrantes ou outliers não serão eliminados da base de dados, devido a variável aleatória que é caracterizada por ter uma distribuição assimétrica. A Figura 4-2 ilustra um box-plot do conjunto de dados até o valor de detecção 1,19 .

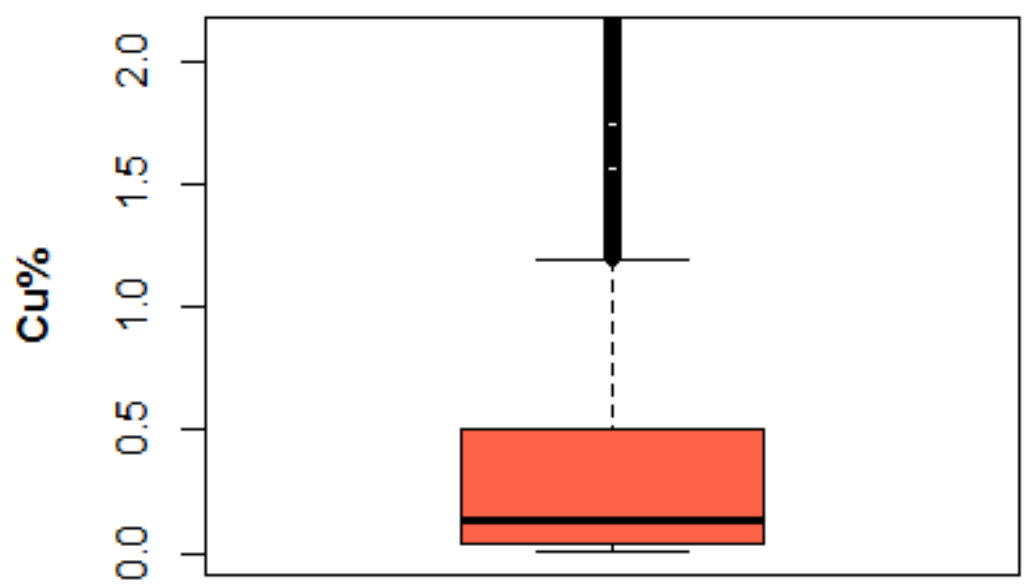

Figura 4-2. Box-plot para a variável $\mathrm{Cu}(\%)$ limitado em épsilon até o valor 2.09. 


\subsection{REGULARIZAÇÃO DA BASE DE DADOS}

Frequentemente, os dados coletados para a estimativa são obtidos em uma variedade de suportes diferentes que devem ser combinados de tal forma que todas as unidades amostrais apresentem suportes de igual tamanho. O processo de adequação é conhecido como regularização ou composite.

$\mathrm{Na}$ base de dados brutos os intervalos de amostragem revelam que as espessuras variam entre 0,03 e $5 \mathrm{~m}$ de espessura. A regularização foi aplicada para 1,3 metros do valor obtido a partir da média dos comprimentos das unidades amostrais nos testemunhos dos furos de sonda. Após a regularização dos dados brutos foi obtido um aumento de cerca de $1 \%$ no número de unidades amostrais. Ademais, foi confirmado mudanças insignificativas na média da variável de interesse (Tabela 4-2). As características da distribuição (assimetria positiva) foram mantidas como está representado no histograma da Figura 4-3 e em suas estatísticas descritivas (Tabela 4-2).

Tabela 4-2. Estatística descritiva do conjunto de dados regularizado da variável $\mathrm{Cu}(\%)$.

\begin{tabular}{cccccccc}
\hline $\mathrm{N}^{\circ}$ de Amostras & Mínimo & $1^{\circ}$ Quartil & Mediana & Média & $3^{\circ}$ Quartil & Máximo & $\begin{array}{c}\text { Desvio } \\
\text { Padrão }\end{array}$ \\
\hline 50.060 & 0,01 & 0,04 & 0,10 & 0,49 & 0,39 & 30,21 & 1,14 \\
\hline
\end{tabular}

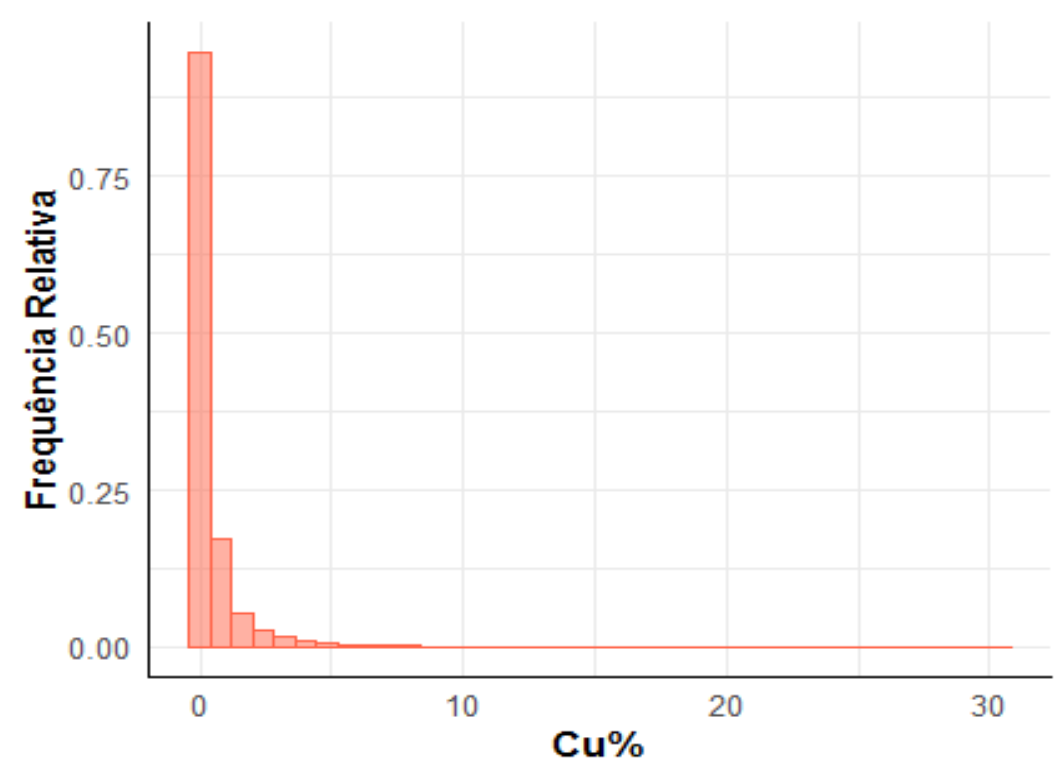

Figura 4-3. Histograma da variável regularizada $\mathrm{Cu}(\%)$. 


\subsection{SIMULAÇÃO GEOESTATÍSTICA}

O uso de técnicas de simulação condicional (por exemplo, SGS) requer que os dados amostrados sejam oriundos de uma distribuição normal. No entanto, nas ciências da terra isso não ocorra com frequência e os depósitos de cobre são caracterizados por ter uma distribuição log-normal por isso, uma análise de normalidade de dados deve ser realizada.

É importante enfatizar que as características da variável cobre, como por exemplo, sua assimetria positiva é similar àquela apresentada por variáveis aleatórias contínuas com distribuição lognormal, isto é, se $\mathrm{X}$ tem distribuição lognormal então $\mathrm{Y}=$ Ln $(\mathrm{X})$ tem distribuição normal com parâmetros $\left(\mu, \sigma^{2}\right)$. Nesse sentido, apenas uma transformação logarítmica da variável $\mathrm{Cu}(\%)$ seria necessária para o uso da simulação geoestatística SGS. No entanto, antes de qualquer transformação Gaussiana do conjunto de dados um teste de normalidade como Shapiro-Wilk pode ser aplicado a fim de avaliar a normalidade dos dados.

\subsection{TRANSFORMAÇÃO DE DADOS}

O primeiro passo será a validação da hipótese de normalidade do conjunto de dados compostos que foram transformados usando a função logarítmica. Para isso, uma reamostragem por Bootstrap é executada (Seção 2.8), onde para cada i-ésima amostra é realizado o teste de Shapiro-Wilk (Figura 4-4). Se o valor de $p$ ou valor de probabilidade for maior que 0,05 ( $p>0,05)$, a hipótese nula (dados que seguem uma distribuição normal) é aceita ou caso contraria rejeitada. As Tabelas 4-3 e 4-4 mostram a estatística descritiva do conjunto de dados transformados $(\mathrm{Y}=\mathrm{Ln}(\mathrm{X}))$ bem como o teste de normalidade dos dados. 
Tabela 4-3. Estatística descritiva do conjunto de dados regularizado $\mathrm{Cu}$ (\%), transformados pela função logarítmica.

\begin{tabular}{cccccccc}
\hline $\mathrm{N}^{\circ}$ de Amostras & Mínimo & $1^{\circ}$ Quartil & Mediana & Média & $3^{\circ}$ Quartil & Máximo & $\begin{array}{c}\text { Desvio } \\
\text { Padrão }\end{array}$ \\
\hline 50.060 & $-2,0$ & $-1,41$ & $-1,0$ & $-0,89$ & $-0,42$ & 1,48 & 0,68 \\
\hline
\end{tabular}

Tabela 4-4. Teste de normalidade dos dados. Onde $\bar{w}$ e $\bar{p}$ são a estatística e o valor da probabilidade média, respetivamente, obtidos por Bootstrap.

\begin{tabular}{ccc}
\hline & $\bar{w}$ & $\bar{p}-$ valor \\
\hline $\begin{array}{c}\text { Teste de Normalidade } \\
\text { Shapiro-Wilk }\end{array}$ & 0,97 & $6,048 \mathrm{e}-31$ \\
\hline
\end{tabular}

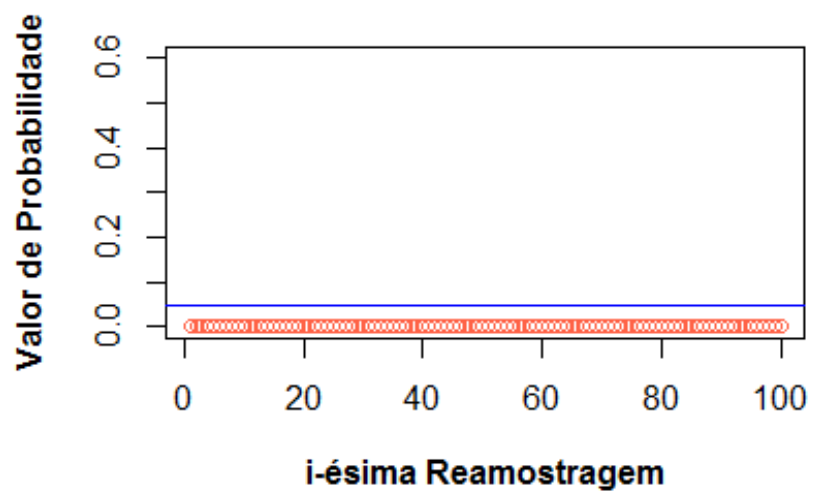

Figura 4-4. Gráfico de valores de probabilidade para as 100 reamostragens obtidas por Bootstrap para o teste de normalidade dos dados. A linha azul indica o valor da probabilidade limite de 0,05 e os pontos vermelhos mostram os valores p estimados.

A partir das informações da Tabela 4-4 e Figura 4-4, a hipótese nula de normalidade dos dados é rejeitada. Além disso, os resultados indicam que a distribuição original de dados não regularizados e regularizados não são log-normalmente distribuídos. Portanto, deve-se realizar a transformação dos dados regularizados em um domínio Gaussiano. A transformação Gaussiana é efetuada para que a distribuição empírica passe a seguir uma distribuição Normal padrão ou seja, com média e variância igual a 0 e 1.

A Tabela 4-5 mostra a estatística de resumo dos dados transformados por normal score e a Figura 4-5 ilustra o histograma da variável $\mathrm{Cu}(\%)$ após a transformação. 
Adicionalmente, foi realizada a análise de normalidade para validar a hipótese de normalidade (Tabela 4-6 e Figura 4-6).

Tabela 4-5. Estatísticas de resumo dos dados transformados de $\mathrm{Cu}(\%)$ pela técnica normal score.

\begin{tabular}{cccccccc}
\hline $\mathrm{N}^{\circ}$ de Amostras & Mínimo & $1^{\circ}$ Quartil & Mediana & Média & $3^{\circ}$ Quartil & Máximo & $\begin{array}{c}\text { Desvio } \\
\text { Padrão }\end{array}$ \\
\hline 50.060 & $-4,16$ & $-0,67$ & 0,0 & 0,0 & 0,67 & 4,16 & 1,00 \\
\hline
\end{tabular}

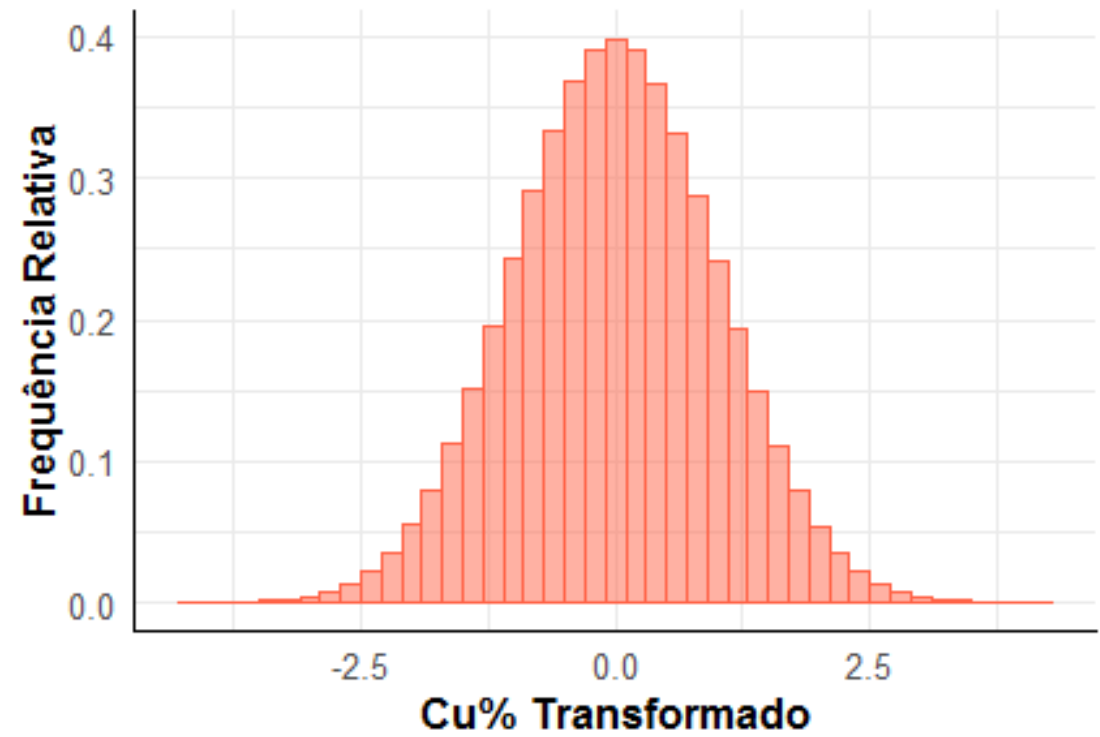

Figura 4-5. Distribuição da variável Cu (\%) transformada por nscore. 
Tabela 4-6. Teste de normalidade dos dados transformados por nscore. Onde $\bar{w}$ e $\bar{p}$ respectivamente são a estatística e o valor da probabilidade média derivados do Bootstrap.

\begin{tabular}{ccc}
\hline & $\bar{w}$ & $\bar{p}-$ valor \\
\hline $\begin{array}{c}\text { Teste de Normalidade } \\
\text { Shapiro-Wilk }\end{array}$ & 0,99 & 0,53 \\
\hline
\end{tabular}

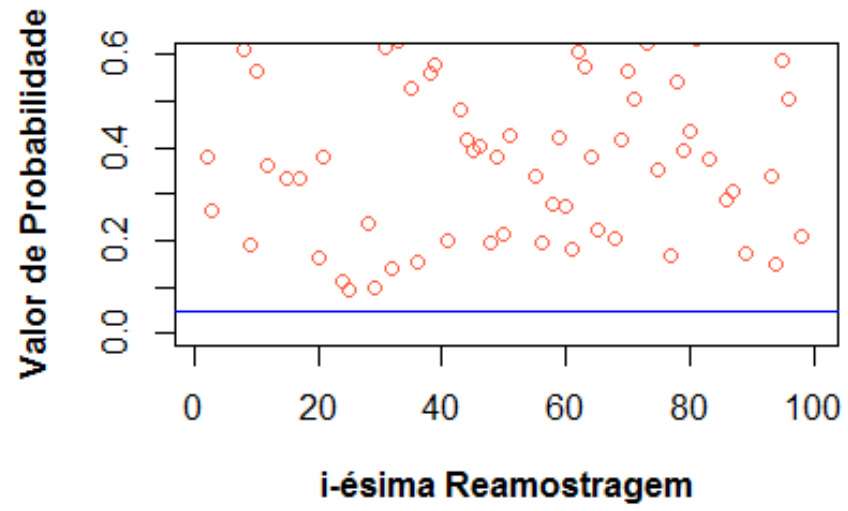

Figura 4-6. Gráfico de valores de probabilidade para as 100 reamostragens obtidas por Bootstrap para o teste de normalidade dos dados transformados nscore. A linha azul indica o valor de probabilidade limite de 0,05 e os pontos vermelhos mostram os valores $\mathrm{p}$ estimados.

De acordo com a Tabela 4-6 e Figura 4-6, a hipótese nula de normalidade dos dados transformados é aceita. Por outro lado, o conjunto de dados transformados deve ser validado, de modo que a hipótese de Bi/Multi-Gaussianidade seja garantida. Esta premissa é avaliada a partir da razão das raízes quadradas do variograma pelo madograma, que deve flutuar próximo ao valor $\sqrt{\pi}$, Figura 4-7. Este teste de biGaussianidade é realizado conforme Cortes (2016).

Assim, sob as duas hipóteses normalidade e bi-Gaussianidade dos dados, a técnica de Simulação Sequencial Gaussiana pode ser aplicada na estimativa de recursos minerais sem qualquer restrição. 


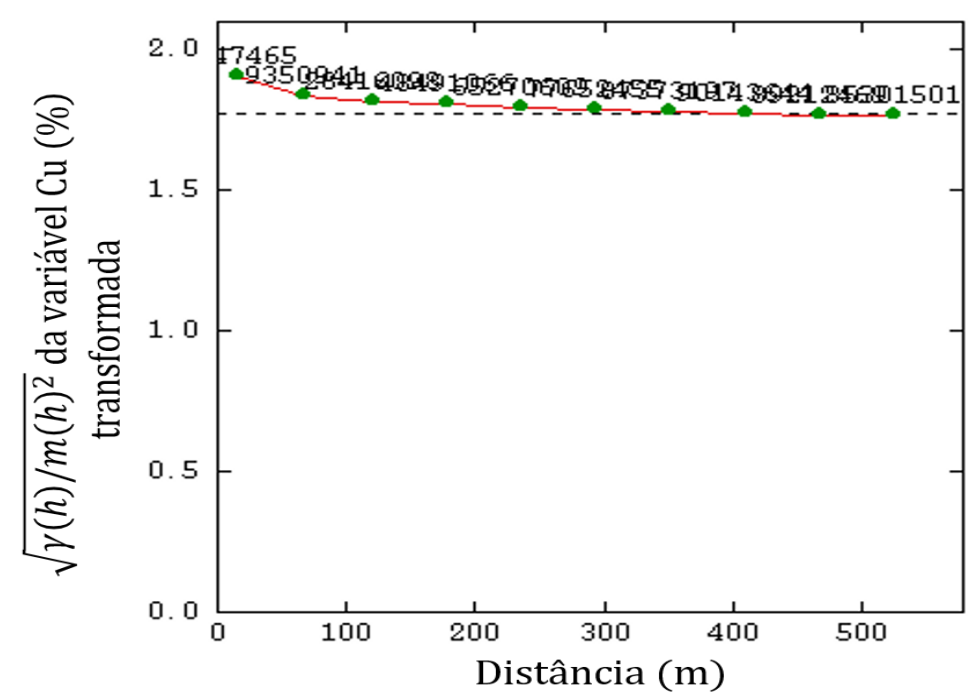

Figura 4-7. Teste de bi-Gaussianidade dada pela razão entre a raiz quadrada do variograma e o madograma.

\subsection{VARIOGRAMA DOS DADOS TRANFORMADOS}

Inicialmente foi realizada uma análise exploratória nas direções ortogonais $160^{\circ} / 50^{\circ}, 250^{\circ} / 0^{\circ}$ e $160^{\circ} /-40^{\circ}$, conforme ilustrado na Figura 4-8. O objetivo foi verificar a existência de anisotropia no domínio. Embora o fenômeno em estudo varie conforme as três direções, evidencia-se graficamente que as direções ortogonais $160^{\circ} / 50^{\circ}$ e $250^{\circ} / 0^{\circ}$ oscilam próximas entre si, por isso, o variograma experimental foi recalculado no plano $160^{\circ} / 45^{\circ}$ como omnidirecional e $160^{\circ} / 45^{\circ}$. Posteriormente, o modelo teórico do variograma foi ajustado e a partir dos resultados a anisotropia presente foi considerada geométrica (Figura 4-8). A Tabela 4-7 mostra os parâmetros de configurações usados para cada direção.

Tabela 4-7. Parâmetros dos modelos teóricos ajustados aos variogramas experimentais do conjunto de dados transformados. $\mathrm{C}=$ Contribuição Espacial, $\mathrm{T}=$ Modelo Teórico de Variograma e A = Amplitude.

\begin{tabular}{|c|c|c|c|c|c|c|c|c|c|c|c|}
\hline \multirow{4}{*}{$\begin{array}{c}\text { Variável Cu } \\
(\%) \\
\text { transformada }\end{array}$} & Rotação & Efeito & \multicolumn{3}{|c|}{ 10 Estrutura } & \multicolumn{3}{|c|}{ 2을strutura } & \multicolumn{3}{|c|}{ 3으strutura } \\
\hline & \multirow[b]{3}{*}{$1650 / 450$} & \multirow[b]{3}{*}{0,09} & $C$ & $T$ & $A$ & C & $\mathrm{T}$ & $A$ & C & $T$ & $A$ \\
\hline & & & & & 60 & & & 310 & & & 120 \\
\hline & & & 0,5 & Esférico & 95 & 0,35 & Esférico & 35 & 0,05 & Esférico & 35 \\
\hline
\end{tabular}



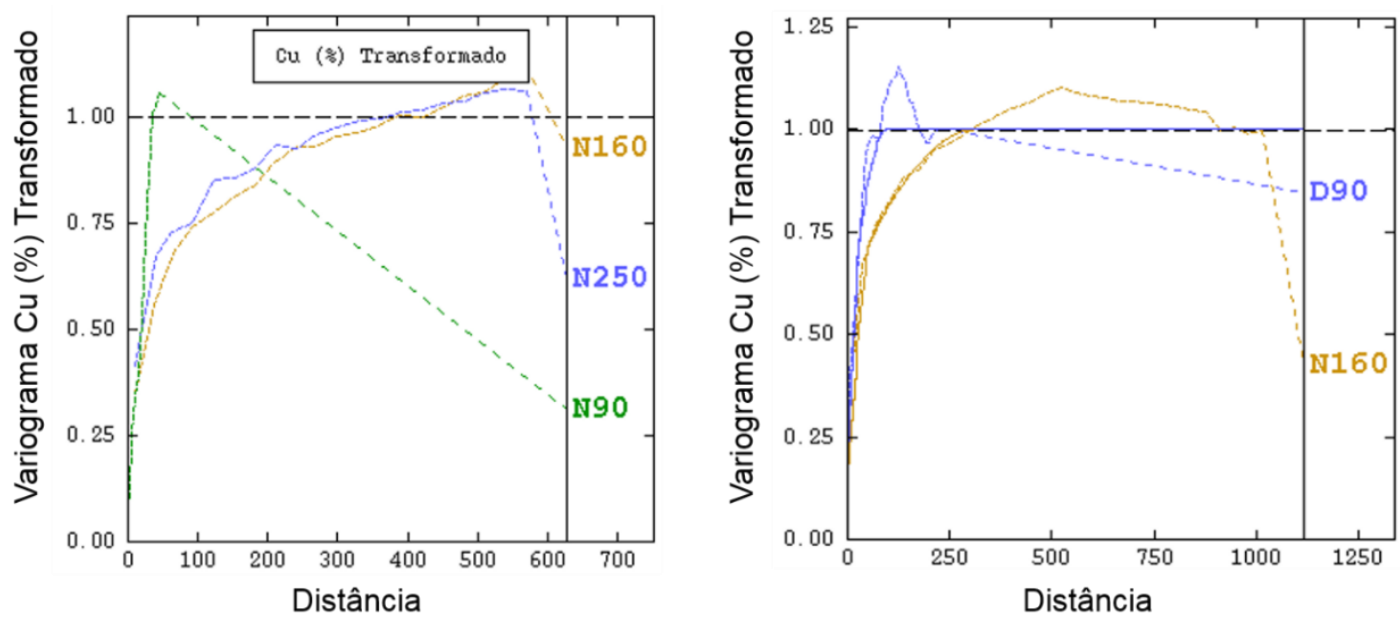

Figura 4-8. Variograma experimental e modelo de variograma ajustado. O lado esquerdo da Figura ilustra o variograma experimental calculado primeiramente nas direções $160^{\circ} / 45^{\circ}, 250^{\circ} / 0^{\circ}$ e $160^{\circ} / 45^{\circ}$, na avaliação da anisotropia, e ao lado direito da Figura é ilustrado o variograma experimental recalculado para direções de $160^{\circ} / 45^{\circ}$ e $160^{\circ} /-45^{\circ}$, assim como seu modelo teórico de variograma ajustado.

\subsection{VALIDAÇÃO CRUZADA}

Diversos parâmetros de pesquisa foram testados até encontrar a melhor estratégia de busca para gerar diversas realizações estocásticas pela SGS. Os parâmetros de busca por unidades amostrais estão ilustrados na Tabela 4-8 e a Figura 4-9 ilustra o diagrama de dispersão dos valores estimados versus os amostrados para a variável transformada $\mathrm{Cu}(\%)$ por normal score.

Segundo o gráfico de dispersão (Figura 4-9) existe uma queda para os valores pertencentes ao intervalo $(-4,-2)$, devido à mistura das duas mineralizações no processo. No entanto, o coeficiente de correlação linear de Pearson é igual a 0,89. Este resultado permite concluir que os parâmetros de busca e o modelo de variograma teórico são adequados na caracterização do fenômeno espacial em estudo. 
Tabela 4-8. Estratégia de busca para Simulação Sequencial Gaussiana.

\begin{tabular}{lc}
\hline \multicolumn{2}{c}{ Parâmetros de busca da Elipsoide } \\
\hline Eixo Maior (m) & 250 \\
Eixo Médio (m) & 200 \\
Eixo Menor (m) & 65 \\
Mínimo de Amostras & 4 \\
$\mathrm{~N}^{\circ}$ Horizontal de Setores Angulares & 4 \\
$\mathrm{~N}^{\circ}$ Ótimo de Amostras por Setor & 2 \\
Distância Mínima entre duas Amostras (m) & 0,70 \\
Descretização por Bloco & $2 \times 2 \times 2$ \\
$\mathrm{~N}^{\circ}$ Ótimo de Nós Previamente Simulados & 4 \\
\hline
\end{tabular}

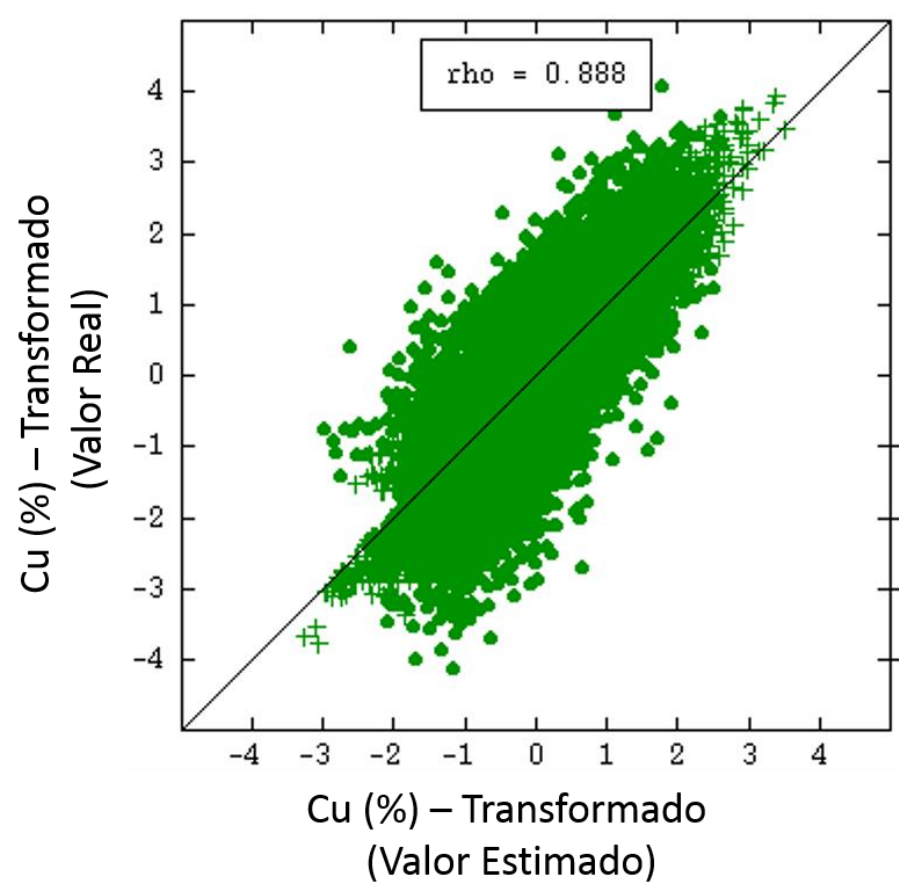

Figura 4-9. Diagrama de dispersão entre os valores estimados e reais para a variável transformada $\mathrm{Cu}(\%)$, com correlação de 0,89 .

\subsection{SIMULAÇÃO SEQUENCIAL GAUSSIANA}

Após definir a estratégia de busca e avaliado o modelo de semivariograma realizou a simulação geoestatística por Simulação Sequencial Gaussiana que gerou 100 simulações do fenômeno espacial. 
Após a simulação os resultados da SGS foram transformados para seu domínio original (Figura 4-3). Os resultados obtidos estão ilustrados na imagem média e desvio padrão calculadas a partir das 100 simulações estocásticas (Figura 4-10 e 4-11). Já as estatísticas descritivas são apresentadas na Tabela 4-9.

De acordo com as estatísticas de resumo da média das realizações e os valores originais regularizados, é possível observar diferenças não significativas. No entanto, em geral as características das distribuições são semelhantes, por exemplo, a assimetria positiva (como evidenciado pelo histograma, Figura 4-12). Além disso, o desvio padrão condicional foi calculado e sua distribuição está ilustrada na Figura 4-13.

Tabela 4-9. Estatística descritiva da média das realizações estocásticas (Etype) para a variável $\mathrm{Cu}(\%)$.

\begin{tabular}{ccccccc}
\hline Mínimo & $1^{\circ}$ Quartil & Mediana & Média & $3^{\circ}$ Quartil & Máximo & $\begin{array}{c}\text { Desvio } \\
\text { Padrão }\end{array}$ \\
\hline 0,01 & 0,09 & 0,19 & 0,37 & 0,46 & 15,53 & 0,49 \\
\hline
\end{tabular}

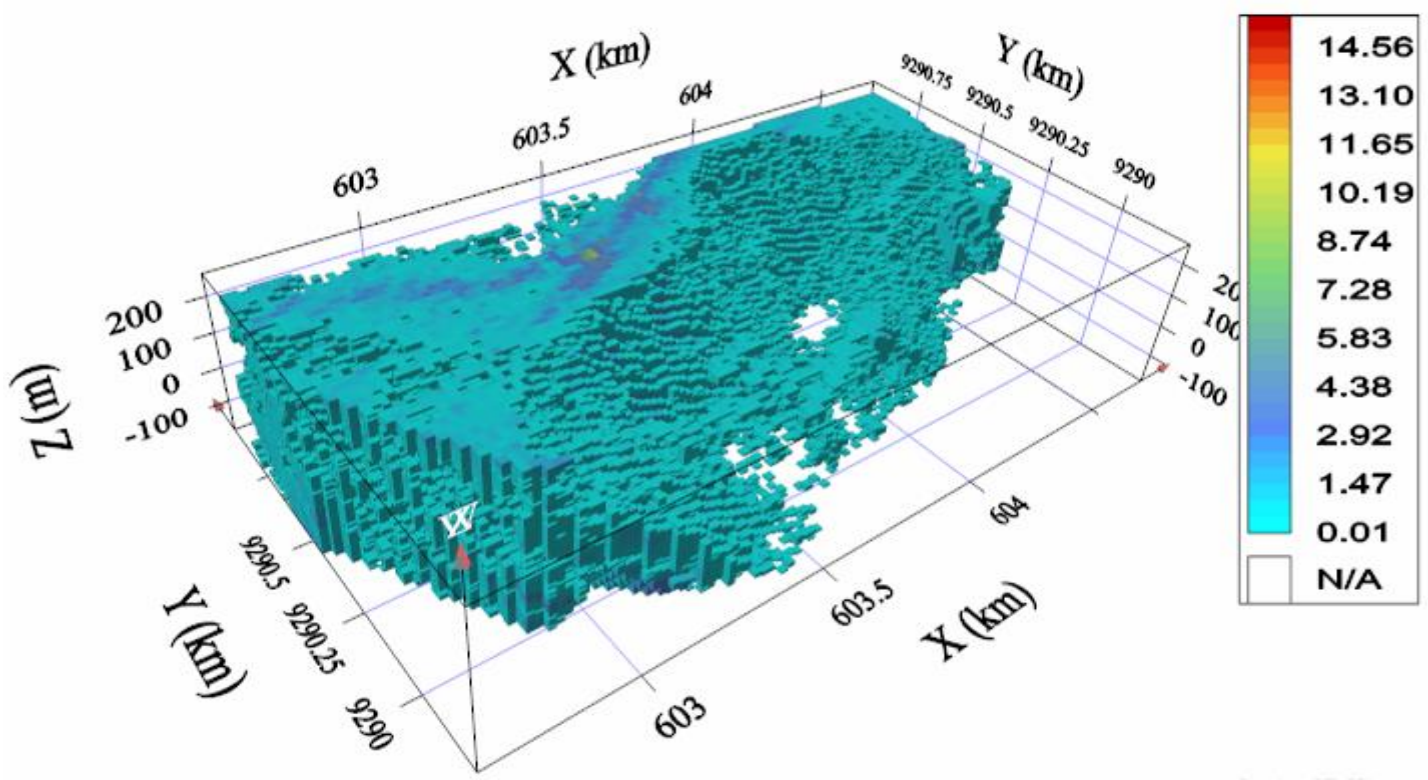

Figura 4-10. Etype das 100 realizações geoestatística por SGS da variável contínua $\mathrm{Cu}$ (\%) para valores acima do valor de corte de $0,33 \%$. 


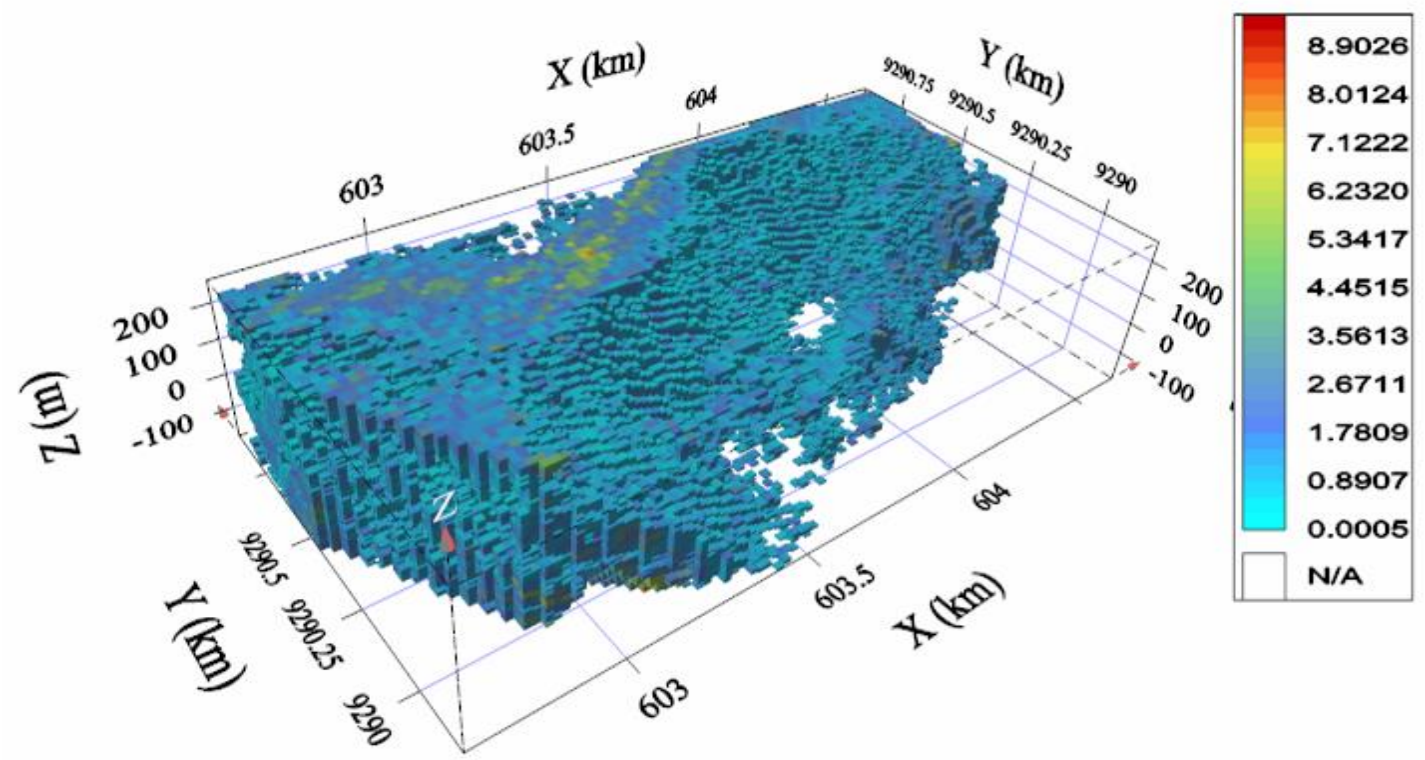

Figura 4-11. Desvio padrão das 100 realizações geoestacionárias pela SGS da variável contínua $\mathrm{Cu}(\%)$ para valores acima do valor de corte $0,33 \%$.

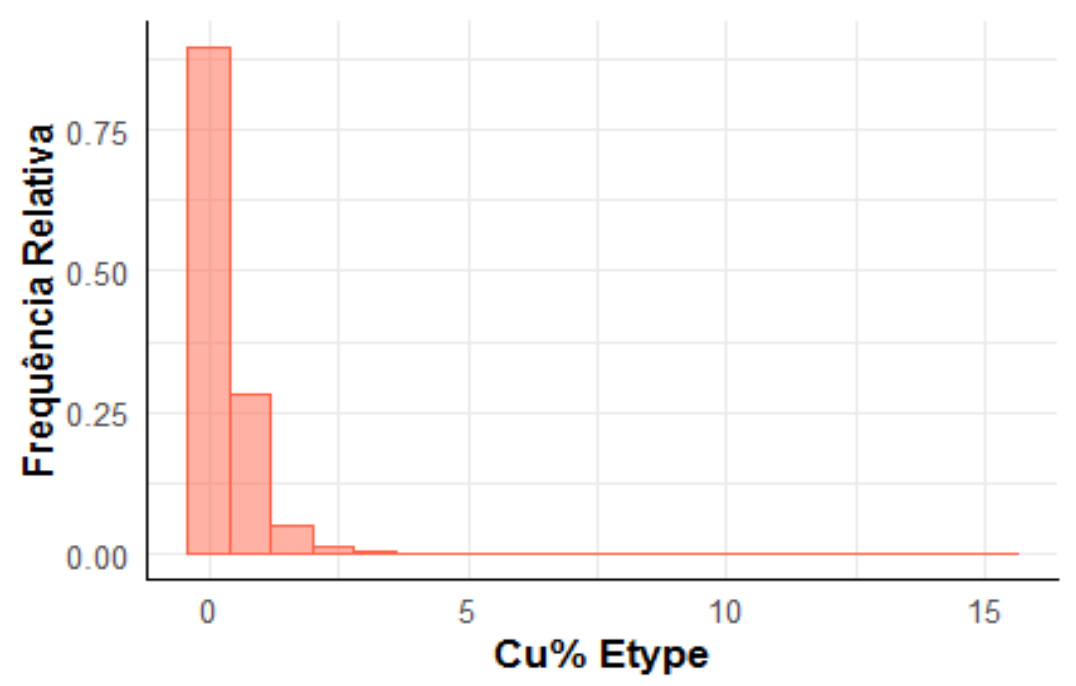

(Etype).

Figura 4-12. Histograma da variável $\mathrm{Cu}(\%)$ obtida a partir da média das realizações 


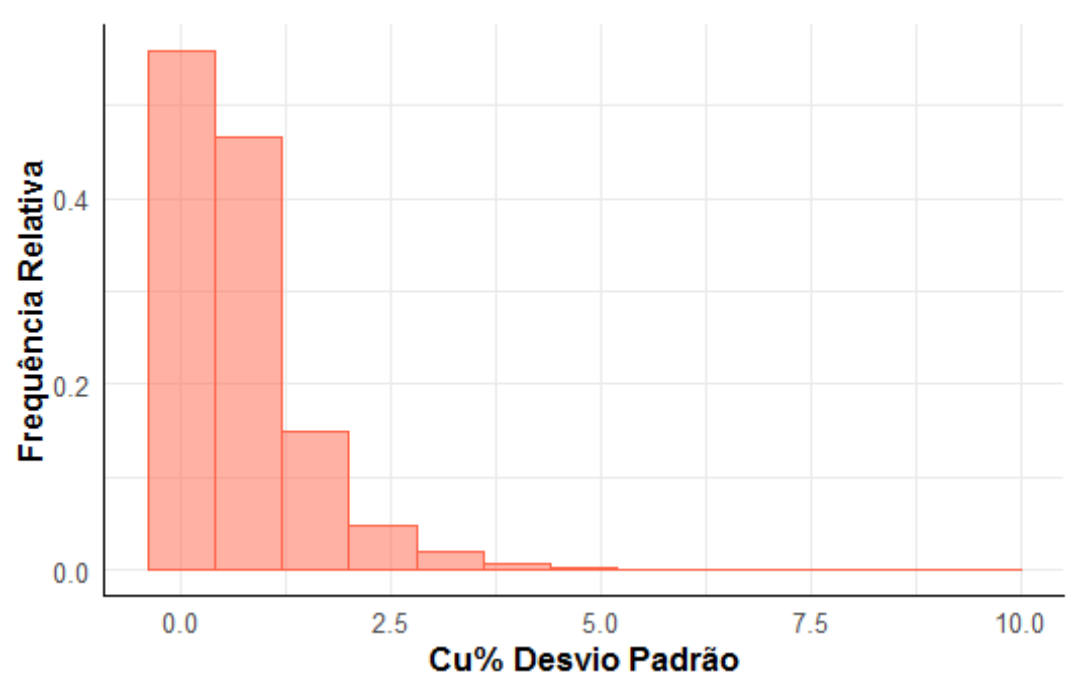

Figura 4-13. Histograma do desvio padrão condicional obtido a partir das 100 realizações estocásticas.

O valor 0,33\% de cobre foi selecionado com base na Tabela 4-10 que apresenta as estratégias de valores de corte da mina de Sequeirinho entre 2011 a 2022 (Golder Associates, 2010).

Tabela 4-10. Valores de cortes estratégicos entre os anos 2011-2022. (Fonte: Golder Associates, 2010).

\begin{tabular}{cc}
\hline Período & Teor de Corte $(\%)$ \\
\hline 2011 & 0,33 \\
$2012-2015$ & 0,40 \\
$2016-2022$ & 0,33 \\
\hline
\end{tabular}

\subsection{CLASSIFICAÇÃO DOS RECURSOS MINERAIS ESTIMADOS POR SGS}

Inicialmente neste trabalho foram utilizados três critérios para classificação de recursos minerais: (1) método de restrições de vizinhança; (2) variância condicional relativa e; (3) probabilidade pontual na categorização dos blocos simulados por SGS (Figura 4-10). Vale citar que a classificação de recursos minerais ocorre apenas para as unidades acima de 0,33\% de cobre (Figura 4-10). 
Seguindo o critério de classificação de acordo com as restrições geométricas do elipsoide de busca, além das restrições geométricas impostas que foram definidas por Dohm (2005), uma nova restrição foi estabelecida para classificar um recurso mineral como Medido ou seja, um bloco específico é Medido se houver pelo menos três observações próximas a ele.

É importante ressaltar que a classificação é sempre subjetiva e dependente da seleção de um critério de classificação pela pessoa competente. No entanto, todos esses métodos podem ser utilizados na estrutura atual dos guias de declaração de recursos e reservas minerais de acordo com a afirmação (CBRR, 2016): "Para classificar um recurso como Medido ou Indicado, deve haver um nível razoavelmente elevado de confiança em relação a quantidade das informações utilizadas para estimar este recurso, bem como na interpretação dessas informações".

Para cada critério foram calculados os teores médios contidos nas três categorias de recursos minerais. Os resultados são apresentados na Tabela 4-11, os diagramas de barras na Figura 4-14 e os modelos de blocos classificados nas Figuras 4-15,4-16 e 417. No total 86.355 blocos foram estimados e classificados.

Tabela 4-11. Resultado da classificação dos recursos minerais, através dos três critérios de classificação apresentados em volume e em toneladas. 1 = método de restrição de busca; $2=$ variância condicional relativa; 3 = Probabilidade Pontual.

\begin{tabular}{ccccc}
\hline Método & Classes & $\mathrm{N}^{\mathrm{o}}$ Blocos & Volume $\left(\mathrm{cm}^{3}\right)$ & Teor médio (\%) \\
\hline \multirow{2}{*}{1} & Medido & 60.277 & $1.69 \mathrm{e}+14$ & 0,37 \\
& Indicado & 13.741 & $3.85 \mathrm{e}+13$ & 0,38 \\
& Inferido & 12.337 & - & - \\
\hline \multirow{2}{*}{2} & Medido & 46.052 & $1.29 \mathrm{e}+14$ & 0,53 \\
& Indicado & 38.696 & $1.08 \mathrm{e}+14$ & 1,01 \\
& Inferido & 1.607 & $4.49 \mathrm{e}+12$ & 1,08 \\
\hline \multirow{2}{*}{3} & Medido & 68.410 & $1.91 \mathrm{e}+14$ & 0,95 \\
& Indicado & 8.563 & $2.39 \mathrm{e}+13$ & 0,41 \\
& Inferido & 9.382 & $2.63 \mathrm{e}+13$ & 0,37 \\
\hline
\end{tabular}

Os gráficos de barras (Figura 4-14) mostram maior restrição pelo critério de variância condicional relativa na categorização dos recursos minerais em relação ao método clássico e probabilístico pontual. Assim, aproximadamente 15.000 e 22.000 blocos que poderiam ser classificados como Medidos em comparação com os critérios clássico e probabilístico foram classificados como Indicados e Inferidos. Implicando uma menor confiabilidade na mineração do ponto de vista do investidor. Apesar do 
método considerar a incerteza local e levar em consideração o efeito proporcional dos blocos classificados e não penalizar em favor de áreas com teores maiores e/ou menores, a proporção de blocos classificados como Medidos é insatisfatória.

O método clássico de classificação comumente utilizado na indústria mineral (restrições de vizinhança) não depende dos valores das observações, portanto, não leva em consideração o efeito proporcional e a incerteza, uma vez que depende apenas das distâncias impostas. Além disso, os pontos previamente estimados ou simulados não são considerados, isto é, à variabilidade global é descartada (Figura 4-11). Neste sentido, os blocos com potencial econômico não podem ser classificados como Medidos ou Indicados. Portanto, esse método implica uma confiabilidade menor no empreendimento de mineração. Além disso, examinando o teor médio por categoria (Tabela 4-11) observa-se que blocos com teores acima de 0,33\% de cobre são dispensados pelo critério de variância condicional relativa (com média para Indicado e Inferido 1,01 e 1,08 respectivamente). Da mesma forma, o critério clássico de classificação com relação aos blocos Inferidos (fora do alcance do variograma). Emery et al. (2006) destacam que a distribuição lognormal é caracterizada por ter um efeito proporcional entre a dispersão local e o quadrado da média local. Ademais, os autores enfatizam que esse efeito aparece em depósitos metálicos que são caracterizados por ter uma distribuição assimétrica positiva. Apesar desta caracterização os recursos minerais realizados pela variância condicional relativa não são satisfatórios, já que a suposição de lognormalidade dos dados não é aceita (veja seção 4.6).

O critério probabilístico pontual de classificação fornece resultados promissores na categorização dos recursos minerais conforme apresentado na Tabela 4-11 para o depósito mineral Sequeirinho. É notório que o teor médio diminui de acordo com o grau de confiabilidade dos recursos minerais a partir do qual se pode inferir que as unidades são melhor classificadas de acordo com sua confiança e incerteza. Da mesma forma que a variância condicional relativa, o critério probabilístico pontual leva em conta o efeito proporcional, uma vez que depende da variância e da média condicional derivadas das realizações (expressão 3.1).

Em suma, a seleção de um critério para estabelecer a classificação dos recursos minerais deve ser feita com base na experiência do profissional, uma vez que diferentes critérios acabam sendo mais adequados a um depósito mineral já que dependem de 
diversas características como por exemplo: (1) tipo de distribuição; (2) tipo de assimetria e (3) continuidade espacial. Além disso, a seleção adequada dos intervalos que dividem as respectivas classes ainda é subjetiva.

É importante destacar que existem vantagens na aplicação da abordagem probabilística pontual já que pode ser aplicada a vários fenômenos espaciais, uma vez que depende apenas da quantidade de simulações estocásticas que garante a aproximação das probabilidades através do Teorema do Limite Central. Aliás, a velocidade de convergência depende do tipo de distribuição de probabilidade de cada bloco, embora apenas 30 simulações geoestatísticas tenham sido suficientes para uma aproximação satisfatória. 

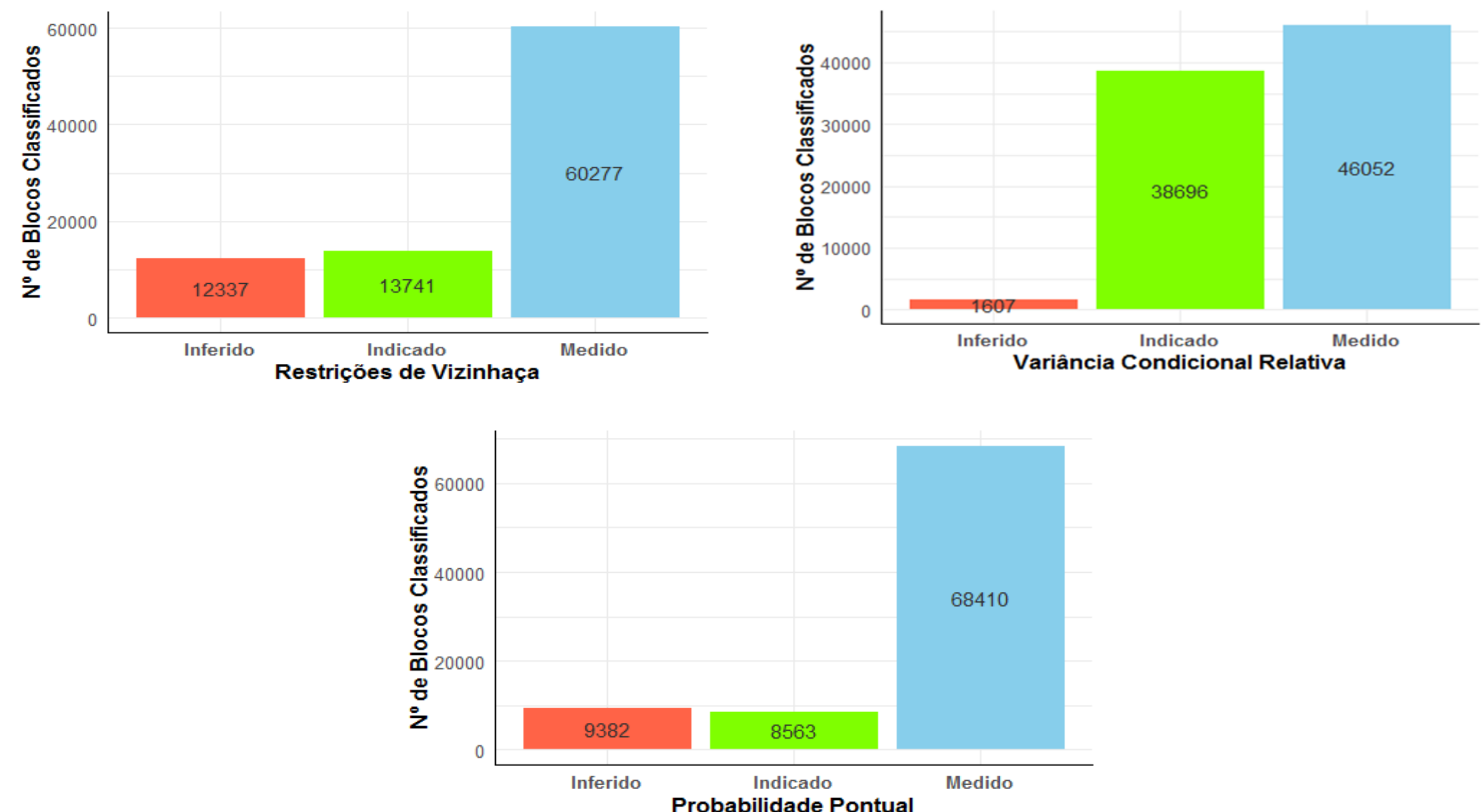

Figura 4-14. Número total de metal quantificado para cada correspondente categoria para os critérios de classificação por restrição elipsoide de busca, variância condicional relativa e probabilidade pontual. 


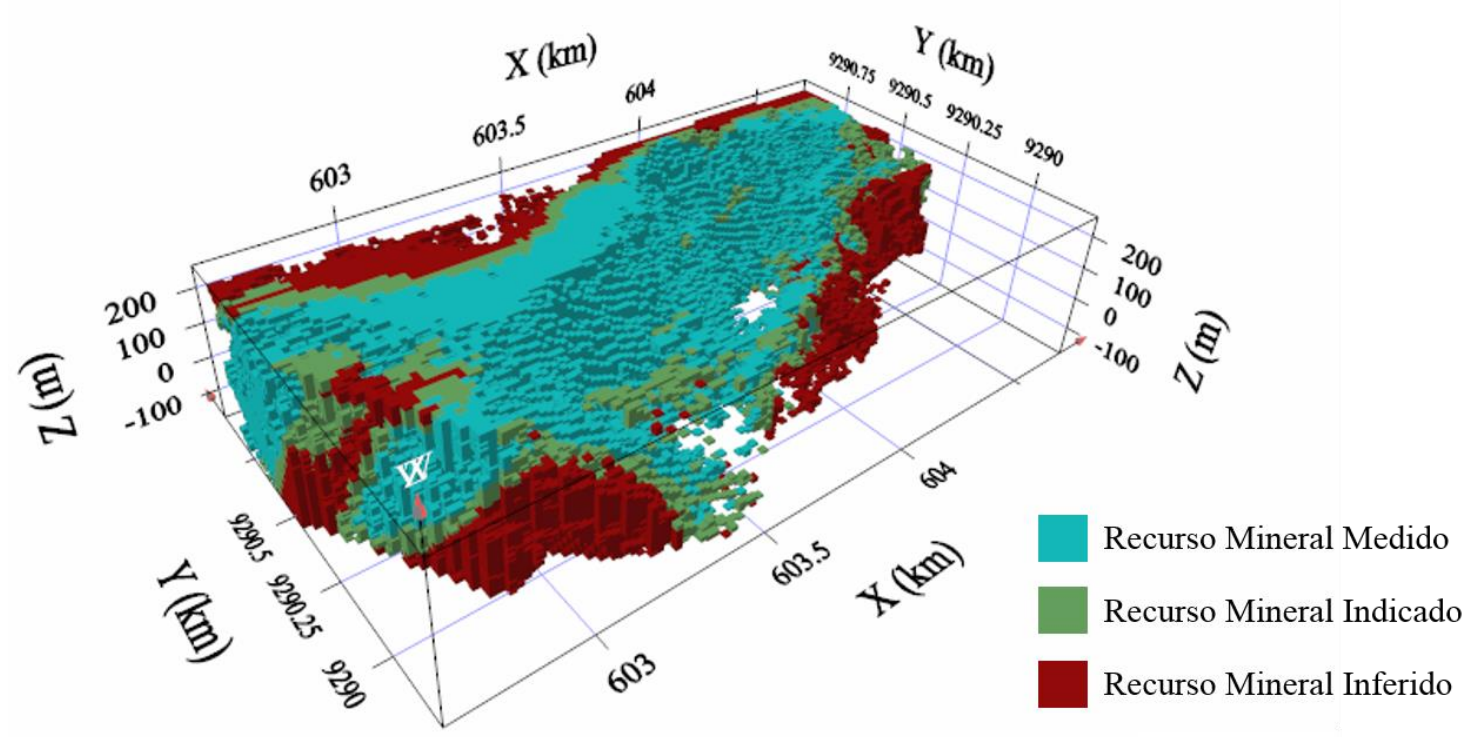

Figura 4-15. Modelo de blocos resultante da classificação dos recursos minerais, pelo critério de classificação restrição do elipsoide de busca.

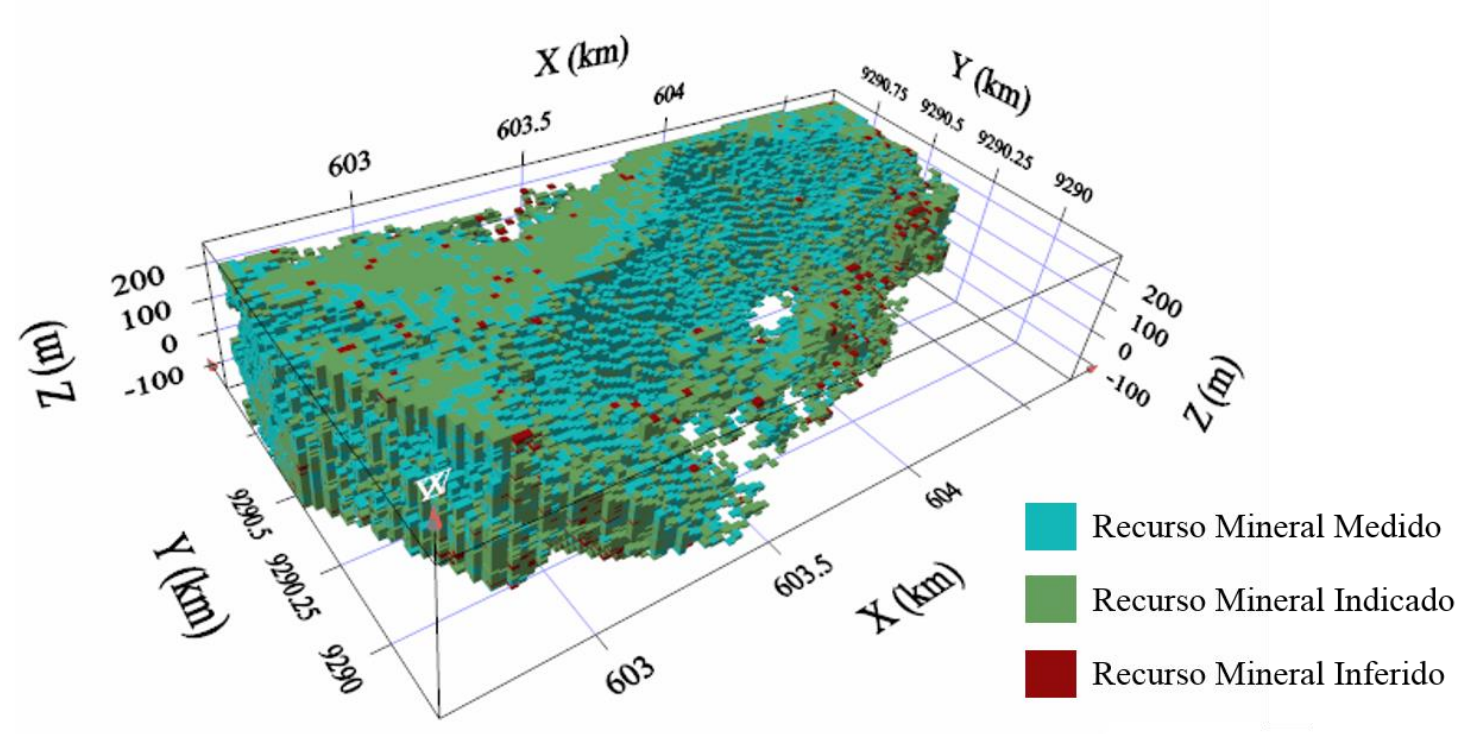

Figura 4-16. Modelo de bloco resultante da classificação dos recursos minerais estimados, pelo critério de classificação variância condicional relativa. 


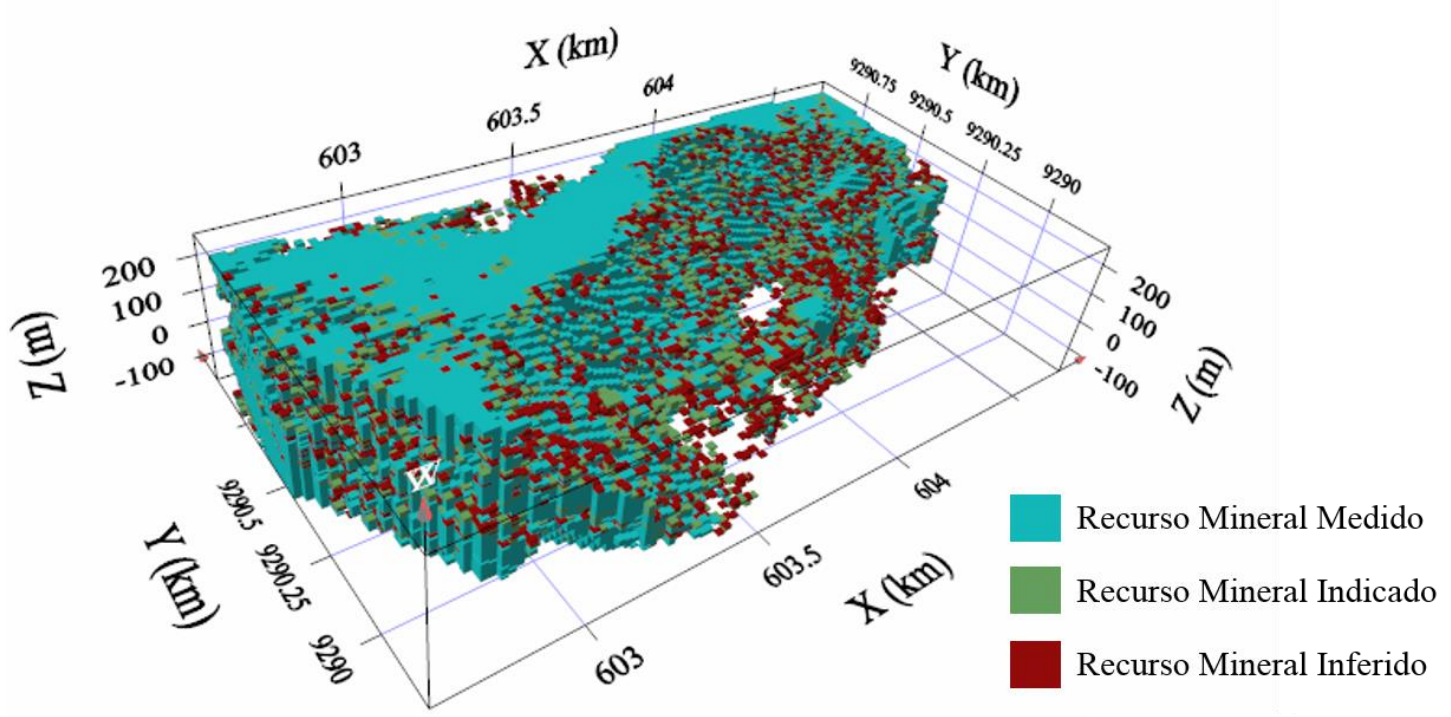

Figura 4-17. Modelo de bloco resultante da classificação dos recursos minerais, pelo critério de classificação probabilidade pontual.

\subsection{RECLASSIFICAÇÃO POR BOOTSTRAP}

Como discutido o método probabilístico pontual destaca-se em temos de resultados da classificação dos recursos minerais. Por isso, neste trabalho a técnica de reclassificação por Bootstrap será aplicada apenas aos resultados obtidos pelo critério de classificação proposto. O algoritmo de reclassificação foi desenvolvido pelo autor na linguagem de programação Matlab e seu passo a passo é discutido na seção 3.2.2.

Os resultados de reclassificação obtidos por Bootstrap, apresentados nas Figuras 4-19, 4-20 e 4-21, mostram mudanças nas classes de recursos minerais que foram inicialmente obtidas através do critério de probabilidade pontual. Na Figura 4-19 destaca-se uma zona de contato ao redor do recurso mineral medido que pode ser associada às diferentes litologias que dividem o corpo entre mineralizado e não mineralizado.

Embora nas Figuras (4-19, 4-20 e 4-21) mostrem visualmente as mudanças na distribuição espacial das classes, a estatística descritiva dos recursos minerais antes e após a reclassificação (Tabela 4-12) revela que não há diferenças significativas. De fato, estas estatísticas de resumo validam os resultados obtidos pelos critérios de classificação probabilística pontual, uma vez que as medianas dos recursos minerais 
antes e depois da classificação e reclassificação diminuem de acordo com o grau de confiabilidade das classes.

Neste seguimento, as médias obtidas para os recursos minerais (Tabela 4-12) confirmam que o uso de um método de reclassificação é necessário, pois permite a captura da variabilidade local de variáveis aleatórias caracterizadas por uma distribuição assimétrica positiva ou negativa, já que o estimador da média é um estimador não robusto, apesar de ser um estimador não-viesado.

Tabela 4-12. Estatísticas descritivas dos recursos minerais classificados e reclassificados, por probabilidade pontual e Bootstrap, respectivamente.

\begin{tabular}{cccccccc}
\hline & Mínimo & $1^{\circ}$ Quartil & Mediana & Média & $3^{\circ}$ Quartil & Máximo & $\begin{array}{c}\text { Desvio } \\
\text { Padrão }\end{array}$ \\
\hline $\begin{array}{c}\text { Medido } \\
\text { (Classificado) }\end{array}$ & 0,36 & 0,55 & 0,74 & 0,95 & 1,10 & 15,53 & 0,65 \\
$\begin{array}{c}\text { Medido } \\
\text { (Reclassificado) }\end{array}$ & 0,38 & 0,61 & 0,81 & 1,02 & 1,18 & 15,53 & 0,66 \\
$\begin{array}{c}\text { Indicado } \\
\text { (Classificado) }\end{array}$ & 0,35 & 0,39 & 0,40 & 0,41 & 0,42 & 0,65 & 0,04 \\
$\begin{array}{c}\text { Indicado } \\
(\text { Reclassificado) }\end{array}$ & 0,34 & 0,39 & 0,42 & 0,43 & 0,46 & 0,85 & 0,06 \\
$\begin{array}{c}\text { Inferido } \\
\text { (Classificado) }\end{array}$ & 0,01 & 0,09 & 0,19 & 0,37 & 0,46 & 15,53 & 0,50 \\
$\begin{array}{c}\text { Inferido } \\
\text { (Reclassificado) }\end{array}$ & 0,01 & 0,09 & 0,20 & 0,38 & 0,48 & 5,54 & 0,49 \\
\hline
\end{tabular}

A Figura 4-18 representa o gráfico de barras dos recursos minerais reclassificados por Bootstrap. Observa-se um aumento na quantidade da classe de recurso Indicado cuja maior e menor contribuição vem da classe de recurso mineral Medido e Indicado com 8.650 e 2.506 blocos reclassificados. Os resultados dessa nova reclassificação estão apresentados na Tabela 4-13 onde estão os novos teores médios e volumes calculados para cada classe. em volume.

Tabela 4-13. Resultado da reclassificação de recursos minerais, por meio de Bootstrap,

\begin{tabular}{cccc}
\hline Classe & $\mathrm{N}^{\mathrm{o}}$ Blocos & Volume $\left(\mathrm{cm}^{3}\right)$ & Teor médio (\%) \\
\hline Medido & 59.760 & $1.67 \mathrm{e}+14$ & 1,02 \\
Indicado & 19.719 & $5.52 \mathrm{e}+13$ & 0,43 \\
Inferido & 6.876 & $1.92 \mathrm{e}+13$ & 0,38 \\
\hline
\end{tabular}




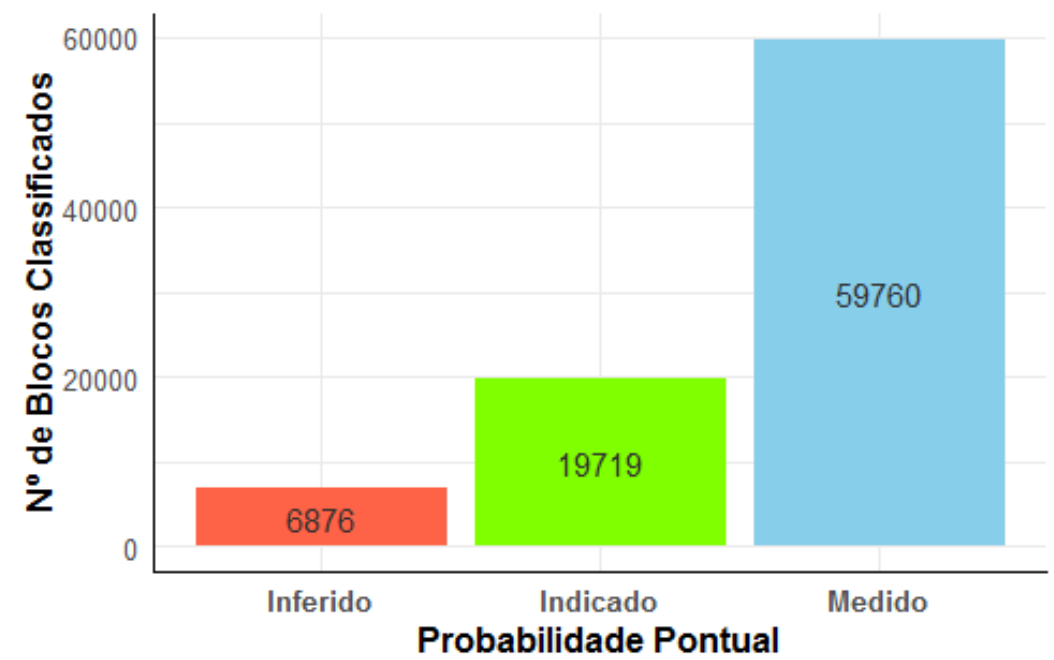

Figura 4-18. Número total de metal quantificado para cada correspondente categoria, obtidos a partir da reclassificação por Bootstrap.

\subsection{FILTROS: MÉDIA E GAUSSIANO}

De acordo com as imagens da seção anterior a reclassificação de recursos minerais por Bootstrap sofrem um detrimento na sua continuidade, conectividade e homogeneização espacial do fenômeno, assim como surgimento do "spotted dog", causado principalmente pela alta variabilidade neste tipo de depósito. Assim, uma solução parcial para o problema é o uso de um filtro adequado que preserve as características do fenômeno espacial. Portanto, neste trabalho dois filtros lineares são aplicados e comparados (seção 2.5).

Para fins de comparação o mesmo modelo de homogeneização foi utilizado tanto para o filtro de Média quanto para o Gaussiano. No entanto, a seleção do modelo/janela de homogeneização para o filtro Gaussiano foi realizada a partir da seleção de um valor “ótimo" de sigma ou desvio padrão no intervalo de dispersão $[0.5,2]$ onde o tamanho do modelo de suavização é dado por $2 *$ ceil $(2 *$ sigma $)+1$. Aliás, ceil é a função de aproximação para o valor mais próximo do infinito e sigma é o desvio padrão ou intervalo de dispersão. Desta forma, quatro tamanhos possíveis podem ser selecionados, $3 \times 3 \times 3,5 \times 5 \times 5, \ldots, 9 \times 9 \times 9$. 

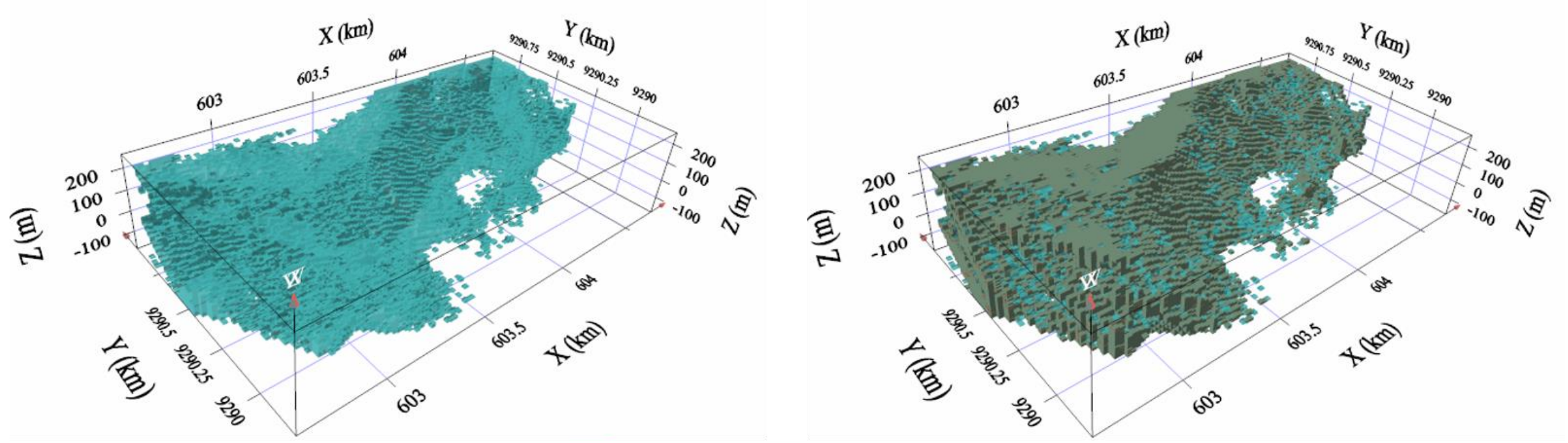

Recurso Mineral Medido

\section{Recurso Mineral Medido}

$$
\text { (Reclassificado) }
$$

Figura 4-19. Blocos classificados como recursos minerais medidos antes (ao lado esquerdo) e após (ao lado direito) da reclassificação por Bootstrap. Ao lado direito da Figura se ilustra superposição dos blocos medidos. 

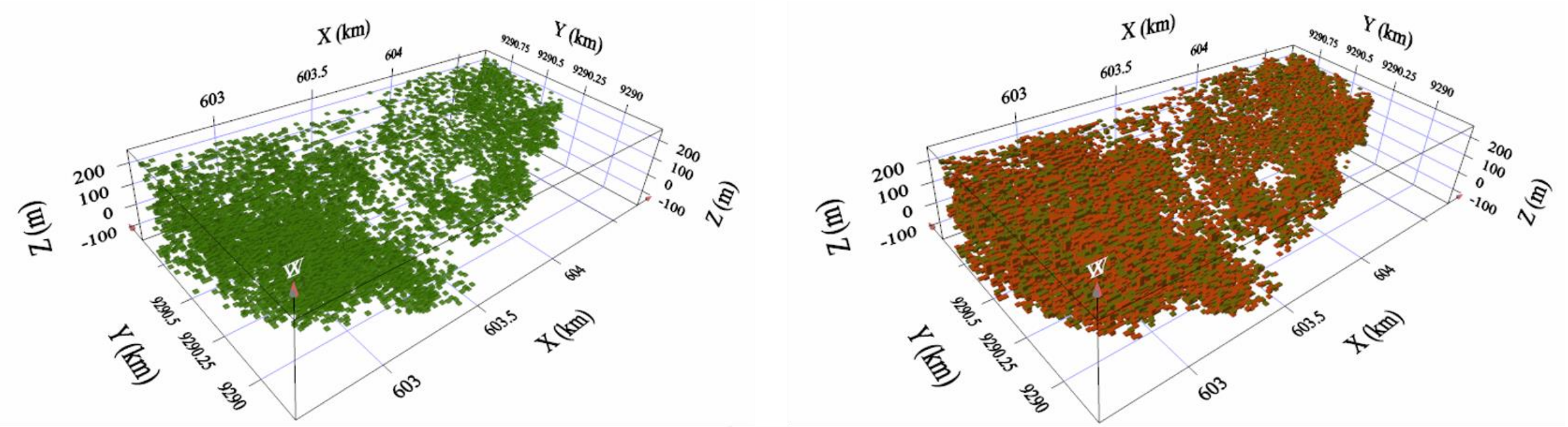

Recurso Mineral Indicado

Recurso Mineral Indicado (Reclassificado)

Figura 4-20. Blocos classificados como recursos minerais Indicado antes (ao lado esquerdo) e após (ao lado direito) da reclassificação por Bootstrap. Ao lado direito da Figura se ilustra a superposição dos blocos medidos. 

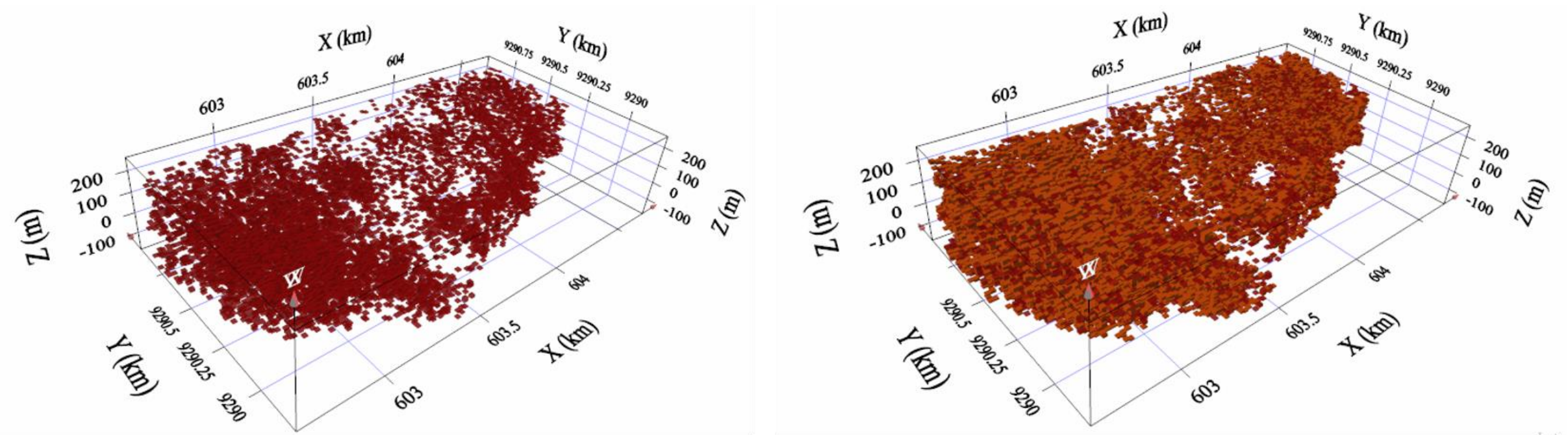

Recurso Mineral Inferido

Recurso Mineral Inferido

(Reclassificado)

Figura 4-21. Blocos classificados como recursos minerais Inferidos antes (ao lado esquerdo) e após (ao lado direito) da reclassificação por Bootstrap. Ao lado direito da Figura se ilustra a superposição dos blocos Inferidos. 
Devido à grande variedade de cenários possíveis para o filtro Gaussiano no intervalo $[0.5,2]$ propomos o uso da máxima verossimilhança log-normal (código do Quadro 2-1) na seleção de um valor “ótimo” de sigma. No entanto, a raiz quadrada do erro quadrado médio, calculado da diferença entre a imagem real e suavizada é usada no lugar da entropia da informação. A Figura 4-22 ilustra o resultado obtido pela aplicação da técnica de verossimilhança log-normal na seleção de um sigma "ótimo", cujo $\sigma=1$ e consequentemente o tamanho da janela é 5 x 5 x 5 .

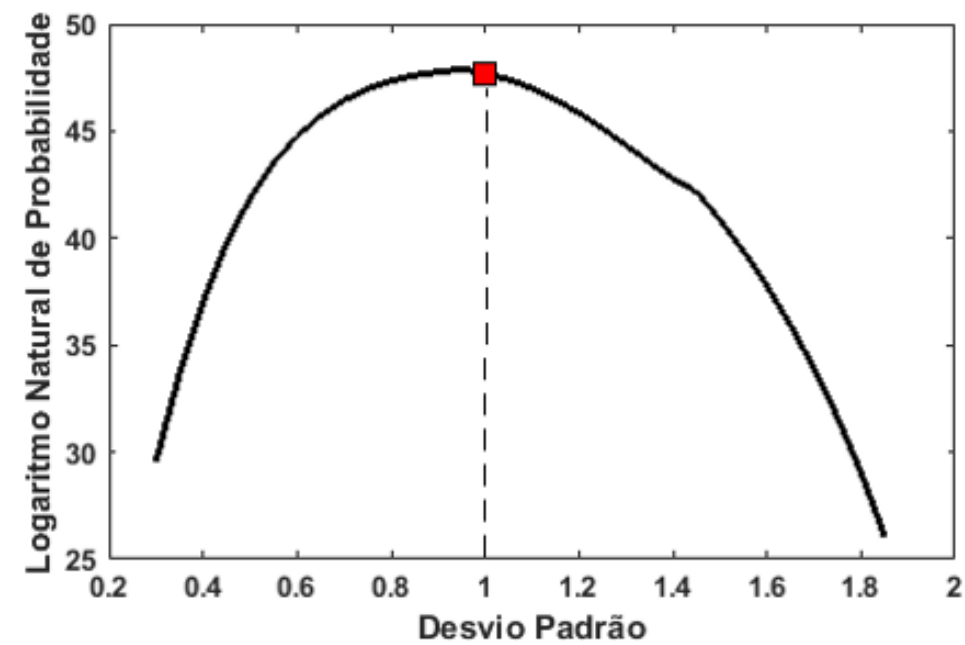

Figura 4-22. Logaritmo natural da função de probabilidade com valor ótimo de desvio padrão igual à unidade.

Definido o desvio padrão "ótimo" e o tamanho da janela para o filtro Gaussiano, foi utilizado o mesmo tamanho de janela ( 5 x 5 x 5) para efeito de comparação com o filtro de Média. Os resultados foram obtidos através da suavização das probabilidades derivadas por Bootstrap. Essa suavização implica em uma nova classificação dos recursos minerais que foram resumidos em termos de volume e teores médios na Tabela 4-14 e nas Figuras 4-24, 4-25 e 4-26, bem como nos gráficos de barras com o número total de blocos em cada classe reclassificada (Figura 4-23). 

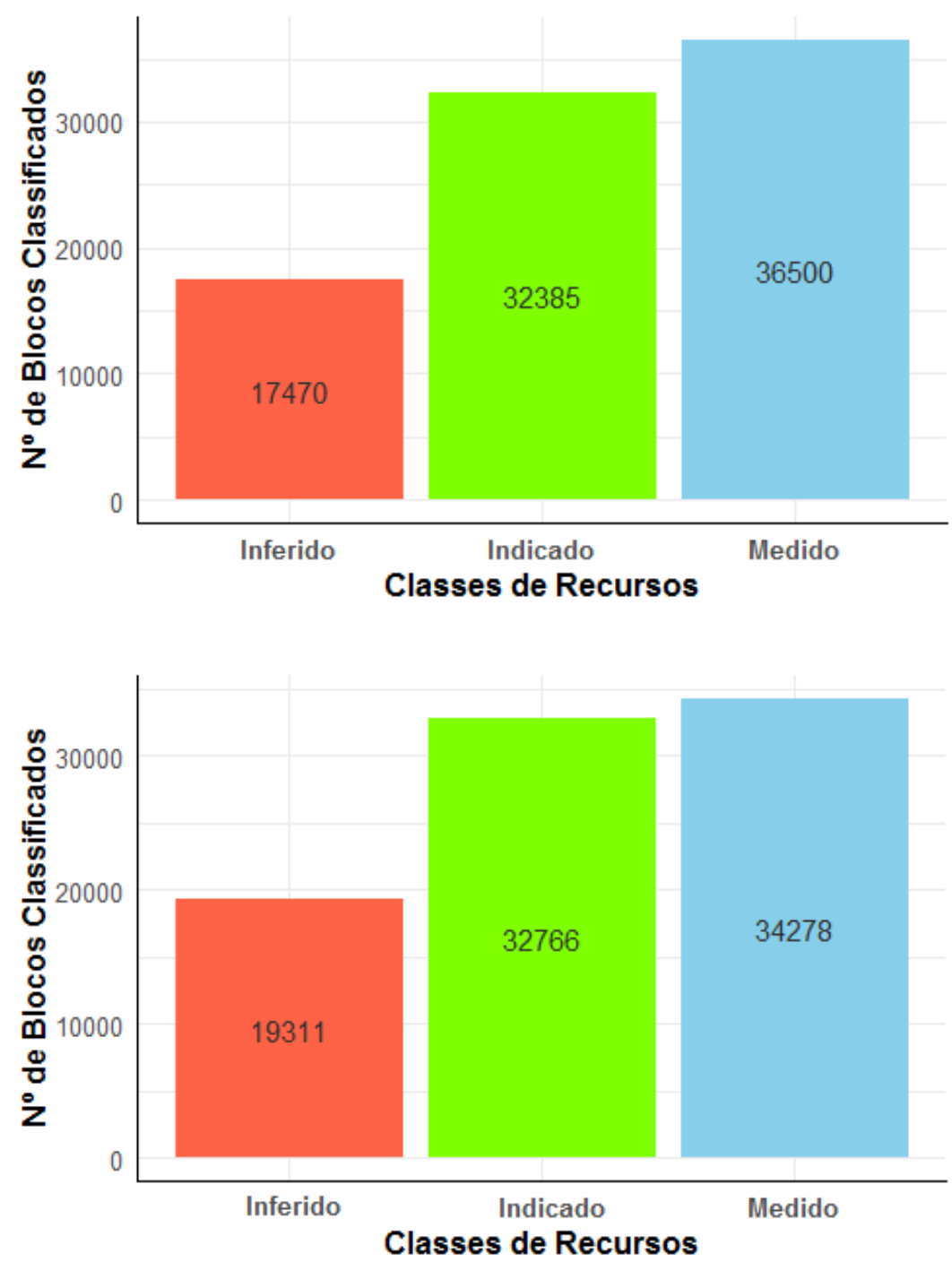

Figura 4-23. Número total de blocos quantificados para cada categoria correspondente, obtidos a partir do pós-processamento das probabilidades suavizadas pelos filtros da média (superior) e Gaussiana (inferior).

Tabela 4-14. Resultado da classificação dos recursos minerais em volume, obtidos a partir das duas técnicas de suavização.

\begin{tabular}{ccccc}
\hline Filtro & Classes & $\mathrm{N}^{\circ}$ Blocos & Volume $\left(\mathrm{cm}^{3}\right)$ & Teor médio (\%) \\
\hline \multirow{3}{*}{ Média } & Medido & 36.500 & $1.02 \mathrm{e}+14$ & 1,14 \\
& Indicado & 32.385 & $9.07 \mathrm{e}+13$ & 0,70 \\
& Inferido & 17.470 & $4.89 \mathrm{e}+13$ & 0,20 \\
\hline \multirow{3}{*}{ Gaussiano } & Medido & 34.278 & $9.60 \mathrm{e}+13$ & 1,16 \\
& Indicado & 32.766 & $9.17 \mathrm{e}+13$ & 0,73 \\
& Inferido & 19.311 & $5.41 \mathrm{e}+13$ & 0,19 \\
\hline
\end{tabular}


Observa-se nos modelos suavizados (Figuras 4-24, 4-25 e 4-26) que o filtro Gaussiano com $\sigma=1$ resulta na melhor continuidade espacial da variável $\mathrm{Cu}(\%)$, embora o recurso mineral Medido apresente menos 2.222 blocos em relação ao obtido pelo filtro médio (Figura 4-24). Apesar das quantidades dos recursos minerais mostrarem diferenças esses resultados são razoáveis de acordo com a reclassificação dado que a soma total entre os recursos minerais Medidos e Indicados para ambos os filtros é de aproximadamente 65.000 blocos. Vale ressaltar que os blocos classificados de acordo com seu grau de confiança formam um envoltório ao redor do corpo mineralizado que é o resultado desejado após a suavização. Ademais, foi calculado o coeficiente de correlação linear entre as imagens suavizadas pelo filtro de Média e Gaussiano. Assim como, a classificação não suavizada para quantificar as semelhanças entre essas imagens, cujo coeficiente de correlação de Pearson foi de aproximadamente 0.90 para ambos métodos.

Este valor confirma que as características espaciais estão bem preservadas, assim como sua distribuição estatística. No entanto, o filtro Gaussiano preserva de uma melhor forma o nível realista de confiança da estimativa geológica e de teor, pois leva em conta a quantidade, distribuição e qualidade dos dados (variável Cu (\%)) como está representado na Figura 4-24. Por esta razão, em seções posteriores o filtro Gaussiano será o único filtro aplicado na suavização das probabilidades obtidas por Bootstrap para o método de simulação geoestatística FILTERSIM. 

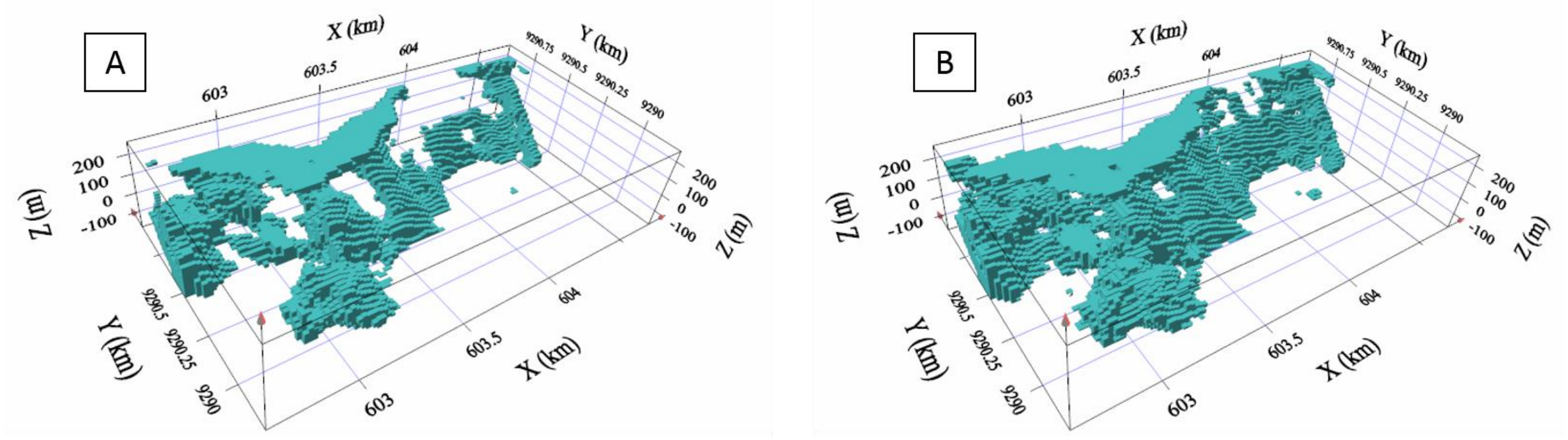

Recurso Mineral Medido

Figura 4-24. Resultado para a classe de recursos minerais Medidos obtido a partir da suavização pelo filtro médio e Gaussiano, com tamanhos de janela de homogeneização igual a 5 x 5 × 5. A Figura A e B representa o recurso mineral Medido após a aplicação do filtro médio e Gaussiano, respectivamente. 

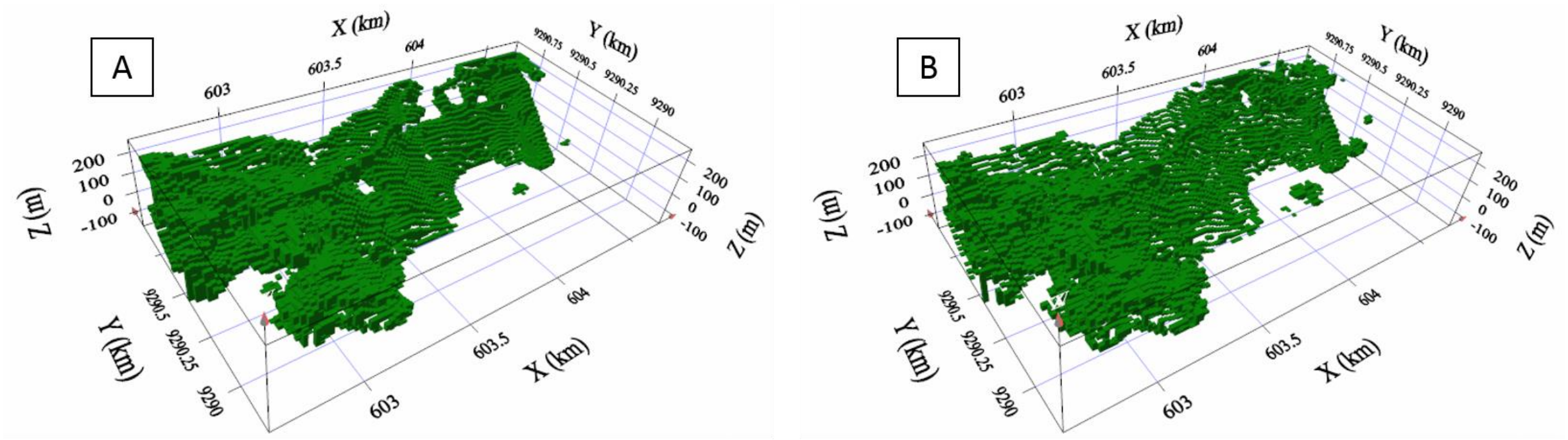

Recurso Mineral Indicado

Figura 4-25. Resultado para a classe de recursos minerais Indicados obtido a partir da suavização pelo filtro médio e Gaussiano, com tamanhos de janela de homogeneização igual a 5 × 5 × 5. A Figura A e B representa o recurso mineral Indicado após a aplicação do filtro médio e Gaussiano, respectivamente. 

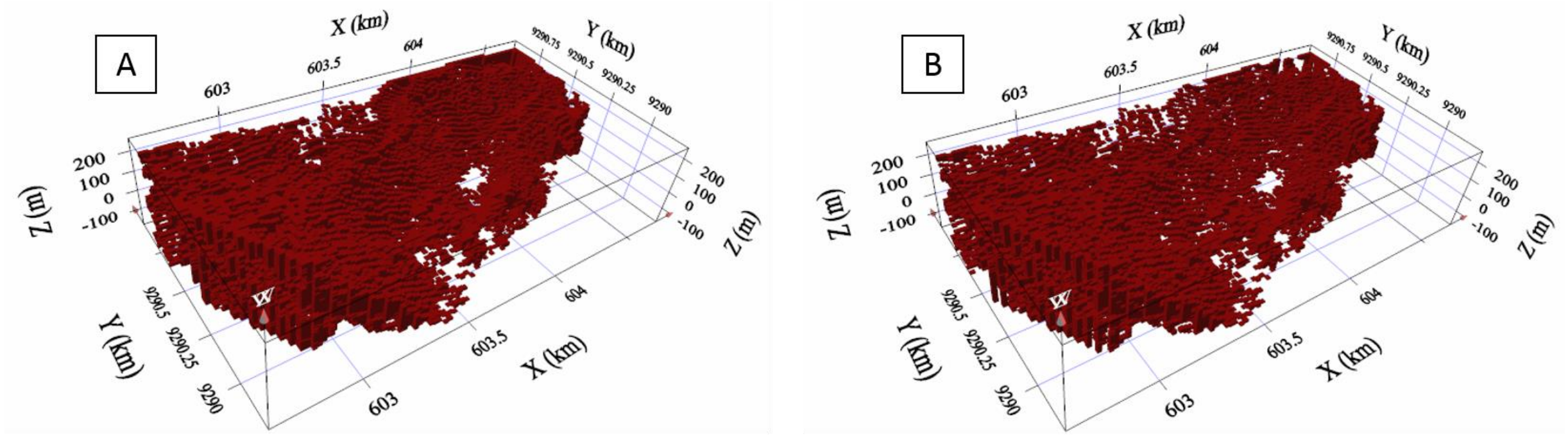

Recurso Mineral Inferido

Figura 4-26. Resultado para a classe de recursos minerais Inferidos obtido a partir da suavização pelo filtro médio e Gaussiano, com tamanhos de janela de homogeneização igual a 5 x 5 × 5. A Figura A e B representa o recurso mineral Inferido após a aplicação do filtro médio e Gaussiano, respectivamente. 


\subsection{SELEÇÃO DA IMAGEN DE TREINAMENTO}

Antes de realizar a simulação por múltiplos pontos uma imagem de treinamento deve ser selecionada. Esta seleção foi realizada de modo que o modelo conceitual represente as características geológicas espaciais da variável $\mathrm{Cu}(\%)$ no depósito mineral. Como é bem conhecido, as técnicas de estimativa/simulação que fazem uso do variograma supõem que a variável pode ser aproximada linearmente. De acordo com isso, neste trabalho a técnica de redução de dimensão e interpretação de dados ACP (Análise de Componentes Principais - seção 2.6.1) é aplicada em conjunto com o gráfico científico Bitplot (seção 2.562), uma vez que as características são linearmente separáveis.

As imagens de treinamento foram obtidas a partir dos métodos de estimativa e simulação: Krigagem Ordinário, Krigagem Ordinário Normal, Simulação Sequencial Gaussiana e a imagem média ou Etype que foi obtido das realizações estocásticas. No total foram analisadas 103 imagens de treinamento representativas da área por meio da técnica ACP e Bitplot, cujos resultados podem ser observados na Figura 4-27.

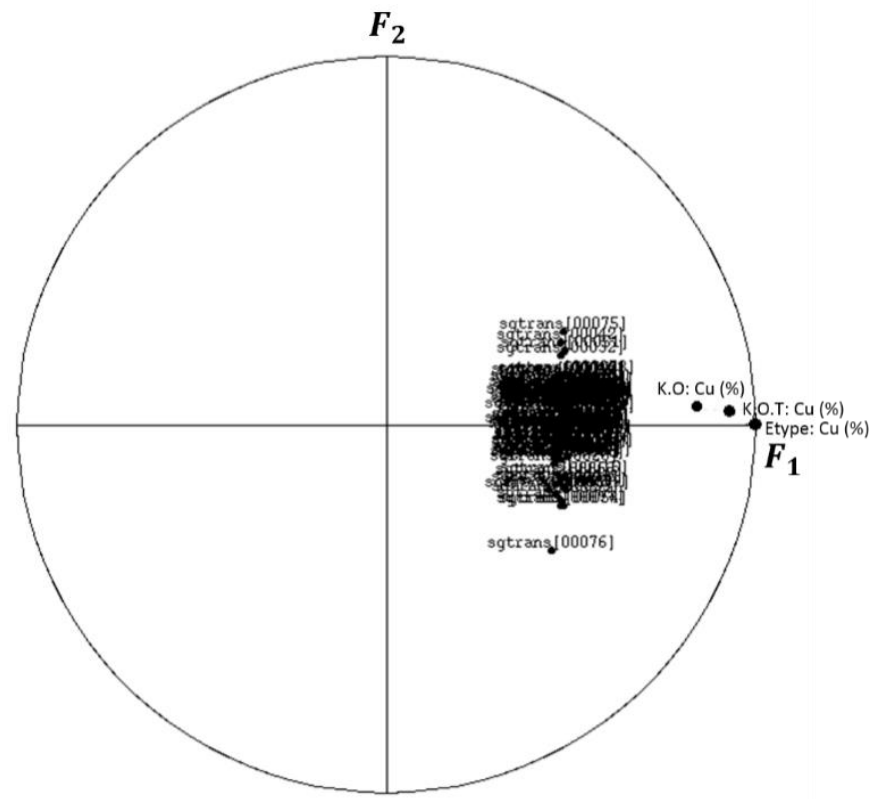

Figura 4-27. Bitplot das 103 IT no eixo de coordenadas F1 e F2. O conjunto de pontos agrupados corresponde às realizações igualmente prováveis da simulação SGS (chamadas sgtrans); K.O: $\mathrm{Cu}(\%)$ é o IT obtido pelo Krigagem Ordinário; K.O.T: $\mathrm{Cu}(\%)$ é o IT obtido pelo Krigagem Ordinário Transformado da variável normal (nscore); Etype: $\mathrm{Cu}$ (\%) é a imagem de treinamento derivada das 100 realizações estocásticas da SGS. 
A Figura 4-27 é formada por dois eixos não ortogonais, $F_{1}$ e $F_{2}$ que totalizam cerca de 30\% da variância explicada pelas 103 imagens de treinamento. Além disso, pode-se observar que as realizações estocásticas como esperado estão a uma distância menor do que as imagens de treinamento próximas ao eixo F1; o que indica que seus padrões de resposta são muito semelhantes entre si. Apesar disso, as imagens de treinamento não contêm todas as características espaciais necessárias da variável de estudo $\mathrm{Cu}(\%)$. Por outro lado, as imagens obtidas por K.O, K.O.T e Etype de acordo com a Figura 4-27, são as imagens de treinamento que estão bem representadas no mapa de fatores. No entanto, a imagem que melhor representa o fenômeno em estudo é o Etype, pois é a mais distante da origem. Ademais, o ângulo formado pelo seu vetor direção e o eixo da F1 é menor. Assim, a TI selecionada a partir da análise dos componentes principais é a média das realizações da simulação do SGS.

\subsection{SIMULAÇÃO GEOESTATISTICA DE MULTIPLOS PONTOS}

Antes de executar as simulações usando FILTERSIM um tamanho de modelo de busca deve ser definido (item 2.4.2) de modo que as características presentes na imagem de treinamento possam ser eficientemente mapeadas e reproduzidas no modelo de saída. Conforme apresentado no item 2.4.3, a seleção de um template "ótimo" para um depósito mineral tridimensional é feita através da aplicação do código do Quadro 2-1 para todos os planos horizontais (XY) e verticais (XZ). Os resultados são ilustrados em gráficos de barras na Figura 4-28. Analisando está figura definiu-se que o tamanho ideal do modelo de busca é 21 x 21 x 17, isto é, os valores mais frequentes.

Uma vez definida a janela de busca dos padrões estruturais da imagem de treinamento, procede-se a simulação de múltiplos pontos FILTERSIM disponível no programa SGeMS que gerou 100 simulações igualmente prováveis do fenômeno espacial. Além disso, os blocos simulados foram localizados dentro do volume ocupado, derivado do número total de amostras conhecido como corpo geométrico Figura 3-1 e Tabela 3-2. Os parâmetros utilizados no processo de simulação são apresentados na Tabela 4-15. 

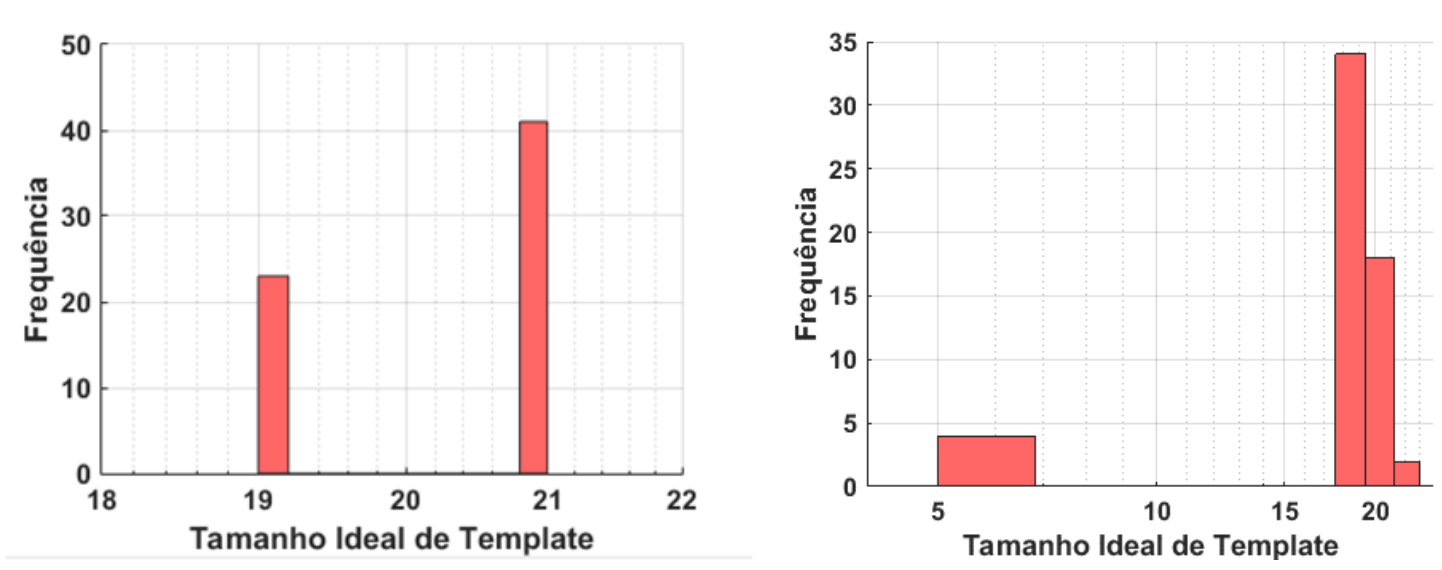

Figura 4-28. Seleção ideal do modelo. Os diagramas de barras dos planos XY e XZ, respectivamente, são mostrados à esquerda e à direita. FILTERSIM.

Tabela 4-15. Parâmetros estratégicos para a simulação de múltiplos pontos Parâmetros FILTERSIM

\begin{tabular}{lc}
\hline Tamanho do Template de Busca (m) & $21 \times 21 \times 17$ \\
Dimensiones do Template Interno (m) & $11 \times 11 \times 5$ \\
Número de Multiple grid & 3 \\
Pesos (Dados, Congelados e Outros) & 0.70 .20 .1 \\
Máximo Número de Agrupamentos & 800 \\
Partições Secundaria & 2 \\
Pixels do Template & Sim \\
Filtros & Não \\
N $^{o}$ Semente para FILTERSIM $\quad$ (default, & 211175 \\
SGeMS) & \\
\hline
\end{tabular}

É importante citar que o número de agrupamentos igual a 800 foi considerado ideal. Os pesos para os diferentes tipos de informações foram selecionados de modo que os dados amostrados regularizados tiveram maior peso e os dados previamente simulados apresentaram uma menor influência dentro da simulação. Os resultados são ilustrados pela imagem média e desvio padrão obtidos das 100 simulações estocásticas (Figura 4-29 e 4-30) e as estatísticas descritivas estão apresentados na Tabela 4-16. De acordo com as estatísticas de resumo do Etype e os valores originais normalizados (Tabela 4-2), bem como aqueles simulados pela SGS (Tabela 4-9), observa-se pequenas diferenças não significativas. Em geral, as características das distribuições são semelhantes como por exemplo a assimetria positiva (como evidenciado pelo histograma da imagem do tipo Etype na Figura 4-31). Aliás, a Figura 4-32 ilustra o 
histograma do desvio padrão derivado das 100 realizações estocásticas por FILTERSIM.

Tabela 4-16. Estatística descritiva da média das realizações estocásticas (Etype) para a variável $\mathrm{Cu}(\%)$.

\begin{tabular}{ccccccc}
\hline Mínimo & $1^{\circ}$ Quartil & Mediana & Média & $3^{\circ}$ Quartil & Máximo & $\begin{array}{c}\text { Desvio } \\
\text { Padrão }\end{array}$ \\
\hline 0,02 & 0,11 & 0,24 & 0,39 & 0,50 & 24,37 & 0,45 \\
\hline
\end{tabular}

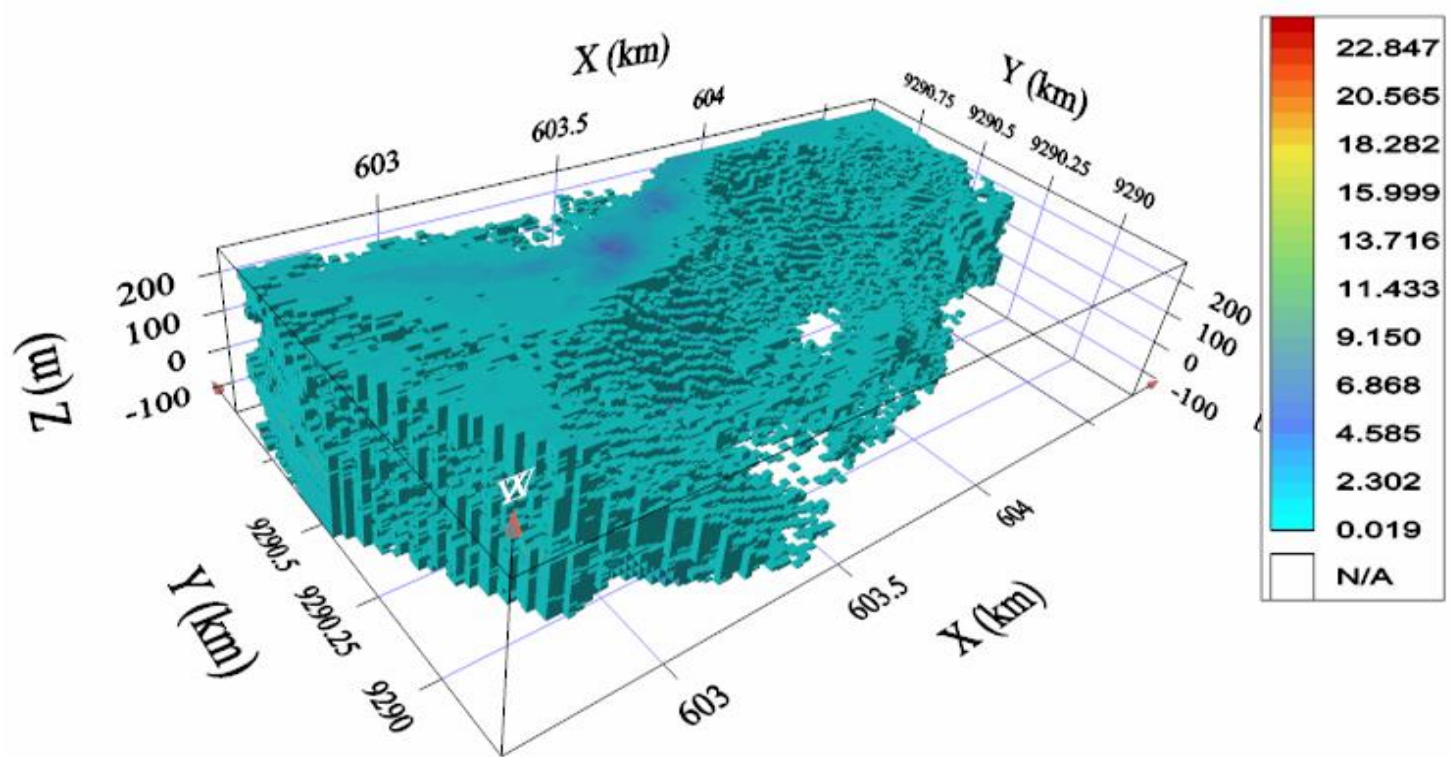

Figura 4-29. Etype das 100 realizações geoestatísticas geradas por FILTERSIM da variável $\mathrm{Cu}(\%)$. Ilustrando-se unicamente os valores acima do teor de corte $0,33 \%$.

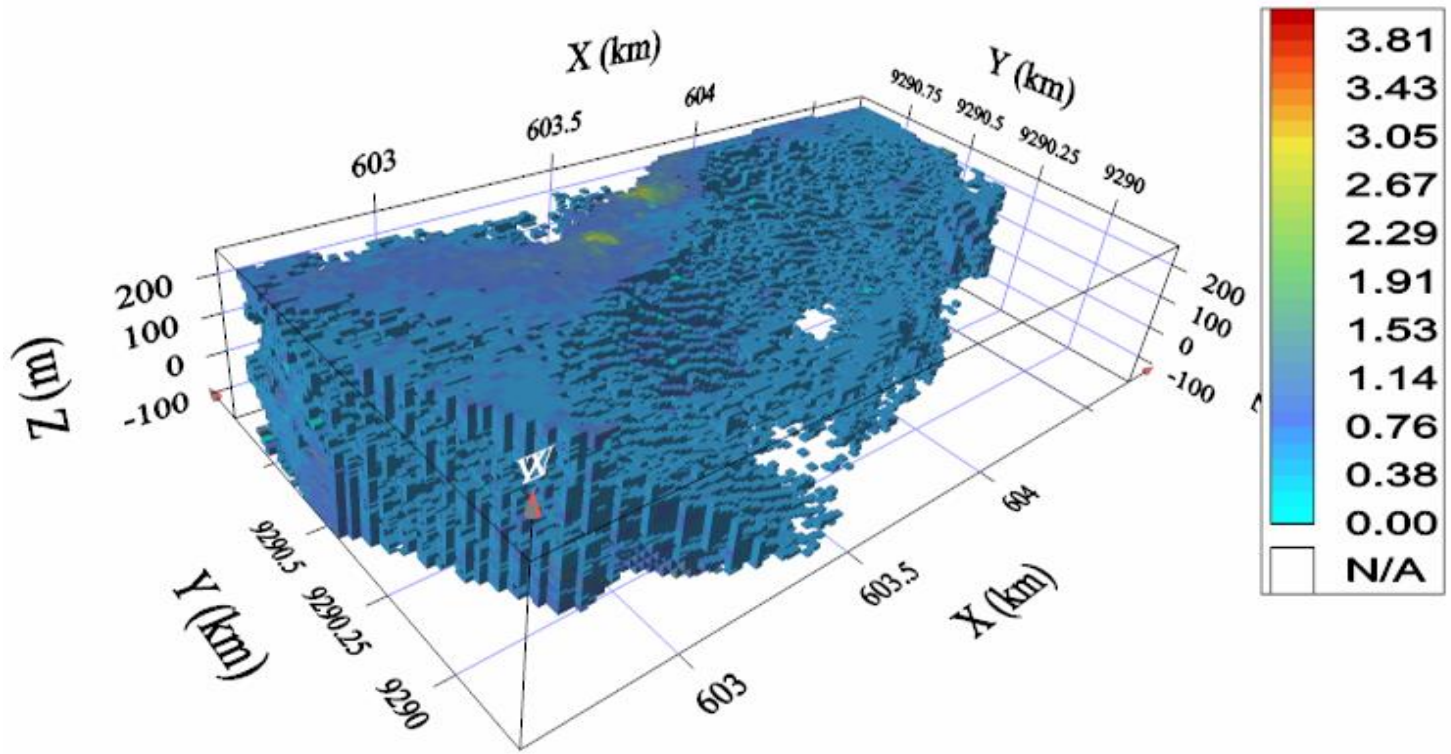

Figura 4-30. Desvio padrão das 100 realizações geoestatísticas geradas por FILTERSIM da variável $\mathrm{Cu}(\%)$. Ilustrando-se unicamente os valores acima do valor de corte $0,33 \%$. 


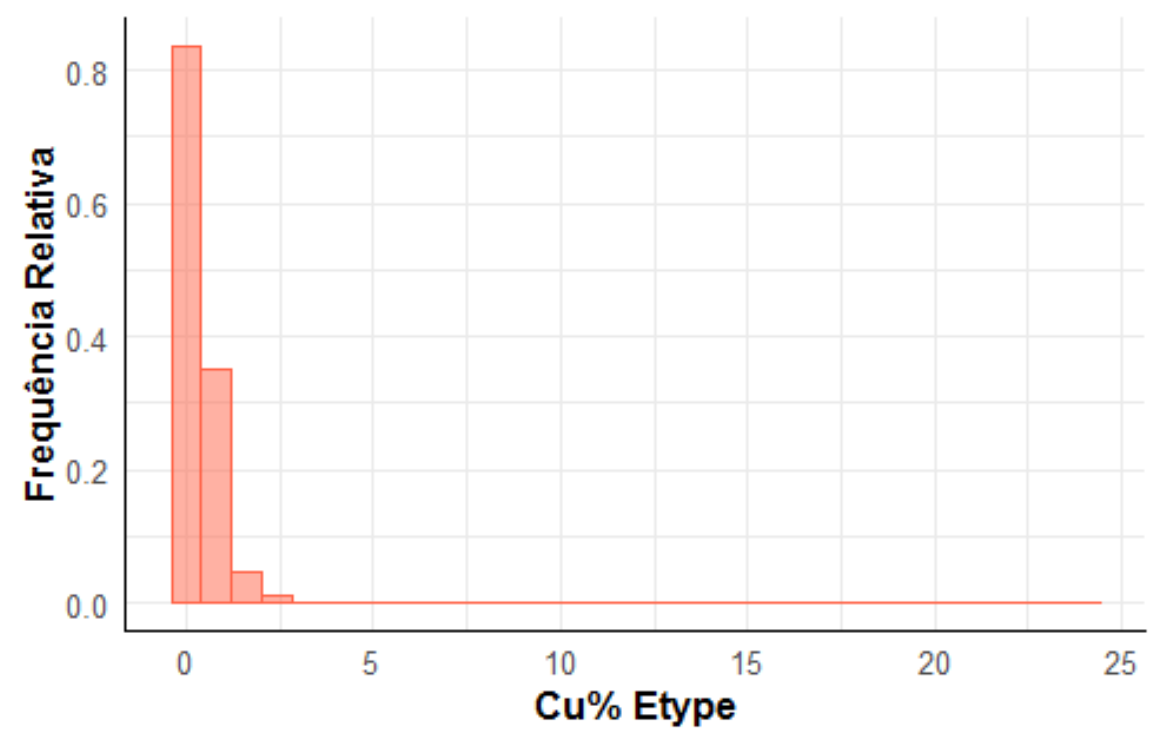

Figura 4-31. Histograma da média das realizações da variável $\mathrm{Cu}(\%)$.

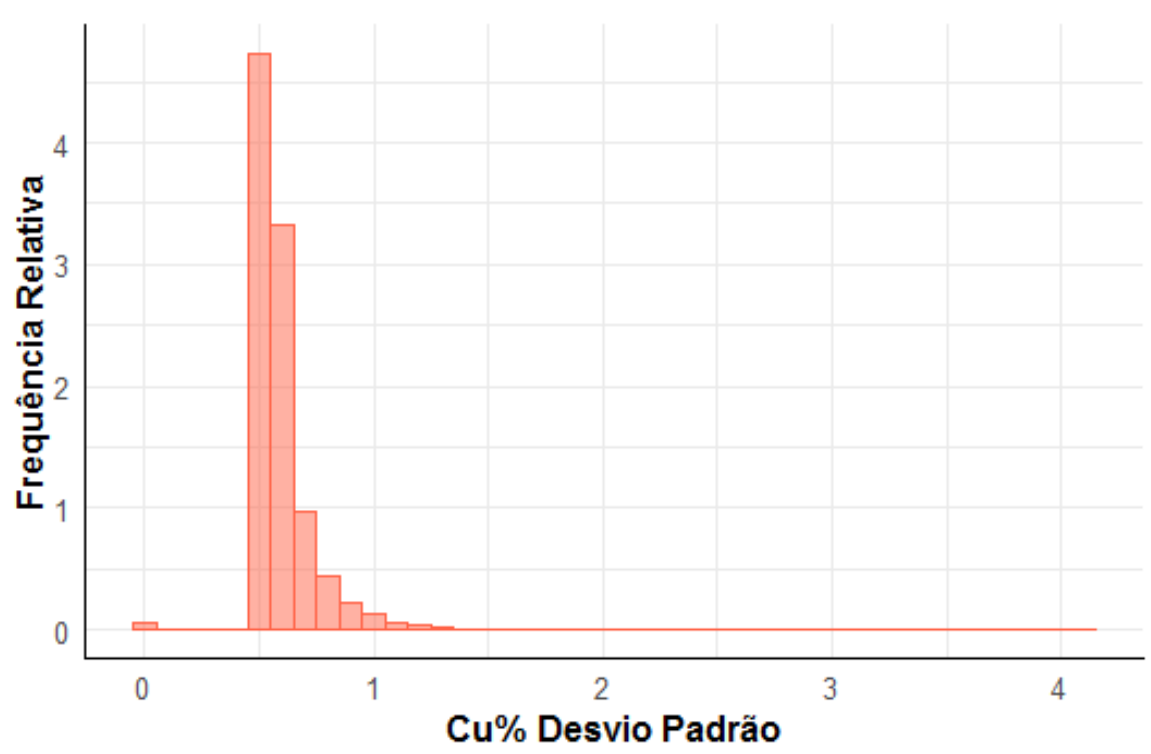

Figura 4-32. Histograma do desvio padrão condicional das 100 realizações estocásticas por FILTERSIM. 


\subsection{CLASSIFICAÇÃO DOS RECURSOS MINERAIS REALIZADO A PARTIR DO FILTERSIM}

A classificação dos recursos minerais a partir dos resultados da simulação por FILTERSIM é feita utilizando a média e o desvio padrão de cada bloco dentro do modelo (Figuras 4-29 e 4-30) fazendo uso da expressão (3. 1). Nota-se que a classificação dos recursos minerais através da probabilidade pontual ocorre apenas para as unidades com teor de corte maior que $0,33 \%$ de cobre.

O número de blocos além do volume e o teor médio para cada classe de recursos minerais estão apresentados na Tabela 4-17 e o diagrama de barras na Figura 4-34. Já os modelos de blocos com suas respectivas distribuições espaciais das classes estão representadas na Figura 4-33. No total 86.355 blocos foram estimados e classificados.

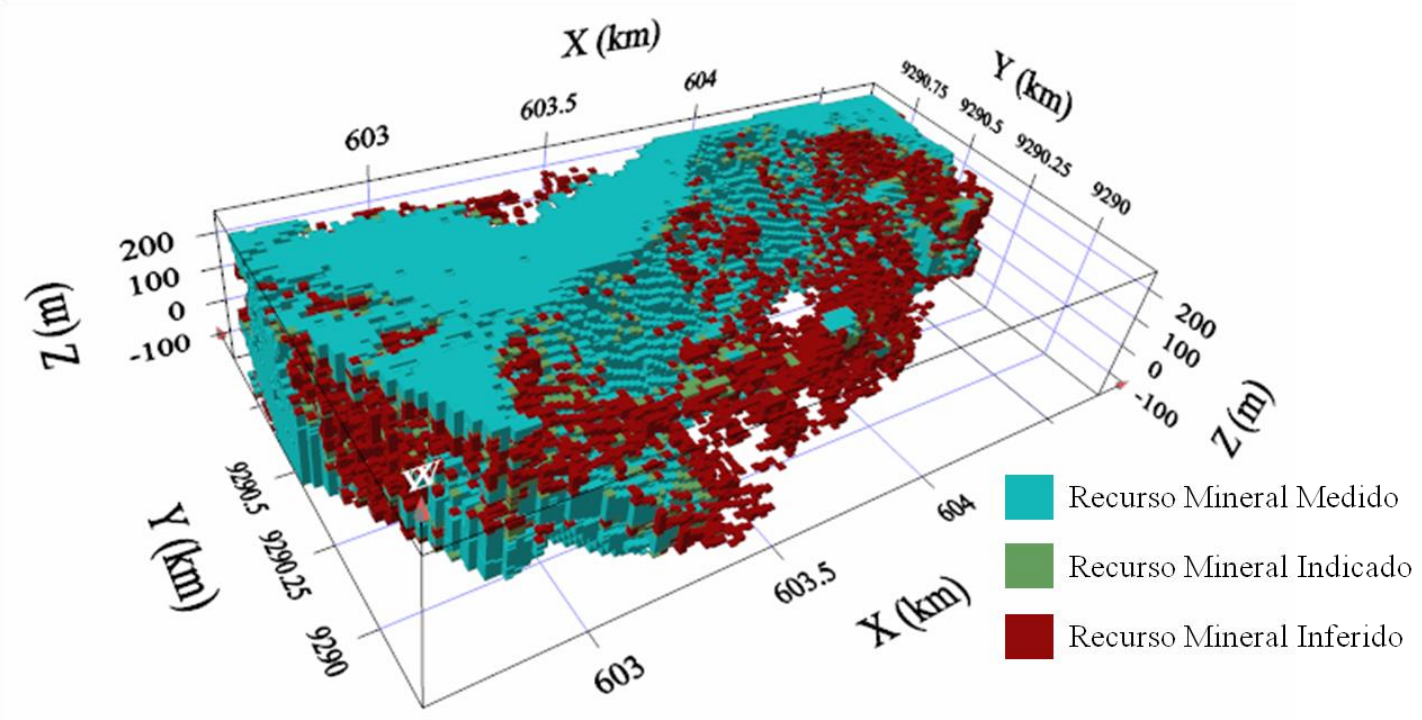

Figura 4-33. Modelo de bloco resultante da classificação dos recursos minerais estimado, pelo critério de classificação probabilidade pontual.

Tabela 4-17. Resultado da classificação de recursos minerais.

\begin{tabular}{cccc}
\hline Classes & № Blocos & Volume $\left(\mathrm{cm}^{3}\right)$ & Teor médio (\%) \\
\hline Medido & 72.879 & $2.04 \mathrm{e}+14$ & 0,88 \\
Indicado & 3.234 & $9.05 \mathrm{e}+12$ & 0,37 \\
Inferido & 10.242 & $2.87 \mathrm{e}+13$ & 0,29 \\
\hline
\end{tabular}




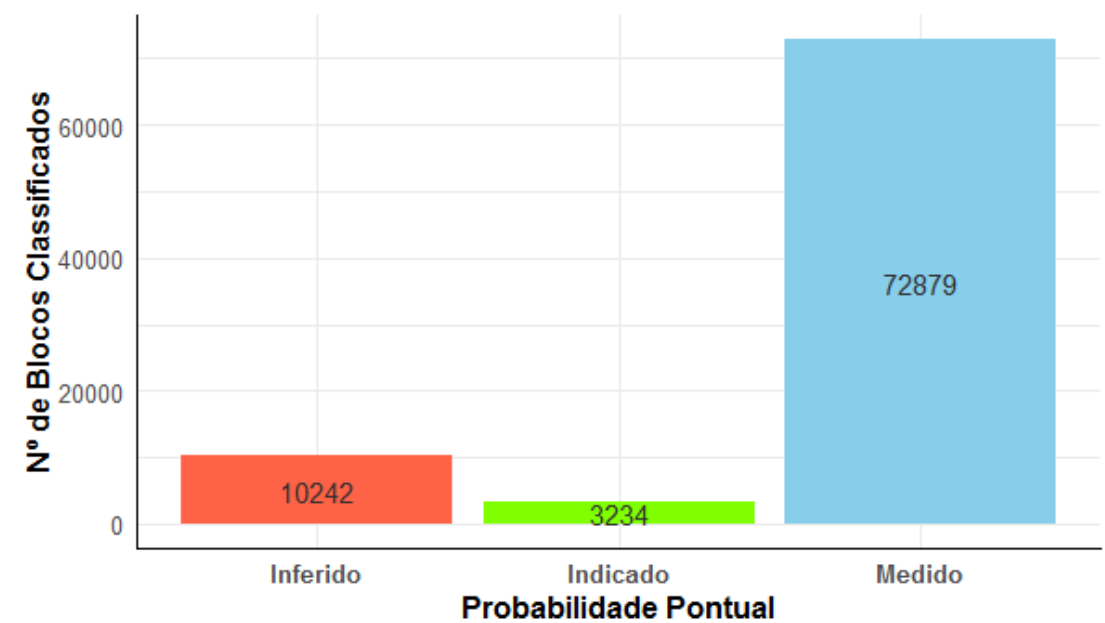

Figura 4-34. Número total de blocos quantificados para cada correspondente categoria calculado a partir da probabilidade pontual.

Na Figura 4-29 e 4-30 observa-se um efeito de homogeneização devido principalmente à dimensão do tamanho do template interno ou Inner Patch (Tabela 415). Este efeito é refletido na diminuição da classe de recursos minerais Indicado, o que implica um aumento no recurso mineral Medido e Inferido. Isso ocorre, pois, os padrões estruturais são colados e congelados no modelo de blocos, o qual implica que os valores não são simulados durante seu respectivo caminho aleatório, ou seja, sua aleatoriedade é levemente afetada.

O tamanho do modelo interno foi selecionado de forma que a média das realizações estocásticas, bem como sua estatística descritiva, honre as características de distribuição da variável $\mathrm{Cu}(\%)$. Mesmo que esse efeito cause um impacto negativo dos resultados da classificação dos recursos minerais. Aliás, os recursos minerais Indicados e Inferidos distribuem-se em torno dos recursos minerais Medidos, como consequência da falta de aleatoriedade afetada pelo uso e tamanho do template interno, vêr Figura 433 e Tabela 4-17. Afinal, os recursos minerais são classificados de acordo com seu grau de confiabilidade. 


\subsection{RECLASSIFICAÇÃO POR BOOTSTRAP}

Os resultados da reclassificação obtidos por Bootstrap são apresentados na Figura 4-35 e na Tabela 4-18, o qual mostra os novos teores e volumes calculados para cada classe. A Figura 4-35 mostra pequenas mudanças nas classes de recursos minerais que foram inicialmente obtidas através do critério de probabilidade pontual. Assim como uma zona de contato formada em torno do recurso mineral Medido que é composto pelos recursos Indicados e Inferidos.

Observa-se na Figura 4-35 que não há mudanças significativas na distribuição espacial das classes, o que também é confirmado nas estatísticas descritivas dos recursos minerais antes e após a reclassificação (Tabela 4-19). Além disso, as estatísticas de resumo validam os resultados obtidos pelos critérios de classificação utilizando a probabilidade pontual, uma vez que as medianas dos recursos minerais antes e após a classificação e reclassificação, diminuem de acordo com o grau de confiabilidade das classes. em volume.

Tabela 4-18. Resultado da reclassificação de recursos minerais, através de Bootstrap,

\begin{tabular}{cccc}
\hline Classes & $\mathrm{N}^{\mathrm{o}}$ Blocos & Volume $\left(\mathrm{cm}^{3}\right)$ & Teor médio (\%) \\
\hline Medido & 77.730 & $2.18 \mathrm{e}+14$ & 0,84 \\
Indicado & 1.925 & $5.39 \mathrm{e}+12$ & 0,34 \\
Inferido & 6.700 & $1.88 \mathrm{e}+13$ & 0,27 \\
\hline
\end{tabular}

Neste sentido, as médias obtidas para os recursos minerais (Tabela 4-19) confirmam que o uso de um método de reclassificação é necessário, pois permite a captura da variabilidade local obtidas da estimativa de uma função aleatória caracterizada por uma distribuição assimétrica positiva ou negativa. Afinal o estimador da média é um estimador não robusto, apesar de ser um estimador não-viesado. 
Tabela 4-19. Estatísticas descritivas de recursos minerais classificados e reclassificados, por probabilidade pontual e Bootstrap, respectivamente.

\begin{tabular}{cccccccc}
\hline & Mínimo & $1^{\circ}$ Quartil & Mediana & Média & $3^{\circ}$ Quartil & Máximo & $\begin{array}{c}\text { Desvio } \\
\text { Padrão }\end{array}$ \\
\hline $\begin{array}{c}\text { Medido } \\
\text { (Classificado) }\end{array}$ & 0,38 & 0,54 & 0,72 & 0,88 & 1,02 & 24,37 & 0,58 \\
$\begin{array}{c}\text { Medido } \\
(\text { Reclassificado) }\end{array}$ & 0,33 & 0,51 & 0,69 & 0,84 & 0,99 & 24,37 & 0,58 \\
$\begin{array}{c}\text { Indicado } \\
\text { (Classificado) }\end{array}$ & 0,36 & 0,38 & 0,37 & 0,37 & 0,38 & 0,43 & 0,01 \\
$\begin{array}{c}\text { Indicado } \\
\text { (Reclassificado) }\end{array}$ & 0,31 & 0,33 & 0,33 & 0,34 & 0,34 & 0,43 & 0,01 \\
$\begin{array}{c}\text { Inferido } \\
\text { (Classificado) }\end{array}$ & 0,12 & 0,26 & 0,30 & 0,29 & 0,33 & 0,37 & 0,05 \\
$\begin{array}{c}\text { Inferido } \\
\text { (Reclassificado) }\end{array}$ & 0,11 & 0,24 & 0,28 & 0,27 & 0,30 & 0,33 & 0,04 \\
\hline
\end{tabular}



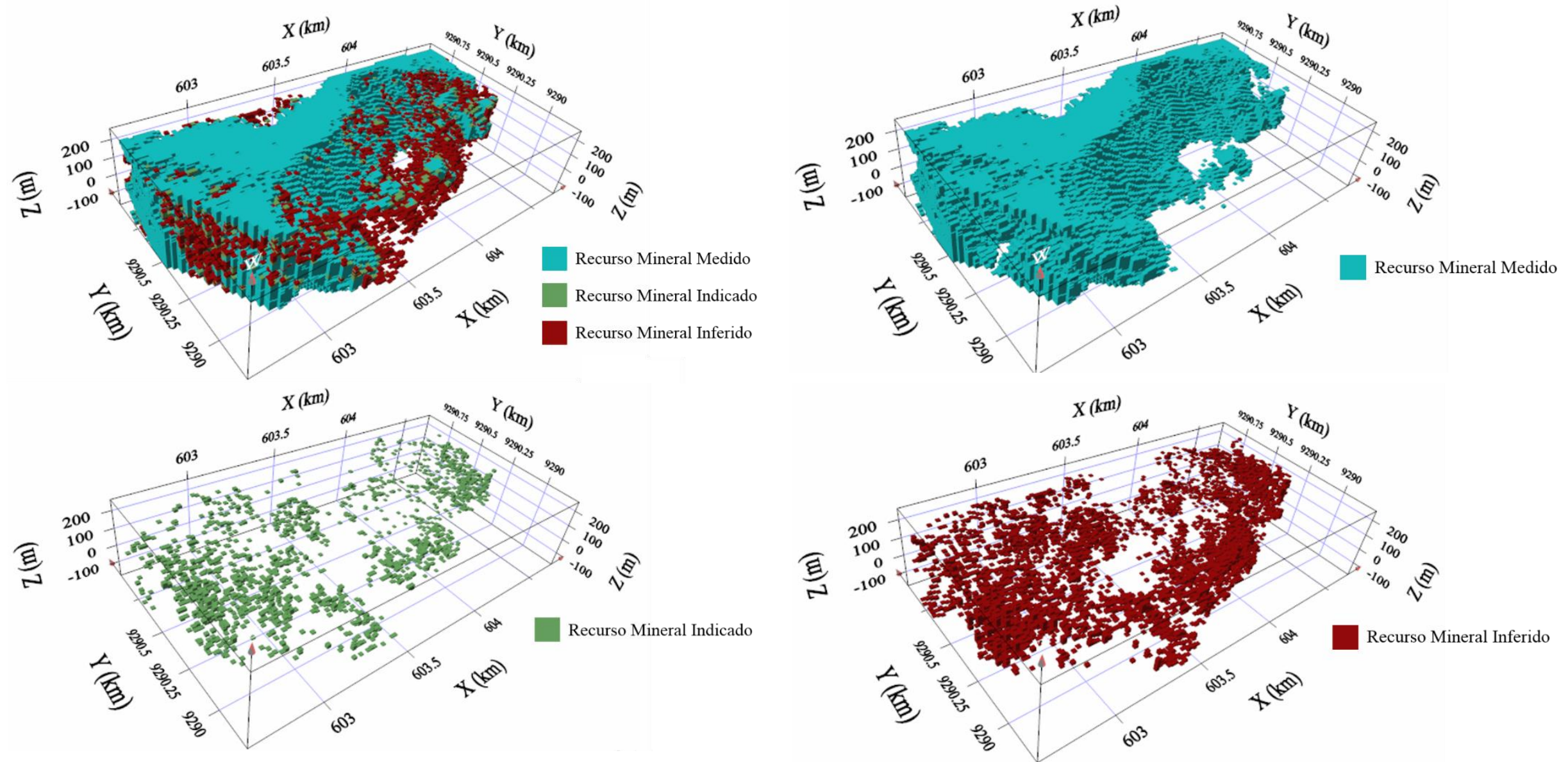

Figura 4-35. Modelos de blocos resultantes da reclassificação dos recursos minerais estimados por Bootstrap. 
Outro resultado a ser destacado pela reclassificação de recursos minerais é o aumento significativo na classe dos recursos Medidos. No entanto, os recursos minerais Indicados e Inferidos resultantes do forte efeito da homogeneização herdado dos recursos estimados foi causado pelo tamanho interno do modelo. No entanto, esse efeito é parcialmente corrigido pela técnica de filtragem Gaussiana como será relatado na próxima seção. A Figura 4-36 ilustra o número total de blocos para cada classe de recurso mineral.

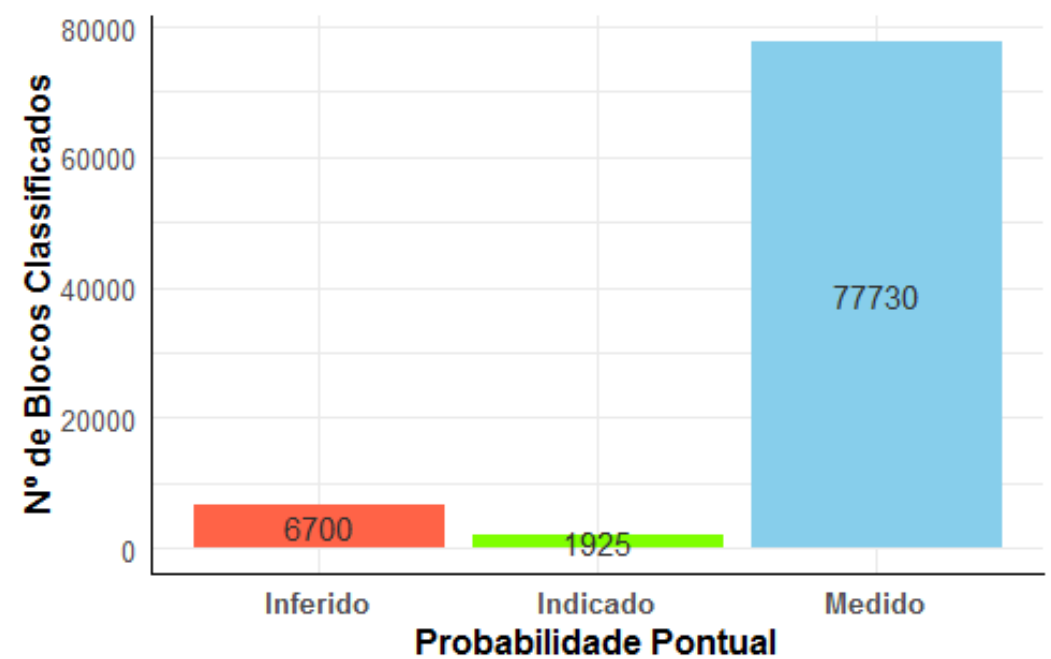

Figura 4-36. Número total de metais quantificados para cada correspondente categoria obtidos a partir da reclassificação por Bootstrap.

\subsection{FILTRO GAUSSIANO}

O filtro Gaussiano é o filtro linear mais adequado na conservação das características do fenômeno espacial: continuidade, conectividade e homogeneização espacial das classes, assim como a diluição dos "spotted dog". Vale citar que a técnica FILTERSIM causa um efeito de homogeneização da variável $\mathrm{Cu}(\%)$, no entanto, o filtro Gaussiano consegue corrigir parcialmente o efeito nas classes de recursos minerais (Figura 4-35). Essa correção é feita com relação à identificação de mais unidades dentro do modelo de blocos que devem ser classificadas como recursos minerais Indicados. Além disso, o recurso envolve o mineral Medido como desejado.

De acordo com os resultados anteriores (seção 4.16) a técnica de reclassificação Bootstrap não apresenta mudanças significativas, pois apresenta uma baixa 
variabilidade dos blocos causada pelo efeito de homogeneização. Por outro lado, a aplicação do filtro linear Gaussiano ao conjunto de probabilidades obtidas por Bootstrap deve ser feita para um sigma "ótimo" (Figura 4-37) e consequentemente um tamanho de janela de homogeneização ideal (calculado como $2 * \operatorname{ceil}(2 * \operatorname{sigma})+1)$.

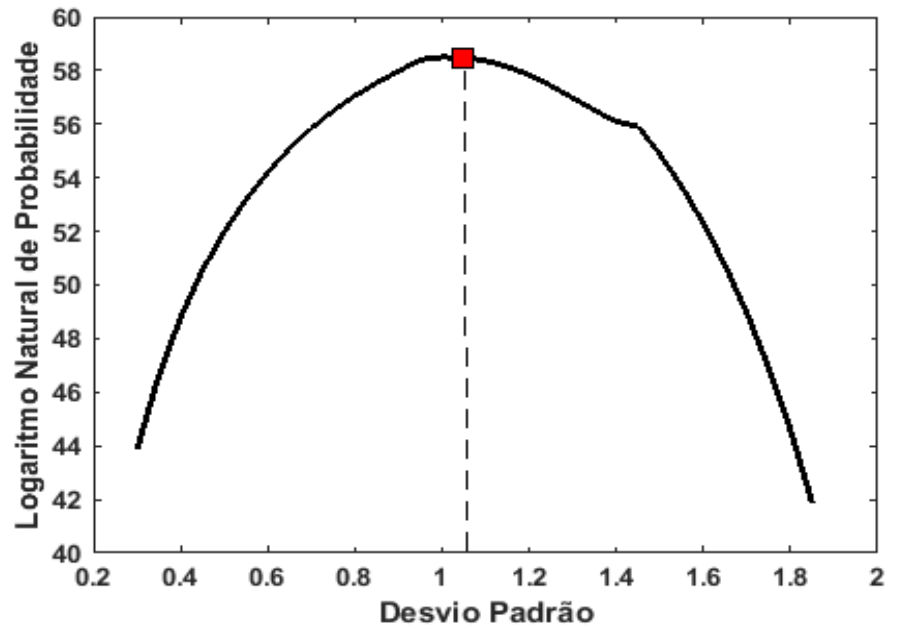

Figura 4-37. Logaritmo natural da função de probabilidade com valor "ótimo" de desvio padrão igual a 1,05 .

A Figura 4-37 ilustra o resultado da máxima verossimilhança log-normal na seleção de um sigma ideal, isto é, $\sigma=1,05$ e consequentemente o tamanho da janela de homogeneização ótima 7 x 7 x 7 . A suavização implica uma nova classificação dos recursos minerais que são resumidos em termos de volume na Tabela 4-20, assim como seus diagramas de barras com o número de blocos para cada nova classe (Figura 4-38) e por fim, os modelos tridimensionais de blocos (Figura 4-39).

Tabela 4-20. Resultado da classificação dos recursos minerais em volume, obtidos a partir do filtro Gaussiano.

\begin{tabular}{cccc}
\hline Classes & $\mathrm{N}^{\mathrm{o}}$ Blocos & Volume $\left(\mathrm{cm}^{3}\right)$ & Teor médio (\%) \\
\hline Medido & 58.726 & $1.64 \mathrm{e}+14$ & 0,96 \\
Indicado & 9.395 & $2.63 \mathrm{e}+13$ & 0,53 \\
Inferido & 18.234 & $5.10 \mathrm{e}+13$ & 0,37 \\
\hline
\end{tabular}




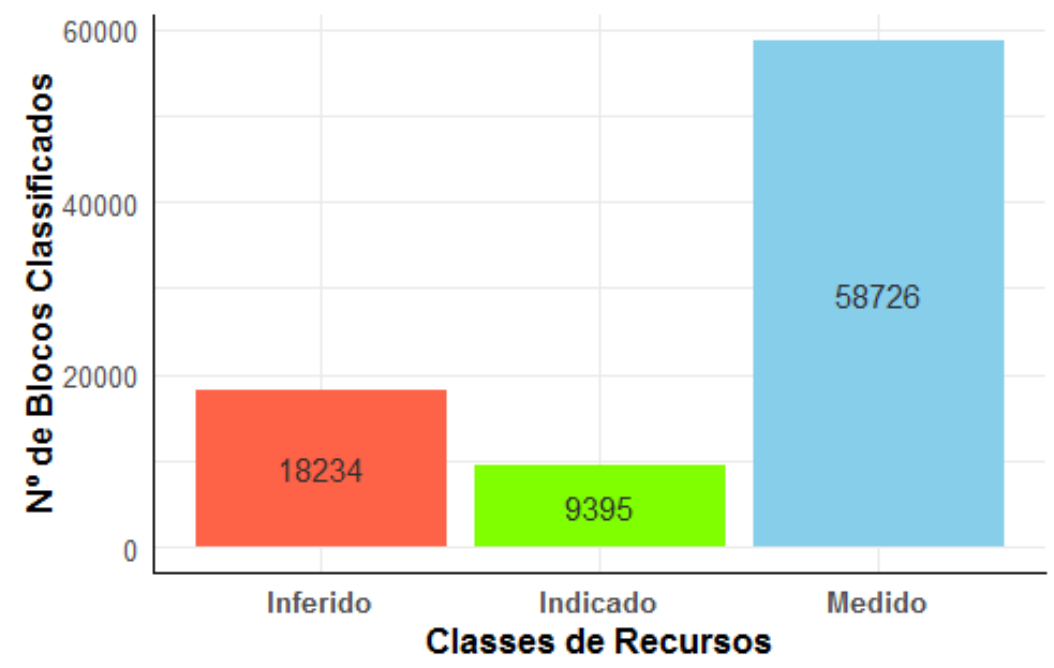

Figura 4-38. Número total de metais quantificados para cada correspondente categoria, obtidos a partir do pós-processamento das probabilidades suavizadas pelo filtro Gaussiano.

Embora a quantidade de recursos minerais revele algumas diferenças, esses resultados são razoáveis de acordo com a reclassificação, uma vez que a soma total entre os recursos minerais Medidos e Indicados é de aproximadamente 65.000 blocos. Ademais, é importante destacar dois pontos: (1) a correção parcial da homogeneização hereditária nas classes de recursos minerais e (2) os blocos classificados de acordo com seu grau de confiança, formando um envoltório ao redor do corpo mineralizado que é o resultado desejado após a suavização.

Por outro lado, foi calculado o coeficiente de correlação linear entre a imagem suavizada pelo filtro Gaussiano e a imagem não suavizada para quantificar as similaridades entre essas duas imagens, cujo coeficiente de correlação de Pearson foi de aproximadamente 0,90. Esse valor confirma que as características espaciais estão bem preservadas, assim como sua distribuição estatística. 

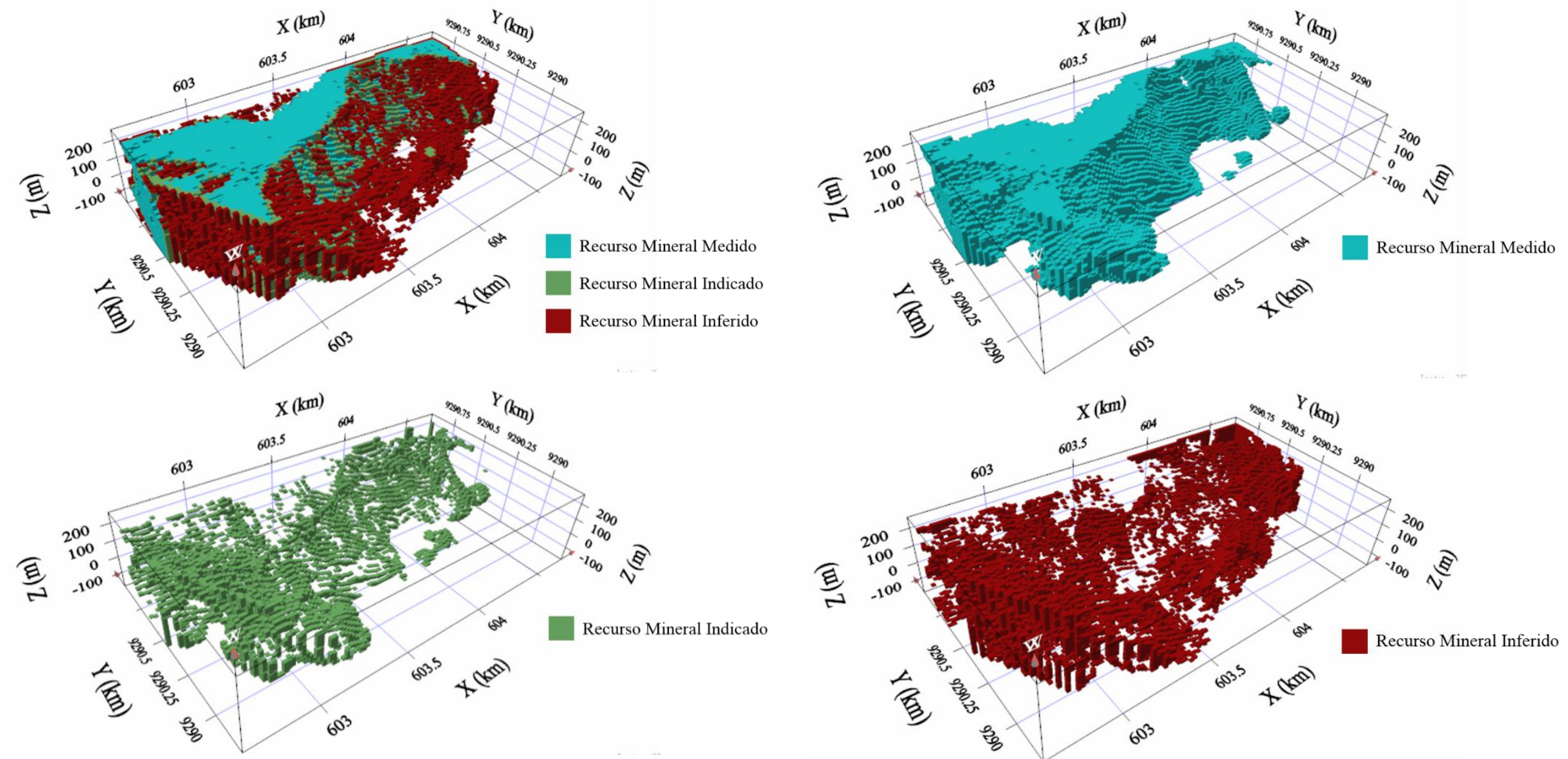

Figura 4-39. Modelos de blocos resultante da classificação dos recursos minerais estimada pelo critério de classificação probabilidade pontual, após a homogeneização das probabilidades máximas obtidas por Bootstrap. 


\subsection{ANÁLISE DE SENSIBILIDADE POR DECOMPOSIÇÃO DA VARIÂNCIA}

Como evidenciado nos métodos que fazem uso da estatística de dois pontos a estimativa e classificação dos recursos minerais de acordo com seu grau de confiabilidade em Medido, Indicado ou Inferido, dependem explicitamente da principal ferramenta da geoestatística, isto é, o variograma e o modelo matemático que descrevem a variabilidade espacial do depósito mineralizado em estudo. O uso destas técnicas geoestatísticas são baseadas em parâmetros matemáticos (ajuste teórico do variograma) que por razões diferentes como falta de tempo ou informações não são adequadamente testados (Revuelta, 2018; Annels, 1991). Neste aspecto, este trabalho faz uso da análise de sensibilidade por decomposição da variância dos parâmetros de ajuste como o efeito pepita, amplitude e contribuição espacial, cuja função objetivo é a média da função aleatória dentro da fronteira convexa (Figura 3-2).

A análise de sensibilidade tem início a partir da reamostragem do conjunto de dados originais. A reamostragem tem como objetivo recriar vários cenários possíveis para avaliar as diferentes influências dos parâmetros em estudo, de acordo com o tamanho da amostra. Os volumes foram calculados para cada novo conjunto de amostras, utilizando a técnica de contorno convexo tridimensional. As estatísticas de resumo são ilustradas na Tabela 4-21 e o histograma das novas amostras na Figura 4-40.

A estatística descritiva e o histograma mostram que o aumento no número de amostras leva à melhor aproximação do volume real do depósito. Além disso, pode ser visto no histograma que apesar de 50 sondagens serem poucas em comparação ao conjunto total 257 perfurações, essas possíveis configurações em alguns casos se aproximam do volume total.

Tabela 4-21. Estatísticas de resumo do conjunto total de volumes obtidos por reamostragem aleatória estratificada $(55,110,165$ e 220$)$.

\begin{tabular}{c|cccccc}
\hline \multirow{3}{*}{$\begin{array}{c}\text { Reamostragem } \\
\text { Total }\end{array}$} & Mínimo & $1^{\circ}$ Quartil & Mediana & Média & $3^{\circ}$ Quartil & Máximo \\
\cline { 2 - 6 } & $1.69 \mathrm{e}+8$ & $2.91 \mathrm{e}+8$ & $3.48 \mathrm{e}+8$ & $3.36 \mathrm{e}+8$ & $3.86 \mathrm{e}+8$ & $4.23 \mathrm{e}+8$ \\
\hline
\end{tabular}




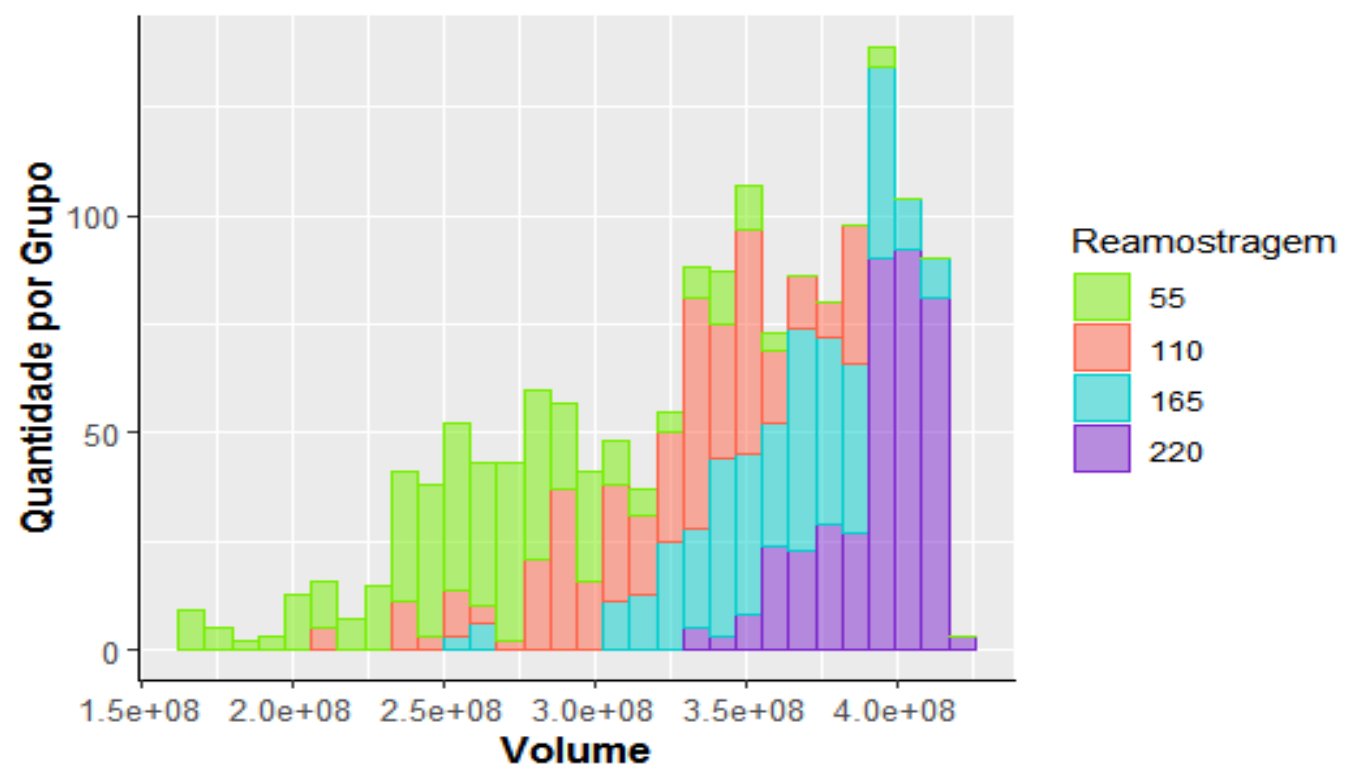
220).

Figura 4-40. Histograma do volume por grupos para cada nova amostra $(55,110,165 \mathrm{e}$

Após a criação dos subconjuntos das 385 novas amostras, procedeu-se ao cálculo dos variogramas experimentais e ao ajuste automático dos mesmos, a fim de se obter a distribuição empírica para cada parâmetro. Os variogramas experimentais para cada conjunto foram calculados em duas direções ortogonais: $160^{\circ} / 45^{\circ}$ e $160 \%-45^{\circ}$. Os parâmetros utilizados para o cálculo dos variogramas experimentais são apresentados na Tabela 4-22. Os resultados derivados do ajuste automático foram resumidos pelas estatísticas descritivas representadas na Tabela 4-23 além de suas distribuições características ilustradas nos histogramas 4-41 até 4-45.

Tabela 4-22. Parâmetros de cálculo do variograma experimental para cada conjunto respectivo de novas amostras. Dir $=$ Direção, Tol Ang $=$ Tolerância Angular, Passo Tol $=$ Tolerância do Passo.

\begin{tabular}{cccccc}
\hline Reamostragem & Dir & Paso & $\mathrm{N}^{\mathrm{o}}$ de Pasos & Tol Ang & Tol Paso \\
\hline 55 e 110 & $160^{\circ} / 45^{\circ}$ & 45 & 15 & 90 & 20 \\
& $160^{\circ} /-45^{\circ}$ & 15 & 8 & 15 & 7 \\
\hline \multirow{2}{*}{165 e 200} & $160^{\circ} / 45^{\circ}$ & 40 & 10 & 90 & 20 \\
& $160^{\circ} /-45^{\circ}$ & 15 & 8 & 15 & 7 \\
\hline
\end{tabular}


Tabela 4-23. Estatística descritiva dos parâmetros de ajuste dos modelos teóricos de variogramas às novas amostras $(55,110,165$ e 220), obtidas pela modelagem automática do variograma experimental. Parâmetros $=$ Parâmetros de interesse $\left(c_{0}\right.$ : efeito pepita da direção $1 \mathrm{e}$ 2, $c_{1}, c_{2}$ : contribuições das direções 1 e $2, a_{1}, a_{2}$ : amplitudes das direções 1 e 2 ).

\begin{tabular}{ccccccccc}
\hline Reamostragem & Params & Mínimo & $1^{\circ}$ Quartil & Mediana & Média & $3^{\circ}$ Quartil & Máximo & $\begin{array}{c}\text { Desvio } \\
\text { Padrão }\end{array}$ \\
\hline \multirow{6}{*}{55} & $c_{0}$ & 0,00 & 0,48 & 0,65 & 0,65 & 0,83 & 1,30 & 0,27 \\
& $c_{1}$ & 1,11 & 1,36 & 1,47 & 1,47 & 1,56 & 1,95 & 0,15 \\
& $c_{2}$ & 0,65 & 1,22 & 1,52 & 1,53 & 1,81 & 2,80 & 0,42 \\
& $a_{1}$ & 72,87 & 98,13 & 137,93 & 146,36 & 175,32 & 353,42 & 60,21 \\
& $a_{2}$ & 28,84 & 36,21 & 45,94 & 46,26 & 55,86 & 59,12 & 13,70 \\
\hline \multirow{6}{*}{110} & $c_{0}$ & 0,22 & 0,57 & 0,68 & 0,68 & 0,80 & 1,25 & 0,17 \\
& $c_{1}$ & 1,18 & 1,34 & 1,44 & 1,44 & 1,55 & 1,89 & 0,13 \\
& $c_{2}$ & 0,81 & 1,28 & 1,38 & 1,41 & 1,58 & 2,07 & 0,24 \\
& $a_{1}$ & 91,40 & 99,03 & 139,52 & 148,21 & 178,64 & 277,44 & 50,56 \\
& $a_{2}$ & 29,02 & 42,54 & 49,97 & 49,97 & 57,99 & 100,45 & 12,14 \\
\hline \multirow{6}{*}{165} & $c_{0}$ & 0,28 & 0,58 & 0,71 & 0,70 & 0,78 & 1,08 & 0,14 \\
& $c_{1}$ & 1,19 & 1,39 & 1,47 & 1,47 & 1,54 & 1,69 & 0,096 \\
& $c_{2}$ & 0,94 & 1,34 & 1,47 & 1,47 & 1,64 & 1,94 & 0,20 \\
& $a_{1}$ & 72,21 & 78,74 & 95,07 & 103,53 & 121,77 & 172,33 & 28,75 \\
& $a_{2}$ & 29,53 & 45,76 & 49,91 & 50,33 & 54,57 & 76,45 & 7,98 \\
\hline \multirow{6}{*}{220} & $c_{0}$ & 0,00 & 0,01 & 0,09 & 0,15 & 0,22 & 0,62 & 0,17 \\
& $c_{1}$ & 1,36 & 1,46 & 1,51 & 1,50 & 1,55 & 1,66 & 0,06 \\
& $c_{2}$ & 0,92 & 1,44 & 1,57 & 1,57 & 1,70 & 2,20 & 0,21 \\
& $a_{1}$ & 74,62 & 78,31 & 79,62 & 93,61 & 108,43 & 143,71 & 19,80 \\
& $a_{2}$ & 34,14 & 45,04 & 48,42 & 51,76 & 55,84 & 95,30 & 11,13 \\
\hline
\end{tabular}

\section{Efeito Pepita}
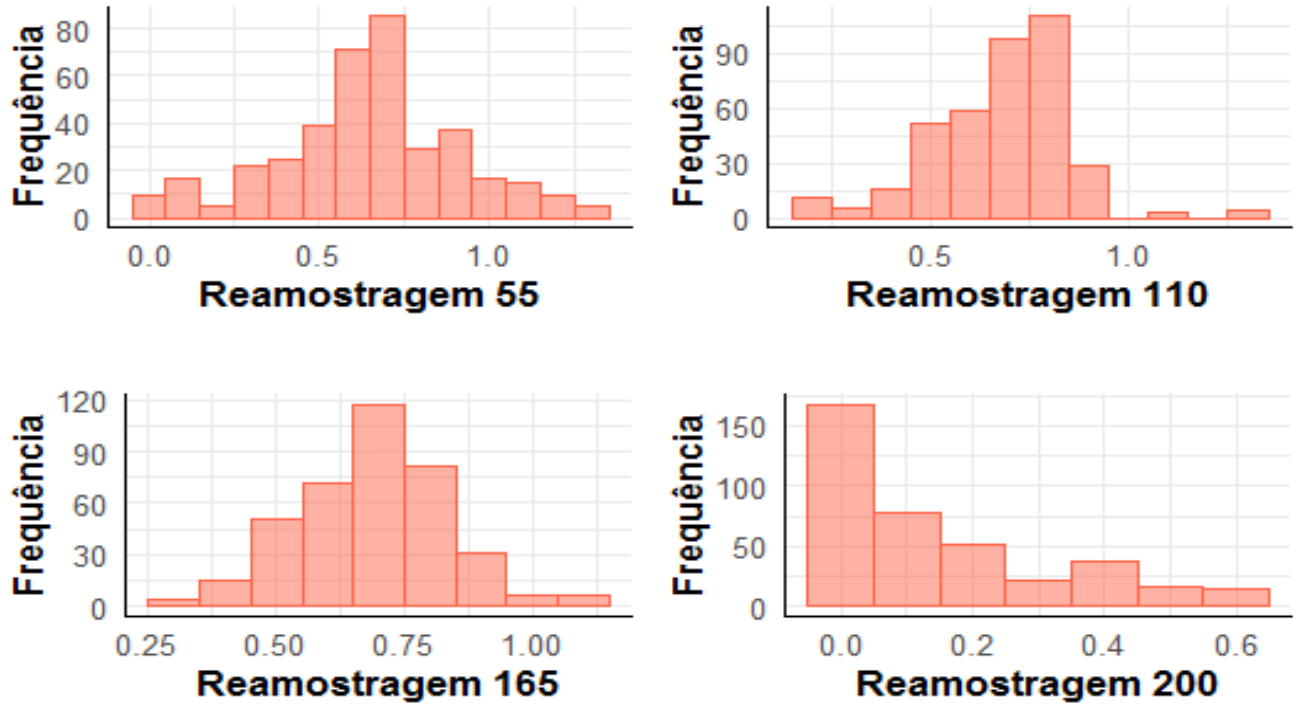

Figura 4-41. Distribuição do parâmetro Efeito Pepita para cada nova amostragem 55, 110,165 e 220. 


\section{Contribuição Espacial $1^{\circ}$ Direção}
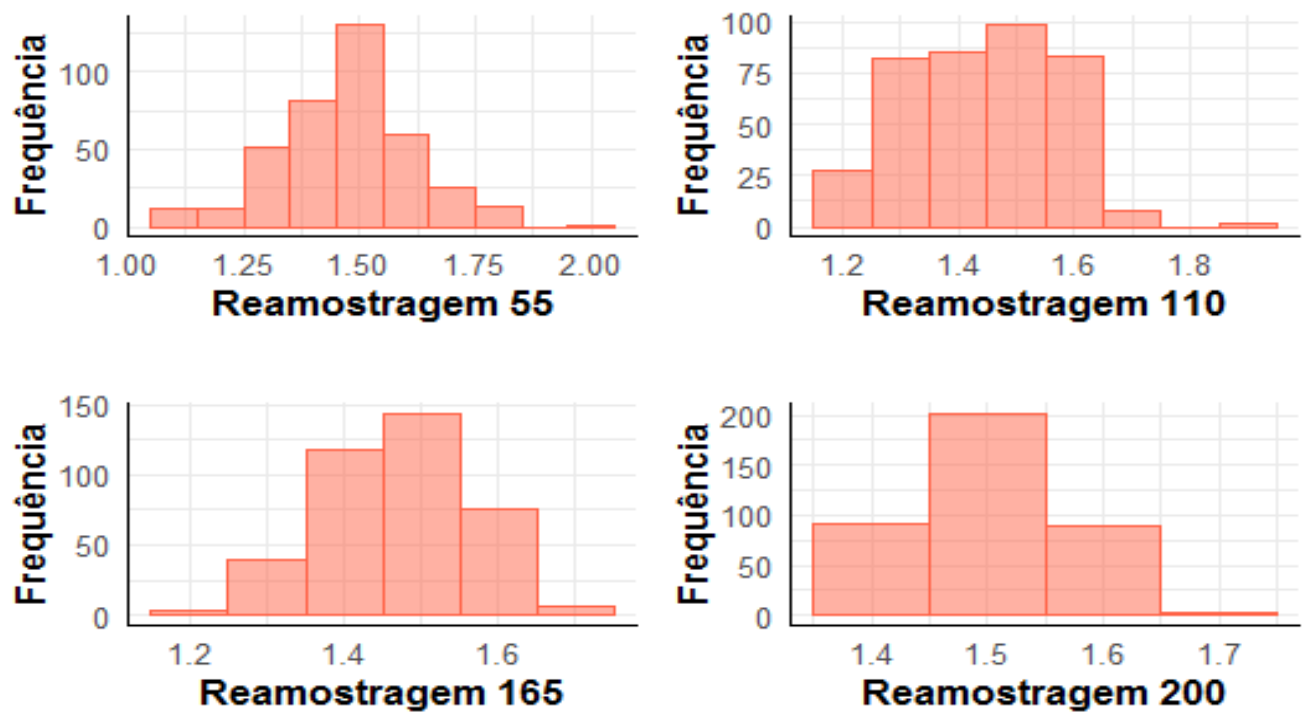

Figura 4-42. Distribuição do parâmetro Contribuição Espacial da $1^{\circ}$ Direção para cada nova amostragem 55, 110, 165 e 220.

\section{Contribuição Espacial $2^{\circ}$ Direção}
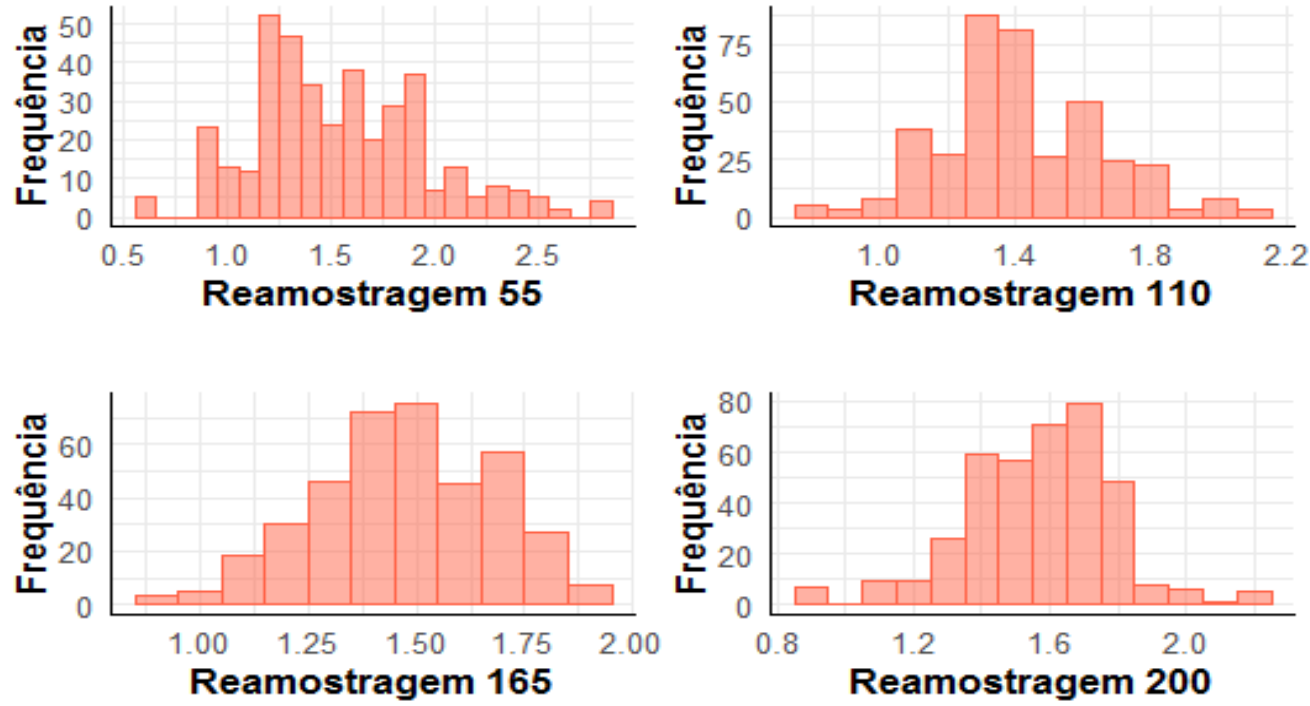

Figura 4-43. Distribuição do parâmetro Contribuição Espacial da $2^{\circ}$ Direção para cada nova amostragem 55, 110, 165 e 220. 


\section{Amplitude $1^{\circ}$ Direção}
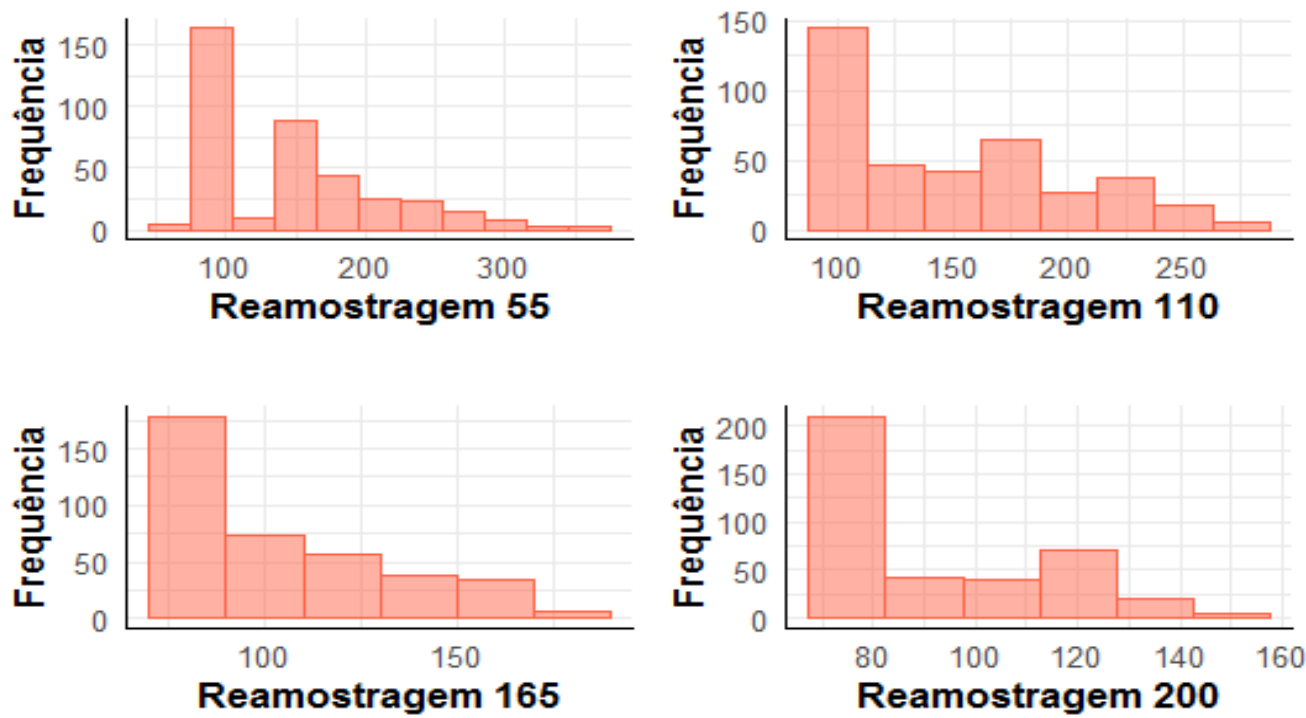

Figura 4-44. Distribuição do parâmetro Amplitude da $1^{\circ}$ Direção para cada nova amostragem 55, 110, 165 e 220.

\section{Amplitude $2^{\circ}$ Direção}
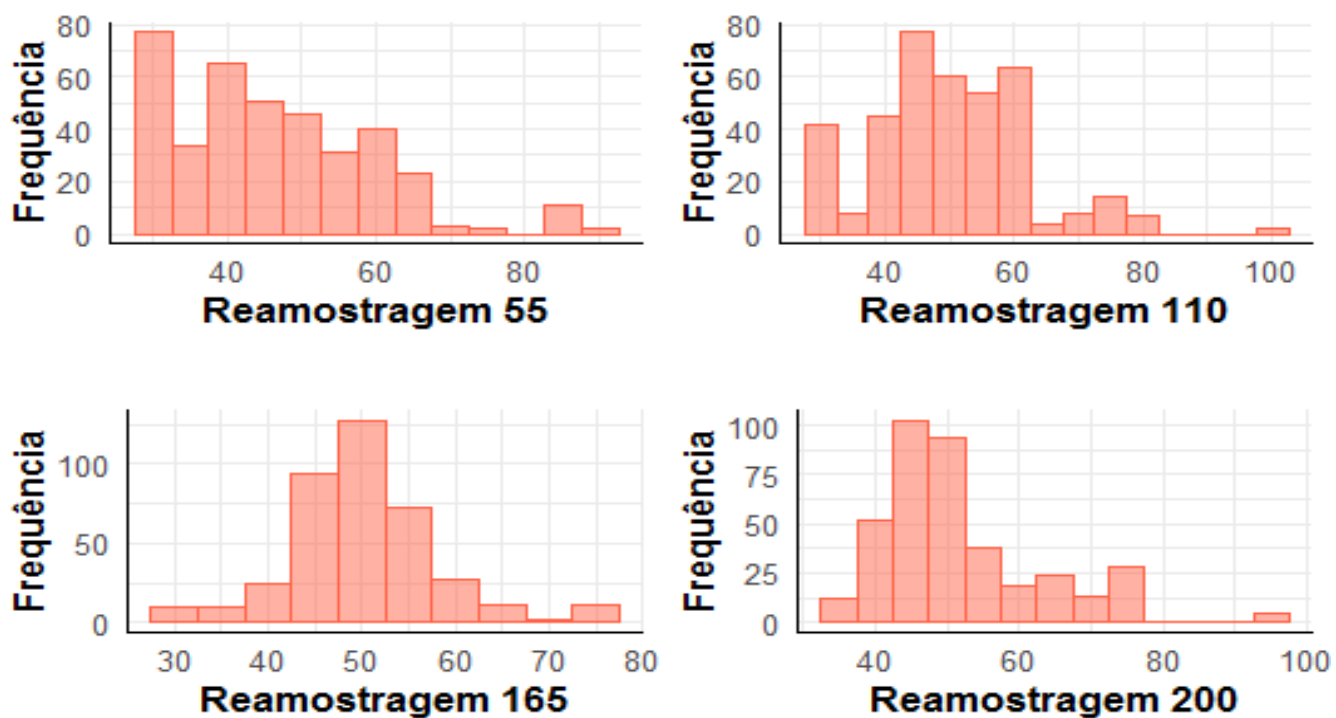

Figura 4-45. Distribuição do parâmetro Amplitude da $2^{\circ}$ Direção para cada nova amostragem 55, 110, 165 e 220. 
Os histogramas das variáveis de efeito pepita e a contribuição espacial um e dois são caracterizados por ter uma distribuição simétrica de baixa variabilidade entre as amostras para a variável $c_{1}$ e alta variabilidade para as variáveis $c_{0}$ e $c_{2}$, conforme Indicado por suas médias e desvios-padrão. A baixa variabilidade da variável $c_{1}$ indica que apesar da reamostragem ser de aproximadamente $21 \%, 42 \%, 64 \%$ e $85 \%$ do número total de perfurações, a técnica de amostragem aleatória estratificada permite capturar em sua totalidade a variabilidade espacial do depósito em estudo no sentido de maior continuidade. No entanto, a variabilidade espacial do depósito na direção ortogonal ou vertical é fortemente afetada pela quantidade ou tamanho da amostra. Além disso, a alta variabilidade do efeito pepita está associada principalmente ao tipo de variável em estudo $\mathrm{Cu}(\%)$. Por outro lado, os histogramas das variáveis de amplitude um e dois são caracterizados por ter distribuição assimétrica positiva de alta variabilidade, conforme indicado por suas medidas e desvios-padrão. No entanto, a alta variabilidade diminui de acordo com o tamanho da amostra conforme indicado pelas suas estatísticas descritivas, pois permite definir com maior precisão as diferentes relações espaciais entre as amostras derivadas do ajuste do modelo de variograma.

Após o ajuste automático dos variogramas experimentais e a criação de um conjunto de valores de forma aleatória (ver seção 3.2.3), prosseguiu-se com a análise de sensibilidade. Neste trabalho foi utilizado um tamanho amostral (n) de 20.000 para que a convergência dos índices de sensibilidade fosse garantida, o que resulta em 140.000 (n [p + 2], ver item 2.8) modelos avaliados para o cálculo dos índices de sensibilidade de primeira ordem e ordem total. Vale citar que a análise de reamostragem por Bootstrap foram feitas 1000 amostras.

Conforme apresentado no item 2.8 os índices de sensibilidade de primeira ordem e ordem total são os resultados básicos da análise de sensibilidade da Sobol, o qual permite o estudo global do modelo em questão. A Tabela 4-24 mostra esses dois índices de sensibilidade juntamente com seus intervalos de confiança para reamostragem de $95 \%$, calculada a partir do método do percentil. Para cada conjunto de amostras (55, 110, 165 e 200) seus respectivos índices de sensibilidade são ilustrados na Tabela 4-24. 
Tabela 4-24. Índices de sensibilidade da primeira ordem e ordem total obtidos por Bootstrap, bem como seus intervalos de confiança (IC). 1 = Reamostragem 55, 2 = Reamostragem 110, 3 = Reamostragem 165 e 4 = Reamostragem 200.

\begin{tabular}{|c|c|c|c|c|c|c|c|c|}
\hline \multirow{2}{*}{ Modelo } & \multirow{2}{*}{$\begin{array}{l}S_{i} \\
c_{0}\end{array}$} & \multirow{2}{*}{$\begin{array}{c}\begin{array}{c}\text { Valor } \\
\text { Sobol' }\end{array} \\
0,00\end{array}$} & \multicolumn{2}{|c|}{$95 \%$ IC } & \multirow{2}{*}{$\begin{array}{c}S_{T i} \\
c_{0}\end{array}$} & \multirow{2}{*}{$\begin{array}{c}\begin{array}{c}\text { Valor } \\
\text { Sobol' }\end{array} \\
0,02\end{array}$} & \multicolumn{2}{|c|}{$95 \% \mathrm{IC}$} \\
\hline & & & 0,00 & 0,02 & & & 0,01 & 0,04 \\
\hline \multirow{4}{*}{1} & $c_{1}$ & 0,11 & 0,07 & 0,15 & $c_{1}$ & 0,10 & 0,06 & 0,14 \\
\hline & $c_{2}$ & 0,24 & 0,17 & 0,30 & $c_{2}$ & 0,23 & 0,18 & 0,30 \\
\hline & $a_{1}$ & 0,01 & 0,00 & 0,03 & $a_{1}$ & 0,02 & 0,00 & 0,03 \\
\hline & $a_{2}$ & 0,63 & 0,50 & 0,75 & $a_{2}$ & 0,66 & 0,55 & 0,75 \\
\hline \multirow{5}{*}{2} & $c_{0}$ & 0,03 & 0,01 & 0,05 & $c_{0}$ & 0,02 & 0,00 & 0,04 \\
\hline & $c_{1}$ & 0,17 & 0,11 & 0,23 & $c_{1}$ & 0,15 & 0,10 & 0,20 \\
\hline & $c_{2}$ & 0,22 & 0,16 & 0,27 & $c_{2}$ & 0,24 & 0,18 & 0,29 \\
\hline & $a_{1}$ & 0,14 & 0,09 & 0,19 & $a_{1}$ & 0,15 & 0,10 & 0,20 \\
\hline & $a_{2}$ & 0,54 & 0,43 & 0,65 & $a_{2}$ & 0,57 & 0,46 & 0,66 \\
\hline \multirow{5}{*}{3} & $c_{0}$ & 0,13 & 0,09 & 0,18 & $c_{0}$ & 0,15 & 0,11 & 0,20 \\
\hline & $c_{1}$ & 0,14 & 0,10 & 0,19 & $c_{1}$ & 0,13 & 0,09 & 0,17 \\
\hline & $c_{2}$ & 0,13 & 0,09 & 0,17 & $c_{2}$ & 0,19 & 0,14 & 0,24 \\
\hline & $a_{1}$ & 0,11 & 0,07 & 0,15 & $a_{1}$ & 0,13 & 0,09 & 0,16 \\
\hline & $a_{2}$ & 0,44 & 0,35 & 0,54 & $a_{2}$ & 0,48 & 0,40 & 0,54 \\
\hline \multirow{5}{*}{4} & $c_{0}$ & 0,42 & 0,32 & 0,52 & $c_{0}$ & 0,41 & 0,34 & 0,47 \\
\hline & $c_{1}$ & 0,12 & 0,08 & 0,16 & $c_{1}$ & 0,09 & 0,05 & 0,13 \\
\hline & $c_{2}$ & 0,14 & 0,09 & 0,19 & $c_{2}$ & 0,16 & 0,11 & 0,20 \\
\hline & $a_{1}$ & 0,19 & 0,14 & 0,24 & $a_{1}$ & 0,13 & 0,08 & 0,17 \\
\hline & $a_{2}$ & 0,09 & 0,04 & 0,13 & $a_{2}$ & 0,16 & 0,12 & 0,21 \\
\hline
\end{tabular}

Os resultados do índice de sensibilidade de primeira ordem $S_{i}$ estão no lado esquerdo da Tabela (colunas 3 à 5), enquanto o índice de sensibilidade de ordem total $S_{T i}$ encontra-se no lado direito da Tabela (colunas 7 à 9). Os índices de sensibilidade de Sobol coluna 3 (7), foram calculados com 20.000 amostras. Além disso, observou-se que os erros resultaram em aproximadamente iguais a zero, o que indica que a reamostragem com reposição não é tendenciosa. Sendo assim, é possível inferir que os intervalos de confiança para cada índice $\left(S_{i}\right.$ e $\left.S_{T i}\right)$ apresentam amplitudes não significativas, indicando uma estimativa precisa e com distribuição simétrica. Do total da soma para ambos os índices de sensibilidade, conclui-se que o modelo é completamente aditivo e que seus parâmetros de entrada são independentes conforme esperado. 
A sensibilidade dos parâmetros depende essencialmente do alcance e distribuição a priori dos parâmetros que são obtidos a partir das informações dos dados dos ajustes realizados automaticamente. Entretanto, como evidenciado por $S_{i}$ na Tabela 4-24, a influência dos fatores está fortemente associada ao número de amostras dentro do domínio, assim como do espaçamento médio entre os furos de sondas.

Em geral, os resultados para o primeiro modelo (Tabela 4-24) mostram que o efeito pepita é o parâmetro menos importante e o mais significativo é a amplitude da direção vertical, seguida pela contribuição espacial $a_{2}$. Em outras palavras, os parâmetros mais significativos apresentam uma maior influência na variância total. Assim, conforme o tamanho da amostra aumenta $(55,110,165$ e 200) o efeito principal do fator $a_{2}$ acaba decaindo como também o índice de sensibilidade do parâmetro $a_{1}$ no modelo. A explicação está relacionada a forte assimetria positiva do parâmetro de amplitude horizontal em contraste com a amplitude vertical (Figura 4-44 e 4-45).

Ademais, no terceiro e quarto modelo (Tabela 4-24) há uma clara perda de influência do parâmetro de amplitude vertical $a_{2}$ na variância total, onde o parâmetro ou fator $c_{0}$ tem uma influência maior sobre o modelo. Embora, os parâmetros de amplitude horizontal e a contribuição espacial da direção horizontal sejam menos influentes, ambos contribuem com $33 \%$ da variância total do modelo. Ainda que o parâmetro $a_{1}$ seja caracterizado por uma distribuição assimétrica positiva, os resultados da Tabela 424 mostram que o componente mais influente para este parâmetro é o segundo mais importante na análise de sensibilidade. Aliás, o aumento no número de amostras causa uma diminuição da distância de acordo com a média entre as sondagens.

A faixa de intervalo de confiança da amplitude vertical variável em média foi de $15 \%$ em comparação com os demais parâmetros em estudo. Isso indica que há uma variação alta dos valores $S_{i}$ para uma amostra simples, enquanto eles são mais estáveis para os parâmetros $c_{0}, c_{1}, c_{2}$ e $a_{1}$. Em outras palavras, as flutuações são menores.

Em conclusão, os resultados revelam a importância da seleção dos parâmetros matemáticos do ajuste do modelo teórico de variograma na estimativa e classificação de recursos minerais. Aliás, para diferentes tamanhos amostrais as influências dos fatores em questão variam de acordo com cada cenário, ou seja, os domínios tridimensionais que são menos amostrados revelam que o fator mais influente será a amplitude vertical. Ademais, conforme o tamanho da amostra aumenta, o parâmetro mais influente é o 
efeito pepita. Vale notar que apesar do efeito pepita estar fortemente associado à variabilidade estocástica natural do depósito mineral, bem como aos erros de amostragem, este parâmetro deve ser cuidadosamente selecionado no momento da modelagem do variograma experimental. 


\section{Conclusões}

\subsection{CONCLUSÕES}

Os sistemas de classificação de recursos minerais enfatizam o uso de uma medida de confiança para identificar os recursos como Medido, Indicado e Inferido, apesar de não especificarem como essa confiabilidade deve ser calculada ou como o recurso deve ser estimado. No entanto, estes códigos destacam a qualidade e interpretação das informações utilizadas na estimativa e classificação, assim como o uso de ferramentas geoestatísticas para atingir os objetivos propostos. Vale lembrar que a classificação dos recursos minerais é sempre subjetiva e dependente fortemente dos critérios adotados pelo profissional. Neste sentido, os relatórios públicos devem ser justificados do modo mais claro possível.

Nesta tese os recursos minerais foram obtidos através de duas técnicas geoestatísticas condicionais: Simulação Sequencial Gaussiana e Simulação de Múltiplos Pontos. Tendo em vista a capacidade da simulação condicional de gerar múltiplas alternativas admissíveis a realidade e a quantificação das incertezas dos valores regionalizados estimados, essas ferramentas se destacam como uma opção aos critérios tradicionais de classificação. A Simulação Sequencial Gaussiana comparada com a Simulação de Múltiplos Pontos é a técnica mais utilizada e consagrada no campo da estatística espacial para o estudo de variáveis aleatórias contínuas. Em contraste, a Simulação de Múltiplos Pontos é amplamente utilizada na reprodução de características geológicas complexas de variáveis aleatórias discretas ou categóricas. Além disso, a simulação de múltiplos pontos pode ser utilizada na aproximação de fenômenos naturais de valores contínuos, uma vez que um modelo conceitual do depósito seja devidamente selecionado.

Neste trabalho a seleção do modelo conceitual ou controle de padrões foi realizado através da análise dos componentes principais em conjunto com o gráfico Bitplot. A imagem de treinamento de técnicas lineares que melhor representa as 
características subjacentes ao fenômeno natural de cobre de Sequeirinho é a imagem média das realizações estocásticas.

Os recursos minerais estimados foram classificados inicialmente por três critérios: restrições geométricas, variância condicional relativa e probabilidade pontual condicional. Com base nos resultados evidenciou-se uma maior restrição pelo critério da variância condicional relativa em relação ao método tradicional e a probabilidade pontual. Afinal, os blocos com potencial econômico com valor de corte acima de 0,33\% $\mathrm{Cu} \%$ foram classificados como Indicados e Inferidos, o que significa uma menor confiabilidade no projeto do ponto de vista financeiro. Aliás, esse critério exige que a variável aleatória seja proveniente de uma distribuição log-normal.

O método de restrição geométrica não penaliza áreas de valores altos, pois dependem apenas de restrições geométricas impostas, isto é, considera a área de influência entre as amostras e as diferentes relações espaciais já que não depende dos valores amostrados. Portanto, essa classificação não leva em consideração a forma de distribuição da variável em estudo, o que implica que o efeito proporcional e a incerteza não sejam levados em consideração. Neste sentido, blocos com maior e menor variabilidade podem ser classificados erroneamente como Medidos, Indicados ou Inferidos.

O método de probabilidade pontual foi capaz de apresentar resultados satisfatórios, pois evidenciou que é um critério mais preciso em comparação aos métodos anteriores. Aliás, o método proposto considera as características locais da distribuição de valores e as incertezas locais associadas. Outra vantagem deste método é a não necessidade de variáveis provenientes de qualquer tipo de distribuição, isto é, depende apenas do número de simulações estocásticas calculadas para garantir sua aproximação a partir do teorema do limite central. Isso mostra que esse critério é um método estatístico promissor para classificação de recursos minerais. Como mencionado, a precisão da classificação de recursos depende da distribuição da variável, ou seja, se ela é caracterizada por uma distribuição assimétrica positiva, negativa ou simétrica. Aliás, uma reclassificação foi aplicada a fim de capturar a variabilidade local dos valores regionalizados.

Foi possível concluir que a técnica de Bootstrap pode ser usada na reclassificação de depósitos minerais altamente variáveis como são os depósitos de 
cobre, dado que o método de classificação probabilística pontual faz uso do estimador médio não robusto e não viesado. Essa abordagem de reclassificação por Bootstrap pode ser aplicada para avaliar a incerteza de alocação das classes de pixels individuais, uma vez que os mapas probabilísticos são obtidos. Além disso, a reclassificação melhora a caracterização dos erros de classificação herdado da estimativa de recursos minerais pela Simulação de FILTERSIM que se apresenta como uma solução parcial para o problema da homogeneização.

A continuidade das classes de recursos minerais é essencial para tomada de decisões por engenheiros ou geólogos, dado que os métodos de estimativa de recursos minerais geralmente geram mapas "desorganizados" que ignoram a continuidade geológica, de modo que propriedades como conectividade entre classes acabam sendo afetadas. Assim, neste trabalho dois filtros lineares foram aplicados para atingir os objetivos. Os resultados revelaram que o filtro linear Gaussiano em contraste com o filtro linear médio é a melhor solução para o problema de conectividade e homogeneização espacial do fenômeno em estudo, pois preserva as características espaciais e estatísticas, devido a aplicação não uniforme dos pesos associados aos diferentes blocos presentes no modelo de busca ou janela de homogeneização. Afinal, a correção parcial da homogeneização das classes de recursos minerais obtido pela simulação FILTERSIM destacou-se do filtro linear Gaussiano. Aliás, apesar do efeito da homogeneização causada pelo tamanho do template interno na simulação geoestatística de múltiplos pontos, os resultados finais após a reclassificação e suavização indicaram que a simulação FILTERSIM conserva a continuidade espacial e conectividade dos valores no corpo mineralizado comparado com os resultados obtidos pela Simulação Sequencial Gaussiana. Neste sentido, esse método revelou-se promissor para a estimativa de recursos minerais, embora dependa de uma imagem de treinamento adequada que contenha em sua estrutura explícita, padrões espaciais representativos da área em estudo.

Afinal, foi realizada uma análise de sensibilidade de Sobol' baseada na decomposição da variância para os mapas estimados da variável $\mathrm{Cu}(\%)$ no depósito mineral de Sequeirinho. Para isso, quatro reamostragens aleatórias estratificadas (55, 110, 165 e 220) foram realizadas a fim de encontrar a importância dos parâmetros matemáticos de ajuste ao variograma experimental, bem como as diferentes influências 
de acordo com o tamanho da amostra. Aliás, os parâmetros de estudo foram o efeito pepita, a amplitude e a contribuição espacial.

Um tamanho amostral de 20.000 unidades foi utilizado para calcular os índices básicos de sensibilidade de primeira ordem e ordem total resultando cinco parâmetros de entrada que influenciaram os valores finais da estimativa e a classificação dos recursos minerais, do qual 140.000 modelos foram analisados e avaliados. Vale lembrar que o tamanho da amostra foi selecionado para que a convergência dos índices de sensibilidade fosse totalmente garantida. Além disso, a reamostragem Bootstrap foi aplicada para inferir os intervalos de confiança para cada fator de entrada de $95 \%$.

Em suma, foi constatado que nem sempre o efeito pepita é o fator mais influente nos resultados, ou seja, sua influência depende fortemente do número de amostras, assim como do espaçamento médio entre elas. Além disso, ficou evidente nos demais fatores a forte dependencia do tamanho da amostra. Outro aspecto importante foi a soma total para ambos os índices de sensibilidade, o que permitiu inferir que o modelo é completamente aditivo e que seus parâmetros de entrada são independentes. Em conclusão, os diferentes parâmetros matemáticos devem ser cuidadosamente selecionados no momento da modelagem do variograma experimental para que seja possível a realização de uma análise profissional de alta qualidade. 


\section{Referências Bibliográficas}

Abzalov, M. (2016). Applied mining geology. Berlin: Springer.

Annels, A. E. (1991). Mineral deposit evaluation: A practical approach. Chapman and Hall.

Archer, G. E., Saltelli, A., \& Sobol, I. M. (1997). SENSITIVITY MEASURES, ANOVA-LIKE TECHNIQUES AND THE USE OF BOOTSTRAP. Journal of Statistical Computation and Simulation, 58(2), 99-120.

Arpat, G. B., \& Caers, J. (2007). Conditional Simulation with Patterns. Mathematical Geology, 39(2), 177-203.

Augusto, R. A., Monteiro, L. V., Xavier, R. P., \& de Souza Filho, C. R. (2008). Zonas de alteração hidrotermal e paragênese do minério de cobre do Alvo Bacaba, Província Mineral de Carajás (PA). Revista Brasileira de Geociências, 38(2), $263-277$.

Bayer, P., Huggenberger, P., Renard, P., \& Comunian, A. (2011). Three-dimensional high resolution fluvio-glacial aquifer analog: Part 1: field study. J Hydrol, 405, $1-9$.

Boisvert, J. B., Pyrcz, M. J., \& Deutsch, C. V. (2008). Multiple-Point Statistics for Training Image Selection. Natural Resources Research, 16(4), 313-321.

Caers, J., \& Zhang, T. (2002). Multiple-point geostatistics: a quantitative vehicle for integrating geologic analogs into multiple reservoir models. (pp. 1-9). Stanford Center for Reservoir Forecasting.

CBRR. (2016). Guia CBRR para declaração de resultados de exploração, recursos e reservas minerais. Comissão Brasileira de Recursos e Reservas. Acesso em 1 de Março de 2019, disponível em http://www.cbrr.org.br/docs/guia_declaracao.pdf

Chatterjee, S., Dimitrakopoulos, R., \& Mustapha, H. (2012). Dimensional Reduction of Pattern-Based Simulation Using Wavelet Analysis. Math Geosci, 44, 343-374. 
Chernick, M. R. (2008). Bootstrap Methods: A Guide for Practitioners and Researchers. New Jersey: John Wiley \& Sons.

Chilès, J. P., \& Delfiner, P. (1999). Geostatistics: Modeling Spatial Uncertainty. New York: Willey \& Sons.

CRIRSCO. (2013). International reporting template for the public reporting of exploration results, mineral resources and mineral reserves. The Committee for Mineral Reserves International Reporting Standards. Acesso em 01 de 03 de 2019 , disponível em http://www.crirsco.com/templates/international_reporting_template_november_ 2013.pdf

David, M. (1977). Geostatistical Ore Reverse Estimation (1 ed.). New York: ELSEVIER SCIENTIFIC PUBLISHING COMPANY.

Daya Sagar, B. S., \& Cheng, Q. (2018). Handbook of Mathematical Geosciences. Springer Open.

Deutsch, C. V., \& Journel, A. G. (1998). GSLIB: Geostatistical Software Library and User's Guide (2 ed.). New York: Oxford University Press.

Diehl, P., \& David, M. (1982). Classification of ore reserves/resources based on geostatistical methods. CIM Bull, 75(838), 127-136.

Dohm, C. (2005). Quantifiable mineral resource classification: A logical approach. In: Springer (Ed.), Geostatistics Banff(Vol. 1, pp. 1-1129). Dordrecht.

Duggan, S., \& Dimitrakopoulos, R. (2005). Application of conditional simulation to quantify uncertainty and to classify a diamond deflatoin deposit. In: Geostatistics Banff (pp. 1-1129). Springer.

Efron, B., \& Tibshirani, R. J. (1993). An Introduction to the Bootstrap (1 ed.). New York: CHAPMAN \& HALL/CRC.

Emery, X., Ortiz, J. M., \& Rodríguez, J. J. (2006). Quantifying uncertainty in mineral resources by use of classification schemes and conditional simulation. Mathematical Geology, 38(4), 445-464. 
Froidevaux, R., Roscoe, W. E., \& Valiant, R. I. (1986). Estimating and classifying gold reserves at Page-Williams $\mathrm{C}$ zone: a case study in non-parametric geostatistics. Can. Inst. Min. Metall, 280 - 300.

Gabriel, K. R. (1971). The Biplot graphic display of matrices with application to principal component analysis. Biometrika, 58(3), 453 - 467.

Goovaerts, P. (1997). Geostatistics for Natural Resources Evaluation. New York: Oxford University Press.

Gringarten, E., \& Deutsch, C. V. (2003). Methodology for Improved Variogram Interpretation and Modeling for Petroleum Reservoir Characterization. CCG Resources, 1-33.

Guardiano, F., \& Srivastava, M. (1993). Multivariate geostatistics: beyond bivariate moments. In: A. O. Soares, Geostatistics - Troia (pp. 133-144). Dordrecht: Kluwer Academic.

Homma, T., \& Saltelli, A. (1996). Importance measures in global sensitivity analysis of nonlinear models. Reliability Engineering \& System Safety, 52(1), 1-17.

Honarkhah, M. (2011). Stochastic simulation of patterns using distance-based pattern modeling. 1 - 387.

Honarkhah, M., \& Caers, J. (2010). Stochastic Simulation of Patterns Using DistanceBased Pattern Modeling. Math Geosci, 42, 487-517.

Isaaks, E. H., \& Srivastava, M. (1989). Applied Geostatistics. New York: Oxford University Press.

Johnson, R. A., \& Wichern, D. W. (1998). Applied Multivariate Statistical Analysis. United States of America: Prentice-Hall.

JORC. (2012). Australasian code for reporting of exploration results, minerals resources and ore reserves. JORC Joint Ore Reserves Committee. Acesso em 01 de 03 de 2019, disponível em http://www.jorc.org/docs/JORC_code_2012.pdf

Journel, A. G. (1983). Non-parametric estimation of spatial distributions. Math Geol, 15(3), 445-468. 
Journel, A., \& Zhang, T. (2006). The necessity of a Multiple-Point Prior Model. Mathematical Geology, 38(5), 591 - 610.

Kroonenberg, P. M. (2008). Applied Multiway Data Analysis. New Jersey: John Wiley \& Sons, Inc.

Kucherenko, S., Rodriguez-Fernandez, M., Pantelides, C., \& Shah, N. (2009). Monte Carloevaluationofderivative-basedglobalsensitivitymeasures. ReliabilityEngineeringandSystemSafety, 94, 1135-1148.

Lopez, S., Cojan, I., Rivoirard, J., \& Galli, A. (2008). Process-based stochastic modelling: Meandering. Special Publications of the International Association of Sedimentologists, 144, 139-144.

Marwanza, I., Hamdani, A. H., Haryanto, I., \& Nas, C. (2016). Classification of geological conditions using geostatistics in coal field, Sagatta, East Kalimantan, Indonesia. Impact Journals, 4(10), 129-140.

Miskelly, N. (2003). Progress on international standards for reporting of mineral $\begin{array}{llll}\text { resources and } & \text { Feserves. FIRSCO. }\end{array}$ http://www.crirsco.com/nmrestonpaper.pdf

Monteiro, L. V. (2014). Metalogênese da Província Carajás. Metalogêneses Das Províncias Tectônicas Brasileiras, 43.

Monteiro, L. V., Xavier, R. P., Hitzman, M. W., Juliani, C., Souza Filho, C. R., \& Carvalho, E. R. (2008a). Mineral chemistry of ore and hydrothermal alteration at the Sossego iron oxide-copper-gold deposit, Carajás Mineral Province, Brazil. Ore Geol Rev, 34, 317 - 336.

Mory, D. F., \& Deutsch, C. V. (2006). A program for robust calculation of drillhole spacing in three dimensions. Centre for Computational Geostatistics CCG, (309) $1-18$.

Murphy, M., Parker, H., Ross, A., \& Audet, M. A. (2005). Ore-thickness and nickel grade resource confidence at the Koniambo nickel laterite (A conditional simulation voyate of discovery). In: Geostatistics Banff (pp. 1-1129). Springer. 
Mustapha, H., \& Dimitrakopoulos, R. (2010). High-order stochastic simulations for complex non-Gaussian and non-linear geological patterns. Math Geosci, 42(5), 457-485.

Mustapha, H., Chatterjee, S., \& Dimitrakopoulos, R. (2014). CDFSIM: Efficient Stochastic Simulation Through Decomposition of Cumulative Distribution Functions of Transformed Spatial Patterns. Math Geosci, 46, 95-123.

Olea, R. A. (1999). Geostatistics for Engineers and Earth Scientists. New York: Springer Science+Business Media New York.

Quenouille, M. H. (1949). Approximate tests of correlation in time series. J. Roy. Statist, 11, 18-84.

Remy, N., Boucher, A., \& Wu, J. (2009). Applied Geostatistics with SGeMS: A User's Guide (1 ed.). Cambridge University Press.

Revuelta, M. B. (2018). Mineral Resources From Exploration to Sustainability Assessment. Springer.

Rossi, M. E., \& Deutsch, C. V. (2014). Mineral Resource Estimation. New York: Springer.

Royle, A. G. (1977). How to use geostatistics for ore reserve classification. Eng. Min. Jour., 52-55.

Sabourin, R. (1983). Geostatistics as a tool to define varios categories of resources. Mathematical Geology, 15(1), 131-143.

Sabourin, R. L. (1984). Application of a geostatistical method to quantitatively define various categories of resources. Geostatistics for Natural Resources Characterization, 1, 201-215.

Saltelli, A. (2002). Making best use of model evaluations to compute sensitivity indices. Computer Physics Communications, 145, 280-297.

Saltelli, A., Annoni, P., Azzini, I., Campolongo, F., Ratto, M., \& Tarantola, S. (2010). Variance based sensitivity analysis of model output. Design and estimator for the total sensitivity index. Computer Physics Communications, 181, 259-270. 
Saltelli, A., Ratto, M., Andres, T., Campolongo, F., Cariboni, J., Gatelli, D., . . . Tarantola, S. (2008). Global sensitiviy analysis. England: John Wiley \& Sons Ltd.

Saltelli, A., Tarantola, S., Campolongo, F., \& Ratto, M. (2004). SENSITIVITY ANALYSIS IN PRACTICE. England: John Wiley \& Sons Ltd.

Shannon, C. E. (1948). A mathematical theory of communication. Bell system technical journal(27), 379 - 423.

Shao, J., \& Tu, D. (1995). The Jackknife and Bootstrap. New York: Springer Science+Business Media.

Silva, D. S., \& Boisvert, J. B. (2014). Mineral resource classification: a comparison of new and existing techniques. The Journal of The Southem African Institute of Mining and Metallurgy, 14, 265-273.

Sinclair, A. J., \& Blackwell, G. H. (2004). Applied Mineral Inventory Estimation. Cambridge, United Kingdom: Cambridge University Press.

Snowden, D. V. (1996). Practical interpretation of resource classification guidelines. AusIMM 1996 Annual Conference (pp. 1-16). Mineral Resource and Ore Reserve Estimation - The AusIMM Guide to Good Practice. Acesso em 01 de 03 de 2019

Sobol', I. M. (1993). Sensitivity analysis for non-linear mathematical models. Mathematical Modelling and Computational Experiment, 1, 407 - 414.

Souza, L. E., Costa, J. F., \& Koppe, J. C. (2005). Measures of uncertainty for resources classification. In: Geostatistics Banff(Vol. 1, pp. 1-1129). Dordrecht: Springer.

Stephenson, P. R., \& Weatherstone, N. (2006). Developments in international mineral resource and reserve reporting. Acesso em 01 de 03 de 2019, disponível em http://www.crirsco.com/mine_manage2006_conf_paper.pdf

Strebelle, S. (2002). Conditional Simulation of Complex Geological Structures Using Multiple-Point Statistics. Mathematical Geology, 34(1), 1-21. 
Tahmasebi, P., \& Sahimi, M. (2016a). Enhancing multiple-point geostatistical modeling: 2. Iterative simulation and multiple distance function. Water Resour Res, 52, 2099-2122.

Tahmasebi, P., Hezarkhani, A., \& Sahimi, M. (2012). Multiple-point geostatistical modeling based on the cross-correlation functions. Comput Geosci, 16, 779-797.

Tahmasebi, P., Muhammad, S., \& Caers, J. (2014). MS-CCSIM: Accelerating patternbased geostatistical simulation of categorical variables using a multi-scale search in Fourier space. Computers \& Geosciences, 67, 75-88.

Wackernagel, H. (2003). Multivariate Geostatistics An Introduction with Applications (3 ed.). Berlin: Springer-Verlag Berlin Heidelberg.

Wellmer, F. W. (1983). Classification of ore reserves by geostatistical methods. ERZMETALL, 36(7/8), 315-321.

Wu, J., Zhang, T., \& Journel, A. (2008). Fast FILTERSIM Simulation with score-based distance. Math Geosci, 40, 773-788.

Yamamoto, J. K. (1999). Quantification of uncertainty in Ore-Reserve estimation: Applications to Chapada Copper Deposit, State of Goiás, Brazil. Natural Resources Research, 8(2), 153-163.

Yamamoto, J. K. (2000). An alternative measure of the reliability of ordinary kriging estimates. Mathematical Geology, 32(4), 489-509.

Yamamoto, J. K. (2001). Avaliação e Classificação de Reservas Minerais (1 ed.). São Pualo: Editora da Universidade de São Paulo.

Yamamoto, J. K., \& Landim, P. M. (2013). Geoestatística: Conceitos e Aplicações. São Paulo: Editora de Textos.

Zhang, T. (2006). Filter-Based training pattern classification for spatial pattern simulation. 1-146.

Zhang, T., Switzer, P., \& Journel, A. (2006). Filter-Based classification of training image patterns for spatial simulation. Mathematical Geology, 38(1), 63-80.

Zoubir, A. M., \& Iskander, D. R. (2004). Bootstrap Techniques for Signal Processing. Cambridge University Press. 
